Helsinki University of Technology SimLab

Publications

Dissertation series: 5

Espoo 2009

\title{
CULTURE AND COGNITION IN INFORMATION TECHNOLOGY EDUCATION
}

\section{Jaana Holvikivi}

\section{Doctoral Dissertation}

Dissertation for the degree of Doctor of Science in Technology to be presented with due permission of the Faculty of Information and Natural Sciences for public examination and debate in Auditorium E, main building at Helsinki University of Technology (Espoo, Finland) on the 26th of March, 2009, at 12 o'clock. 
Helsinki University of Technology

Department of Computer Science and Engineering

Information Networks

SimLab Enterprise Simulation Laboratory

P.O.Box 9220

FIN-02015 TKK

Telephone: +358-9-4515037

Facsimile: $\quad+358-9-4514698$

Internet: $\quad$ www.simlab.tkk.fi

(c) 2009 Jaana Holvikivi

Cover artwork: Anna-Kaisa Ant-Wuorinen, Fence Ball, 2006

ISBN 978-951-22-9785-6

ISBN 978-951-22-9786-3 (pdf)

ISSN 1458-8226

The series deals with current issues in the management of innovation and learning in business processes and business models of the networked economy.

All rights reserved. No part of this publication may be reproduced, stored in retrieval systems, or transmitted, or otherwise, without permission in writing from the publisher.

Multiprint

Espoo 2009 


\begin{abstract}
There has been a substantial expansion in the provision of both undergraduate and postgraduate programs offered in English in Finland since the early nineties. It was not until a decade later that research into the results of this education and student experiences begun. The particular focus of the present study is on cognitive processes and learning strategies in multicultural groups of a Bachelor of Engineering programme in information technology in a polytechnic, and the subsequent development of professional expertise in engineering.
\end{abstract}

This work combines anthropological theory of mental schemas and new findings in neuroscience with sociocultural theories of learning in order to formulate a theoretical framework for engineering education. The framework has proven its usefulness in explaining student behavior in multicultural groups and in devising efficient modes for education. The study brings to light the often ignored embodied, emotional, motivational, and social aspects of cognition in learning. The cross-disciplinary approach has robust support from empirical research findings in information technology education. The research consists of surveys, field observations, and analysis of materials produced by students as part of course work.

Social scripts and cultural communication patterns dominate behavior, not only in immigrant students but in all humans. The schema of procedural instruction, which has been assumed to be a universal cognitive ability, appears to be product of certain cultural or educational practices. This research shows that even though the ability may be innate, its application in particular context is learnt. Internalized cultural schemas in scientific thinking explain differences in cognition. Familiarity with technology is acquired through constant exposure. Logical, systematic thinking, as well as an ability to integrate theoretical knowledge to practice should be more heavily emphasized in education. A noteworthy finding that resulted in this research is the intricate interplay between English writing, Asian and African character systems, program coding, embodied writing skills, and visual perception. Neuroscience assists in understanding the connection of programming skills, different types of mathematical thinking, and the development of numerical abilities.

This study supports the view that standardized, technology-centered instruction does not meet the needs of multicultural student groups. On the other hand, a holistic and integrating approach to learning that includes a variety of teaching methods provides means to support the development of student self-regulation. Collaborative learning assists students in sharing experiences and coping strategies. The best recipe for a functional study community is a mix of cultures where no single culture is overly dominant. In fact, a cultural mix appears to be conducive to creative teamwork and innovative projects. Moreover, preparatory courses, personal guidance and tutoring, and the formation of a cohesive student community alleviate integration problems.

Keywords: Information technology education, engineering competence, cultural schema, neuroscience and learning, immigrants 


\section{Tiivistelmä}

Kansainvälisesti suuntautuneiden, englanninkielisten koulutusohjelmien tarjonta on viime vuosina kasvanut nopeasti Suomen korkeakouluissa. Koulutuksen tuloksia ja vaikutuksia on tutkittu vielä niukasti. Tämä tutkimus kartoittaa opiskelijoiden kognitiivisia ja oppimisprosesseja sekä insinööriajattelun kehittymistä ammattikorkeakoulussa tietotekniikan Bachelor of Engineering ohjelmassa.

Työssä on yhdistetty antropologian sisäistettyjen skeemojen käsite sosiokulttuuriseen oppimisen teoriaan käyttäen hyväksi aivotutkimuksen oppimista koskevia tuloksia. Näin muodostettua teoriapohjaa on testattu vertaamalla empiirisiin kokemuksiin, ja todettu sen selittävän hyvin opiskelijoiden käyttäytymistä monikulttuurisissa ryhmissä. Tutkimus tuo myös esiin oppimisen ruumiillistuneet, emotionaaliset, yhteisölliset ja motivoitumiseen liittyvät näkökulmat teknillisessä koulutuksessa. Käytännön tutkimustyö koostuu kyselytutkimuksista, kenttähavaintoaineistosta ja opiskelijoiden tuottamien tekstien analyysistä.

Ihmisten käyttäytyminen riippuu kasvatuksessa omaksutuista ajattelumalleista eli skeemoista ja toimintatavoista eli skripteistä. Aiemman käsityksen mukaan kyky noudattaa yksityiskohtaisia proseduraalisia ohjeita on ihmiselle synnynnäinen ja kulttuurista riippumaton. Tämän tutkimuksen perusteella se on vahvasti riippuvainen kontekstista ja siihen vaikuttavat kulttuuri- ja koulutustausta. Samoin tieteellinen ajattelu on kulttuurisidonnaista, ja erityisesti tässä tutkimuksessa on havaittu koulutustaustan aiheuttavan eroja teknisessä osaamisessa ja teknologian omaksumisessa. Jotta koulupohja olisi riittävä tekniikan opiskeluun, on koulutuksen pitänyt kaikissa vaiheissa järjestelmällisesti kehittää loogista ajattelua, ongelmanratkaisukykyä ja teorian soveltamista käytäntöön. Myös numeeristen taitojen varhainen oppiminen vaikuttaa matemaattisiin kykyihin aikuisiässä. Tässä tutkimuksessa havaittiin myös, että ohjelmointitaitoihin vaikuttaa sekä opiskelijan englanninkielen taito että äidinkielen kirjoitusjärjestelmä, varsinkin jos se on ollut ideografinen tai tavukirjoitus, koska nämä kehittävät erilaisen merkkien hahmotustavan aivoissa. Hahmotuksen yksityiskohtainen tutkiminen tulee olemaan haaste aivotutkimukselle.

Tutkimuksen perusteella on ilmeistä, ettei tavanomainen, suomalaisille ryhmille suunnattu tekniikan opetus sellaisenaan sovellu monikulttuuristen ryhmien opetukseen. Opetuksen suunnittelussa on kiinnitettävä huomiota opetuskokonaisuuksiin, opetusmenetelmien monipuolisuuteen, ja opiskelijoiden itseohjautuvuuden järjestelmälliseen kehittämiseen. Maahanmuuttajille tarvitaan valmistavia opintoja ja henkilökohtaista ohjausta. Yhteisöllinen oppiminen ja ryhmätyöskentely edistävät opiskelijoiden sopeutumista ryhmään ja suomalaiseen opiskelukulttuuriin. Parhaiten toimivat monikulttuuriset ryhmät koostuvat useista kansallisuuksista, joista mikään ei ole dominoiva, ja ne myös tuottavat innovatiivisia ja luovia ratkaisuja.

Avainsanat: insinöörikoulutus, kulttuurinen skeema, neurotiede ja oppiminen, tietotekninen asiantuntijuus, maahanmuuttajat 


\section{Acknowledgements}

My students are first to be acknowledged. The book is theirs as much as mine.

I wish to thank my advisor professor Riitta Smeds for her open-mindness to accept me as her student and her guidance and encouragement throughout the project. I am grateful to the preliminary examiners Judith Green and Ritva Engeström for their dedicated reading and invaluable advice, which has added clarity to the manuscript. Professors Christina Krause at the University of Helsinki, and Eila Järvenpää at Helsinki University of Technology kindly supervised my studies in cognitive science. Special thanks are due to Saku Mantere for his research methods course and advice regarding theoretical foundation.

I have benefited greatly from my interactions with the cross-disciplinary team of the Centre for Research on Networked Learning and Knowledge Building in the Department of behavioural sciences at the University of Helsinki. I wish to express my gratitude to Kai Hakkarainen who invited me to their seminars, and seminar participants Liisa Ilomäki, Kari Kosunen, Minna Lakkala, Jiri Lallimo, Hanni Muukkonen, Sami Paavola, Antti Salovaara, and Seppo Toikka. They read many of my draft papers, and made innumerable helpful suggestions. I also learnt much from their research pursuits and presentations.

The research seminars at SimLab helped me advance my project. Anna-Kaarina Kairamo, Jussi Koskinen, Anna Vianello, Marika Vänttinen, Erja Väyrynen, and other participants and fellow students are to be acknowledged. My research assistant Laura Salonen very competently entered survey data to Excel sheets, and Teemu Vauhkonen performed SPSS analysis on the data.

Colleagues at EVTEK provided support all along the project, showing admirable patience in listening, sharing their views and experiences, and participating in my surveys. I am especially grateful to Markku Karhu, Timo Leinonen, Liisa Vehkaoja and Kirsti Äystö for personal, intellectual, and practical support. Moreover, Ulla Forsström and Arja Pihlajisto gave untiring research assistance. Raakel Peltola helped me to conduct the survey by overseeing it in her classes. Kimmo Saurén and Jarkko Vuori allowed me to publish their social circuit drawing as an example of engineering thinking. My deepest thanks go to the entire community at EVTEK for all the fun and struggle.

My friend Marja Vehviläinen has remained supportive since our research collaboration on women and technology began in 1982. Our endless conversations over science and life have shaped my thinking in many ways and provided new ideas. Special thanks go to Merja Karppinen for the final spark to start this research project. When she was working on her own dissertation, we had long discussions on 
culture, engineering thinking, and multicultural education. Her multidisciplinary project inspired me to look for possibilities to seriously start my own. Our conversation with James V. Wertsch directed my thoughts back to the idea of social formation of mind. Interviews with Anne Alitolppa-Niitamo were extremely helpful in planning the research, as she was able to outline the situation of immigrant studies in Finland. I am also indebted to Andrea Colussi and Anna-Kaisa Ant-Wuorinen for helping me think through the ideas on engineering mind and characteristics. Warmest thanks to Kaisa for the cover graphics as well!

I remain in debt to Hilkka and Yrjö Seppälä for intellectual guidance and friendship. Their memory will always be an inspiration for me. There are many more people in my life who have influenced my views on culture and cognition: first of all Natsuki, with whom I have practiced cross-cultural communication over the years, as well as colleagues and friends in the United Nations community and all over the world. I am deeply grateful to them all.

My parents always encouraged my intellectual pursuits whatever directions they took. They have provided us children an excellent knowledge base in their large library. I wish to extend my thanks to my sisters and brothers, and to my talented little nieces for inspiration and insights to the development of thinking: conversations with Helena, Anna, and Elsa have been delightful and happy moments.

My greatest debt is to Aiko who read and commented on several versions of the manuscript providing editorial assistance throughout the project. I want to thank her for her love, patience, scientific insight, and companionship.

Espoo, February 2009

Jaana Holvikivi 


\section{Contents}

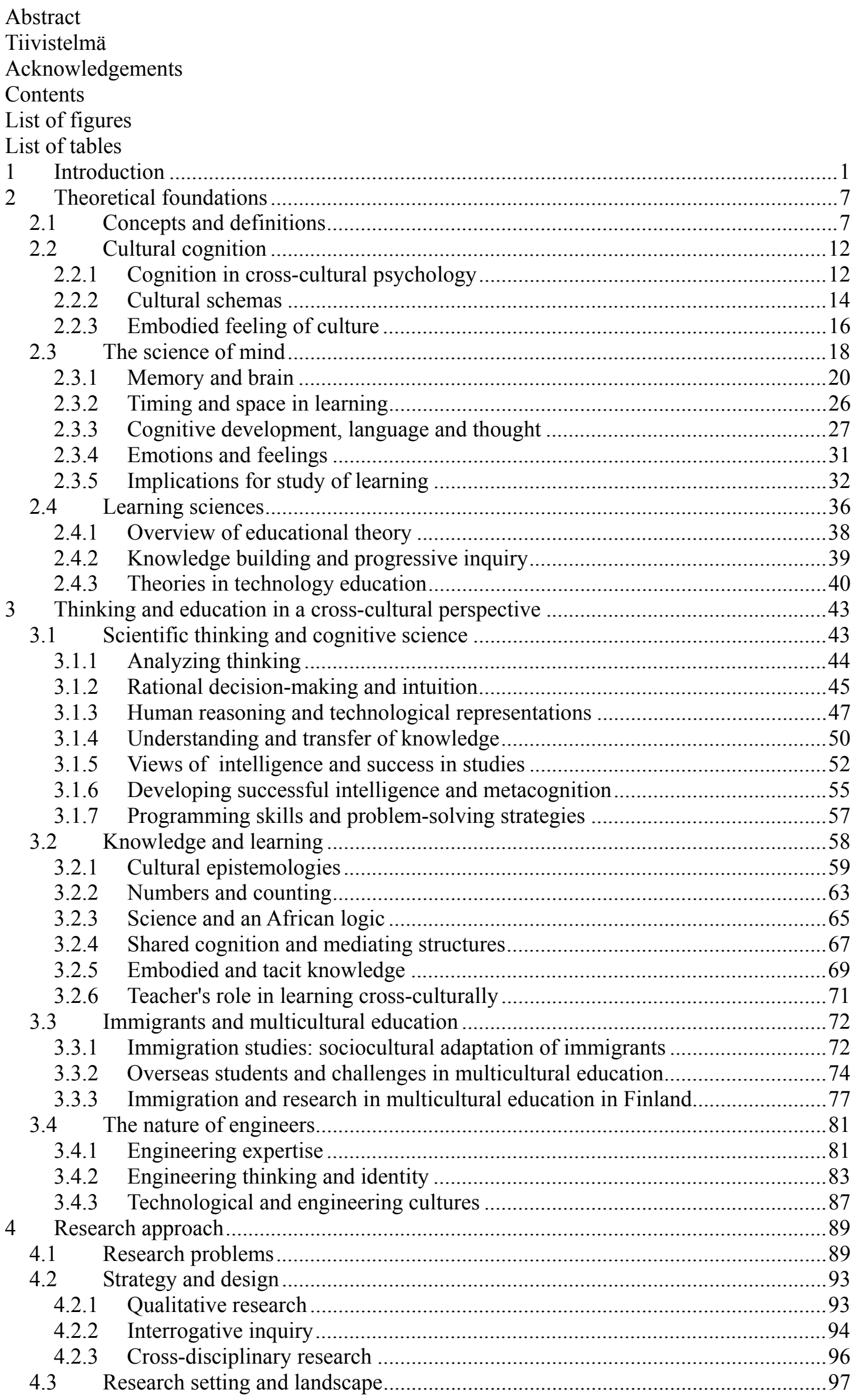




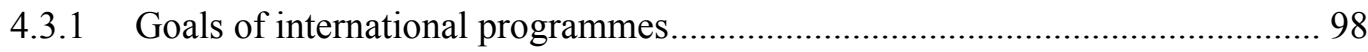

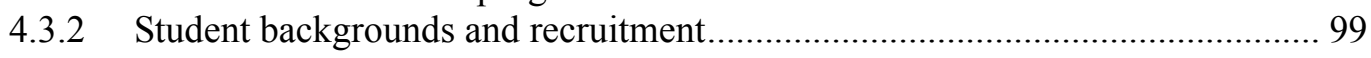

4.3.3 EVTEK experiences: efforts to address multiculturalism............................. 100



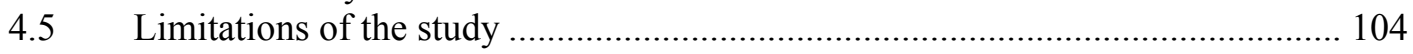

4.5.1 Researcher and research subjects: ethical questions ..................................... 104

4.5.2 Possibilities and challenges of educational research .................................... 106

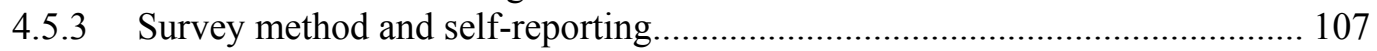

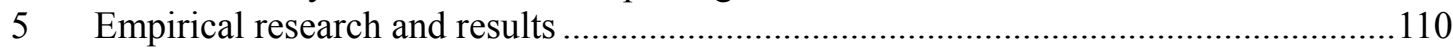

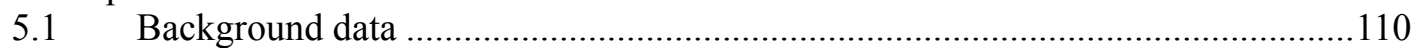

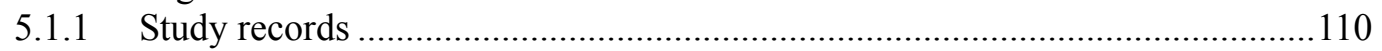

5.1.2 Self-conception and study motivation ............................................................11

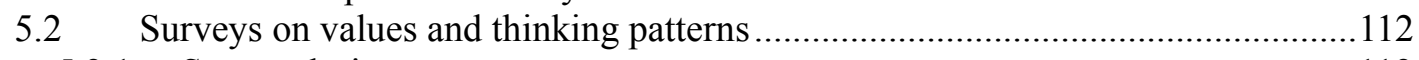

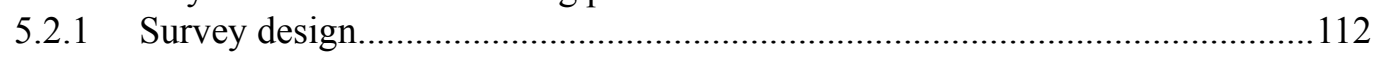

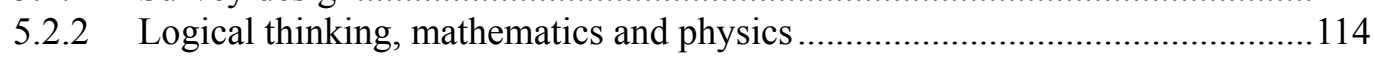

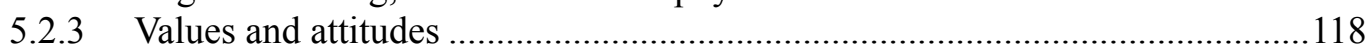

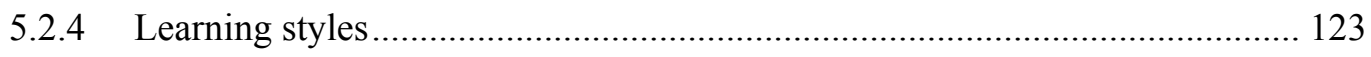

5.2.5 Assessment of survey method in measuring values........................................ 124

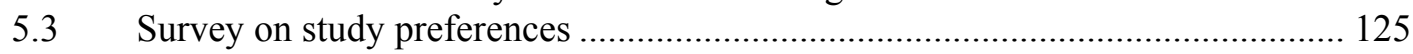

5.3.1 Finnish and international preferences for teaching modes ............................ 126

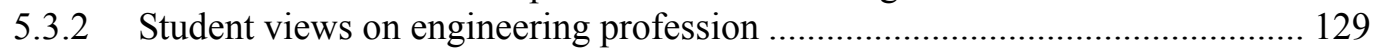

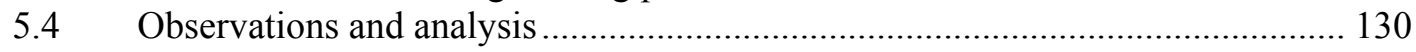

5.4.1 Classroom observations in first-year courses ................................................ 130

5.4.2 Alphabetical order, student names, and character systems ........................... 135

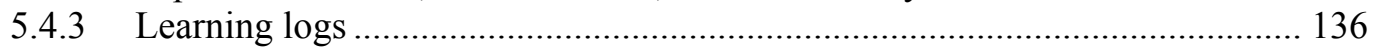

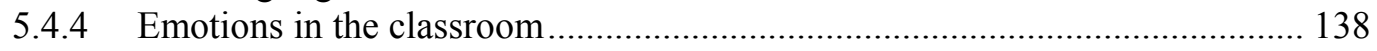

5.4.5 Space and time and group relations in multicultural classrooms..................... 142

5.4.6 Summary and evaluation of observations .................................................... 144

5.5 Following instructions - puzzle solved? ...................................................... 148

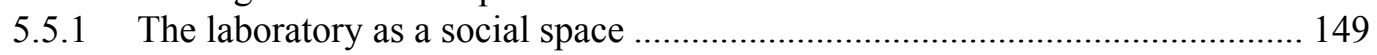

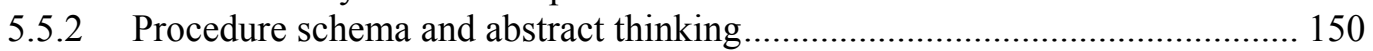

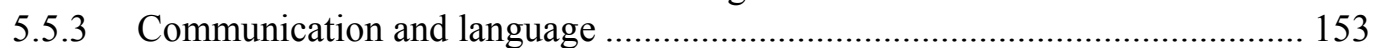

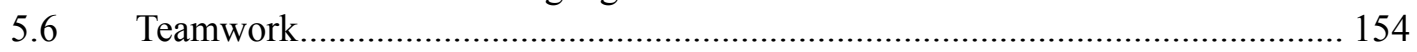

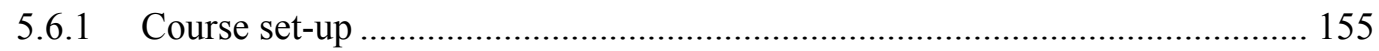

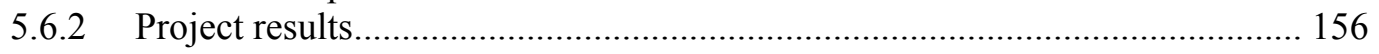

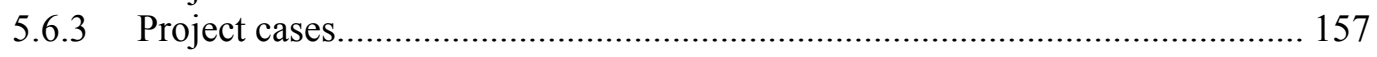

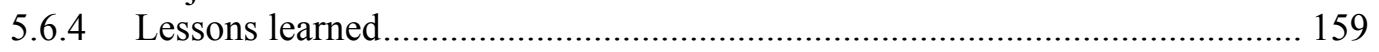

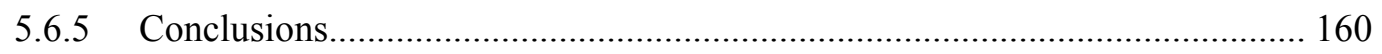

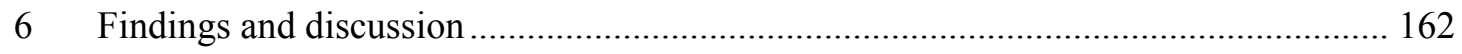

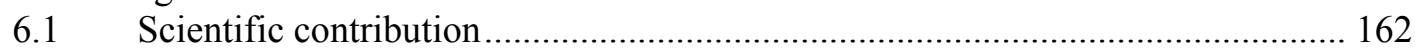

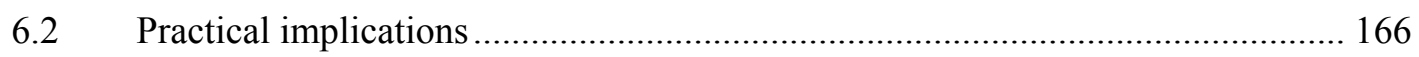

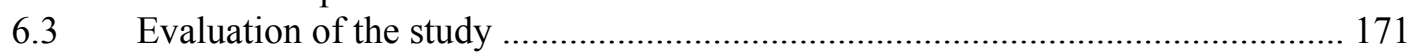

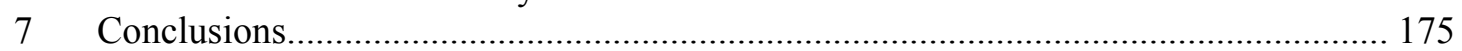

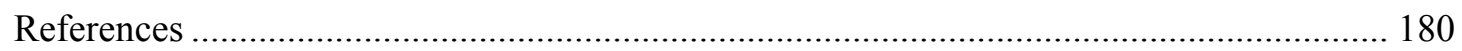

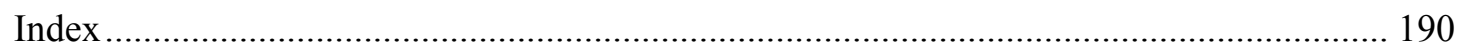

\section{Appendices}

1 Questionnaire 1: Scientific thinking

2 Questionnaire 2: Studies

3 List of sources for value questions and classification of questions

4 Study preferences, responses

5 Relationships of cognitive theorists

6 Relationships of educational theorists 


\section{List of figures}

Figure 1: Theoretical framework 6

Figure 2: The ecocultural framework 13

Figure 3: Left hemisphere of the brain 21

Figure 4: Polymodal perception $\quad 22$

Figure 5: Functional model of memory 24

Figure 6: Factors contributing to the learning process 37

Figure 7: Interpreting an image $\quad 49$

Figure 8: A framework explaining the variability of school

$\begin{array}{ll}\text { performance of children with an immigrant background } & 78\end{array}$

Figure 9: Social relations in the IT department 84

Figure 10: Research process $\quad 95$

Figure 11: Research approach 96

$\begin{array}{ll}\text { Figure 12: Venn diagram of three hypothetical types of } & \\ \text { central representation of component processes } & 108\end{array}$

Figure 13: Linux directories $\quad 132$

Figure 14: Acculturation strategies in ethnocultural groups $\quad 144$

Figure 15: Constructing engineering expertise 176

\section{List of tables}

Table 1: Cognition, motivation and emotion in self-regulation 56

Table 2: Expectations on academic activities of international students and supervisors $\quad 76$

Table 3: British and Chinese academic expectations 77

Table 4: Shares of Finnish and international students in English
BEng programmes

Table 5: Nationality distribution of EVTEK international students 99

Table 6: Materials and data 101

Table 7: Course results for national and international students:
passing rates

Table 8: Completion of courses in 2005-07 111

Table 9: Results of analytical thinking tasks 114

Table 10: Number of correct responses by faculty,
by the language of the questions

Table 11: Examination success in file transfer calculation 118

Table 12: PCA of the value survey 121

Table 13: Survey respondents $\quad 125$

Table 14: Types of typical assignments $\quad 127$

Table 15: Student views on engineering 129

Table 16: Use of artifacts in the EVTEK computer environment 132

Table 17: Cognitive competences and problem areas 163

Table 18: Cultural differences in cognitive competences
and examples of findings

Table 19: Tentative requirements for student cognitive abilities $\quad 168$

Table 20: Data analysis domains, use of theoretical tools 173 



\section{Introduction}

This is my report. It's the first time that I follow an exam with so free rules like this and I'm not so sure to have understood how it should be written...

This is my journal written day after day about my experience in the class.

I hope there aren't too many grammar mistakes and that it is not too boring; sometime same concepts are rewritten two or more time with different words, in different class stamp, like it was in my mind...

Lesson after lesson some ideas became certain and some others were missed on the way...

Do I like this way to work? I love it...

An exchange student at EVTEK 2007

Finnish higher education experienced a surge of new international degree programmes in the early nineties. The newly established polytechnics, now called universities of applied sciences, encouraged by the government, were eager to start offering Bachelor of Science and Engineering programmes. Information technology education, in particular, has been emphasized on the policy level (Committee on the international strategy of higher education institutions 2001). The launch of international programmes by and large consisted of simply translating lectures into English. Changes to the curriculum were negligible. It was not until a decade later that research into the results of this education and student experiences begun. The body of research on student adaptation to a new country and culture, studies concerned with the consequent problems experienced by immigrants and sojourners, and foreign student experience in Finland is already notable (Alitolppa-Niitamo 2004, Kinnunen 2003, Helenius 2007, Teräs 2007). However, the impact of research findings on educational planning and practice has until now been lacking (Rogers 2007).

This research was conducted at the EVTEK University of Applied Sciences, which merged with another polytechnic in August 2008, changing its name to Helsinki Metropolia University of Applied Sciences. However, as this research has been conducted between 2001 and 2008, it is more accurate to speak of EVTEK, which was the name during that period. Since 1998, I have worked as a lecturer in information technology at EVTEK, teaching various student groups, including regular day classes for young Finnish students, evening classes for adult students in degree programmes and in continuing education, international students in degree programmes, as well as exchange students. The groups have been strikingly different displaying considerable variety in learning approaches and engineering abilities. Even though course assessment runs on a linear scale from 0 to 5 , student talent cannot be ranked similarly in one dimension. The multidimensional character of student scientific thinking and cognitive styles seems to call for a variety of teaching approaches and flexibility in education.

This research is an exploration of the variety cognitive styles among engineering students. Its immediate goal is to understand the diverse and ever-changing EVTEK international student body. Many new students come directly from their native countries in Asia or Africa with no prior personal experience of life in the West. Some students find it difficult to adapt to the study environment and to achieve their goals, partly because of a mismatch of cultures of learning. This study assumes that the 
challenges are due to differences in education systems they come from, cultural differences in cognition, and perhaps also ontological and epistemological differences in student thinking. These hypotheses are explored in this thesis.

The particular focus of the present study is on cognitive processes and learning strategies of students in multicultural groups and the subsequent development of professional expertise in engineering areas which have been studied very little internationally and hardly at all in Finland. Because of the scarcity of research in this field, the subject of the study also has international significance, particularly in the development of theory of education and cognition in engineering. The aim of the research is to produce results that can be used to improve engineering education at polytechnics and universities.

The research was accomplished in connection with the SimLab experimental research centre at the Helsinki University of Technology (TKK) under the supervision of professor Riitta Smeds. Supporting studies and collaboration in theoretical development have been carried out at the University of Helsinki Faculty of Behavioural Sciences, in particular in the Laboratory of cognitive science and together with the Networked learning and knowledge building research team led by professor Kai Hakkarainen. Nevertheless, the practical research is a one-person enterprise, constrained by scarce funding.

\section{Research objectives}

The need for this research surfaced when I conducted pedagogical studies to qualify as a teacher in 2000 - 01. Part of the studies consisted of a research project in collaboration with colleagues Timo Leinonen and Lauri Toivio, which, in our case, was a development plan for the computer engineering degree programme curriculum (Holvikivi et al. 2001). During the background study for that research it became apparent that there was a substantial gap in knowledge concerning multicultural engineering education. Evidently, new research was needed to seek answers to questions with regard to the universality of engineering thinking and knowledge. Do actual differences exist in learning and problem-solving in engineering students that depend on their home culture? How could student algorithmic thinking, ability for systematical analysis and understanding of abstract concepts be enhanced? And finally, how could instruction be developed to improve student understanding of technology?

Moreover, teachers at EVTEK often encountered puzzling situations with students from other cultures that they could not fully comprehend. Student behavior was unexpected and difficult to understand, as they did not achieve the goals of their studies. Communication between students and teachers failed in a manner that was difficult to amend. More questions emerged concerning intercultural communication and absorption of scientific thinking. A deeper understanding of cognitive and learning 
processes of international information technology students was needed. Eventually, a better mutual understanding could help EVTEK and other universities benefit from the variety of student backgrounds. We should seek approaches that enrich our ways of working.

This study attempts to develop explanations that could bridge the gap in communication and help in developing an well-functioning and productive working environment. However, the current research has concentrated mainly on the incoming students and beginning of studies. Therefore, the development of student thinking over the four-five year study period has not been traced yet.

\section{Situating myself}

When Regina Harrison $(1989,4)$ translated Andean songs to English, she observed: "In the process of understanding the Quechua-speakers' system of values we may come to embrace the mystery of our own selves, which we often neglect in pursuit of our own revered objectivity". We need to see the difference in order to gain understanding. I aim at learning through difference in this research project; it is a journey in which everything is interconnected - as is always the case when human behavior is the object of research.

We are all products of life experiences, our selves consist of the autobiographical memory, and thus we carry cultural influences in our minds, brains and bodies. I myself have been exposed to five different cultures in my life, and I share some habits and cultural schemas with the Finnish, Tanzanian, Japanese, American, and French cultures. Each living environment leaves traces eventually forming a multicultural, 'nomadic' person, in my case a half-Japanese diet, a dash of American optimism, French flexibility and tendency for griping, and hopefully some African tolerance.

Moreover, certain theories used in this research relate to my own experience, and therefore they became more vivid in my mind and were easier to understand. Karin Knorr Cetina (1999) studied scientists at CERN, a place I knew during my sojourn in Geneva. Edwin Hutchins (1995) presents a study on Micronesian navigation, which reminds me of my brief consultancy in Ponape, Federated States of Micronesia, and an unforgettable boat trip that we made to the ruins of the ancient city of Nan Madol. Additionally, studies of cognitive development offer a chance to compare the experiences with my own child and my dear nieces, who always open new ways of seeing the world with their surprising questions and remarks.

My first effort to describe the use of information technology in different cultural settings was the paper Working with microcomputer users in developing countries- cases from Tanzania, Micronesia and the Maldives (Holvikivi 1991) in the Women, work and computerization IFIP conference. My experience in three developing countries had exposed differences in practical settings, as well as differences in the attitudes towards work and use of technology. I did not notice any cognitive differences at that time, 
though, or rather, I attributed the differences to attitudes. Incidentally, a recent study to conditions for the use of computers and communication technologies and education in Tanzania interestingly reveals that the situation remains broadly the same as during my stay over 20 years ago (Vesisenaho 2007).

\section{Introduction to theory and arguments}

It is to be noted that when any part of this paper appears dull there is a design in it. Sir Richard Steele

Learning has mainly been studied by two very different disciplines, educational science (pedagogy) and psychology. Educational sciences have studied processes in the classroom, whereas psychology has concentrated on individual memory and learning processes that can be measured in the laboratory. Though several researchers have tried to close the gap between these two lines of research (Sternberg, Gardner, Vygotsky, Bereiter, Hakkarainen \& Lonka), more cross-fertilization between the two would be desirable. In addition, neuroscience has produced remarkable results in the last twenty years, which have not yet been integrated with the psychological knowledge. Neuroscience probably has much to offer to the theory of learning.

The theoretical goal of this research is to contribute to multicultural education, engineering and information technology education studies where a lacuna of theory is apparent. These fields are principally applied sciences without any significant theory of their own (Banks 2004, Landis 2004, Gärdenfors \& Johansson 2005, Crawley et al. 2007). Most of the research is pragmatic, concentrating on best practices and case studies, as can be observed in journals in the field, and conferences of the ACM, for example. Moreover, when psychological or pedagogical theories are used, they may be outdated in their respective fields, as my presentation of the use of Kolb's learning styles in section 5.2 illustrates (see Holvikivi 2007b).

The first major part of this thesis covers an extensive theoretical review. It is uncommonly long because of the cross-disciplinary nature of the research, and the novel approach to engineering education. The theoretical construction is an amalgam of several theories, therefore it is indispensable to build a foundation from which the conclusions are drawn. What I propose here is a theoretical framework that is up-to-date vis-à-vis research in principal disciplines that study learning processes, cognition, and cultures. This is the first effort to construct a coherent theoretical foundation in multicultural information technology education, and, therefore, this research elevates studies in IT and engineering education to a new level.

The research is cross-disciplinary, covering anthropology, cognitive sciences, and learning sciences. Anthropology has many competing views but no uniform theory that the scientific community could agree on. My views are based on the theory of internalized cultural schemas by Claudia Strauss and Naomi Quinn (1997), which is relevant in the multicultural classroom, and distributed cognition by Edwin Hutchins (1995), which is relevant for knowledge building and technological education. 
According to the assessment of Strauss \& Quinn, the two views do not conflict. They will be presented in section 2.2 .

Modern neuroscience is capable of explaining functions of the brain to a degree that can assist in developing the established modern learning theories. With the help of an understanding of perception and memory, many aspects of learning can be explained. The presentation of brain studies and science of mind in section 2.3 is highly selective, and aims at giving a preliminary sketch of how learning processes in the brain are believed to function, and how these processes are related to the learning conditions of a human student.

The presentation of learning sciences in section 2.4 is largely an overview of the most important and influential theories in Finland, and a summary of current trends in ICT education. My main contribution in this part is the selection of views that I find useful for my research.

The pedagogical ideas applied in this research which are incorporated in the progressive inquiry model are based on epistemic logic by Jaakko Hintikka (2001). His interrogative process of scientific inquiry is also applied here as a research method. However, this is very much an engineering thesis in that it attempts to find pragmatic solutions using all available means and theory. The basis of the theoretical framework emerged during the research process through reading, inquiry, testing of ideas, and in dialogue with data and other researchers. The foundations of the theoretical framework depend on prior work in other disciplines, and therefore much of it refers to secondary sources. However, through a careful validation process I have tried to ensure that the sources represent prominent work in each respective field. The framework is depicted in figure 1.

In the sections on scientific thinking (3.1), knowledge (3.2), and engineers (3.3), I present other material that has significance for the theoretical view. Despite the diverse nature of disciplines and theories included, they have been cross-checked to be compatible on a general level. Many scholars explicitly refer to each other, proposing a compatibility, and, moreover, some writers refer to the same influential thinkers and theories, agreeing on their central points (Appendices 5 \& 6). Many theories that are used here share common fundamental ideas: zone of proximal development and mediating artifacts; embodied knowledge; the interrogative method of inquiry; shared cognition; connection of feeling and cognition. Even though the theories examine reality from extremely different angles and represent differing levels of abstraction, they allow a pragmatic synthesis. 


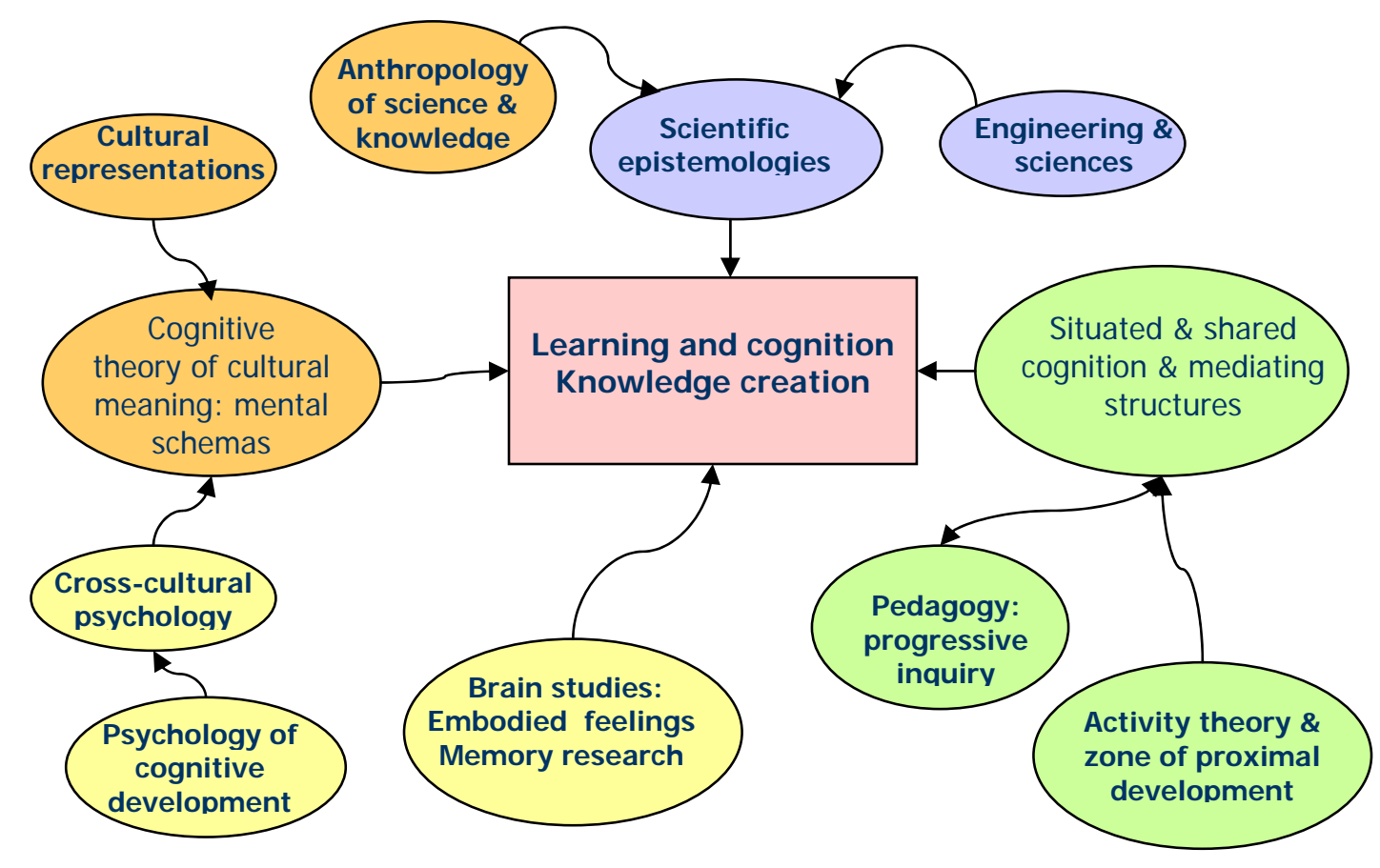

Figure 1: Theoretical framework

The research setting and methods are presented after establishing the theoretical framework. The methods are varied: background information was collected from student statistics, conferences, and meetings on multicultural education, as well as through interviews with colleagues and other researchers. The research started with surveys on student attitudes (reported in 5.1, 5.2 and 5.3), and with a continuous field note collection that contained observations in the classrooms and among faculty. I owe thanks to many colleagues who teach different types of courses for their valuable observations, as well as other staff. Much of the textual research material has been produced by the students: over 120 learning logs, about 100 project reports, assignment reports, and assignments such as programs and Websites that enlighten their learning process. The observations are reported in sections 5.4 and 5.5. The case study presented in section 5.6 was action research of a study module that was repeated every year, in slightly improved versions. Chapter 6 summarizes research findings and gives some practical advice for planning of education. The conclusions are drawn in chapter 7 . 


\section{Theoretical foundations}

\subsection{Concepts and definitions}

The principal question in this thesis concerns the cultural variability in learning information technology. How much does culture affect cognition? Are cognitive abilities universal or contextdependent? Cross-cultural studies in different disciplines have attempted to answer these questions, often comparing large, unspecified cultural units such as Western (often equated with U.S. American), Chinese, or a particular indigenous culture. For the purposes of this study, cultural influences in the minds of individual students have to be reached, therefore a more accurate definition of culture is needed. In this section, the concepts culture and cognition are discussed in order to help the reader to understand how they are used in this thesis. Moreover, the related terms multiculturalism, national cultures and schemas are defined.

\section{Culture}

The authoritative textbook on Cross-cultural psychology by Berry, Poortinga, Segall and Dasden contains a comprehensive presentation on the research and applications of the field of cross-cultural studies, including also an overview to the history of the concept of culture (Berry et al. 2002). The meanings and definitions of culture have changed considerably in anthropology and cross-cultural psychology over the decades. The very first definition was given by Tylor in 1871 who defined culture as "that complex whole which includes knowledge, belief, art, morals, laws, customs and any other capabilities and habits acquired by man as a member of society". The definition proposed by Herskovits (in 1948) "culture is the man-made part of human environment" has been influential in many studies. It differs from many other definitions as it includes the material world. Berry et al. (2002) cite the description of culture given by Kroeber \& Kluckhohn in 1952, which they find practicable:

"Culture consists of patterns, explicit and implicit, of and for behavior acquired and transmitted by symbols, constituting the distinctive achievements of human groups, including their embodiments in artifacts; the essential core of culture consists of traditional (i.e. historically derived and selected) ideas and especially their attached values; cultural systems may on the one hand be considered as products of action, on the other as conditioning elements of further action".

In the early years of cognitive anthropology in 1950s, culture was formulated as knowledge (D'Andrade 1995, 244), particularly verbal, linguistic knowledge, which resulted in creation of categorizations and taxonomies of cultural features. The idea of culture consisting of mental phenomena was challenged by Clifford Geertz and David Schneider, among other proponents of symbolic anthropology, which treated all cultural practices as part of the symbolic system. "The first task of anthropology, prerequisite to all others, is to understand and formulate the symbols and meanings and their configuration that a particular culture consists of." (Schneider 1984, 196) Symbolic anthropology removed culture from minds of people changing it to a web of meanings that has a structure. Meanings are interpretations evoked in a person by an object or event at a given time. 
Cultural meanings are shared by a group of people. Meanings are a useful conceptual tool in the analysis of technological artifacts, or to explain signs embedded in student products such as programs or home pages. Additionally, meanings can be used in analyzing engineering practices as markers of that professional culture. However, this is a static view that ignores processes and material practices, and its application has not been attempted here.

In opposite to symbolic anthropology, environmental determinism saw that environment is the decisive factor in shaping culture. However, according to current views the relationship between environmental conditions, material culture and human organization is not deterministic, rather, it is shaped in social interaction. It is also dependent on a set of cultural attitudes which cannot be predicted from or reduced to an environment. Most theories agree that culture is meaningfully constituted, which implies that aspects of culture are irreducible. The cultural relationships are not caused by anything else outside themselves. "They just are". (Hodder \& Hutson 2003)

Moreover, culture should not be considered 'a thing' that is static, instead, it is always in flux (D'Andrade 1995, 248). Culture does not exist outside individuals or communities, rather, it is intersubjectively negotiated. Hence, culture is a complex repertoire people experience, learn and act out, constantly recreated and molded. Culture is socially distributed, variably internalized, and embodied in external forms. Hutchins (1995) defines culture as a process instead of a collection of things. Berry et al. (2002) summarize that culture is the shared way of life of a group of people.

This study takes a pragmatic approach to the uses of culture. Culture will mainly be discussed in reference to culture as internalized in individuals, which is a human cognitive process. Additionally, culture is also a collection of shared meanings of a social group, such as engineering cultures and educational cultures that have certain practices, beliefs and artifacts. This study attempts to avoid references to 'national cultures' or 'ethnic cultures' because of the vagueness and inherent complications accompanied by these concepts. Neither do I see that replacing them by euphemisms like 'Confucian Heritage students' (Haller et al. 2007) allows us to escape from stereotyping, to the contrary. The study aims at finding the variety of individual cultural meanings in a multicultural community that would create a liberating space of cultural nomadism (Braidotti 1994, see also 3.3), and foster new ideas and creativity.

\section{Multiculturalism and cross-culturalism}

This study examines learning in multicultural settings. Multicultural refers here simply to a classroom with a diverse student body that consists of many nationalities. Cross-culturalism is distinct from multiculturalism. Whereas multiculturalism deals with cultural diversity within a particular social group, cross-culturalism is concerned with exchange beyond the boundaries of a nation or cultural group. Cross-cultural comparisons typically focus on a certain feature across many cultures. By the 
1970s, the field of cross-cultural communication (also known as intercultural communication) developed as a prominent application in international business studies, in response to the pressures of globalization which produced a demand for cross-cultural awareness training in various commercial sectors (Landis et al. 2004). The term transculturalism has also been used in a similar context, although some uses propose going beyond cross-cultural understanding in order to achieve a 'transculture' which is a holistic, multidimensional cultural space (Milhouse et al. 2001).

On the government policy level, some states such as Canada have adopted official policies of multiculturalism, which contain the promotion of tolerance of ethnic and cultural diversity as opposed to integration into the mainstream culture, more typical for example in the United States (Berry 2004). In Finland, the policy still seems to be undetermined.

\section{National culture and values}

As noted above, culture is often equated with national culture in many intercultural or cross-cultural studies. However, the existence of national culture has been debated in intercultural studies especially in connection with cultural values. The best known value survey is Hofstede's (1984; 1991) pioneering study of cultural differences in organizations, which aimed at understanding work related values of IBM employees in over 40 countries. Hofstede created five value dimensions by statistical analysis, and published lists of how countries are ranked on the dimensions. The dimensions are masculine versus feminine values, individualism - collectivism, power distance, uncertainty avoidance and long short -term orientation. The individualism - collectivism dimension in particular has been subject to much research by scholars such as Harry Triandis (2004), and it has been widely acknowledged as being a universal feature that describes cultural values. On the other hand, recent findings suggests that individualism and collectivism should be seen as separate dimensions and not opposites (Berry et al. 2002, 69).

A number of studies have been devoted to the evaluation of Hofstede's research. Perhaps most notably, McSweeney (2002) conducted an assessment of his methods and simultaneously reviewed other research done so far. McSweeney points out that the plausibility of a systematic causality from national cultural values to individual preferences is questionable. Applying the idea to individual thinking could lead to misguided results such as Hofstede's example of Sigmund Freud: Hofstede proposed that psychoanalytical theories were a consequence of Freud's Austrian value system. He did not discuss Adolf Hitler's ideology or Ludwig Wittgenstein's theories in the same context, however, despite their same national background. Obviously, culture does not automatically generate a certain kind of thinking or values albeit it undeniably influences behaviors. Earley (2006) proposes to use cultural meanings instead of value dimensions in organizational studies, because values as individual preferences and values on societal level easily become entangled in analysis and constructs. 
Additionally, there are many other extensive value surveys in social sciences, such as the World Values Survey and the Eurobarometer. The European Social Survey covered 22 countries in $2002-03 ; 40000$ people were interviewed on 21 questions about life values (http://www.europeansocialsurvey.org/). Interestingly enough, Finland's closest pair in values turned out to be France, whereas other Nordic countries were located differently in the value map. A cluster of Greece, Austria and Israel was most different from other countries. A closer examination of the ranking of the countries yields many surprises, for example citizens of Switzerland were very low (18th) in appreciating traditional values and rules despite their conservative reputation, whereas Finland and Belgium were in the middle (11th and 10th). This demonstrates that results of value surveys are difficult to interpret in regard to actual behavior of people.

As researchers in cross-cultural training, Bennett \& Castiglioni (2004) claim, we learn culture by embodied and emotional experience, not as a cognitive construct. When people need to encounter a new cultural environment, learning lists of cultural values or classifications is not directly transferred to action and behavior. In fact, attitudes such as tolerance and openness are decisive in the adaptation to a new culture and in trying to understand people in new settings. The present day globalized world requires flexible thinking and open attitudes, because people of all cultures become less stereotypical under multicultural influence. Even national cultures change, especially in consumer habits and onset of new youth subcultures. A preparedness for unpredictability becomes increasingly important. McSweeney (2002) concludes: "Instead of seeking an explanation for assumed national uniformity from the conceptual lacuna that is the essentialist notion of national culture, we need to engage with and use theories of action which can cope with change, power, variety, multiple influences - including the non-national - and the complexity and situational variability of the individual subject."

\section{Schemas}

Schema in psychology means a mental picture of a thing, which the mind uses to help perceive it more clearly. Cognitive scientists, on the other hand, use the term schema to refer to generic knowledge of almost any sort, like a television commercial schema, a marriage schema, or a sauna-evening schema. This more general sense, which indicates a standard or principle which the mind forms from past experiences, is used in this study. Schemas are learnt or innate mental structures that organize our knowledge. Moreover, a schema is an abstract entity that has no fixed physical shape in the brain. Rather, it is a network of neural connections that fire in approximately the same way each time the schema is activated. A schema that appears in a form of a series of actions or processes in time, is called a script. In the case of shared activity, scripts can reside in the minds of several people.

Schemas that are shared by a large group of people, could also be called cultural schemas or cultural models. Strauss \& Quinn (1997) introduce a theory of cultural meaning that is internalized in individuals, as opposed to models where cultural schemas are seen as common and shared by a 
'culture'. They emphasize that there are no homogeneous, stable cultures in modern society, and even within one culture people are complex and subscribe to conflicting schemas on different levels of thinking. For instance, people have their everyday concepts on one hand and scientific concepts on the other hand - concepts that may be mutually contradictory. Cultural schemas have to be studied in relation to action, emotions, and motivations.

\section{Cognition and cognitive science}

Cognitive science is the study of cognition. As the understanding of cognition has broadened, the scope of cognitive science has expanded to include new sub-disciplines. Bechtel \& Graham $(1998,37)$ trace the origins of cognitive science to the 1956 symposium on information theory at Massachusetts Institute of Technology. It gathered scientists interested in cognition to discuss related issues. In the beginning, cognitive science was strongly connected to AI (artificial intelligence), symbolic information processing, and language theories of universal grammar. Cognition was defined as information processing which follows rules and patterns that could be discerned by science, in particular by computer modeling, and it was understood to be systematic. Neural networks and language capabilities were explained using mathematical models. The brain was conceived as a kind of piece of machinery that could be controlled. Among scientists who had a great influence in the rise of cognitive science were Noam Chomsky, who developed the transformational grammar and consequently a Universal Grammar; information theorist Claude Shannon, computer scientist and pioneer in AI Marvin Minsky; decision-making theorists Allen Newell and Herbert Simon; and psychologist George Miller. Cognitive psychology became an important subfield of psychology around 1960 (ibid., 46) when memory models with short-term and long-term storage were presented.

The first Finnish textbook on cognitive science defined cognition to include thinking processes, perception, reasoning, and language (Hautamäki 1988). A renown cognitive scientist, Paul Thagard summarized still in 2004: "The central hypothesis of cognitive science is that thinking can best be understood in terms of representational structures in the mind and computational procedures that operate on those structures." However, A companion to cognitive science (Bechtel \& Graham 1998) takes a broader view on cognition, and includes emotional, social and instinctive aspects of cognition. That handbook also covers areas such as animal and social cognition, anthropology, education and psychology of emotions. Since computer technology revolutionized neuroscience in 1990s, the analysis of cognitive processes has been increasingly based on real observations on brain functioning. Biological sciences such as neurobiology, brain sciences, and cognitive evolution theories have recently gained more weight within cognitive science.

Also in this study, the term cognition is mainly used in its wide meaning to cover all aspects of thinking processes, and the broad meaning is, in fact, central to my approach. Cognitive processes will be discussed more in depth in sections 2.2 Cultural cognition and 2.3 Science of mind. 


\subsection{Cultural cognition}

Culture is the shared way of life of a group of people, including their practices, beliefs and artifacts. In this thesis, the concept of culture is mainly used to refer to culture as internalized in individuals; therefore, it is a human cognitive process. Cognition has been defined to include thinking processes, perception, reasoning, and language. As cognition, feeling and body cannot be separated in living organisms, in this study cognition is understood to include emotional, social and instinctive aspects, as proposed by Hutchins (1995). Cognition is a culture-specific domain of psychological functioning that is constantly evolving.

"Cognition is an area of cross-cultural research that has a history of strong controversies", Berry et al. (2002) warn. Indeed, discussion on cultural differences in cognition often lends itself to racist undertones which have caused avoidance of the whole subject. Nevertheless, cognitive processes are embedded in culture, and an artificial denial of their connectedness does more injustice to the subjects of study (see also Craig \& Beishuizen 2002). Therefore the starting point of this study assumes that cross-cultural differences are anticipated in the organization of cognitive activities, and they produce qualitatively different intelligent behaviors.

Unfortunately, difference often leads to inferior treatment of the minorities, because human beings have an innate tendency of valuation (Frank 2004), attaching instinctively a negative or positive value to difference. Difference is also a central concept in European philosophy throughout the ages, largely functioning on dualistic oppositions, which create subcategories of otherness. Simone de Beauvoir (1949) noted that power relations between sexes reduce difference to inferiority. In this respect, the system always represents 'otherness' as negativity, otherness including women, immigrants, blacks, etc. (Braidotti 2002). The dualistic philosophy separates body and mind, reason and emotion. Ahmed (2004) points out that the projection of 'emotion' onto the bodies of others not only works to exclude others from the (white male) realms of thought and rationality, but also works to conceal the emotional and embodied aspects of thought and reason. However, in this study difference is meant to present an opportunity, a challenge, and a resource, from which we can learn and which could increase innovation capacity.

\subsubsection{Cognition in cross-cultural psychology}

In cross-cultural psychology, cognition has been understood from four different perspectives (Berry et al. 2002):

1. A unitary view of cognition includes general intelligence (GI) that can be perceived and measured in all people. The GI concept is discussed further below.

2. Genetic epistemology that is based on the theories of Piaget distinguishes different cognitive structures that develop by age following genetic rules. I discuss it more in section 2.3.

3. Cognitive styles are tuned to the demands of the environment. 
4. Contextualized cognition that sees cognition as task specific and embedded in sociocultural contexts.

Current scientific views on cognitive abilities are predominantly based on the assumption that all humans basically share the same cognitive apparatus and potential, thus there is no systematic genetic or racial difference. The belief in inborn capacities has very little scientific support anymore. The opposite view suggests that cognitive processes are embedded in culture. The universalist perspective (Berry et al. 2002) takes up the middle ground. It considers that basic cognitive processes are shared species-wide. The main characteristics of cognitive functions and processes appear to be common to all human beings, as universally shared properties of our intellectual life. Culture influences the development, content, and use of these processes, but does not alter them in a fundamental way. This is illustrated in figure 2 .

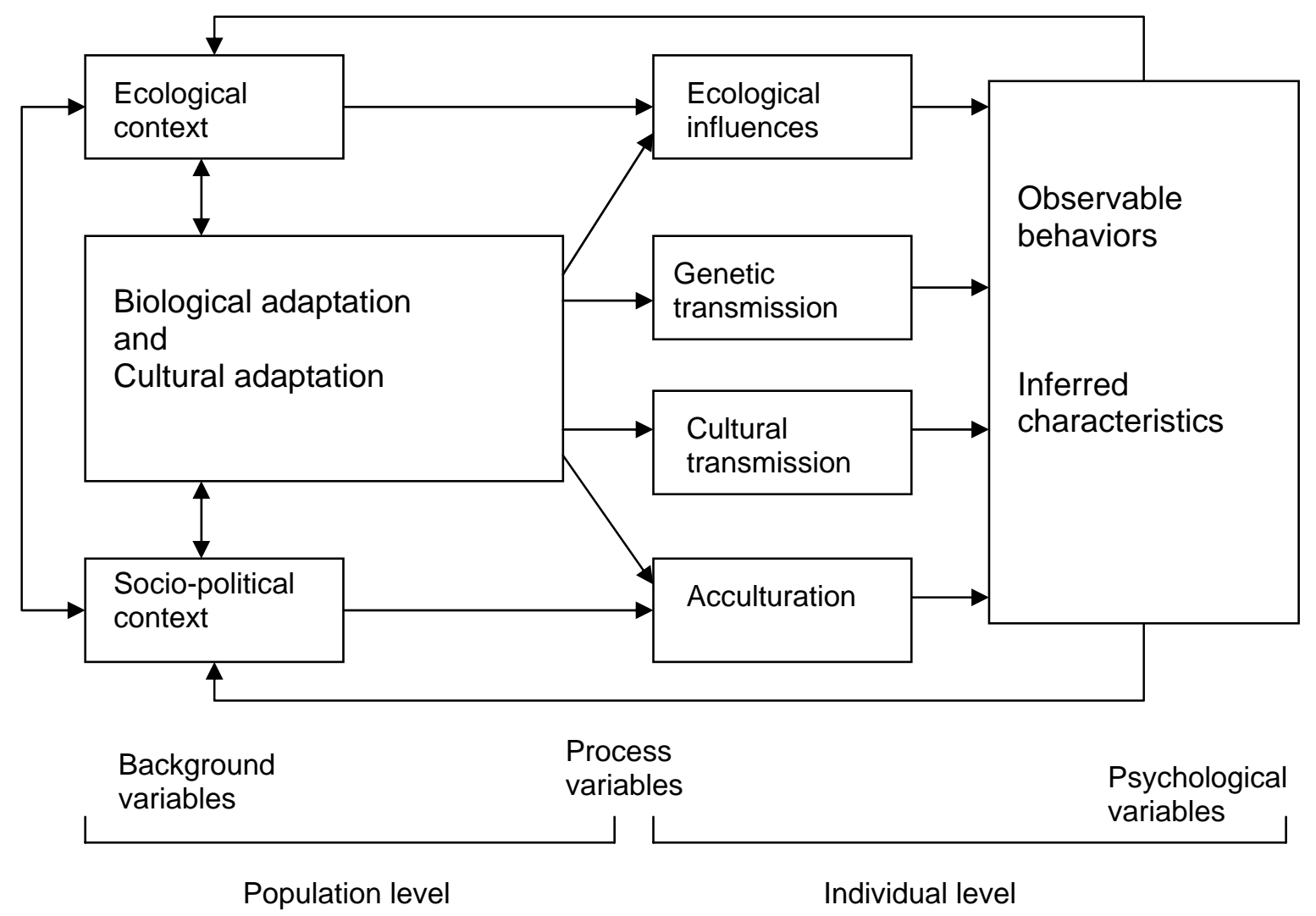

Figure 2: The ecocultural framework (Berry et al. 2002, 11)

However, the question remains: what is fundamental? Neuroscience has shown that, for instance, nutrition and mother's substance abuse during pregnancy affect the developing brain of an embryo and cognitive abilities later in life. Additionally, research has shown that children who have been kept in isolation or deprived conditions, have suffered cognitive impairments that could only partially be compensated for later. However, even a short six-week targeted training could result in general improvement of skills such as language, mathematics, and IQ in pre-school age children (Neville 
2007). Such findings indicate that our lives and potential are shaped by environment from the very beginning (Kalat 2004).

Berry et al. (2002) argue that biologically speaking we cannot go against our genes, though the observable repertoire in behavior is the outcome of a range of possible responses to the environment. Cognitive competencies develop according to common rules, but can result in highly varied performances that are responsive to ecological contexts and to cultural norms and social situations encountered during socialization and the situation where they are required. Therefore, genes are not a deterministic force that pre-empt choices in life, and no actual dichotomy between nature and nurture exists.

Roy d'Andrade (1995) gives a comprehensive overview of studies about differences in intellectual abilities between cultures in anthropology. He concludes his discussion about variation in cognitive abilities by saying "The simple point is that most people are smart because someone taught them the right models." Since so much of our intelligence and ability comes from having good cultural models, and these cultural models are held by a group which maintains the existence of these cultural models by teaching them to others, one can speak of cognition as socially distributed. Renown neuroscientist Chris Frith (2007) reminds us that without the ability to build and share mental models of the world there would be no language or culture.

\subsubsection{Cultural schemas}

The simplest images in the mind that are formed in the working memory and stored in the episodic memory are often called representations. A larger unit of an abstract representation of the environment is called schema in psychology and anthropology. A schema combines and organizes typical features to a pattern, or a framework in the mind to act upon. The extent of a schema can vary from simple tasks (cooking rice) to more complex schemas (preparing a dinner or a dinner party) that include subschemas. Schemas are an efficient way to comprehend events, and to process them in the mind. Consequently, schemas also develop and change based on experience.

Anthropology calls schemas that are shared by a group of people cultural schemas or cultural models (D'Andrade 1995). Strauss \& Quinn (1997) introduced a theory of cultural meaning that is internalized as schemas in individuals, in contrast to abstract meanings, which are detached from individuals. The schema theory sees individuals and groups of individuals as carriers of culture. Moreover, people are active carriers of culture who process and adapt their schemas continuously. In this study, it is a fruitful approach to see cultural schemas through individuals, because a variety of internalized cultural meanings meets and evolves in a multicultural community. 
The concern raised by proponents of situated cognition and activity theory is that focus on internalization ignores the way actions are shaped through ongoing interactions of people with each other and their material environment in the course of action. However, as the treatment of Vygotsky in section 2.4 elucidates, there is no actual conflict in these views. Strauss \& Quinn (1997) agree that it is important to look at situated cognition: "Interaction between people and their material environment or human peers can indeed lead to results that are surprising." Edwin Hutchins (1995) also asserts that his studies about the way cognition is distributed among people and cultural artifacts is not meant to "dissolve the individual and the psychology of the individual" but only to "connect what is in the person to what is around the person".

Quinn studied in detail how U.S. Americans picture marriage. (Strauss \& Quinn 1997) Through analyses of numerous interviews certain defining characteristics of the schema of American marriage emerged: It consists of successful events that have qualities of lastingness, sharedness, mutual benefit, fulfillment, compatibility, difficulty, effort, success, and risk of failure that are causally related. According to Quinn, the general schema of success in life is behind the schema of marriage, and it is closely related to the self-reliance that is a fundamental value in American culture.

Hutchins (1995) presents two schemas of navigation by comparing Western and Micronesian navigation. The Western navigation system is based on technical devices like the astrolabe, compass, maps and, more recently, GPS and radars. Hutchins describes the development of the Western navigation, starting with the regularities of the world such as the sky and stars, that are common with all navigation models. The Western tradition had three strands of development that set it apart: the increasing crystallization of knowledge and practice in the physical structure of artifacts, in addition to mental structure; the development of measurement as analog-digital conversion (such as the chip log) and the reliance on technologies of arithmetic computation; and the emergence of the chart and the plotted course as the principal computational metaphor for the voyage.

The mental framework in the Western navigation is a moving ship and stationary land, and the horizon is a circle. In the Micronesian system the canoe, the star points and the navigator are conceived as stationary, but the land moves and the horizon is a line. Moreover, the navigation is done without external aids or devices, it is fully based on the experience of the navigator. Though the Micronesian navigation model displays a completely other kind of cultural representation compared to Western navigation, its validity has been proven by the extensive sea voyages and migration of peoples in the Pacific. During a long period of observation, nearly all canoes succeeded in hitting land in an area where only $0.2 \%$ is land.

The concept of personality is another scientific cultural schema that has been defined in several ways in Western psychology. The prevalent view is based on the so called Big Five personality traits: 
extraversion, agreeableness, conscientiousness, neuroticism, and openness to experience (Berry et al. 2002). This view shares the essential feature of its predecessors that it considers personality residing within the individual mind. It also assumes a certain understanding of the self, a person with an identity and rather permanent abilities typical for individualist cultures. In contrast, the self in collective cultures is defined through a person's community relations and obligations.

The African view of personality and personal health as explained by the Senegalese psychiatrist Sow connects the person with her ancestors, family lineage and community. The personality consists of four concentric layers (ibid., 105):

1. Body, the outmost layer.

2. Physiological vitality principle that is influenced by the environment and community. A disturbance can cause mild diseases.

3. Psychological vitality principle that connects the person to the family lineage, and a disturbance in it can cause serious illness.

4. The spiritual principle has an existence of its own (like a soul), and exists even after the death. Psychology and medicine based on this view would differ dramatically from their Western counterparts. A study by Eminah (2003) investigated how a group of university students conceptualized HIV/AIDS in Ghana. While some of the research subjects attributed the disease to natural causes and risky sexual behaviors, about $40 \%$ attributed it to witches, demons, the invocation of curses and the breaking of taboos, and therefore believed that the best cure was traditional medicine (witchcraft).

\subsubsection{Embodied feeling of culture}

There is an intuitive feeling of culture that is built on sensory feeling, but it resides more at the interface between physical sensation and conscious awareness - what is referred to as embodied feeling (Bennett \& Castiglioni 2004). The reader might get a sensation of it by imagining a pleasant situation:

You are having lunch in an Italian trattoria. Close your eyes and feel the sounds, smells, and air around you. Are you relaxed, alerted or tense? How do you feel the space, how do you breathe? Then shift to a dinner in a Japanese style restaurant: can you recall the sounds, smells, and air around you? Are you relaxed, alerted or tense? How do you feel the space, how do you breathe?

Parts of the experience of cultural environments consists of food, drink, smells, sounds, appearance of people, and warmth. For instance, my personal experience of the Maldives includes the saline, smelly tap water; the hot sun on quiet, sandy beaches, and the underwater tranquility when watching colorful fish pecking on corals. Bennett \& Castiglioni (2004) discuss cultural self-awareness in the context of intercultural training, stressing that it does not suffice to simply know the values and common patterns of behavior of one's own culture. It is also necessary to become sensitive to the feeling of appropriateness that accompanies those patterns. The word feeling is used by Bennett \& Castiglioni (2004) in both its physical and metaphorical aspects. The physical aspect of feeling refers to sensory 
experience, like feeling hot. In the metaphoric aspect, feeling refers to the intuitive grasp of a situation, such as "He has a feeling for how the group wants to proceed."

Culture as bodily experience includes the physical distance between people, and frequency of touching. The young Finnish philosopher Pekka Himanen related in a television talk show (17 April 2005) an incidence how he attended a workshop in Davos together with bishop Desmond Tutu. Tutu, who sat next to him, placed his arm around his shoulders and kept it there during the conversation. This was an episode for Himanen to remember but apparently just normal behavior for Tutu, and if Tutu remembered the workshop later, it was not for this reason. In Finnish culture, touching another person is not customary, and it is rare even within families. While in southern cultures, people tend to feel troubled by a lack of physical proximity, many Finns find touching threatening or even a cause of anxiety.

According to Bennett \& Castiglioni (2004), intercultural communication trainers generally believe that understanding cognitive constructs such as the values of a target culture can be directly translated into actions, such as modified social behavior in that culture. Intercultural training often includes learning of lists of cultural values and studying cases where "others" behave in strange way. When the mind and body, and cognition and behavior are separated, the body is seen as a vehicle for action initiated by the mind. The cultural experience itself is ignored, and this approach is unable to adequately explain the translation of cognition and attitudes into behavior. I claim in this thesis that it is not only in social behavior where the feeling of culture matters, but it also affects our relation to technology and the way we learn computer science.

Even intellectual tasks, such as writing and doing arithmetic, have an embodied cultural component. Tools for writing vary from pen and paper to brush and ink, and to typewriters or computer keyboards. Writing Chinese characters with a brush requires full body control and the strokes are learnt as body movements. Thus, learning characters is not only an ability to recognize the pattern but to repeat it in a certain order as well. Karppinen (2006) proposes that the Japanese writing system, in particular, develops creativity and innovative thinking because of its many forms. Japanese may be written in three directions, and it uses two syllabaries (kana), one ideographic character set (kanji, Chinese characters), and the Latin alphabet. Additionally, the writing of kanji develops hand coordination and aesthetic sense significantly more than writing Latin characters. Learning Chinese characters is a lifelong enterprise because of their large number and complex shape.

Embodied feeling of culture resides also in cultural artifacts, for instance in the kind of clothing we wear and feel comfortable in, what kinds of utensils we use for eating, and so on. A friend from Kosrae, Micronesia, explained to me that she enjoys eating with fingers, because the touch of food is one aspect of the experience. I, on the other hand, find it trying to eat with fingers because I tend to burn 
them in the process. Presently, the global marketing of products has drawn attention to the cultural features of artifacts, and studies in usability and preferences try to tackle cultural habits.

Finally, another exercise in cross-cultural understanding:

Imagine that you are employed by a global electronics company. You are on the way to inspect a mobile phone factory in a foreign country. Your task is to introduce a new quality control system, and you know that the local management is not favorable to it. You sit in a company car together with a local driver and two local managers. Imagine first that this happens in Sweden, and the local managers are tall blond young ladies. Then imagine the same situation in Southern China, in Dubai, in Brazil. How do you feel about the proximity of those people, touching them accidentally in the small vehicle, having a conversation about technical plans? Do you feel equally sure and competent in all the situations, being able to confront their resistance?

\subsection{The science of mind}

"Mind is brain. Brain is body."

Eric Kandel

The statement by Nobelist Eric Kandel above reflects my position towards the philosophical question of mind and body, or mind and brain. Mind is a product of the human brain just as the speech act is a product of the brain and vocal chords, and the brain perceives it in a similar fashion. Damasio (1999) defines consciousness as the most important feeling, "the feeling of what happens". Modern neuroscience has made impressive progress in exploring human thinking and the working of the mind, especially concerning learning, perception, and memory (Dennett 1991, Kalat 2004, Frith 2007). The recent developments in cognitive science and neuroscience have a potential for making a significant impact in the development of learning sciences and education, as recent investments in projects such as the OECD sponsored Brain \& Learning Sciences (2007) and CICERO Learning network coordinated by the University of Helsinki underscore.

In the light of current knowledge, many theories in psychology, pedagogy and philosophy that see the brain as a modular organ that has separate places for memories, different types of perceptions, language processing, rational and emotional thinking need to be reconsidered . "The processes of mind and behavior result from the concerted operation of the many regions that constitute brain systems, small and large. None of the grand functions of the human mind - perception, learning and memory, emotion and feeling, attention, reasoning, language, motion - arises in a single center of brain." (Damasio 2003, 299, emphasis original) For instance, the understanding that impulses entering the brain are processed in an interconnected manner and not separated from emotions has important implications for teaching (Kandel 2006). Especially science education often assumes that logical and rational thinking are natural to the human brain and detached from other mental activity despite the fact that they are exceptional modes of thinking that are learned by long training. Modes of instruction need to be developed in accordance with a holistic understanding of the mind.

A recent study on learning Roman numerals illustrates the possibilities that brain scanning offers in understanding number learning mechanisms (Masataka et al. 2007). In this study, Japanese students 
were taught to read Roman numerals. The Japanese use Arabic and kanji (Chinese) numerals, and write two native syllabaries (hiragana and katakana) in addition to using Chinese kanji characters and Latin alphabet. However, the students who were subjects of this study were not familiar with Roman numerals. The study examined the neuronal correlates of reading Roman numerals and the changes that occur with extensive practice. Subjects were scanned by functional Magnetic Resonance Imaging (fMRI) three times the first day of the experiment and once following two to three months of practice. This allowed comparison of brain activations with varying levels of practice. The results revealed that upon learning that the alphabetical symbols had numeric meaning, subjects immediately activated a network of brain areas, many of which have been previously implicated in numerical processing. Subsequent practice led to a change in the pattern of neuronal activity in a single region of the middorsolateral prefrontal cortex in the left hemisphere. However, Roman numerals were still processed as calculations and not automatically recognized as number patterns. The result is very interesting because it implies that internalizing numbers takes a long time, as it was not achieved in three months time in young adults.

The kind of research that was described above has become possible only with advanced non-invasive brain scanning techniques. It gives an understanding of how information is processed and memories are formed physically, whereas earlier the only possibility was to rely on indirect deduction from traditional psychological laboratory experiments. Admittedly, brain scanning technologies still have many limitations, and interpretations of results are mostly tentative (Neuroscience and Education 2007). Winston \& Dolan $(2004,208)$ list limitations in current neuroimaging methodologies: these include limited spatial resolutions of a few millimeters; a restricted resolution in the temporal domain of seconds; and regional variability in time-courses of neuronal activation.

Based on the Japanese study described above, as well as other studies that are referred to in the same paper, I would like to propose some tentative ways for the application of the results in the theory of learning. I would suggest that the studies support the idea of cognitive schemas and different ways of processing textual and numeric information depending on the education. Implications of these findings may also give support to my hypothesis that people who are familiar with other scripts and number systems than Latin will need more time to be trained in program coding. Separate brain regions are specialized in numbers and letters, and the processing does not overlap, or if it overlaps, it requires considerably more effort. It has been shown that processing of Canadian or UK postal codes, such as KY169UH, that mix numbers and letters is difficult and requires more concentration than exclusively numerical or alphabetical codes (Polk \& Farah 1998). However, postal workers develop a brain mechanism to treat them together after practice. In the study above, the Roman numerals were never recognized or processed as numbers but in the short-term memory processing region as calculation tasks. However, an analogous situation might occur in programming studies if students are not familiar with the character or notational system used. 
Researchers warn of over-enthusiasm in the application of brain studies, but at the same time, they see great potential in the collaboration of psychologists, neuroscientists and educators (Neuroscience and Education 2007). The complex interplay of culture, practice and perception in learning is contextdependent and situational, but the understanding of underlying biological mechanisms assists in interpreting and developing learning conditions.

\subsubsection{Memory and brain}

The questions of remembering and memory have intrigued many great thinkers and authors. Question $\S 184$ by Ludwig Wittgenstein (1953) begins:

I want to remember a tune and it escapes me; suddenly I say "Now I know it" and I sing it. What was it like to suddenly know it? Surely it can't have occurred to me in its entirety in that moment! - Perhaps you will say: "It's a particular feeling, as if it were there" - but is it there? Suppose I now begin to sing it and get stuck? -- But may I not have been certain at that moment that I knew it? So in some sense or other it was there after all! -- But in what sense?

The way Marcel Proust understood it comes close to explanations of current brain science, as we will see in this section:

II y avait déjà bien des années que, de Combray, tout ce qui n'était pas le théâtre et le drame de mon coucher, n'existait plus pour moi, quand un jour d'hiver, comme je rentrais à la maison, ma mère, voyant que j'avais froid, me proposa de me faire prendre, contre mon habitude, un peu de thé. Je refusai d'abord et, je ne sais pourquoi, me ravisai. Elle envoya chercher un de ces gâteaux courts et dodus appelés Petites Madeleines qui semblent avoir été moulés dans la valve rainurée d'une coquille de Saint-Jacques. Et bientôt, machinalement, accablé par la morne journée et la perspective d'un triste lendemain, je portai à mes lèvres une cuillerée du thé où j'avais laissé s'amollir un morceau de madeleine. Mais à l'instant même où la gorgée mêlée des miettes du gâteau toucha mon palais, je tressaillis, attentif à ce qui se passait d'extraordinaire en moi. Un plaisir délicieux m'avait envahi, isolé, sans la notion de sa cause. II m'avait aussitôt rendu les vicissitudes de la vie indifférentes, ses désastres inoffensifs, sa brièveté illusoire, de la même façon qu'opère l'amour, en me remplissant d'une essence précieuse : ou plutôt cette essence n'était pas en moi, elle était moi. J'avais cessé de me sentir médiocre, contingent, mortel. D'où avait pu me venir cette puissante joie ? Je sentais qu'elle était liée au goût du thé et du gâteau, mais qu'elle le dépassait infiniment, ne devait pas être de même nature. D'où venait-elle ? Que signifiait-elle ? Où l'appréhender? Je bois une seconde gorgée où je ne trouve rien de plus que dans la première, une troisième qui m'apporte un peu moins que la seconde. II est temps que je m'arrête, la vertu du breuvage semble diminuer. Il est clair que la vérité que je cherche n'est pas en lui, mais en moi.

À la recherche du temps perdu. Du côté de chez Swann (Proust 1919) Gallimard

\section{Brain organization and functioning of the memory}

This description of brain functions and memory is written for a reader who wants to understand how the conclusions in following chapters are derived. Readers who find biological explanations tedious, may skip this section. It is largely based on neurobiological and medical sources, in particular Erkinjuntti et al. (2006), Rose (1998), Kalat (2004), and Frith (2007), which have been enhanced by new research reports.

The description of brain organization concentrates on functions that are central to the memory. They are mostly located in the forebrain. The forebrain consists of two hemispheres, left and right, which 
mainly receive sensory information from the opposite side of the body. The cellular layers of the outer surface of the cerebral hemispheres form grey matter known as the cerebral cortex. Axons of the neurons of the cortex extend inward to the brain, forming the white matter that enables communication between brain areas.

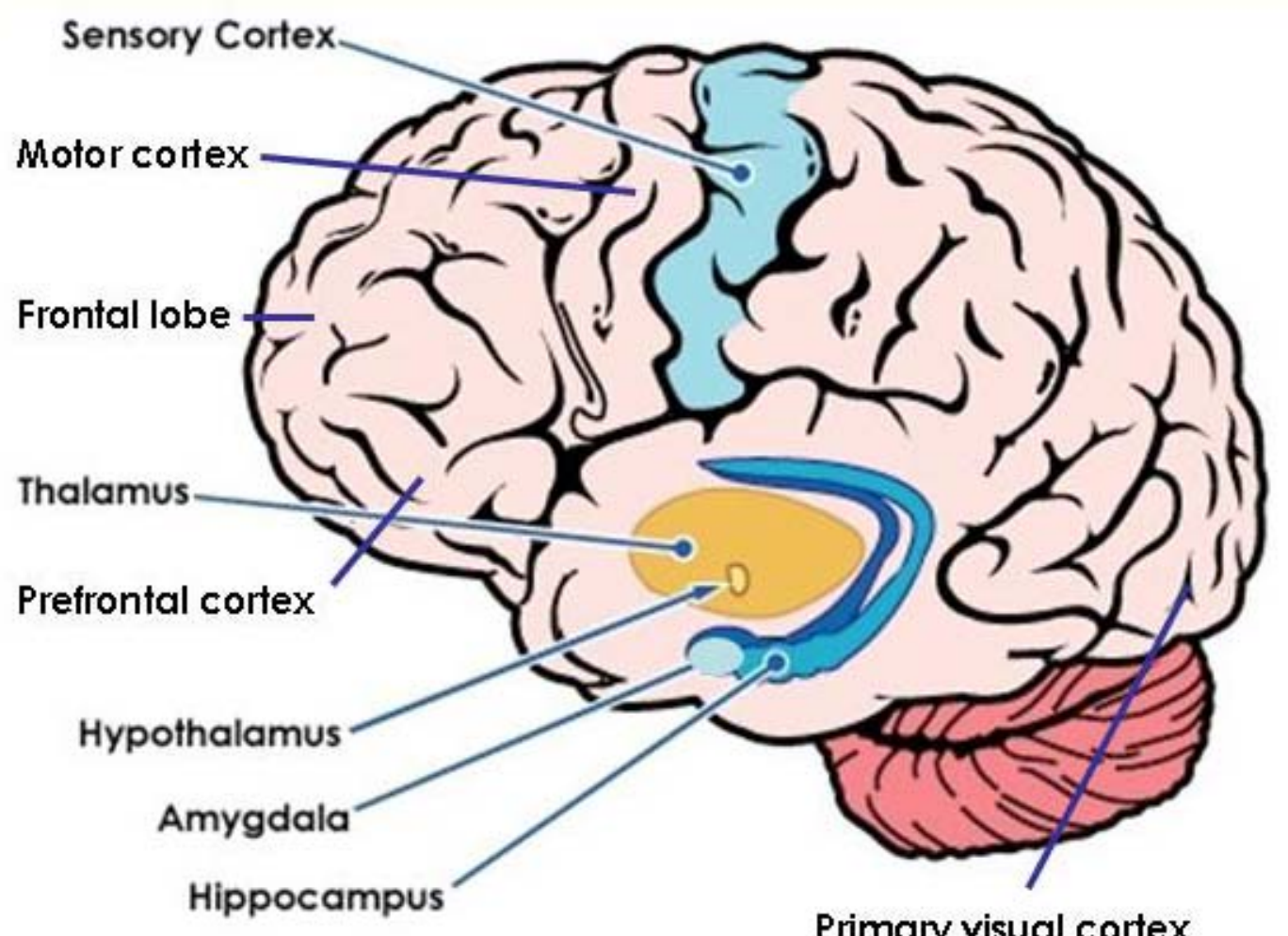

Figure 3: Left hemisphere of the brain

The outer portion is the cerebral cortex that is the location of human perception, skills and knowledge (Figure 3). The cortex has specialized areas for input from sensory systems, control of motor systems in different parts of the body, and for all cognitive tasks. The two hemispheres control the opposite side of the body, and additionally, certain functions are lateralized into one hemisphere in the human brain. In most people, the left hemisphere is specialized for language and analytical processing. It controls speech, as well as the right hand and the right side of the body, and sees the right side of the world. The right hemisphere is specialized for certain complex visuospatial tasks and synthetic processing. It is dominant for the emotional inflections of speech and interpreting other people's emotional expressions in either speech or facial expression. The right hemisphere also controls one's own expressions of fear, anger, and disgust. In vision and other modalities, it attends mostly to overall patterns, in contrast to the left hemisphere, which is better for details. Both left and right hemisphere contribute to all but the simplest behaviors. Brain lateralization is unique to humans. 
Inside the forebrain reside other structures such as the hypothalamus, hippocampus, and amygdala that are particularly important for motivations and emotions. The brain receives information through all modalities, which converge in the thalamus. Thalamus is the main source for input to the cerebral cortex, and most sensory information goes first through it, except for olfactory information that has its own route. Many nuclei of the thalamus receive their primary input from one of the sensory systems, such as vision, and then transmit the information to a single area of the cerebral cortex, while receiving feedback from the same area. That feedback modifies the continuing input from thalamus and other structures, and previous reinforcement prolongs thalamic activity.

The adult brain contains about 100 billion (milliard in Europe) brain cells, neurons. Neurons receive information or convey it to other cells. Neurons have long arms called axons that are connected to other neurons, thus forming synapses. The communication in synapses uses chemicals known as neurotransmitters. The nervous system also contains glia cells that facilitate neuron connections. Adult neurons rely heavily on glucose in their functioning, thus brain activity is often measured via amounts of glucose in different areas.

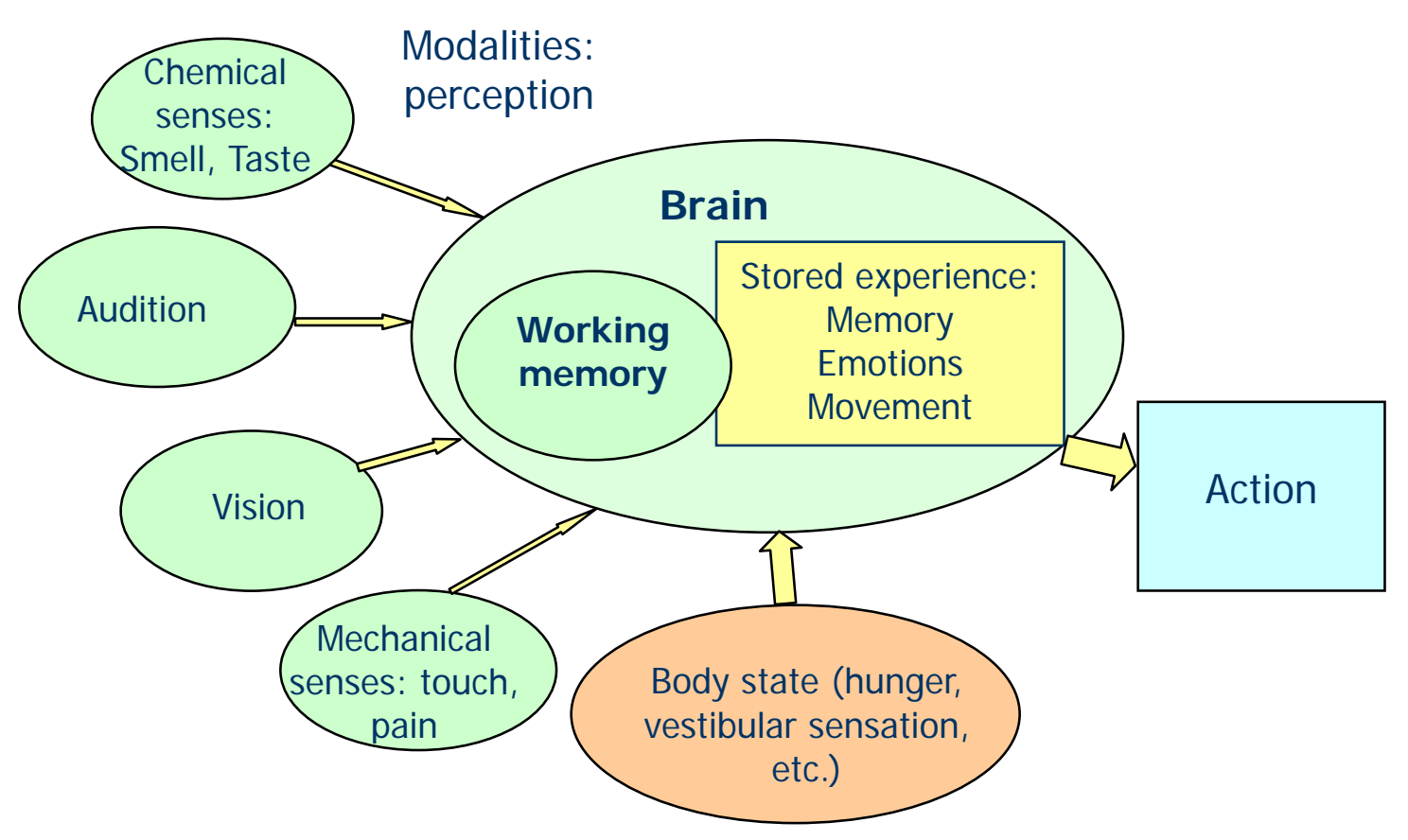

Figure 4: Polymodal perception

The information from all modalities is processed and compared with the internal, stored information, and combined with the information about the person's bodily state (Figure 4). Based on the episodic information, the brain decides its actions, partly consciously and partly unconsciously, and initiates movements. The consciousness has to filter the enormous amount of information that the brain receives and focus its attention. The incoming information is combined and associated by the working memory mainly in locations in the prefrontal cortex and subsequently stored in respective memory 
areas. The working memory is closest to the concept of thinking, though only part of it is under conscious control.

The persistent firing of certain neurons in the delay period of working memory tasks shows that the brain has a mechanism of keeping representations active without external input. Memories start to form when the information passes from the prefrontal cortex to the hippocampus from where it is sent to long-term memory in the cortex. The first processing phase takes only a few minutes. If the hippocampus degenerates, which is what happens in Alzheimer's disease, a person is no longer able to form new episodic memories. Damage to the medial temporal lobe or hippocampus is responsible for amnesia, and a degree of emotional placidity.

Memory consolidation refers to a process by which newly learned information is made resistant to disruption. Despite extensive research on the consolidation process, many findings are still tentative. Research suggests that even repeated, important items that we would clearly classify as long-term memories go through a gradual strengthening process that can continue for a very long time. Memory consolidation is a dynamic process involving gradual reorganization of the circuits supporting memory over time.

But when from a long-distant past nothing subsists, after the people are dead, after the things are broken and scattered, taste and smell alone, more fragile but more enduring, more unsubstantial, more persistent, more faithful, remain poised a long time, like souls, remembering, waiting, hoping, amid the ruins of all the rest; and bear unflinchingly, in the tiny and almost impalpable drop of their essence, the vast structure of recollection.

Marcel Proust, À la recherche du temps perdu. Du côté de chez Swann

As the quotes above and in the beginning of the section show, Proust had an excellent insight to remembering. He was also right about the importance of taste and smell (actually they called it odor in Combray) in forming memories: smell indeed activates memory consolidation in the hippocampus.

Episodic memory stores information in the neural networks as spatiotemporal representations. Thus, a hint through one modality, such as smell, can invoke the entire representations or memory episodes that include all the information about space and time. Representations in working memory are a subset of the representations in long-term memory. The working memory is a theoretical construction that has no particular physical location in the brain. Rather, working memory and consciousness might consist of brain wave oscillations, as one theory suggests. Evidently, the brain has no single site at which all kinds of information funnel to a central integrator. Apparently, the only places where all the information comes together are in the cells that prepare and plan for movements (Kandel 2006).

Different brain areas perform different functions, although no area can do anything by itself. For example, vision sends information through three pathways in the cerebral cortex, where movement perception, color and brightness, and complex shape analysis are located separately. Indeed, the visual system consists of more than fifty separate areas. The brain is a modular organ consisting of modules 
which function in parallel (segregation), though interdependently (integration) (Frith 1998, 383). Even specific neuronal locations for separate memory items have been detected in epileptic patients during probes to their cortex. A famous case is a patient in California who had a neuron that could recognize the actress Halle Berry- either her name or her picture (Searle 2007). Dennett recites a story about another patient who had his favorite piece by Guns N' Roses, "Outta get me", in a certain brain location (Dennett 1991). However, higher mental activities such as consciousness, mind and self, depend on the entire brain system.

\section{Taxonomy of memory}

The taxonomy of human memory distinguishes between declarative and procedural memory knowing what and knowing how. Knowing that an object is called a bicycle is declarative; knowing how to ride on it is procedural. Declarative memory subdivides into semantic (knowing what dentists do) and episodic (remembering seeing a dentist and having a filling). (Figure 5)

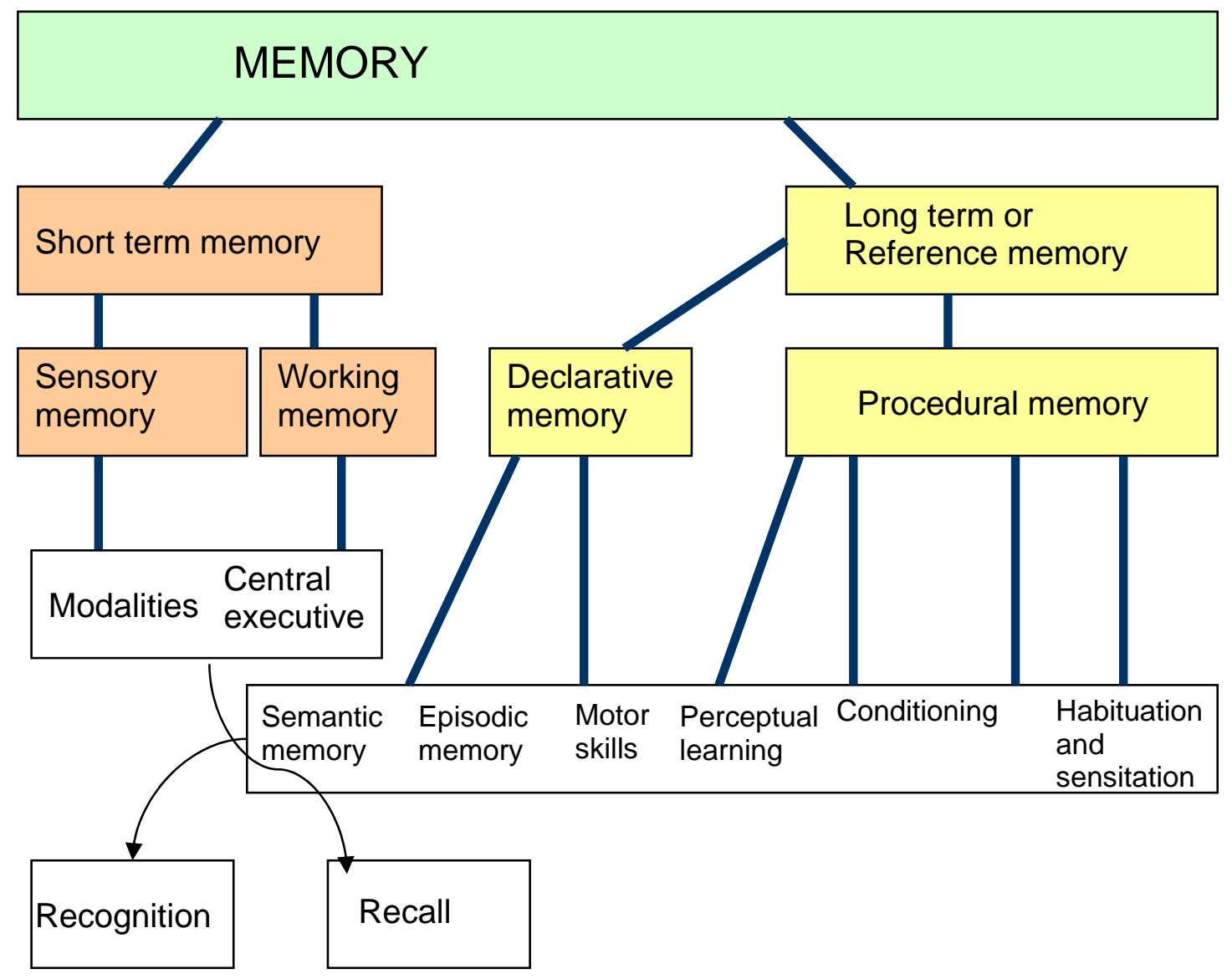

Figure 5: Functional model of memory (adapted from Erkinjuntti et al. 2006)

Short-tem memory has a temporal gradient, which has been abundantly tested: subjects are asked to remember lists of separate facts (numbers, words) and then to recall them. The limit of short-term memory storage is about seven to eight units. However, recalling arbitrary units is different from recalling chunks of information that belong together, therefore working memory can hold a larger 
number of grouped items. Another kind of memory experiment illustrates the large capacity of memory: psychologist Standing showed groups of subjects sequences of photographs, each for a few seconds. A week later, they were shown pairs of photographs, one that they had seen before, and the other novel, and asked to identify the one they had previously seen. The subjects could recognize up to 10,000 photographs with $90 \%$ accuracy. Recognition obviously operates separately from recall (Rose 1998).

The separation to short-term and long-term memories is not clear-cut. We can easily recall recent events that are of no importance or only of short-term importance, such as our previous meal, a telephone conversation, how much money there is in our purse, etc., but after some days or weeks they will be forgotten (Frith 1998). However, an excellent dinner may become unforgettable, because meaningful and emotional information is retained better than factual information.

Human memory is inaccurate and unreliable, because it cannot be protected from changing. Some evidence indicates that consolidated memories, when reactivated through retrieval, become labile (susceptible to disruption) again and undergo reconsolidation. Because memories are interrelated in complex associative networks rather than stored in isolation, an interesting question is whether reactivation of one memory makes associated memories labile in a way that requires reconsolidation. However, research suggests that memory reactivation produces content-limited rather than wholesale changes in a memory and its associations; each time a memory is retrieved and updated, the entire associative structure of the memory is not grossly altered. (Debiec et al. 2006)

Sensory and motor skills are located in specific areas of the frontal lobe. Because these skills modify the brain areas permanently, they are retained through life much better than semantic information. Much of the learning of movements happens unconsciously. People with a highly specialized skill might have the corresponding portion of brain larger than other people; for example experienced London taxi drivers have been found to have a larger hippocampus (location of spatial information) (Maguire et al. 2000), and professional musicians have a larger auditory cortex (Kalat 2004). Control of movements of body parts can be located so accurately that sensors attached to these parts of the brain can be programmed to direct movements of artificial limbs. Some experimental devices have been built to help quadriplegic patients. In one experiment, a sensor in the brain of a subject who was in New York moved a robot hand in London through internet connection (Warwick 2007).

However, not all movements are controlled by the motor cortex. Sign language resides in the brain analogically to spoken language (Hickok et al. 2002). Signers with damage to the right hemisphere (and impaired motor skills) were fluent and accurate in their production of signs when tested, they used normal grammar and comprehended signs with ease. This held true even in patients whose nonlinguistic visual-spatial abilities had been severely compromised by their brain damage. The 
organization of the brain for language does not appear to be particularly affected by the way in which language is perceived and produced.

Control of cognitive processes in the brain is modeled as executive processes, divided into four stages that each require a set of capabilities. These are goal setting, planning of action strategy, goal-oriented implementation, and evaluation of activity that are predominantly performed in the frontal cortex. Their performance depends on awareness, control, concentration, cognitive skills and capabilities, and ability to react to changes and adjust action accordingly.

\subsubsection{Timing and space in learning}

All animal cells, including neurons, have similar qualities. Learning and memory mechanisms have been studied in laboratory experiments using many animals, for example slugs, flies, birds, and small rodents. Even fruit flies Drosophila have the same learning chemistry as humans (Marguelis et al. 2005).

Steven Rose and his collaborators $(1998,152)$ explored the biochemical events that occur in a young chick's brain in learning experiments. If the chick is offered a small object such as a bead, it will peck vigorously at it within a few seconds. The bead could be made to taste bitter, in which case the chick decides to avoid it and other similar looking beads. The researchers could find changes in the brain regions that recognized beads, there was a dramatic increase in the number of synaptic connections twenty-four hours after the task. There was an initial sprouting of large numbers of new connections, that was subsequently reduced to what is, presumably, a sufficient number. The new connections were not made solely in a single brain region but were widely distributed. In particular, Rose found that there is a specific time interval, about six to eight hours after the training, when the neural activity was particularly strong. When they experimented by giving an inhibiting chemical at that period, it prevented memories from forming.

Rats have thousands of specialized brain cells, called grid cells, that track an animal's location in the environment. Each grid cell projects a virtual latticework of triangles across its environment and fires whenever the rat is on the triangle's corner. Every time the rat moves, it announces its location on multiple grids; collectively, the grid cells thus track the rat's location and path. Grid cells populate cortical areas next to the hippocampus, long recognized as a center of memory. Many researchers believe the grid cells' spatial data enable the hippocampus to create the context needed to form and store autobiographical memories. (Knierim 2007)

Spatial memory has been studied in rats learning to navigate in a maze. A recent study suggests that rats learn to navigate new spaces by replaying memories in reverse order (Foster \& Wilson 2006). After exploring an environment such as a maze, rats typically paused to eat, groom, or rub their 
whiskers. Electrodes in rat's hippocampus monitored so-called place neurons, which fire in specific sequence as a rat navigates a path. Surprisingly, when various rats paused on completion of a run, the place neurons fired in reverse order from the firing that had occurred during navigation. This reverse replay occurred more frequently after walking through new mazes than familiar ones, implying that the technique plays a role in learning.

Tim Tully's team used mild electrical shocks to train fruit flies to avoid a particular odor (Marguelis et al. 2005). Massed training, giving the flies the same number of training experiences in rapid succession, did not produce an enduring memory, but spaced training, with 15 minutes session intervals, did. This proves that distributed practice works better than massed practice.

Memory consolidation takes place during sleep, and it takes time for the molecular reactions controlling gene and protein synthesis to record long-term memories. But if the interval between sessions is too long, the short-term memory will have weakened too much to benefit from repetition.

The above examples of learning processes in various animals allow us to deduce some important lessons regarding learning in humans. These findings lend themselves to developing our understanding of using memory and learning processes in education. In sum, there are several time points, which are decisive in learning and memory consolidation: the first minutes when the information circulates to hippocampus, then the six to eight hours for active consolidation, next sleep is needed, and finally a two week consolidation period.

\subsubsection{Cognitive development, language and thought}

Initially, during the embryonic development and early infancy, the human nervous system develops far more neurons than will actually survive. Developing neurons proliferate, migrate, differentiate, myelinate, and form synapses in embryos. As they send out their axons, some make synaptic contacts with cells that release to them nerve growth factor or other neurotrophines. The neurons that receive neurotrophines survive; the others die. The destruction of neurons continues in the infant brain when new synaptic connections are formed, and the brain is molded by early experiences. Variations in the experience can alter overall brain growth and increase or decrease the amount of brain devoted to a particular sensory system (Kalat 2004). A massive selection process destroys cells that are not needed and builds connections between neurons that are activated. For example, a baby of six months has an ability to differentiate facial features of macaque monkeys but for a child of 12 months and older, all macaques look the same, because humans normally do not need that ability which, nevertheless, has a potential in the brain (Pascalis et al. 2005).

A famous series of experiments from early 1970s in which rats were raised in so-called enriched versus impoverished environments showed quite dramatic changes in brain structure and chemistry. 
Laboratory rats were normally kept in small cages without any stimulus. When they were placed in larger cages with company and several items to explore, they developed a thicker cortex, more dendritic branching, and performed better in learning tests. A great deal of this benefit was due to exercise. Exercise releases neurotrophines that increase the development of neurons and synapses (at any age). (Neuroscience and education 2007)

It has been thought that babies do not build explicit memories, but new non-verbal tests indicate that developments in recall are well underway by late in the first year of life; by the end of the second year, long-term recall is reliable and robust. New research combining electrophysiological and behavioral measures is identifying the loci of age-related changes: they are attributed to more effective and efficient encoding, consolidation and storage processes associated with developments in the temporalcortical network that subserves recall. The emerging framework, which applies to episodic and autobiographical memory, highlights the essential developmental continuities in memory from infancy onwards such as the early language development; the ability to differentiate between certain morphemes takes place in a child's interaction with her caregivers when the child is less than six months old (Neuroscience and education 2007).

After the second year, the selection process slows down, but the brain still remains plastic. The brain tissue is flexible and organization can take place in many alternative ways, for instance in cases where the preferred organization is impossible because of damage (Kalat 2004). In people who become blind early in life, certain parts of the visual cortex become responsive to auditory and touch stimuli, including Braille symbols. People who begin learning Braille as adults do not become as adept as those who start in childhood (Kalat 2004, 182). Moreover, auditory attention deficit and dyslexia can be corrected in preschool-age children by targeted training of brain functions, thus forming new response patterns in certain brain areas (Neville 2007).

After ten years of age, the plasticity reduces but the formation of the brain continues at least until 18 years of age, even until 27 years according to some recent studies (Neville 2007). Certain functions of the brain have an experience expectant period, when that function or capability is sensitive to stimuli and develops particularly fast. Verbal ability is a typical example, and children learn to speak almost effortlessly between 18 months and 4 years. If they have no opportunity to learn language at that age, it becomes nearly impossible by the age of fourteen (Crystal 1987). Similarly, sign language resides in the brain analogically to a spoken language. There are many sign languages, and an adult who acquires a second sign language will actually sign with a foreign accent (Hickok et al. 2002). Just as linguistically sensitive periods have been linked to synaptic pruning in very young children, continuing synaptic pruning in adolescence suggests the possibility of sensitive periods here too. For example, research has shown that teenagers activate different areas of the brain from adults when 
learning algebraic equations, and this difference has been associated with a more robust process of long-term storage than that used by adults (Neuroscience and education 2007).

The brain has a strong propensity for imitation. Children learn their mother tongue and their behaviors by observing and imitating others. Some recent research results (Rizzolatti et al. 2006) strongly support the idea of the existence of an execution-observation matching system in the brain (mirror neuron system). It has been proposed that this system is involved in polymodal action recognition and might represent a precursor of language processing. That would indicate that language learning and processing is one of the advanced functions of the brain but not a separate unique human feature. Mirror neurons are abundant in brain areas that are associated with movement and perception as well as regions that correspond to the abilities to comprehend someone else's feelings, understand intention and use language. Broca's area (which is central in speech production) has lots of mirror neurons, and it has been proposed that it understands an action like 'hand grasps ball' the same way be it a spoken sentence or a real action (Dobbs 2006). However, even though language is important, it is not necessary for thinking and consciousness. Damasio $(1999,108)$ who studied patients with severe language disorders caused by neurological diseases, observed that no matter how much impairment of language there was, the patients thought processes remained intact in their essentials, and, more importantly, the patient's consciousness of his or her situation seemed also to be intact.

Behavioral differences in the visual processing of objects and backgrounds as a function of cultural group are well documented: North Americans focus on the object more than East Asians who perceive the environment and context (Nisbett \& Masuda 2006). Neuroimaging evidence also points to cultural differences in neural activation patterns that develop during adulthood. Compared with old East Asian adults (test subjects about 67 years), Westerners of the same age have more object focused visual processing, and they activate neural structures that reflect this bias for objects. In a recent adaptation study, East Asian older adults showed an absence of an object-processing area but normal adaptation for background areas. (Goh et al. 2007)

In short, the first three years of life are a crucial period for brain development. A second wave of reorganization of the brain is taking place in adolescence. Therefore, formal education, as well as social experience, has an important role in molding the teenage brain. The brain's continuing plasticity in adulthood suggests that it is suited for lifelong learning and adaptation to new situations. The brain is capable of learning because of its plasticity that allows it to change in response to stimuli from the environment.

Developmental psychology has been concerned with the cognitive development of a child from the early $20^{\text {th }}$ century. A strongly influential theory was developed by Jean Piaget (Piaget \& Inhelder 1969). 
He identified four major stages in cognitive development that were always assumed to occur in the same order:

Sensorimotor stage in infancy. In this period, intelligence is demonstrated through motor activity. Knowledge of the world is limited because it is based on physical interactions and experiences. Physical development of mobility allows the child to begin developing new intellectual abilities. Some symbolic (language) abilities are developed at the end of this stage.

Pre-operational stage in toddlers and early childhood. In this period, intelligence is demonstrated through the use of symbols, language use matures, and memory and imagination are developed.

Concrete operational stage in elementary and early adolescence. In this stage, intelligence is demonstrated through logical and systematic manipulation of symbols related to concrete objects. It is characterized by understanding of seven types of conservation, developed in this order: number, length, liquid, mass, weight, area, and finally, volume. Operational thinking develops to include reversible mental actions.

Formal operational stage that is reached in adolescence or later. Intelligence is demonstrated through the logical use of symbols related to abstract concepts (decontextualization).

Piaget carried out detailed analyses of early sensorimotor intelligence focusing on the young child's interaction with physical reality. For instance, according to his studies, children acquire object permanence at about seven months of age when the memory is formed. Piaget viewed internalization primarily in terms of schemas that reflect the regularities of an individual's physical action (Piaget uses schemas in a more restricted sense than this thesis). In contrast, the other important theorist of early $20^{\text {th }}$ century, Lev Vygotsky, focused on social processes, and thus was interested in the internalization of speech. In Vygotsky's theory, internalization is a process involved in the transformation of social phenomena into psychological phenomena (Wertsch 1985, 62). Nonetheless, Piaget also emphasized the interaction of ontogenetic, social, and affective factors.

Later studies have proven Piaget's theory of the appearance of certain intellectual operations at a certain age partially mistaken. Rather, recent research suggests that infants are endowed with an innate set of principles that allows them to begin to interact with the world. For instance, a research team tested the spontaneous understanding of geometrical concepts and maps in a remote Amazonean community of people without schooling, providing evidence that core geometrical knowledge is a universal constituent of the human mind (Dehaene et al. 2006). However, there is little doubt that geometrical knowledge can be substantially enriched by cultural inventions such as maps, mathematical tools, or the geometrical terms of language.

The innate theories function as a beginning of the conceptual development. A child has an intuition of what distinguishes a living being from an artifact or an object. She has separate intuitive theories of 
physical objects, biology, psychology and social behavior. The child assumes that external states of affairs may cause mental states and there is a causal chain from perceptions to beliefs to intentions to actions. Of the innate principles in humans, one of the most important is the intuitive theory of physical causality that includes principles of continuity, cohesion, and contact in movement (Viale 2006). Even though this part of the theory is least controversial, cultural variation has been detected also here (Verran 2001). Contrary to the Piagetian theory, causality operations have been shown to be domain-specific and cross-culturally varied.

\subsubsection{Emotions and feelings}

Emotions in the human brain develop quickly, sometimes even when we are not consciously aware of the event that aroused them. Emotions ready us to immediate, often vigorous responses which are usually appropriate to the situation. Due to pathways that run from the eye to the brain's rapidresponse emotional-control centers, bypassing the thinking part of the brain, the cortex, we often feel before we analyze. That is for example how we judge new people, and often the first impression persists. The first impression activates a previous mental model of a certain kind of person we have known. Once the initial valence has been assigned, a biased cognitive filter appears to become activated, so that the reinforcement of positive beliefs and dejection of contrary information operate (Frank 2004).

Emotions, feelings, passions and affect are words on the same semantic field, which however, are not used consistently in sciences (Manstead et al. 2004). Philosophers often use the word passion, whereas psychology prefers affect as a general term. Unfortunately, the multidisciplinary sources of this thesis cause an incoherent use here, as well. Brain science researchers are nearly unanimous in distinguishing emotions from feelings. Emotional processes exist independently of awareness. According to the classic James-Lange theory, emotion is one's perception of body changes. The body reacts first, before the experience of emotion, and each emotional state has its own distinctive sensation. Feelings are thought to reflect feedback from bodily responses and action. Feelings are the mental representation of the physiologic changes that occur during an emotion. "The essence of feelings of emotion is the mapping of the emotional state in the appropriate body-sensing regions of the brain. But feeling an emotion also includes the mapping of changes that occur in the cognitive processing style, as well as the evocation of thoughts that are congruent with the feeling state." (Damasio 2004, 52)

Feelings can be induced physically, with no connection to mental processes (Damasio 1999). A patient with Parkinson's disease had electrodes installed in her brain stem. When electric current passed through one of the four contact sites on the patient's left side, she showed signs of sadness. After a few seconds she began to cry. Soon she started talking about how deeply sad she felt. About ninety seconds after the current was interrupted the patient's behavior returned to normal. Similarly, out-of-the-blue laughter could be induced in a patient: electrical brain simulation in the left frontal lobe known as the 
supplementary motor area (SMA) evoked laughter. The patient could not control the laughter but soon gave explanations to it like "You guys just look so funny".

In another much quoted study (ibid, 71), Paul Ekman asked subjects to move certain muscles of the face in certain sequence, such that, unbeknownst to the subjects, the expression became one of happiness or sadness, or fear. The subjects did not know which expression was being portrayed on their faces. In their minds there was no thought capable of causing the portrayed emotion. And yet the subjects came to feel the feeling appropriate to the emotion displayed.

Keltikangas-Järvinen (2000) stresses that feelings are not a part of the personality; instead a person lives, experiences and observes (perception) through her emotions. "Emotions play out in the theater of the body. Feelings play out in the theater of the mind." (Damasio 2003, 57) Emotions are automatic reactions, and an effort to suppress the natural expression of emotion consumes much energy. Subsequent feelings are partly known and controlled by the mind, but not in isolation from bodily sensations. PET scans clearly show that states of feeling are correlated with significant engagement of somatosensing brain regions and the mapping of body states is modified during the process of feeling. Feelings are the essence of the mind, and instead of trying to control them, people should try to make the best out of them. Emotion is a part of intelligence (Manstead et al. 2004).

Berry et al. $(2002,186)$ discuss the social construction of emotions across cultures. Universality of emotions is challenged by several studies in linguistics (Wierzbicka 1999) and anthropology (Manstead et al. 2004). The basic emotion theory of neurobiology assumes that people have an innate set of emotional reactions, but on the other hand, interviews, surveys and psychological testing have indicated that there is a diversity in display of emotion across cultures. For example, the Chinese differentiate five types of shame. However, Berry et al. (2002) report on a study where also North American students were found to be able to distinguish similar emotions even though there is no name for all of the combinations in English. Being able to recognize and name an emotion is a learnt in early childhood, but the same basic emotions exist everywhere. A recent analysis on emotion antecedents and reactions endorses this view. It examined how reports on emotional experience, expression and physiological sensations were related to each other within and across cultures (Matsumoto et al. 2007). The study found that most of the variance was within countries, at the individual level.

\subsubsection{Implications for study of learning}

"Intelligence can only be directed by desire. For there to be desire, there must be pleasure and joy. Intelligence only grows and bears fruits in joy. The joy of learning is as indispensable to studies as breathing is to runners."

Simone Weil

Simone Weil's intuition is in accordance with modern neuroscience. Renown neuroscientist Antonio Damasio $(2003,178)$ claims: "The process of learning and recalling emotionally competent events is different with conscious feeling from what it would be without feelings. Some feelings optimize 
learning and recall. Other feelings, extremely painful feelings in particular, perturb learning and protectively suppress recall. In general, memory of the felt situation promotes, consciously or not, the avoidance of events associated with negative feelings and the seeking of situations that may cause positive feelings."

Because living organisms attempt to maintain homeostasis, it has been proposed that resistance to variance is a main cause of our experience of emotion (ibid.). On this hypothesis, part of what we feel would correspond to a resistance to the upheaval caused by emotion, to the tendency to control the ongoing emotive perturbation. People struggle to maintain a stable status. Learning processes are often painful because they open contradictions and perturbation, and thus people must have an innate aversion for learning. On the other hand, ability to learn is vital for survival. Thus, learning has to give significant rewards in terms of satisfaction to become desirable. The feeling of 'flow', or elevation when working with intellectual or artistic accomplishments only comes when a person is deeply involved in the learning process.

It has been shown in many studies that happiness and positive mood increases flexibility in problem solving. Isen (2004) gives an overview of research on affect and thinking. As a psychologist, she uses affect as the most general term for the emotional domain. 'Affect' is used to refer not just to the feeling component of which the person is aware, but to the entire affective cascade, with its cognitive, neurological, physiological, motivational, and behavioral components, as well as the feeling component. Affect, cognition, and motivation influence one another. However, how the connection of affect, memory and learning actually works is not well understood (Levine \& Pizarro 2004) and the details of the mechanism need to be studied more.

Isen's (2004) survey covers research that involves a mild positive affect; the effects of very intense affect are probably differing. Mild positive affect can be induced for example by offering a box of candy (not consuming it). As a matter of fact, mild affect inductions have often been found to have similar effects to those of affective traits or dispositions. Positive affect has been found to promote social interaction, helpfulness, generosity, and social responsibility, while not undermining attention to a person's own long-term welfare. Furthermore, positive affect

- facilitates flexible thinking and problem-solving,

- flexible categorization of neutral material, involving semantic categories, brand extensions, social groups

- more diverse and less typical word associations to neutral stimuli

- openness to ideas (even those that contradict their own ideas).

- increasing creativity.

- gives rise to careful, thorough and systematical thinking. 
It has been suggested that positive affect leads to reliance on existing cognitive structures; but in fact it fosters both the ability to take in new data and knowledge and the ability to activate and use existing knowledge structures. Positive affect appears to increase risk-taking in low-risk or hypothetical situations in some studies, but it actually leads to risk-avoidance in situations of high, real risk, or possible meaningful loss. People in positive affect distinguish between safe and dangerous situations, avoid taking dangerous risks, but consider the potential loss in the situation carefully en route to that decision (Isen 2004).

Meaningful and emotional information is retained better in memory than purely factual information (Kalat 2004). It does not necessarily indicate, however, that the memories are accurate in relation to factual events. On the other hand, memories are better retained even if the factual information is neutral but it was presented in an emotional context. Emotional events are bestowed with special prominence in memory. This may reflect greater attention oriented to these events during encoding, and/or enhancement of memory consolidation after emotional events have passed.

The amygdala is a brain structure that directly mediates aspects of emotional learning and facilitates memory operations in other regions, including the hippocampus and prefrontal cortex. Epinephrine and cortisol are produced in stressful and emotionally exciting experiences. They activate amygdala and hippocampus, thus enhancing the storage and consolidation of experiences. However, prolonged cortisol production has a negative effect. Stress weakens attention and the working memory. It raises levels of noradrenalin, dopamine, and cortisol and induces neuron destruction in the hippocampus. The production of new neurons in hippocampus is also reduced as a result of stress, which, however, could be compensated by exercise as it helps increase neuron production. (Kalat 2004)

Laughing has numerous benefits for health as well as learning. The pituitary gland releases its own opiates which suppress pain; the production of immune cells increases; antibody levels in the blood and saliva rise; and the number of natural killer cells increases accelerating the body's natural anticarcinogenic response. Laughing reduces stress and the level of cortisol is reduced, decreasing levels of epinephrine. Moreover, laughing has been shown to improve memory in psychological tests (long-term memory, recall one week later). Students who watched an episode of the sit-com "Friends" after studying for an exam, got $20 \%$ better grades than the control group. (Berk et al. 1989, Liebertz 2005)

Similarly, music has many beneficial effects for thinking and mood, as well as stress reduction. In one study, dementia patients who joined a sing-song group became more communicative. Music activates many areas in the brain, including areas of executive processes and reasoning. A Finnish study has shown that listening to music accelerates recovery from a brain stroke (Särkämö et al. 2008). 
Attention is a way of devoting our limited abilities to the most important information and actions. People (except, perhaps, mothers) are not good at doing many tasks simultaneously. Usually, doing one task or attending to one stimulus interferes with another. Some brain conditions such as the ADHD cause particular problems in attention. A number of behavioral techniques have been proposed to reduce ADHD problems (Kalat 2004), such as reduce distraction; use lists, calendars, schedules, and so forth to organize your time; practice strategies to pace yourself; learn to relax (tension and stress can magnify attention deficits). These techniques can be recommended for any student.

People learn unconsciously to perform sensorimotor tasks (Frith 2007), but research has discovered unconscious learning of semantic information as well. Damasio $(1999,42)$ tells about a brain injured patient called David who could not learn any new fact at all. For instance, he could not learn to recognize a new person from face, sound, or physical appearance. In a test, he was to meet with three differently behaving people, one of them friendly, one neutral, and one brusque and unfriendly (this one was a beautiful young neuropsychologist). David could not recognize their faces later on, but when shown pictures of good guys and bad guys, and asked to show his friend, he selected the good guy by $80 \%$ probability. Though his conscious mind did not learn anything, his emotions were active, and his organism made the selection, even against his otherwise proven preference for pretty women.

Unconscious learning has been tested repeatedly in psychological experiments, as well. For example, researchers have asked people to choose a card from one of several packs, some packs giving more winning cards than other. The pattern was so complex that the subjects could not explicate their preferences but they soon seemed to recognize the pattern and chose the winning packs more often (Koch \& Preuschoff 2007). In another type of experiment, subjects were shown images on screen so quickly that they did not realize seeing them. Nonetheless, they could later recognize the images.

Human memory has an enormous capacity, but retrieval is unreliable. Moreover, memories may be inaccurate, and people have false beliefs. Learning new contradictory facts does not necessarily change previous beliefs; neither does it always raise an awareness of intellectual conflict. The human mind is tolerant to a great amount of cognitive ambiguity, as the left hemisphere of the brain has been shown to be excellent in fabricating explanations (Damasio 1999, Frith 2007). Therefore, a computer is not a fitting metaphor for human memory. Computers deal with organized information, whereas humans deal with meaning (Rose 1998) and complex patterns of multimodal reality. Much of the thinking is analogous and heuristic compared to a tiny amount of step-by-step algorithmic deduction. Moreover, people learn unconsciously in many ways, which supports the view that teaching cannot be done solely through explanations and distributing information.

Broca's area in the left cortex is important in the production of speech, but also visual impulses and motor activity converge there. Another area where spatial information meets other information is 
hippocampus. Visuospatial and sensorimotor activation can improve problem-solving and thinking in general. It has been claimed that for example mushroom picking improves creative thinking, and I can personally confirm that I get new ideas when walking in the forest in August, gathering mushrooms. Instruction that takes into account learning conditions and environment in their entirety could be more effective, in particular if it includes practicing patterns of behavior. Timing of activities is crucial, as having a break and relaxing after intensive working often releases creativity and yields a solution to the problem under consideration. The combination of analytic thinking and unconscious processing increases innovation.

The polymodality of memory and learning offers possibilities in instruction that have not been fully exploited yet. How it should be done, needs research, as the promises of polymodality and narrowness of attention need to be reconciled. Serving madeleines with tea would perhaps work once, but to sustain a long-lasting effect is probably more difficult.

\subsection{Learning sciences}

Do not be led by rumor, or tradition, or by the authority of religious texts, nor by false arguments, nor by appearances, nor by theories, nor even by reverence. But rather when you know through your own experience that certain things are wrong and unwholesome, do not lead to calm and happiness and are not beneficial, then give them up. When you know for yourselves that certain things are right and wholesome, lead to calm and happiness and are beneficial, then follow them.

Buddha

Engineering education has until recently been mainly based on best practices and experience of teachers. It was feasible as long as conditions remained the same; students had similar abilities, the requirements for learning outcomes were constant, and technologies were relatively stable. Today's conditions are strikingly different: working life requires a flexible professional competence, technologies develop at a fast pace, and particularly, in the case of the international degree programmes, student populations have very different qualities than before. The development of a new pedagogy and new methods of instruction calls for adoption of a theoretical basis that has thus far been missing from engineering education. The theoretical framework developed here is based on the latest developments in learning sciences, as well as cognitive science, in particular the findings of recent neuroscience, therefore it has a biological, natural science foundation. The approach is similar to the OECD sponsored project on the Brain \& Learning Sciences (OECD 2007).

Theory of multicultural education is still in its infancy and, moreover, it is mired by value and ethical questions such as (Banks et al. 2004, Landis et al. 2004): Is the goal of the education to produce graduates who adapt easily to the society and working life, and reject their own cultural values? Or should multicultural education respect all cultures and encourage different approaches? And if diversity is valued, how can it be promoted at a tolerable cost? 
The aim here is to compose a theoretical framework that is suitable for multicultural engineering education in Finland. It is a combination of several modern strands in learning sciences that is adapted to information technology education and specifically to multicultural settings. However, the main ideas of this framework are not exclusive to the specific educational group this study deals with. Rather, these ideas can also benefit homogeneous groups at post-secondary level, multicultural education in other discplines, as well as education outside Finland.

My understanding of learning sciences is largely based on ideas of knowledge creation through progressive inquiry (PI) that have been developed at the University of Helsinki (Hakkarainen et al. 2004a, 2004b). Indeed, it does not deviate from them in any significant perspective. However, my construction is adapted to the particular problem area of multicultural education, and consequently, it highlights different aspects. Progressive inquiry builds on a wide range of earlier theories of learning, including constructivism, activity theory, and sociocultural construction of knowledge by Lev Vygotsky $(1962,1978)$. Its cornerstones are the scientific interrogative model of inquiry by Hintikka (2001) and Bereiter's (2002) knowledge building with conceptual artifacts that will be presented below in relation to this work.

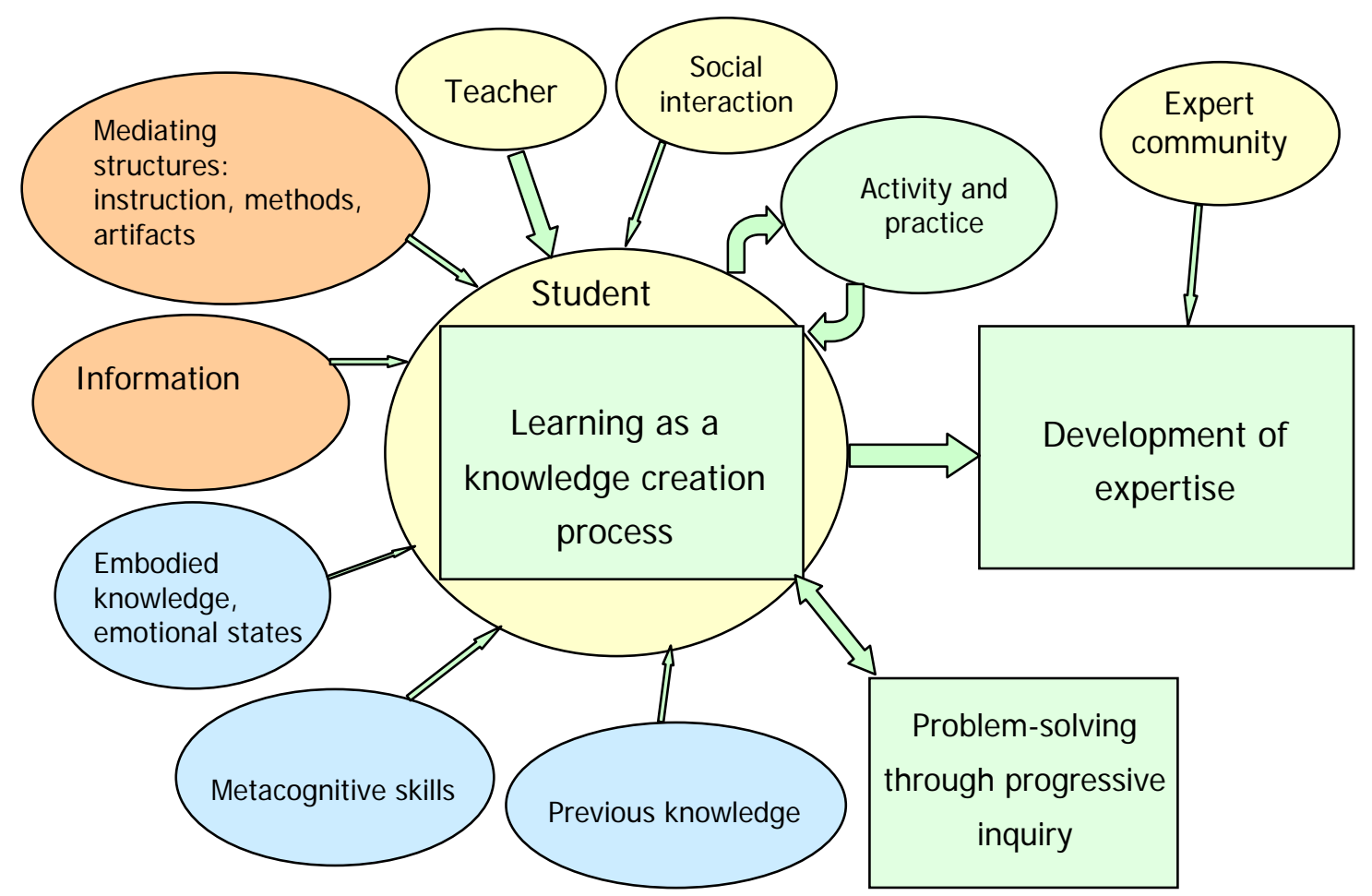

Figure 6: Factors contributing to the learning process

In this thesis, learning is understood to be an active process by an individual learner. The learner constructs and creates knowledge with the help of a supportive learning environment that consists of an expert community, teachers, and artifacts like computers, networks, and information sources. However, my view is that, in higher education, teaching and learning environments are merely conditions for learning, and that, ultimately, the motivation, capabilities, and activity of the learner 
determine what and how she actually learns or understands. Thus, the view promoted here is not constructivist in absolute terms, neither does it require a connection to real life problems as necessary. The view of the learning process (Figure 6) is merely a foundation for many types of instructional methods and pedagogical approaches. Learning as knowledge construction can take place in countless ways; from simple drills and learning verses or facts by heart, to efforts to construct scientific theories, or to apply new methods in a novel situation.

\subsubsection{Overview of educational theory}

\section{The social formation of mind}

Lev Vygotsky was a Russian scientist who developed theories of human mind and social action mainly between 1924 and 1934 (Wertsch 1985). His influence is still strong partly due to the work of his many students, including Leontjev and Luria in the Soviet Union, and developers of his ideas in the West such as Michael Cole, James Wertsch, and Yrjö Engeström. In fact, Vygotsky's multidisciplinary approach and genial insights have created a renewed interest in his ideas in many disciplines ranging from organizational sciences and social psychology to anthropology in the last two decades. The three themes that form the core of Vygotsky's theoretical framework are

1. reliance on a (genetic or) developmental method,

2. the claim that higher mental processes in the individual have their origin in social processes,

3. and the claim that mental processes can be understood only if we understand the tools and signs that mediate them.

The developmental method is in Vygotsky's theory a central method in psychological science that is applicable to child as well as adult learning (Vygotsky 1978).

According to Vygotsky, internalization is a process involved in the transformation of social phenomena into psychological phenomena, which he wanted to place at the center of his research (Wertsch 1985, 61). In order to understand higher mental functioning on the intrapsychological plane, one must conduct a genetic analysis of its interpsychological precursors. Vygotsky defines a zone of proximal development as the distance between a child's actual developmental level as determined by independent problem-solving and the higher level of potential development as determined through problem-solving under adult guidance or in collaboration with more capable peers (Vygotsky 1962). Cognitive development and instruction have an interrelationship, as instruction creates the zone of proximal development. Vygotsky stressed that: "Instruction is good only when it proceeds ahead of development. Then it awakens and rouses to life an entire set of functions which are in the stage of maturing, which lie in the zone of proximal development." (Wertsch 1985, 71)

Yrjö Engeström (2001) has developed these ideas into the cultural-historical activity theory that has a model of subject working on an object with a set of tools in a socio-cultural setting that is constrained by rules. It defines learning as co-configuration of the object and expansion of the present activity. His 
expansive learning model has been applied predominantly to learning in organizations, but Teräs (2007) has also applied it successfully in multicultural vocational training for immigrants in Finland.

Also Hutchins (1995) bases his views on shared cultural schemas and use of mediating artifacts on Vygotsky. His views are discussed in detail in section 3.2, and applied in section 5.5.

\subsubsection{Knowledge building and progressive inquiry}

One of the cornerstones of the progressive inquiry model is Bereiter's view of knowledge building. Interestingly, it is partially based on the 1990's connectionist view of mind, that reflected the contemporaneous theories of neuroscience, which saw brain functioning as a network. The theory of internalized cultural schemas by Strauss \& Quinn (1997) too got its inspiration from connectionist models. (The cross-references of these theories are displayed in appendices 5 and 6.) Bereiter characterizes the mind as self-organizing system which interacts with the physical environment. His view is more or less in accordance with the present understanding of the functioning of neural networks, at least in the broad outline (Bereiter 2002). Bereiter's knowledge building takes place through the development of conceptual artifacts, which is essentially a social learning process where scientific concepts evolve. He attacks the view of "mind as container" as an essentially harmful metaphor that ignores the internal processing of knowledge and its fluctuating characteristics. Moreover, he critisizes learning-by-doing, and project-based learning for overlooking the building of theoretical understanding and conceptual artifacts, and instead concentrating only on activities. A recent study in Finland supports his critique: Reinikainen (2007) found that project and teamwork in $7^{\text {th }}$ grade science courses actually had a negative effect on learning.

The progressive inquiry model aims at providing didactic guidelines for teachers and students in the critical epistemic activities of knowledge-advancing inquiry. It expands the following three metaphors of learning into a holistic model (Hakkarainen et al. 2004a):

1) The knowledge acquisition metaphor sees the mind as container. People have mental models that need to be changed or improved in order to make them scientific or professional. Emotions, attitudes, and values are part of mental models, therefore, they are not easily changed. In order to change a mental model, a person has to reflect on it, and feel a need to change it.

2) Dialogical learning is learning in a community, and learning in social interaction.

3) The trialogical learning metaphor is based on the idea of strongly distributed intelligence in a community that functions in an intelligent partnership with activity systems.

In the progressive inquiry process, students' genuine questions and previous knowledge of the phenomena under investigation are a starting point for knowledge acquisition. Students, with the help of instructors, try to explain phenomena, share their expertise, and build new knowledge in 
collaborative activity through an iterative process. Moreover, learners shape their identities as knowledge constructors in the progressive inquiry process (Paavola 2006). Therefore, the process works simultaneously on individual and social levels, where the practices of the community influence the direction of learning.

\subsubsection{Theories in technology education}

Many current educational approaches in technology education are based on the idea of a student as active learner as opposed to the traditional lectures and examinations scheme. Just to mention a few, the constructivist approach, dialectical method, problem-based learning (PBL), and project-based learning assume that the student is active and shapes her learning experience. In engineering education, however, the practice largely favors the folk theory of knowledge, what Bereiter (2002) calls 'mind-ascontainer'. Teaching is seen as an activity where knowledge is transferred from teacher (or books, etc.) to the mind of the learner. The reasons have been discussed in depth in my paper in the EJEE Special Issue (Holvikivi 2007b).

Even latest international efforts to develop engineering education are characterized by lack of deeper theoretical foundation. The CDIO approach that is promoted by Kungliga Tekniska Högskolan, Chalmers and MIT, explicitly states that it is mainly based on best practices in engineering work (CDIO at http://www.cdio.org). Even though it mentions the background pedagogical theories that are constructivism, Piaget's and Kolb's models, the substance and epistemology of the theories is not discussed (Crawley et al. 2007). Similarly, problem/ project-based learning (PBL) efforts have recently been reported from other engineering schools in Europe (Heylen et al. 2007) and Australia (Stewart 2007).

Activity theory and constructivism have a strong influence in Finnish education practices, though engineering educators in science universities in Finland seldom have any kind of pedagogical training. In contrast, the requirement for tenure in polytechnics includes a certificate in adult education, which is offered by teacher training institutes on polytechnic level. The one year training provides an adequate overview of pedagogical theory though it does not address the particular problems of engineering education. In fact, interviews of teachers in polytechnics, for instance at the EVTEK University of Applied Sciences where over 50 teachers have attended pedagogical study programs, reveal frustration and prejudice with the studies that are commonly considered to give little benefit to practical work (Holvikivi 2007b).

U.S. universities and companies have dominated computer science and computer industry since the beginning. Therefore, also textbooks in ICT education come mainly from the U.S. and follow the dominant didactic traditions of behaviorist methods, and naïve constructivism. Thus, major approaches are emphasis on facts, drill exercises, and step-by-step instructions. Additionally, computer science 
instruction is influenced by the algorithmic character of software and hierarchical structures in data and information storage. Probably also research in artificial intelligence has had its impact on the views of learning by computer professionals. Educational papers in journals and conferences by professional associations such as ACM and IEEE often refer to outdated theories such as Bloom's taxonomy from 1956 and Dewey's requirement of practical interest from 1916 (see i.e. Fitzgerald et al. 2005).

Johansson \& Gärdenfors (2005) present an overview of historical developments in the theory of ICTs in education. They start with the behaviorist school that was created by Skinner in the 1950s, and note that in spite of being generally shunned, behaviorist ideas still motivate the development of most educational software. In behaviorist instruction, the student is considered an active learner who is guided individually through practice work that gives immediate feedback and reinforcement of learnt skills. The instruction proceeds in an incremental fashion, with small and manageable steps toward a well-defined learning goal. Most tutoring software is continuously designed according to these principles.

Cognitivism that emerged after behaviorism considered the brain as a kind of computer, and had its main influence to the development of artificial intelligence, expert system based learning and other research in software development, though its direct influence in mainstream ICT education has been modest. One could ask, however, whether the folk model of brain among computer scientists deviates from the functions of a computer: input, processing, storage and output?

The last tradition that Johansson \& Gärdenfors present is constructivism in its many variations, starting from the Piagetian tradition. They claim that constructivism is currently the dominating paradigm in education, which probably is true when PBL, computer-supported collaborative learning, etc. are included under the same umbrella term. They list the general goals of constructivism that are for the learner to develop problem-solving and reasoning skills, critical thinking, and an ability to engage in independent thought. Constructivist instruction is embedded in a complex, realistic, and relevant environment, and it is presumed to nurture self-awareness of the knowledge creation process. Finally, Johansson \& Gärdenfors conclude that all paradigms are still useful and need consideration in the development of ICT enabled education.

The EVTEK pedagogical strategy work in 2005-06 took inspiration from many concurrent pedagogical views, including the ideas of progressive inquiry. Accordingly, the classroom practices are varied, emphasis being still in traditional teacher -led instruction, laboratory practice, and project work. The infrastructure that includes curricula, schedules, classroom arrangements, on-line tools, assessment schemes, etc. supports best traditional modes of instruction. As Biggs (1999) has pointed out, only a constructive alignment of teaching philosophy, methods, and evaluation could bring about 
enduring changes in higher education. The participatory on-line learning environments at EVTEK support learner's building understanding through the collaborative construction of a shared product. Nevertheless, because project-based methods have a strong appeal in the engineering world, the advancement of conceptual thinking has attracted less attention in the development of educational practices. The education should aim at developing the knowledge, skills, ethics, communication, and emotional component of the particular professional expertise to meet the need for highly integrated competence in the present day working environments. 


\section{Thinking and education in a cross-cultural perspective}

\subsection{Scientific thinking and cognitive science}

"I can see or understand a whole thought in a flash in exactly the sense in which I can make a note of it in a few words or a few penciled dashes. What makes this note into an epitome of this thought?" Wittgenstein 1953, §319

"Can one think without speaking?" - And what is thinking? - Well, don't you ever think? Can't you observe yourself and see what is going on? It should be quite simple.

Wittgenstein 1953, §327

When Ludwig Wittgenstein asked these questions, the thinking process was predominantly the domain of philosophical investigation, and he looked for an answer by painstaking deduction. The biological functioning of the human mind has been explored in section 2.3, where some answers to the nature of thinking were provided. In this section, the logic of thinking is examined further through cognitive science. Since its birth in 1956, cognitive science has concentrated on the questions of cognition, thinking, perception, and language (Bechtel \& Graham, 1998). In the beginning, cognitive science was strongly connected to artificial intelligence, symbolic information processing, and linguistic theories of universal grammar. Cognition was defined as information processing that followed rules and patterns that could be discerned by science, in particular by computer modeling, and it was understood to be systematic.

The brain was conceived as a kind of controllable machinery, which lead to construction of mathematical models to explain neural functions and language structures. Cognitive psychology emerged around 1960 (ibid., 46), with the creation of memory models that divided memory into shortterm and long-term storage plus processing in between. Early efforts in cognitive science were largely based on information processing models that got their inspiration from information sciences, symbol processing, and mathematics, and they were necessarily of theoretical nature. Since computer technology revolutionized neuroscience, the analysis of cognitive processes has been more and more based on real observations on brain functioning.

Many leading philosophers, such as Churchland, Searle, Johnson, and Dennett, have successfully applied neuroscientific knowledge to explain philosophical questions regarding the nature of thinking and consciousness, though their position is still fiercely challenged within philosophy (Lakoff \& Johnson 1999, Manstead et al. 2004). For example, Bennett and Hacker insist that the ascription of cognitive attributes to the brain is fundamentally mistaken, and the human mind is something more than the product of a brain. Cognitive neuroscience should not even attempt to explain human thinking (Bennett et al. 2007). They base their critique on poor Wittgenstein who was dead before modern neuroscience even existed. As Dennett and Searle point out, Wittgenstein did not argue against locating the consciousness in the brain as his main concern was the thought process and uses of language unique to humans (Bennett et al. 2007). Moreover, it should be remembered that 
Wittgenstein was able to develop his own thinking ("early" and "later" Wittgenstein) (Hintikka 2001), and so should his followers. An excellent recent overview of ideas of rational thought in philosophy and cognitive science can be found in Lakoff \& Johnson (1999).

Since this thesis has a practical goal to improve learning processes, it does not attempt to get involved in philosophical debates. However, I will use insights by great thinkers to advance the train of thought. The focus of this section is in Wittgenstein's question 369:

One would like to ask: "What is it like - what happens - when one does a sum in one's head?" And in particular case the answer may be "First I add 17 to 18, then subtract 39 ..." But that is not the answer to our question. What is called doing sums in one's head is not explained by such an answer.

Wittgenstein 1953, §369 [emphasis original]

\subsubsection{Analyzing thinking}

Hutchins (1995) has done a detailed analysis of several processes of organized action that include mental processing such as calculations. He offers three answers to the question "Why can't we say what we do"? His first explanation is that the process involves a relation to the environment through automatisized motor medium (physical actions). Because physical environments and situations have an endless variety, an exhausting verbal explanation is impossible. Secondly, the skill may have become automatic to such an extent that the memory of how it was learnt and reasons for steps have been forgotten. A third situation arises when the mediating structure is present as constrains in the environment that shape the development of the motor medium directly. (See also Scherer's view in section 4.5)

The performance of geniuses who can calculate complex number problems in seconds relies much on mental imagery that cannot be verbalized or shown in calculation steps; a conscious process description would take much longer time than the calculation itself. These are internal patterns that do not necessarily have any corresponding patterns in outside reality. Wittgenstein is right that there is no precise answer to how mental processes are performed because the processes are not exact. Instead of describing the processes we have to revert to understanding the premises and looking for ways to facilitate problem-solving and analytic processes.

Thinking and problem-solving processes have been studied extensively, for example using verbalizations and think-aloud studies. Think-aloud protocols became the standard data collection method for formulating models of problem-solving for a long time. However, they are better in describing step-by-step algorithms or simple heuristics than analogical thinking (Dunbar 1998). The application of an algorithm always guarantees the correct answer, but it is restricted to well-defined problems. Think-aloud is a less useful method in analogical reasoning because so much of the processing is unconscious and consequently, words are only means to justify the conclusion, not a record of actual thinking. Conscious thought is not simply being conscious of something that 
otherwise goes on unconsciously, it is a special kind of activity where paying attention plays a crucial part (Suchman 2007).

Schwartz et al. (2005) relate an experiment that highlights impacts of small changes in condition in reasoning. People were asked to reason about pouring liquid from glasses. There were two glasses of equal height but different diameters. Each glass had a line drawn the same distance from the rim to indicate the level of water (although there was no actual water in the glasses). People were asked to imagine that both glasses were filled to the marker line, and asked that if both glasses were tilted at the same angle, whether the water would pour out of one glass sooner than the other. In the experimental first-hand condition, people held the glass, closed their eyes, and tilted the glass until they saw the water reach the rim of the glass in their imagination. In theoretical reasoning, that is, second-hand condition, participants could only look at the glasses and had to reason verbally describing what would happen. In the first-hand condition, everybody who was tested except for one person, correctly showed that the glass with a wider opening would start to pour sooner than a comparable glass with a narrower opening. In the second-hand condition, people performed less well or at a chance. In addition, when people worked in pairs and increased their reliance on communicated description, they were never correct. The research indicates a dissociation between theoretical and empirical knowledge, which do not always coordinate with one another, as the same test persons got correct results in one condition but not in another. Moreover, the perception-based knowledge did not turn into explicit description, and it was not sufficient to induce a rule.

Schwartz et al. (2005) also underscore that the ability to perceive accurately is not self-evident. For instance, wine-tasting is learnt by comparing two wines, thus through juxtaposing and contrasting cases. It takes considerable practice to differentiate tastes precisely. Learning perception has been discussed by Suchman (2007), as well, who alluded to a certain chemistry process where apprentice researchers had to produce 'jet-black' fiber. To discern jet-black from other shades of black had to be taught systematically by their professor. Conscious knowledge and perception represent only a fraction of thinking processes that mostly remain outside our awareness.

\subsubsection{Rational decision-making and intuition}

In modern society, people are assumed to behave rationally, to understand the rules of society and to follow them. The myth of rational decision-making persists despite of numerous counterexamples such as well-known behavior of money markets that are openly admitted to react emotionally, to fears and expectations. In everyday life, risk-taking in traffic is typically irrational: Drivers know that it is illegal to use a mobile phone without a hands-free device when driving. Most also know that talking on the phone increases the risk for an accident four-fold. However, in many adults this knowledge is not transferred to understanding risks or rational action. 
Important decision situations in life and business are normally so complex that it is impossible to fully calculate or logically deduce the outcome. Additionally, a person needs intuition, and a facility to consider the facts and likely outcomes based on personal experience. The ability to recognize overall patterns rising from past experience depends on feelings. When we make decisions we pay much attention to future outcomes, and what kind of emotions they raise. The importance of this ability is illustrated by people who lack it. Patients with severely impaired emotions (caused by frontal cortex or amygdala damage) are unable to make use of their emotion-related experience. They have trouble imagining which outcomes they would prefer in complex situations because they cannot imagine their emotional responses to those outcomes. When these patients face a situation of choosing a career, or deciding whether to marry, they fail to activate an emotion-related memory that would help them choose more advantageously among competing options. Decisions made in these emotionimpoverished circumstances lead to erratic or downright negative results, especially so in terms of future consequences. (Damasio 1999)

The evolution of the human brain depended on its capacities to support survival (Claxton 2005). Therefore, the brain developed to be good in sensing, acting and survival skills. For example, the response to fear is automatically processed in the brain before it reaches consciousness, bypassing any rational decision-making. The evolutionary reason for this is that quick response is important for survival in real danger, and having false positives is less dangerous than having false negatives (Öhman \& Wiens 2004). Human language and rational thought are exceptional and secondary modes of brain capability (Claxton 2005). Language developed as a byproduct of increased control of action and perception. Basically logical thinking and rational thought are skills that need to be learnt by practicing, and evoked in particular situations. On the other hand, switching off the controlled mode of thinking enables the creation of new insights and intuitive decision-making.

Until recently, our understanding of effective decision-making processes in business and engineering has exclusively relied on formal logic and statistics. Braverman's textbook on management decisionmaking from 1972 announced: "A real decision situation, no matter how complicated, can, with patience, be broken down into its component parts to any level of detail desired, a process of reduction; solutions then can be found for the individual components; and the overall solution can be achieved by a continued application of the logic process." (Braverman 1972) On the other hand, studies in artificial intelligence and computerized models on decision-making tried algorithms and heuristics to model human thinking. As noted before, rule-based models work only with well-defined problems, and therefore, the focus later shifted to neural networks and connectionist models.

In today's management studies, the role of intuition in decision-making has called much attention (Dane \& Pratt 2007). Intuition and tacit knowledge have been recognized of being essential in the process of complex and time-limited decision-making, but how intuition should be applied and when it 
is beneficial requires examination. Intuition is based on experience that has been accumulated over years in profession, and that is partly unconscious or inexplicable. The intuitive, experiential information processing system consists of cognitive frameworks that psychologists such as Epstein refer to as schemas, which are inductively derived from emotionally significant experiences (ibid.). Furthermore, intuition is highly valued in non-Western cultures, for instance Koreans rank "being an intuitive person" more important for success in work than "being a logical person" (Norenzayan 2006).

However, the value of intuition could be compromised by three risks: first, that the situation is novel compared to the experience, and previous rules do not apply, but the person is unable to realize it. The second risk is caused by overconfidence of the decision-maker whose experience is not adequate or sufficient but he fails to notice it. The third category of risks includes implicit prejudices and internalized, irrational fears (Myers 2007). Implicit prejudice could, for instance, lead to the appointment of a white male in a managerial position without noticing equally competent women or immigrant candidates. Irrational fears are our evolutionary reactions (fear of strangers or snakes), fears stemming from previous experiences, as well as the tendency to appreciate more immediate threats (airplane accident) than long-term dangers (lethality of smoking). In sum, successful application of intuition requires professional expertise that is well under cognitive and emotional control.

\subsubsection{Human reasoning and technological representations}

$\S 185$ "Let us return to our example (143). Now - judged by the usual criteria - the pupil has mastered the series of natural numbers. Next we teach him to write down other series of cardinal numbers and get him to the point of writing down series of the form

$0, \mathrm{n}, 2 \mathrm{n}, 3 \mathrm{n}$, etc.

at an order of the form ' $+n$ '; so at the order ' +1 ' he writes down the series of natural numbers. Let us suppose we have done exercises and given him tests up to 1000. Now we get the pupil to continue a series (say +2) beyond 1000 - and he writes 1000, 1004, 1008, 1012." Wittgenstein (1953)

Wittgenstein emphasizes that the pupil in his example has made his own rule that is different from what the designer of the exercise had devised. The pupil follows a logic, however, and it is a matter of common agreement, which logic is valid in each situation. In addition to Wittgenstein's hypothetical pupil, also real children make up new counting rules. My little test subject (five years) counted:

$" 1,2,3,4,5,6,7,8,9,10,20,30, . .100,101,102, . ., 110,1000,1001,1002, . .1010$, million, millionone, ... million-ten, billion, billion-one, ... billion-ten, billiard, billiard-one, billiard-two!"

Often the rules and conventions of a society are so well established that every person is presumed to be able to follow them. However, it seems surprisingly difficult for an average person to follow any formal signs or signals as the following incident shows: One day at noon in the Kamppi bus terminal in Helsinki, I observed people who intended to take a bus that was already at the pier. There was a red cross signal above the gate, and the gate-opening button had red light indicating that there was no access to the pier. Still, about half of the fifteen people who arrived to the gate went to press the button and tried to walk through the closed gate disregarding the queue of other passengers, as well as visual signals. 
When photocopying was first developed, Lucy Suchman (2007) performed an analysis of human photocopying machine communication in the laboratories of Xerox. The designers of photocopying machines relied on hierarchical menus and a couple of buttons that had to be pressed for a selection. In Suchman's experiment, two humans and the machine ended up in a misunderstanding because the humans had made one wrong selection without noticing it. The machine has certain states when it is only able to do certain actions; as a result of a wrong user selection the desired state (action) is not accessible. The machine cannot offer appropriate selections or communicate its status.

Humans and machines differ in certain aspects significantly in their modes of communication. Humans are open to any action (wide range of actions any time), flexible, and open-ended; whereas machines proceed in preconceived sequences, cannot step back and see all possibilities unless instructed to do so, and must follow navigation paths.

These days photocopying machines have improved user interfaces (less hierarchy and combined options), but the amount of options and interpretation of symbols still makes them a challenge for an occasional user. Moreover, human - machine communication has improved since the 1980s with the arrival of graphical user interfaces on computers and hypertext applications that do not endorse strict hierarchies and allow alternative paths to the result. Efficient search engines have made it remarkably simple to locate information in a few steps without navigation of lengthy menus. Interestingly enough, other devices have not been quick to follow the example of computers. Remote controls, mobile devices, household appliances, and other specific use gadgets rely heavily on menu trees and step-bystep procedures that require the user to build a model in her mind. Instead, the user should be supported in her choices by visual design, aesthetics, and a range of possibilities. Kirsch (2005) who has studied user interfaces proposes that a good interaction design displays cues as possibilities for action to the user; these are action affordances of a space.

Kirsch (2005) defines intelligent action as deciding what to do next; in interfaces it is normally supported by an environment that is imbued with cues, constraints, and indicators that reduce the complexity of decision-making by providing resources. If the environment is well-designed and wellknown to the person, intelligent action is greatly facilitated. People are not particularly good at tasks that require abstract reasoning or intensive recall but they excel at using resources in a systematic but creative fashion to work their way to solutions. This is what Sternberg (2005) calls practical and creative intelligence (see below).

When Clancey (2005) presents a case of the use of pictorial representations in teaching new concepts, he concludes that it requires a correct interpretation to start with. In his experiment, a computer program was designed to teach linear equations and their representations in graphs, and the pupils 
were expected to modify equation's constant and angle. However, in the case presented, the pupils focused on peripheral features of the graphing software, mainly because of the low quality of the display. The learning was done in groups of two, and the pupils were instructed to take turns in answering questions and writing their interpretations. The two pupils in the presented case took the social challenge seriously, so that they let the cooperative effort override the academic task of understanding the equations. In disagreement, they preferred cooperation to what they maybe felt was their conceptual understanding, and that led to mistaken paths of thought / lines of reasoning. Moreover, one of the students was a second language speaker who interpreted the word 'straight' line through her native Spanish equating linear with vertical, which caused a significant conceptual confusion in her mind. Finally, Clancey concluded that the "process of 'viewing as' and interpreting is inseparable of human experience, so seeing something meaningful and conceiving what it means occurs together and is only subsequently followed by a coherent linguistic statement by which the meaning is represented." (Clancey 2005, 114)

\section{Does the airplane fall?}

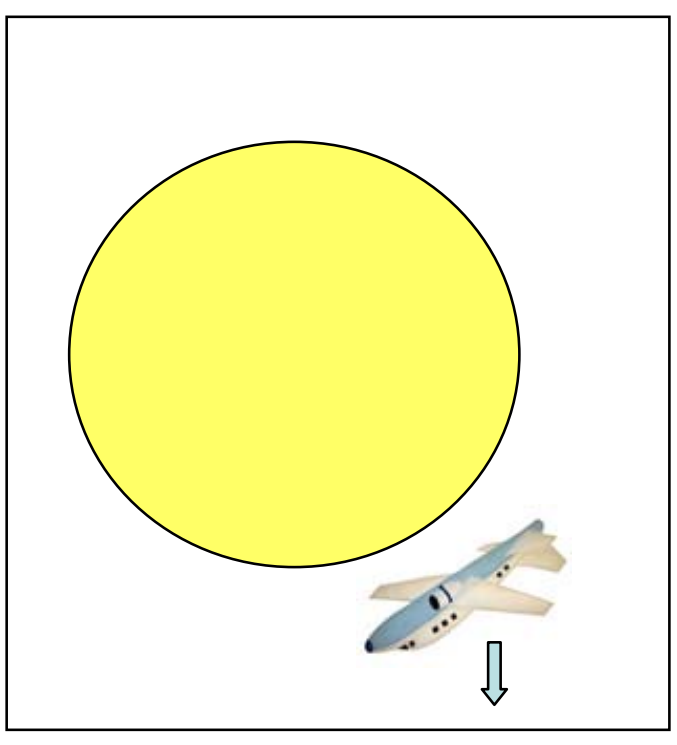

Mental framework 1

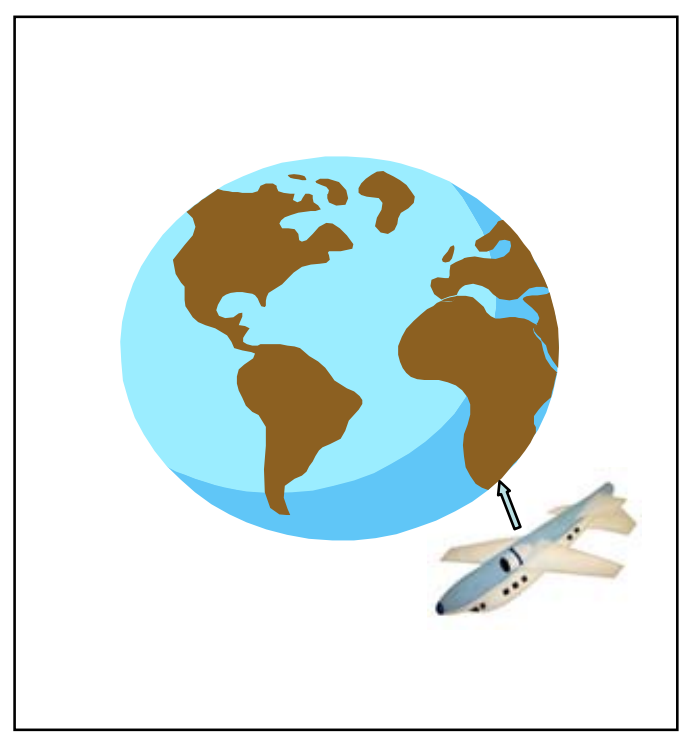

Mental framework 2

Figure 7: Interpreting an image

Similarly, Ivarsson \& Säljö (2005) discovered that users interpret visual cues according to their experience and mental frameworks. In a modern technology culture, individuals have to be familiar with relevant canons of visual representations in order to function and perform required actions. Ivarsson \& Säljö present an experiment with school children who tried to interpret a picture of the globe on computer screen. The children were asked to explain the position of the airplane vis-à-vis the globe and tell if it will fall or not (Figure 7). Even though all children understood the concept of 
gravity and globe, many were not able to interpret the visual construction on the computer screen. Evidently, a novel interface required adaptation. The study illustrates the complex relations between representational technologies, perception, cognition, and human action, especially when computer screens are used.

Ivarsson \& Säljö (2005) interpret the results through the sociocultural perspective where artifacts are seen as objectifications of human intentions and insights. Cognitive development is not universal but depends on the specific social practices and the tools and technologies that children are exposed to and learn to use as mediational means. In a technologically complex society, children develop skills in using a range of symbolic artifacts. According to Wartofsky's historical epistemology the forms or modes of perception, their very structures, are historically variant. Wartofsky (1979) argued that "the specific feature of perception as a mode of action is that it is mediated by representation." Historical epistemology differs from Piagetian genetic epistemology for example in how it explains the use of perspective in pictures. Piaget calls use of perspective 'visual realism', which is a phase of child development that is achieved at the age of 8 or 9. (Piaget \& Inhelder 1969, see also 2.3) However, use of perspective is well-known to vary across cultures, and in many historical visual cultures it was never used. For instance, in ancient Egypt, faces of people were always drawn in profile. The Piagetian view is, according to Wartofsky, based on $17^{\text {th }}$ - century mechanistic model of perception that is known as geometrical optics, assuming that vision directly creates an optical image in the brain. The change from 'intellectual realism' to 'visual realism' is a socioculturally learned mode of representation in Western culture. The rules and conventions of drawing have to be learned through a process of cognitive socialization. Visual perception is the most extensively studied part of how the brain creates an understanding of the world (see i.e. Kalat 2004, Frith 2007).

\subsubsection{Understanding and transfer of knowledge}

It has often been observed in science and mathematics education that students are not able to apply their theoretical knowledge in practice or in a different setting. They learn but they do not really understand. But what does it mean 'to understand'? Bereiter (2002) analyses the concept of understanding finding a number of different meanings. He starts with a classic American text, the "Taxonomy" written by a committee headed by Bloom, where the levels of cognitive attainment are presented in order: knowledge, comprehension, application, analysis, synthesis, and evaluation. The order that has comprehension before analysis relies on the notion of mind-as-container, and does not consider the depth of understanding. Understanding is decomposed into cognitive behaviours. In the cognitive view that was developed some years later, mind is still a container, but knowledge is described as a mind map or network of conceptions in the head. Bereiter calls this the 'correspondence' view of understanding. A third view of understanding was the 'performance view' by Perkins, where understanding was assumed to be achieved when the pupil is able to act, feel, or think intelligently with respect to a situation. 
Bereiter's definition is as follows: "Understanding implies abilities and dispositions with respect to an object of knowledge sufficient to support intelligent behaviour." He points out the difference between understanding that is measured as performance in a test, and understanding as knowledge about the world and its objects. In this sense, understanding one thing increases your capacity to understand other things.

Bereiter (2002) discusses the meaning of understanding a joke: when do you understand a joke? Obviously when you laugh in the right way at the right time. But there is no requirement of being able to explain it (jokes are often hard to explain) or to remember it or being able to relate it later. Sharing jokes is a social act; it creates bonding in a group, and simultaneously eases tension and stress. People can share a joke only if they share an understanding of what it is about, a certain amount of cultural knowledge. Bergson (1900) says that there must be something suddenly contradictory, conflicting, repetitive, or contrasting to create a comical effect. You have to share what to expect. Comical effects are born from everyday situations that get an absurd turn. Perhaps it is the element of surprise that also makes jokes so difficult to remember.

Woodruff (2006) develops Bereiter's concept of understanding further by viewing it as an emergent phenomenon resulting from interacting relational perspectives. He proposes that teachers should not attempt to explain things in many ways but they should provide different angles to the same topic. We cannot teach the explanations directly - indeed, the explanations are not always transformed into understanding - rather, we teach something like changing frames of reference. Seeing problems from many perspectives helps students develop their understanding. Understanding is accordingly dynamic and evolving instead of a piece of knowledge in the container of the mind. In the sense of modern neuroscience, human knowledge is not a thing, but it is essentially cognition that is built in the selfreferential system of the mind.

The mental models and concepts of students do not change automatically when they adapt new information. People naturally see their intuitive mental models as truth, and they are emotionally against changing them (Evans 2002). Therefore, it is not easy to initiate critical reflection and a change in thinking. Instructors should assist students in diagnosing mistaken conceptions, and then provide support to the learning process and reflective processes. In a successful learning process, students need to become aware of their deficient mental models, prepare to change the frames of reference, and consequently develop their understanding.

Unfortunately there is much evidence that the transfer effect of learned mental patterns is small when mathematical skills are concerned, as schooling and abstract operations are not necessarily carried over to everyday practice (Crump 1990). Hannula (2005) has demonstrated that learning mathematics 
becomes enjoyable when students conceive it as a problem-solving process, a creative action. School learning does not often reach this stage, but remains a technical skill of performing given calculation tasks. If students realize the mathematical thinking process, they are able to apply it in different situations. Even in universities, students often study mathematics as a set of operations. When they learn to perform an operation in one course, they restrict its use in that context, and fail to apply it in other courses. The transfer effect remains minimal.

Also Schwartz et al. (2005) discuss outcomes of learning and how to measure it. The goal of schoolbased interaction should not be to train students to solve a specific class of problems efficiently or to transfer a specific procedure untouched to a new context. They argue instead that the goal should be to prepare students to adapt and learn in the future, therefore they dismiss testing memorizing as an inadequate indication of understanding. Many other assessment methods test sequestered problemsolving, without access to resources. Neither of these methods aim at developing real-life expertise. Schwartz et al. (2005) developed a method called DKE (Design for Knowledge Evolution) where the goal is to unite the mechanisms of perceptual learning for developing first-hand knowledge with model building for developing second-hand knowledge. In one of the example cases, first-hand knowledge was developed by trying statistical data sets without any theoretical instruction. When tested, the students were not able to develop the correct theory of variance. However, when tested in a new context, they could reason better about statistical problems than students who had been given lectures about statistics. The best formula in instruction turned out to be a combination of experimenting and theory: some advance reflection and first-hand trials combined with a small amount lecturing that gave the correct theory basis. (Schwartz et al. 2005) First-hand theories focus on direct experience, and second-hand theories focus on descriptions of experience, such as communicated knowledge and symbolic structures. On the other hand, second-hand knowledge, such as declarative knowledge or instructions, needs to be converted into procedural knowledge (actions). In sum, learning complex ideas depends on recruiting multiple cognitive, as well as social and motivational mechanisms and resources.

\subsubsection{Views of intelligence and success in studies}

Wit is the sudden marriage of ideas which, before their union, were not perceived to have any relation.

Mark Twain

Intelligence is commonly defined as general factor or 'g-intelligence' (GI) that is measured by IQ (intelligence quotient) tests. The g-intelligence measures analytical and verbal cognitive abilities and capacity to process information. Many studies support the belief that school success correlates with GI. Moreover, Töttö (2004), for instance shows that statistically, in many academic fields, the level of general capability as measured by high school grades is the best predictor for success in university studies in the first years of study. A review by ACT of more than 100 retention studies in the U.S. show, however, that general intelligence and high self-confidence do not predict successful completion of 
studies, but that this depends more on motivation and determination as well as good study and time management skills (Lotkowski et al. 2004).

Many scholars argue that a more encompassing definition of intelligence than the GI would be superior in predicting success in working life and life in general. Robert Sternberg claims that IQ tests define intelligence in a limited and culture-specific fashion. People from other cultures and minority children are in a disadvantaged position.

"Conventional views of intelligence favor individuals who are strong in memory and analytical abilities. They disfavor most other individuals. The result is that individuals who may have the talents to succeed in life may be labeled as unintelligent, whereas some of those labeled as intelligent may be less endowed with such talents."

Sternberg 2005.

Sternberg (2005) introduces the concept successful intelligence, which incorporates three aspects of intelligence: analytical, practical and creative. Furthermore, executive processes to plan and control activity are instrumental for successful performance. Practical intelligence, as well as executive processes are not permanent abilities of a person but rather can, as Sternberg \& Gardner have shown, be taught. Having established this, they suggest that the development of these study skills should be part of every school curriculum. In spite of research results that tend to show a consistent IQ level at different ages, it is not unchangeable. Most IQ test segments can be rehearsed and performance in IQ tests thus improved by practice.

Gardner, on the other hand, developed the idea of eight different types of 'multiple intelligences' that everyone seemed to possess to a greater or lesser degree (Gardner 1993). Each intelligence represents a set of capacities that are brought to bear upon two major focuses: the solving of problems, and the fashioning of significant cultural products. These eight intelligences include linguistic, bodilykinesthetic, spatial, musical, logical-mathematical, intrapersonal, interpersonal and naturalist intelligences. Later researchers have suggested adding for example emotional intelligence to types of intelligence.

Obviously the views to intelligence presented above enhance our understanding of the variety in learning approaches and human activity. I will avoid using the term intelligence because its association with everyday understanding of IQ intelligence. Students have varied cognitive abilities in many dimensions. Cognitive competence includes capabilities in perception (visual, spatial, audio, oral, verbal); thinking abilities (abstract, practical, formal, pragmatic); social and emotional capabilities. Research on cognitive competence has thus far been mainly the domain of psychology. Contemporary investigators of cognitive development have yet to resolve the problem of integrating natural and sociocultural phenomena into an overarching theoretical framework that would fully explain the development of cognition (Wertsch 1985). In fact, Hakkarainen et al. (2004a) prefer to speak of intelligent activity instead of intelligence as a personal mental capacity. Intelligent activity depends on the environment, and it is a socially distributed process of human actors and supporting artifacts. 
Schooling encourages a tendency towards decontextualization and thinking in abstract terms. Western ability tests presuppose all kinds of conventions and values that are shared by the test taker and the test administrator, but that are unlikely to apply in other societies. Therefore, cultural background causes difficulties in ability testing if the same tests are used in different contexts (Berry et al. 2002, 121). Culture-blind comparison of test scores gives misleading results. A study of practical intelligence in Kenya illustrated how Western schooling influenced test results of school children. Children from traditionally oriented families scored high in practical intelligence (about local knowledge of medicinal herbs) and low in abstract-reasoning-based abilities, whereas children with more formal schooling showed a reverse pattern (Sternberg 2005).

The complexity of psychological testing in a multicultural society is discussed by Craig \& Beishuizen (2002) who stress that psychometric testing brings about ethical and value questions. They demand that value questions must be openly admitted because there are no straightforward solutions to the question of universal or particular competencies. Cognitive abilities are dependent on cultural backgrounds, thus minorities are necessarily in a disadvantaged position when the testing standards are set by the majority culture. They argue that finding an ethical, fair for all solution, would require a tremendous effort and probably even be impossible.

Indigenous views of human capabilities or intelligence often emphasize social factors of behavior. A study among the Cree in Canada found that they regard showing respect, self-control, and listening attentively as essential parts of intelligent behavior, in addition to good sense of direction (the Cree are hunters), wisdom and a quick wit. Insensitivity, living like a white, and craziness were seen as negative competences (Berry et al. 2002). On the other hand, Chinese views of intelligence focus on hard work and effort, not personal competencies as such. Intelligence is not a quality of a person but behavior. Asian learners regard the self as malleable and capable of improvement through one's effort, in addition to recognizing individual differences in natural ability. The Japanese view of intelligence encompasses social competence such as one's ability to sympathize with others. African conceptions of intelligence focus on wisdom, trustworthiness and social attentiveness. (Li \& Fischer 2004)

Accordingly, Duckworth \& Seligman (2005) got results in the United States that point away from pure IQ in explaining school performance. gave 300 eight graders, their teachers and parents a questionnaire about the students' ability to control impulses and follow rules and conducted behavioral tests. The reported self-discipline predicted final grades, school attendance and work habits better than IQ did. Similarly, rigor in school work is the strongest predictor of minority student success in college according to several studies in the U.S. (Oakes et al. 2004). The level of mathematics studied in high school has an effect on bachelor's completion more than any other pre-college variable. The cumulative effects of rigorous middle and high school math and science courses are particularly strong 
for low-income students. Low income students who take algebra and geometry are almost three times as likely to attend college as those who do not.

Oakes et al. (2004) conclude that there is a number of questions that call for research in order to advance science education for minorities. In particular, they call for development of a system in which students hold identities that are simultaneously multicultural and academic. The questions are similar to what I pose in my research:

- How can math and science courses capitalize on diversity and heterogeneity to maximize learning? How, for example, might a greater emphasis on diversity contribute to all students' multiple ways of knowing math and science?

- What are the key features of multicultural curricula and culturally relevant pedagogies in math and science?

- What is the impact of our culture's framing of mathematics and science achievement as "culture-free" and neutral?

Minority achievement is affected by cultural prejudice and stereotypes, which has been shown to also influence student self-conception and achievement identification, as Steele (2004) has shown. A problem-solving test was presented in two different ways to a group of Black and White university students in the United States. When it was presented simply as a problem-solving task, Black students performed as well as White students, there was no intergroup variation. But when the Black students were told that the test was a valid measure of intellectual ability, they underperformed White participants, thus unconsciously conforming to lower stereotypical expectations. Steele claims that the stereotype threat explains lower college graduation rates among African Americans and women in science.

\subsubsection{Developing successful intelligence and metacognition}

Learning without thought is labor lost. Thought without learning is perilous. Confucius

Metacognitive skills in learning include setting goals for studies, choosing appropriate learning strategies, self-reflection, and monitoring progress. Coffield et al. (2004) reviewed a large body of literature on educational interventions that aimed at improving the quality of education, comparing the cost and effect of different kinds of interventions. The findings suggest that advantageous approaches tend to include development of metacognition. "Approaches which were directed at the metacognitive level of setting goals, choosing appropriate strategies and monitoring progress are more effective in improving knowledge outcomes than those which simply aim to engage learners at the level of presenting information for understanding and use." (ibid., 54) Improving instructional quality and formative assessment belong also to effective intervention types. Actually, individual guidance and reinforcement seem to be most effective, but because of the high cost involved, they could hardly be efficient in mass-education. The Oxford university tutorial system followed by leading English 
universities where students meet their academic tutors one-to-one weekly to discuss their progress certainly would be ideal (Oxford site at http://www.learning.ox.ac.uk/).

An important research finding regarding higher-level expertise has been that an individual's ability to develop his or her content-specific knowledge and to apply it in varying situations often co-evolves with the development of general thinking skills and metacognitive strategies (Sternberg 2005). Selfreflection, becoming aware of one's working habits and learning strategies enables a student to begin improving them. for example, writing has been found to be an efficient tool in developing metacognitive capability. At the same time, writing also helps acquire deeper understanding of the subject matter (Hakkarainen et al. 2004a).

Metalevels of mind incorporate emotion and an awareness of cognitive and emotional states (Table 1). Therefore, full self-regulation includes regulation of cognition, motivation, and emotion (Dai \& Sternberg 2004). The better the student's ability to control these in long-term as well as in a particular situation is, the better she manages her learning. Hannula (2004) discusses affect in the context of learning mathematics stressing the importance of understanding affective traits that lead to success in mathematics. An optimal student enjoys mathematics and has confidence in it, perceives mathematics as a sense-making activity, and considers effort to be an essential element in success. Furthermore, interest, intrinsic motivation, and learning orientation (as opposed to performance goals) predict better performance.

\begin{tabular}{llll}
\hline Domain/ Concept & Cognition & Motivation & Emotion \\
\hline Self-regulation & $\begin{array}{l}\text { Information about } \\
\text { self and environment }\end{array}$ & $\begin{array}{l}\text { Direction for } \\
\text { behavior }\end{array}$ & $\begin{array}{l}\text { Goal-directed self- } \\
\text { regulation }\end{array}$ \\
State & Thoughts in mind & Active goals & $\begin{array}{l}\text { Emotional state } \\
\text { (mood) }\end{array}$ \\
Trait (memory) & $\begin{array}{l}\text { Concepts, facts, } \\
\text { scripts, etc. }\end{array}$ & $\begin{array}{l}\text { Needs, values, } \\
\text { desires }\end{array}$ & $\begin{array}{l}\text { Emotional } \\
\text { dispositions (attitude) }\end{array}$ \\
\hline
\end{tabular}

Table 1: Cognition, motivation, and emotion in self-regulation state/ trait aspects (Hannula 2004)

Sternberg (2005) tested how different modes of teaching worked with students that had different cognitive profiles. He had several groups of students with a combination of measured intelligence profiles (according to his classification into analytical, practical, and creative intelligence, see previous subsection), and tried different conditions of teaching on the test groups. All groups listened to the same lectures, but the way they were asked to process the information was divided into four conditions. One group was subjected to the "traditional" teaching method that is called memory condition, which includes presenting the material which students have to memorize and represent. In the analytical condition, students are asked to compare and contrast theories. In the creative condition, they are asked to formulate their own theory based on the facts, and in the practical condition, they are asked 
to apply the theoretical knowledge in a real-life problem. All students were evaluated in the same way for memory, practical, analytical, and creative quality. The results confirmed that students who got instruction that matched their cognitive style, performed better than others. However, students who were strong in analytical skills, had an advantage over others in all conditions, which Sternberg believes is a consequence of the emphasis on analytical way of teaching in all school instruction.

Moreover, in a follow-up study, Sternberg and his collaborators have found that memory condition teaching resulted in an inferior outcome than other methods. Students who were subjected to a multicondition teaching that included analytical, practical, and creative methods, performed best in all types of tests that included practicing analysis, creativity, and practical application, even in better memorization of the material than the memory condition students (Sternberg 2005).

\subsubsection{Programming skills and problem-solving strategies}

When students come to study computer science and information technology, they already have mental models about computers, programming, internet, and data management. Many of the models are inaccurate or even mistaken, therefore they could actually obstruct deeper understanding of the concepts. Instructors have to make students aware that they have mistaken conceptions and to activate a new thinking process. To quote Roger Needham (2000) in his keynote speech at ITiCSE'00: "Deprogramme the incoming students by teaching them things none of them know."

There is a considerable agreement in the literature that students experience many difficulties in learning to program (Stein 2000). For instance, an ACM/ICER working group 2001 reported on beginning computing students' inability to program. The authors tested first year students in several universities in the U.S. and other countries on a common set of programming problems, and the majority of students performed much more poorly than expected (Fitzgerald et al. 2005). The research did not reveal what the principal reasons behind failures were: whether they were caused by fragile knowledge and skills or by poor problem-solving skills. An extensive follow-up research aimed at determining what strategies were likely to lead to success versus those that were likely to lead to failure in program code tracing. The findings indicated that successful and failing students did not actually employ different kinds of approaches, or 'higher' or 'lower order' thinking skills. Most students used multiple strategies in working on a given question, different strategies were used for different questions, and many strategies that were used successfully by certain students would be used incorrectly or unsuccessfully by other students. Success was determined not just by which strategies were employed but rather by how well the particular strategies were employed (ibid.). Therefore, programming skills do not appear to be mechanical, surface level skills, but they require a profound understanding (a mental schema, perhaps). 
Eckerdal \& Berglund (2005) discuss programming thinking by presenting a first year programming course where object oriented programming was introduced. Students that were interviewed about object oriented thinking had difficulties in describing it, because the object oriented paradigm is built on a set of abstract concepts that are not easily adopted. Students need to reach a certain level in their understanding in order to be able to use the concepts for analysis and design in object oriented programming tasks. There are ways for educators to assist students to reach such understanding. The researchers suggest that these may include problem-solving skills and a systematic way of thinking, as well as thinking about learning, metacognition.

In sum, fluency in programming requires a deep understanding of abstract concepts, capability in algorithmic thinking and logical reasoning. Many studies indicate that ability in logical reasoning is not separate from overall intellectual capacity and that students who master reasoning and problemsolving tend to perform better in any science subject. Cognitive decontextualization is learnt through years of systematic education in Western schooling designed to override the natural biases of human thinking (Stanovich 2003).

\subsection{Knowledge and learning}

Those who saw can tell, and those who didn't see can't say anything!

When Regina Harrison was learning Quechua in the beginning of her field work in an Ecuadorian village, people used to ask her teacher "Does she live yet?" meaning "Does she speak our language well enough yet?" For them, language skill is commensurate with the acquisition of logical analysis; children are said to be 'sin razon' until reaching the age of ten (Harrison 1989). For us, knowing is often equaled to the ability to put words in writing to create knowledge artifacts. For the Andean informant, Sisa, songs are not verse line, rhyme, stanzas centered on a white page. "For her, a song is an emotional response voiced in a wide range of musical tones." (ibid., 1) Contrasted to Western culture, intelligence and emotion are not seen as separate categories of the mind. Therefore, a full cultural translation is an impossible task, because it would require adopting the other world-view.

Recently, the value of indigenous knowledge has been understood to extend far beyond exotic customs and rituals, when the scientific knowledge that is incorporated in it has raised scientific and commercial interests. Pharmaceutical companies interview traditional healers about medical herbs, and some projects apply ancient farming methods in Mesoamerica to increase biodiversity and sustainability (Demarest 2004). The Andean people classify manioc in 35 categories, and the varieties of potato reach four hundred, many of which have valuable genetic properties that have been lost in the development of high yield varieties (Harrison 1989). By growing tens of varieties in the same field, the Andean farmers ensure the harvest every year despite changes in weather conditions. 
Cultures do not construct knowledge in the same way. People in non-Western cultures often have a spiritual aspect in their relationship with nature, as well as with inanimate objects such as stones. It has been claimed, for example, that the Japanese have no problems in accepting robots as domestic helpers because they do not draw a strict line between inanimate and inanimate objects (Karppinen 2006). Western science aims at explaining and controlling nature (Braidotti 1994, Keller 1983) whereas Chinese science, for instance, looks for a harmony between man and nature (Chen 2001). Nisbett \& Masuda (2006) characterize ancient Greek thought as analytic, placing the focus on an object, whereas Chinese thought was holistic, attending also to the field in which a salient object was located. In traditional cultures, in general, the world is seen as a unity, and all beings are interdependent, including humans and nature. Categories are rather flexible or blurred, and causal relationships complicated, even vague. In this section, I explore differences between cultures in the construction of knowledge and in scientific views, and seek to understand how they might influence education.

\subsubsection{Cultural epistemologies}

Some cognitive anthropologists believe that cognitive abilities, such as inference, could differ crossculturally (Nuckolls 1998, 141). Nuckolls recalls a classic study by the Soviet neuropsychologist Luria that seemed to show that East and Central Asian peasants were generally unable to provide answers to syllogisms that contained unfamiliar information.

"'In the Far North," said Luria to his informants, "where there is snow, all bears are white. Novaya Zemlya is in the Far North and there is always snow there. What color are the bears there?"'

The conversation went as follows:

"Informant: We always speak only of what we see; we don't talk about what we haven't seen. Ethnographer: But what do my words imply? (The syllogism is repeated.)

Informant: Well, it's like this: our tsar isn't like yours, and yours isn't like ours. Your words can be answered only by someone who was there, and if a person wasn't there he can't say anything on the basis of your words.

Ethnographer: ... But on the basis of my words - in the North, where there is always snow, the bears are white, can you gather what kind of bears there are in NZ?

Informant: If a man was sixty or eighty and had seen a white bear and had told about it, he could be believed, but I've never seen one and hence I can't say. That's my last word. Those who saw can tell, and those who didn't see can't say anything!" (ibid.)

Luria's informants refused to answer the question, except individuals from the same culture who had received a single year of schooling. They could respond correctly, however, demonstrating that the difference was not developmental, but related to exposure to Western education and styles of reasoning.

Nevertheless, Nuckolls failed to understand that the uneducated informant actually did not discuss argumentation but the way to assess knowledge, that is epistemology. In many traditional cultures, there is a difference between first-hand knowledge and hearsay. The informant in Luria's example simply refused to play his 'pretending game', which he probably found childish and superficial, and tried to educate him about what is really known and what he just believes he knows. The informant probably shared the view with the Japanese culture where to argue with logical consistency is discouraged because it is regarded as immature (Norenzayan 2006). 


\section{Native American education and learning}

The Omaha, a Native American group, live in the state of Nebraska. When they gather to have fun together, they dance and sing. Roger Welsch, a White American, tells how he attended a party with his Omaha friends (Welsch 1994). He was invited to join the dance but he felt too shy because he did not know how to dance. Others teased him by collecting money for his 'dance lessons'. The very idea of dance lessons is a big joke for the Omaha. Lessons are the White man's idiotic way. To learn to dance Omaha dance, you dance Omaha dance. Among the Omaha you learn by observing and doing.

Many Native American groups share this relation to knowledge. The Dene believe that true knowledge is acquired only at first-hand. They learn by careful observation, not by asking questions. Knowledge in their culture is acquired in dreams and in personal encounters, often from animal helpers. Only one's own personal experience is valuable knowledge, medicine. The more knowledge and power a person integrates, the better she is able to control the world. When a man has exceptional success hunting moose, the Dene attribute his achievements to the knowledge and power that he has assimilated through dreams and other experiences. Authority in any area of life is connected to the 'knowledge' about the subject and is not transferable to other areas. They are reluctant to cite others, even storytellers are concerned about telling lies, or giving unreliable information. When they draw maps, they include only places which they have seen themselves, other areas are left blank (Watson \& Goulet 1992). Accordingly, the Inuit language of Inuktitut has many verbs for the word 'know', ranging from 'utsimavaa' - meaning he or she knows from experience to 'nalunaiqpaa' - he or she is no longer unaware of something. (Foundation for Endangered Languages on-line)

Native American writer Leslie Marmon Silko contemplated Western and indigenous science (Coltelli 1990, 138): "I was trying to reconcile the Western European ideas of linear time - you know, someone's here right now, but when she 's gone, she's gone forever, she's vaporized - and the old belief which Aunt Susie talked about, and the old folks talked about, which is: there is a place, a space-time for the older folks. I started to read about space-time in physics ..[] To me physics and mathematics read like poetry, and I'm learning what I try to tell people from the sciences: you know, don't get upset, don't demand to follow it in a logical step-by-step [fashion]. Just keep reading it. Relax. "

Certain studies indicate that the conflict between traditional values and academic practices is hard to reconcile (Lomawaima 2004, Mankiller 1993). Indigenous students have developed resistance strategies that would nevertheless allow success in academia, but the effort to preserve traditional values and at the same time acquire education is a arduous path for an individual. Education is seen as an essential component in the fight for indigenous people's rights and in the protection against the majority culture. 


\section{Chinese and Asian science}

Chinese science is one of the oldest continuous knowledge traditions, which has also provided the Western world with great technological inventions (Gernet 1996). For instance, the enormous handbook of Chinese science that Needham has compiled has at least 27 parts. In technological and astronomical applications, inventions traveled across cultures despite epistemological differences. However, the Chinese focus on context instead of the object itself lead to an earlier understanding of magnetism, acoustics, and reason for tides, because they recognized action occurring in a field of forces. The Chinese envisioned the world as constantly changing, which can be observed also in contemporary Chinese students who tend to be more open to future changes in predicting trends than their American counterparts (Nisbett \& Masuda 2006). Epistemological differences about knowledge acquisition and presentation are even more prominent in education and human sciences.

To compare Western and Chinese approaches in social sciences, I present an example of value comparisons between cultures, which is, moreover, of relevance to subject of this research. The comparability of value structure level data across cultures is depreciated if it is not reflected against the deep down level of worldview. The well-known IBM value survey that was first reported and published by Geert Hofstede in 1984 (Hofstede 1991) was developed from a Western social science point of view. It was criticized of ignoring Asian values, and therefore, a new dimension called Confucian Dynamism was added after the group 'Chinese Culture Connection' (in 1987) tested the generalizability of the dimensions using a methodology with a Chinese bias. Scholars of Chinese culture have pointed out that a cultural classification from Chinese point of view leads to a more refined and less fixed classification system than Hofstede's (Fan 2000).

Ying Fan created a classification of Chinese cultural values based on the earlier 1987 survey among Chinese social scientists, which contained 40 values. Fan added 31 that he grouped in to eight categories. Interestingly enough, Fan started with two Western - created sets of values, namely Hofstede's Value Survey Model and Kluckhohn and Strodtbeck's five dimensions. "However, the problem with these models is that the scope is too narrow or simplistic with only four or five variables." (Fan 2000, 5) He also explains that some values may be in contradiction with others, for example adaptability and being conservative. "This is not surprising as any culture itself is bound to have contradictions and paradoxes." Moreover, Fan rejected the femininity - masculinity duality claiming that "Chinese culture can be said as neither masculine nor feminine but emphasizes the unity of both."

Fan's discussion illustrates the intercultural problem of defining cultural features. Another Chinese scholar, Guo-Ming Chen (2001), also resists oversimplification in her analysis of Chinese communication. She develops four propositions, 23 axioms and 25 theorems to clarify the nature of Chinese communication. Duality and simplicity are not valued Eastern scientific traditions, which 
prefer pluralistic and holistic approaches. The Buddhist tradition, in particular, is fascinated by large numbers, and the predictive value of numerology. Also Indian science has very advanced classifications of any sort of objects and a great interest in numbers as the invention of 'Arabic' numerals and zero prove (Menninger 1985). Karppinen (2006) proposes that the differences in worldviews that have only one god, and worldviews where the number of gods or truths is flexible, also has epistemological consequences that influence even technology, such as development of robotics and communication technology.

Additionally, cognitive traditions and ways of thinking in East and West have been compared by Peng and Nisbett (Berry et al. 2002). They distinguish between differentiation in thinking (i.e., comparison of opposites and selection of one as the correct position) and dialectical thinking (i.e., seeking reconciliation between opposites). In a series of experiments they found that Chinese students demonstrated relatively more preference for dialectical solutions when confronted with social conflict situations or logically contradictory information. American students were more inclined to polarize conflicting perspectives and to choose one alternative as correct. Even though there was significant overlap in the answers of Chinese and American students in the abovementioned study, to interpret the difference as cognitive has been challenged on the basis that it is a question of social factors and behavior instead of cognitive styles. Which, incidentally, is a Western way to see affect and social context separated from cognitive processing.

Some Eastern traditions such as acupuncture have become a part of Western medical practice, even though it continuously causes controversy and gets classified to alternative medicine because of the Chinese scientific descriptions of energy flows, yin and yang etc. The verbatim translation of concepts gives an impression of magical beliefs, even though within the original ontology, acupuncture makes perfect sense. The concept of life energy that is one of the main principles of Eastern science is shared by traditions in China, Japan and India.

\section{African science}

A major critique against Western science is directed to its claims of universality and superiority to other traditions. Afrocentrist scholars, such as Molefi Kete Asante (2001), go as far as demand that African society is studied only based on African cultural and scientific traditions. Proponents of Afrocentric empirism place emphasis on discovery rather than validation of existing knowledge (Taylor \& Nwosu 2001). They require that research is based on core African values that include the relationship to the metaphysical and spiritual world, the relationship to time and work, and the relationship to the group and one's place in it. For instance, the African does not consider work as a duty that has some eternal reward but as a means to an end, a necessary but not sufficient condition for survival, whereas among Westerners, work is seen a duty central to one's existence (ibid., 306). 


\subsubsection{Numbers and counting}

The number sense in infants develops early, already six-month olds can make a difference when the numbers are clearly different, for instance between 8 and 16 disks, according to research done at Harvard by Elizabeth Spelke's team (Izard et al. 2008). Spelke believes that humans share a rich system of common core knowledge, but it is not unique to humans: "a six-month-old baby understands numbers, space, objects and faces much as a mature rhesus monkey does." (Dobbs 2005, 42) Many animals are sensitive to numerical regularities in their environments, can represent these regularities internally, and can perform elementary and approximate computations with numerical quantities.

In studies on 3-year old Finnish children, Hannula and Lehtinen found evidence of the importance of conscious development of enumeration skills. An intentional separate sub-process in enumeration is one of the essential factors developing in interaction with mathematical skills during early childhood. However, conceptual and procedural proficiency in counting takes a considerably long time to develop from the first number words and pointing trials to mastery of accurate counting and a full understanding of the goals of quantifying in determining the cardinality of a set in a variety of tasks (Hannula \& Lehtinen 2005).

My personal observations of two 3 and 4 years old girls' counting also points towards the idea that children enjoy counting the game and shouting out numbers. However, the 3-year old counted coins by pointing her fingers asynchronically, thus she got varied results depending on how fast her finger pointed to each coin. Also the 4-year old counted happily in disorder, even repeating same numbers. Apparently, the counting game was more like naming or repeating a song, and she did not worry about the quantity. In the case of the younger child, the coordination of fingers and speech was not yet developed sufficiently. The 4-year old, on the other hand, had a well developed ordering instinct: she used to take out all utensils from kitchen drawers and arranged them neatly according to size and type on the floor. Ordering and classification seems to be a separate cognitive category from enumeration.

Hannula and Lehtinen (2005) suggest that young children do not spontaneously focus on the aspect of numerosity and utilize knowledge concerning small numbers of objects, although they may have the enumeration skills required for the tasks. Numerosity is a separate mental process from exact enumeration. However, children's tendency to focus on numerosity, subitizing-based enumeration, and counting skills are related. Even for utilizing knowledge about the shape of objects in activities requires analytical, conscious processes in children.

Björklund (2007) observed toddlers in daycare to discern mathematical thinking in everyday activities. According to her study, adults working with young children play an important role in setting conditions for children's experiences and possibilities to explore mathematical concepts and phenomena. Toddlers encounter various mathematical concepts, similarities and differences, and the 
relationship between parts and whole, and their understanding of mathematics determines how they are able to use mathematics to uphold societal rules, to describe their surrounding world, and as a tool for problem-solving. The critical conditions for a successful learning process are variation, simultaneity, reasonableness, and fixed reference points for comparison.

Also the alphabet is learned early in the childhood, often through an 'alphabet song', and similarly, there are recited lists or songs for names of months and weekdays. They get internalized to such an extent that giving time expressions or doing quick counting or mental calculations in a second language often requires a return to the mother tongue and subsequent translation of the result.

Hutchins $(1995,315)$ proposes that counting with fingers is a strategy to form a functional system that includes representational media (fingers) that permits other media to be coordinated in new ways. He relates a simple situation:

Suppose today is Tuesday, December 29. What will the date be on Saturday? I might say to myself 'Let's see: Wednesday, Thursday, Friday, Saturday.' and extend a finger for each day spoken. Then I would look at my hand. Next I would coordinate again, this time bringing in the sequence of number names - ' 30 (um, December has) 31, and 1, 2' - directing my attention to the first raised finger when the first day number is spoken, and moving it to the next raised finger with each successive spoken day number until I arrived at the last finger.

Hands, counting, and internal speech serve as a functional, embodied system to perform a cognitive task without much effort. When Hutchins (ibid.) recounts another simple task, dialing the code of his combination lock, he points out that the mediated process also serves to enforce memory each time the lock is opened, thus memorizing a list of numbers becomes easier when combined to action, a visuosensual task. Hutchins concludes that following a written procedure and counting have important structural similarities. Both involve similar coordination of a sequence of tags with a partitioning of objects or events.

Finger counting is a European tradition that is also shared by the Chinese and Japanese (Menninger 1969), even though Kipling had noted that there are systematical differences in how it is done: bending or extending fingers. Among many tribes in Papua New Guinea, counting is extended to body parts (Wertsch 1985, Biersack 1982), thus generating number systems that are based on twenty or occasionally on 14. The Paiela are horticulturalists who keep pigs, which are of high value: they are eaten in feasts and given as presents. The most important event when the Paiela need to count is when pigs are given as wedding presents. The groom's relatives gather 28 pigs for the family of the bride. For purposes of presentation and distribution, these 28 pigs are divided into two equal sets. 14 pigs are tied to one long line of stakes for the family of the bride's father, and another 14 pigs are tied to another line for the family of the bride's mother.

The Paiela count their fingers and the upper body. The count begins on the small finger of either hand. The count then 'ascends' to the thumb, the wrist, the shoulder, the head, stopping at the nose, where the unit 'one at-the-nose' is summed. A second unit of 14 is traced on the other side of the body. This time 
the count 'descends' from the head to the shoulders to the hands, finishing on the small finger of the opposite hand for the 27 th count. The hands are then clenched and brought together, the two thumbs knocking against each other, to signal the completion of a second 14-count unit, 'two at-the-nose'. The word 'pondo' for 28 is said as the fists join and bump. The words from 1 to 5 are just number words without any other meaning, but numbers from 6 to 14 are names of actual body parts. The Paiela make a difference between upper and lower parts of the body. The upper body: the head and the arms, is the more important, and it is the part of body to be counted. The lower portion, the 'legs', is considered somewhat dirty, and the lower members of the body are 'not to be counted' (Biersack 1982). This really is an embodied sense of numbers.

Thomas Crump $(1990,19)$ has compared mathematical and number systems in many different cultures, and based on that he believes that the human brain has a certain capability for mathematic operations and the diversity of skills and intelligence is on individual, not cultural level as such. He concludes that symbolic counting indeed is a universal skill that develops gradually with age and is relatively unaffected by variations in the counting system employed, culture, cognitive development and schooling. He sees that the reason is in the structure of mathematics that is in some sense isomorphic with the structure of reality (ibid., 3 ): "Numbers as a purely formal system are independent of external reality, because all cultures have developed a mathematical and number system, even though some are very rudimentary, and they are based on the same fundamental rules and basic operations (addition, multiplication, integers, fractions)."

\subsubsection{Science and an African logic}

To follow the example of Hintikka (2001) in quoting detective stories, I refer to Agatha Christie (1955):

'Actually, you helped a lot,' said Sally. 'All your thinking - about the boracic.' Mr. Akibombo brightened up. ... 'Please, Miss Sally.'

'Yes, Akibombo.'

'If you meet my professor at University party tonight will you tell him, please, that I have done some good thinking? My professor he says often that I have a muddled thought process.'

Dame Agatha repeats here the observation by numerous Western educators who have been perplexed when faced with African scientific thinking. Helen Verran (2001) has made similar observations, and consequently carried out an extensive analysis of this gap in understanding. Verran's study is one of the very few that addresses directly science education in indigenous cultures, therefore it is of great importance for my thesis, despite its rather unusual approach.

Verran taught science and mathematics education in a teacher's training college in Nigeria between 1979 and 1986. According to Verran's experiences the local understanding of mathematics and physics was different from hers, and the efforts to teach Western science in a Western style was doomed to fail (Verran 2001). Her trainees were Yoruba primary school teachers, who taught partly in English and partly in Yoruba language. The Yoruba are a people of 30 million in West Africa. Verran found 
differences in thinking concerning the concepts of conservation and spatial continuity, for example when measuring lengths and assessing volumes. According to her, the Yoruba measure length in units of for example ten centimeters, whereas in Western science, length is a continuum. However, sometimes length appears more as consisting of units also in the West, like in the road signs that give distances as $3 / 8$ or $5 / 8$ mile. Repetitive units are not uncommon elsewhere either, such as the use of the size of a tatami mat to describe room sizes in Japan.

Verran particularly noticed that in the much repeated psychological test of pouring an amount of water into a wide bowl and similar amount in two narrow cups ("which cup has more water?") that Yoruba children tended to conclude that the small cups had more because there were two of them. English speaking children usually made the mistake that the larger bowl had more. The concept of conservation comes already from Piaget's studies (see section 2.3), and it is supposedly reached at a certain age. However, some recent studies indicate that in older people it deteriorates again (Léoni et al. 2002). Cross-cultural comparisons usually conclude that the ability to estimate quantity depends very much on practice and familiarity of the task. In fact, tests elsewhere in West Africa (among Kpelle) have shown better performance than tests of U.S. adults even in cultures where numeracy is rudimentary otherwise (Crump 1990). Verran's results concerning volume are in fact not uniform, especially in case of bilingual (Yoruba-English) children. In her study, monolingual village children lagged behind the bilinguals in learning to construe features as permanent, which Verran attributes to environmental factors. She also noticed that bilingual children seem to be transferring across languages, and the transference is associated with general developmental enhancement. Verran concludes that it seems likely that bilingualism enhances children's development in learning concepts of quantification. Her conclusion is confirmed by new brain research that also shows enhanced development in the brains of bilinguals, i.e. in all language-related functions (Neville 2007).

Verran develops a proposal that "Yoruba life emerges through and with a logic of whole / part organization. In contrast, life in English language communities emerges through and with a logic of one / many ordering" (Verran 2001, 220). Verran concludes that 'generalizing logic' could be both multiple and singular. She believes that, for instance, in local projects to promote biodiversity, the specific local logic would be able to make a positive difference in results. Verran's concept of transitional / transactional logics requires a minimalist set of assumptions that all people collectively share. Unfortunately for my enterprise, it does not include a shared science. According to Verran the African logic is different, and methods of science teaching should be modified to accommodate the difference. Hallen (2003) warns about dangers that incur when the differences in cognition are emphasized: "And then there is the further consideration that, in the past, supposed 'differences' in African cognition were sometimes used as evidence that Africa's indigenous intellectual heritage was thereby inferior to or less advanced than that of the West." He does not accuse Verran of cultural 
colonialism, and admittedly, Verran does not hesitate to give credit to the ingenuity of the Yoruba thinking.

Verran makes a comparison of Yoruba number words and 'English' numerals. Based on her analysis, she claims that the Yoruba understand a number of five fruits in the market as one unit, as opposed to the English understanding of a quantity. Her remarks may be true but this kind of understanding is not limited to Yoruba only: in Finland eggs were sold in units of 20 (called 'tiu', the English equivalent is 'score') or these days in units of 6 (half dozen), and paper is sold in units of 500 (ream), etc. Moreover, the English imperial measures such as ' 8 stone 11' sound much more as thinking in units than continuous quantities. The Yoruba numbering practices according to Verran are multi-base (base 5, base 10 and base 20). She gives a detailed account of number names, which actually indicates more to a direction of vigesimal rather than multi-base. In Verran's view, Yoruba numbering affords highly flexible and rapid mental calculation far surpassing what can be done in base 10 mental calculation. The implications of this go far: Yoruba numbers are different to European numbers in the way they deal with unity and plurality. That is, numbers are generated by differing forms of number-naming that themselves stem from six different bodily and linguistic practices. Distinctions between hands and feet, left and right figure directly in Yoruba multi-base numbering, whereas ten fingers 'are treated as a set of homogeneous elements taken as linearly related' (ibid., 66). (Compare with body-counting in the previous section.)

Verran calls the decimal system 'Indo-European' despite the fact that also the 20-based counting system is shared by many languages and cultures, also in Europe. For example French has strong traits of it left, and some numbers are calculated analogically to Yoruba (the number 97 is called 'quatre vingt dix sept' $=4 * 20+10+7)$. In fact, Basque counting seems to be very similar to Yoruba counting (Menninger 1969). Verran believes that the Yoruba understanding of natural numbers is based on a concept of a number containing all smaller numbers. Hintikka (2001) points out that the human mind finds it difficult to understand many nested quantors, such as number fourteen containing thirteen which contains twelve and so on.

However, the influence of language to scientific thought would require a more extensive analysis than Verran's comparison of English and Yoruba languages. My thesis adopts the view that cognitive differences are produced by an embodied cultural experience that is internalized in cultural schemas, and that deviates from one person to another depending on her life-experiences.

\subsubsection{Shared cognition and mediating structures}

Edwin Hutchins (1995) conducted anthropological field work in the U.S. navy on board an amphibious helicopter transport carrier, observing the functioning of the navigation team during ten days. Hutchins describes how he first recognized the distributed nature of knowledge and skills of the 
team when observing a successful arrival to a port under an emergency. He conducted a detailed analysis of pilotage as recorded on the aircraft carrier, the activities of various persons that were involved, their level of experience, and their working practices. The operation required seamless cooperation and distributed and situated cognition of the ship's crew.

Hutchins highlights the complexity and richness of interaction of mediating structures in cognitive activities. Mediating structures include written instructions, interactions between people, calculators and other physical objects. Artifacts like computers and radars are more advanced extensions of human mental ability. In addition to various artifacts, Hutchins lists environment, work organizations, social settings, and co-operation as shared intelligence that is part of human learning and professional operation. Whereas the traditional cognitive perspective emphasizes knowledge, a situated approach emphasizes participation in social practices and actions.

Other high-tech environments depend on shared cognition, as well, such as an operating theatre in a hospital, where the expertise of the operating team depends on seamless and synchronized contribution of all team members. Knorr Cetina $(1999,218)$ claims that high level expertise is a characteristic of a working team instead of an individual, embodied in the functioning of the experts. For example in surgical teams, the expertise becomes a working machinery. When surgeons enter the operating theatre, they are highly constrained in their movements and actions by the clothing and tools, fully depending on assistance from nurses. They are tied to the operating equipment and the patient's body, thus becoming a part of a collectively functioning machinery. The operation is a complex procedure of strictly constrained actions.

Hutchins' proposed model for cognition emphasizes the elements of cognition that are outside the mind, in social interaction. He warns that if individual minds are treated as operating in isolation, then properties of complex sociocultural systems become properties of individual minds. If one believes that technology is the consequence of cognitive capabilities, then differences between the 'technologically advanced' and 'technologically primitive' culture becomes evidence of primitive minds $(1995,355)$. Hutchins claims that a proper understanding of human cognition must acknowledge the continual dynamic interconnectivity of functional elements inside with functional elements outside the boundary of the skin (ibid., 136). Real power of human cognition lies in the ability to flexibly construct functional systems that accomplish our goals by bringing bits of structure into coordination. His example of the pilotage is a case of computation and interpretation of formal representational systems. Culturally constituted settings for activity are usually rich in the kinds of artifactual and social interactional resources that can be appropriated by such functional systems. In this matter, his view is similar to the understanding of indigenous and non-Western cultures. 
In cross-cultural comparisons, the difference between individualist (Western) and collective cultures is the most prominent (Berry et al. 2002, Landis 2004) categorization. In collectivist cultures, for example in Japan, innovations are seldom attributed to an individual but to a team or the company as a unity. The success of an individual is the success of the community, therefore intelligence is inherently understood as shared.

\subsubsection{Embodied and tacit knowledge}

Tacit and intuitive knowledge are terms that emerged in business studies about a decade ago, following Nonaka's (1995) publication on tacit knowledge in organizations. Tacit knowledge is variously understood as a sort of unconscious or non-verbal information. Michael Polanyi who introduced the term tacit knowledge argued that at its core, the process of scientific creativity is the elevation of tacit or personal knowledge from its initial unconscious representational form to an articulable, conscious form in which it can be communicated to others. In Polanyi's epistemology, the implicit system is always ahead, as it were, of the explicit system, but later researchers have expanded his views (Boden 1987). Mäki (2007) has recently classified knowledge outcomes in organizations as follows: embrained knowledge (explicit information in a person), embodied knowledge, encultured knowledge (shared meanings in a community), embedded knowledge (systemic routines), and encoded knowledge. The list illustrates well the multiple nature of knowledge.

Knorr Cetina (1999) studied creation of knowledge at CERN, interviewing and observing physicists. The physicists work on large research projects where they participate in building experiments with high-energy particle accelerators. First they plan and construct the particle detector, but when it is in use, they only get data from the experiments, and the device itself becomes inaccessible and starts to have a character of its own. Detectors are thereafter conceived as behavioral and social beings that have a life-span. According to Knorr Cetina, physicist live as symbionts with the detectors, and they characterize detectors even in more human terms than other humans. As trust is an important characteristic of working relations, the trustworthiness of experiment data is assessed similarly. Newcomers to the team are described as ignorant and trusting the data too much: "they believe in what doesn't actually crash" (ibid., 135). Trust in the experiment is a category that feeds upon the knowledge capital physicists draw from living with the detectors. Expertise is a capacity that develops together with experience. It is described in terms of 'knowing', intuition. Therefore, it is essentially tacit knowledge that accumulates in the team, as opposed to the hard data from the experiment that needs to be evaluated.

Acquiring embodied knowledge, such as learning of actions that include motion and handling objects, is necessarily by practice: the correct movements have to be adapted by control mechanisms in the brain until they are automatic and can be performed without conscious control. Thereafter, when the movements are stored in the brain circuits, they can be mentally analyzed and rehearsed. For instance, 
a robot arm can be controlled directly through brain sensors, which has led to the development of auxiliaries for the handicapped. In most areas of kinesthetic skills, practice has to be started in early childhood in order to achieve a high level, such as ballet and gymnastics. Precise rapid movements require very complex brain activities that develop more easily at a young age (Kalat 2004).

Knorr Cetina's (1999) studies also revealed how molecular biologists need advanced hands-on skills to perform laboratory work. Novice researchers who fail in their experimental work have to leave the lab after a trial period and seek other kinds of employment. Knorr Cetina gives a lively description of a young student who started practicing how to remove germ cells from live mice and transplant them into another individual in order to create transgenic animals. The surgical procedure involved was difficult and the first efforts of the student were failures that had to be terminated by killing the animals. The knowledge to perform experiments becomes embodied by practice, and it includes the scientist's sensory skills in a holistic sense (Knorr Cetina 1999, 96).

Knorr Cetina (ibid., 85) describes the character of a molecular biology laboratory as two-fold, consisting of a structure of tools, resources, and working materials on one hand, and experimental activities on the other hand. The work is sequentially organized in terms of steps and substeps laboratory protocols. The protocols may contain over one hundred steps, and after they have been developed they are part of the laboratory's intellectual capital, which can be used in exchange between collaborating teams.

Sternberg (2005) defines tacit knowledge as what one needs to know in order to work effectively in an environment that is not explicitly taught and that often is not even verbalized. He has measured people's tacit knowledge using work related problems in several professions. Tacit knowledge in his definition includes abilities such as managing oneself, managing others, and managing tasks. He found that practical intelligence as embodied in tacit knowledge increases with experience, but it is profiting from experience, rather than experience per se that results in increases in scores. Some people can have been in a job for years and still have acquired relatively little tacit knowledge.

Obviously, tacit knowledge is a competence that can be developed in an individual, or in a team. It is also culturally dependent. In the Japanese society where Nonaka developed his theses, non-verbal communication has been developed to an art. Merja Karppinen who is specialized in Japanese-Finnish communication suggests that in Finland tacit knowledge has a different meaning from Japanese, partly because there is so little communication in the first place, and partly because the silence in communication does not actively transfer tacit knowledge, whereas in Japan the silence is usually meaningful (Karppinen 2006). The minimalistic Finnish communication style probably is one of the reasons why expatriates need considerable time to adapt to Finland. 


\subsubsection{Teacher's role in learning cross-culturally}

Nothing that is worth knowing can be taught.

Oscar Wilde

The role of a teacher has undergone a drastic change in Finland in the last few decades. The traditional view of a teacher is the wise authority figure who distributes knowledge to pupils, and acts as a charismatic role model for future generations. This view is still partially subscribed to by teachers' unions and teacher training institutes who try to instill an 'devoted teacher' ideology on aspiring teachers. An indicator of the persistence of this spirit is the magazine of the Finnish teachers' union, "Opettaja", that stresses the vocation and professional devotion. Nevertheless, in the dominant pedagogical ideology, the role of a teacher has switched from teacher-centered to student-centered learning.

Other cultures might see teacher's role differently. Massoudi (2002) makes a revealing comparison of expectations to students and teachers in Eastern and Western traditions in order to develop a model for the ideal or 'true teacher'. He presents the qualities of a teacher, a master, 'sensei', from an Eastern perspective using examples from ancient writings. He reminds us that in many cultures, a teacher is considered even more important for the development of a young person than the parents. He strongly opposes the idea that teachers should entertain students and make studying fun. "What a true teacher is supposed to convey to the students is a sense of wonder, a sense of enquiry, a sense of joy in discovery, a sense of appreciation, a sense of understanding based on reasoning, a sense of inspiration, and most of all a sense of being sensitive and compassionate" (ibid., 153). Massoudi proposes the adaptation of the spiritual leader concept for teachers in Western engineering colleges as well.

Sternberg (2005), a North American, presents a more pragmatic view, seeing that teaching as expertise includes a variety of skills, that are not necessarily embodied in one individual but there could be many teacher profiles. A team of teachers can divide the tasks included in the teaching process to separate individuals according to their strengths and interest areas. One may be a charismatic lecturer, another an inspiring teamwork instructor, and one may be excellent in developing on-line materials.

However, all the researchers quoted in this thesis agree that teaching cannot be automatisized. When Clancey (2005) discusses the possibilities of describing fully the expertise that is needed to guide students in problem-solving, he concludes that knowledge consists of more than descriptive models. A human teacher cannot be 'perfect' and cannot expect to follow, understand and correct all aspects of student's behavior. Students (or any persons for that matter) often find their own individual experience inscrutable, not being able to confidently describe what they are doing at each step, nor exactly what they are thinking or intending. "That is, they are lost." The internal learning process is simply beyond algorithmic description. Students need expert assistance, which necessarily is heuristic and adapted to the situation and context. 
The values that are attached to learning assume different pedagogical approaches depending on the culture, as a comparison of Chinese and U.S. students shows (Li \& Fischer 2004). The U.S. students categorize learning components in a manner that is reflected also in the present research: learning content and learning processes are highest level categories that are split into social context and learner characteristics such as cognitive skills, motivation, tools, and developmental foundation. Methods and people in teaching have a minor role. Chinese students, on the other hand, divide learning approaches into desirable and non-desirable. Desirable approaches include seeking knowledge (humility, diligence, life-long pursuit, contribution to society, activity) and achievement. The model includes student respect for teachers, though the emphasis is in student attitudes and desire to learn. The Chinese view emphasizes the development of the person's moral character, whereas the Western view aims at increasing knowledge. Li \& Fischer (2004) conclude that Chinese learners learn best when they have clear long-term goals.

\subsection{Immigrants and multicultural education}

\subsubsection{Immigration studies: sociocultural adaptation of immigrants}

Colleen Ward (2004) presents an overview of research on immigrant adaptation. Based on her summary she develops an $A B C$-model of culture contact that includes all factors that have been found to facilitate or complicate the adaptation process. She warns against commonly repeated oversimplifications such as the U-curve model of adaptation where an initial enthusiasm is followed by a disillusionment and finally an improved feeling towards host culture. In fact, most studies indicate that the sojourner adaptation process more or less follows a normal learning curve.

The ABC-model of culture contact consists of (ibid., 187):

- Affect: refers to stress and coping with change, and results in psychological adjustment. It depends on personality, coping styles and social support, as well as potential discrimination in the host country.

- Behavior: includes acquiring culture skills, and results in sociocultural adaptation that, in the ideal case, amounts to successful integration.

- Cognitions: The perceived problems in understanding host culture have been found to depend on distance between home and target culture; language skills and interaction with members of host culture; previous cross-cultural experience; and social interaction in general.

This understanding of adaptation highlights the complex nature of the process.

Similarly, Earley's (2006) construct cultural intelligence in international business studies comes close to this model. It focuses on understanding an individual's capacity to adapt to varying cultural settings based on his ability in cognitive and metacognitive processing, motivational mechanisms and 
behavioral adaptation. Cultural intelligence focuses on an individual's capabilities to adapt in a different cultural setting. A study that compared job requirements in expatriate public-sector assignments for U.S. professionals in 156 countries found that several requirements were higher in expatriate assignments than in domestic positions (Shin et al. 2007). These were in particular: social and perceptual skill, reasoning ability, and adjustment- and achievement-orientation personality.

Cultural meaning is expressed in schemas that members of a culture share. However, people are complex and subscribe to conflicting schemas on different levels of thinking. Especially in a multicultural environment, there are contradictions between consciousness as a product of a dominant ideology versus consciousness as a product of lived experience. Young adults as immigrants are in a doubly liminal state, between an old life and old role as a young family member, and the new role as an independent adult in a new country (Alitolppa-Niitamo 2004). They face a number of conflicting discourses in study and in private life: for example, they may have to change their conception of what is the appropriate behavior of a student towards a teacher. Immigrants encounter numerous conflicts that cause considerable mental strain. Immigrant students need to devise a strategy to adapt and internalize conflicting discourses, whether this means choosing new schemas and rejecting the previous ones, or keeping many and finding ways to integrate them.

A long-term study by Minoura of Japanese expatriate children in the U.S. compared the adaptation of the interpersonal behavior of the host culture depending on the age of immigration and the duration of the stay abroad. Japanese are often assumed to be sensitive to the needs of others, communicating wants indirectly, and conforming to group standards, whereas the American model of behavior expects children to be self-assertive, and to say no directly. Children changed their behavior to a varied degree: some remained Japanese in their manners, some behaved American only in school, and some children adapted fully the American way. Only children who entered the U.S. before the age of nine internalized the American model. Other decisive factors were proficiency in English, density of interaction with Americans, and length of stay (D'Andrade 1995).

Immigrants often have to reconcile conflicting schemas. They face a situation where conflicting cultural meanings in their new environment meet the consciousness that is a product of their previous lived experience. The process of becoming aware of conflicting discourses is painful, and there are several strategies of how new schemas could be internalized (Strauss \& Quinn 1997, 213). One approach is to choose one schema and reject the rest, for example to fully adopt the engineering culture and reject one's native background beliefs. A more demanding way would be to more or less consciously select parts and integrate them in a single schema. The mental conflict could also result in an unconscious compromise or even in ambivalence where the person feels torn. A typical result is compartmentalization where schemas are activated in different contexts, for example young immigrants obeying family traditions at home but behaving according to dominant culture norms at 
school. Most people can accommodate parallel schemas such as using scientific thinking in theoretical context but believing in horoscopes, omens, good luck rituals, etc. in their everyday lives.

An immigrant faces contradictions and a need to negotiate between past, present and future identities. She needs to redefine herself, either to attach herself to the new country or to remain a sojourner. Engineering students could opt for building an identity on professionalism, on engineering expertise. Though a professional engineer identity is not bound to specific nationality, it does remain linked to a Western worldview.

The feminist philosopher Rosi Braidotti advocates cultural and epistemological nomadism for modern people who expatriate, staying in transit but anchored to a historical position (Braidotti 1994). Her starting point is a truly international person, who has maybe lived her youth in many different environments and has ancestors in more than one place. Braidotti herself belongs to the small academic elite of polyglot nomads who has many home countries, and who studied on different continents. The children of diplomats and UN staff adopt an 'international school' identity that is not tied to nationalities or any country of residence, and which they do not find problematic. On the contrary, they use it for efficient global networking. However, to create an identity outside classifications and to remain genuinely multicultural does not happen overnight to an ordinary young migrant. It could be seen as a kind of positive state following from a conscious ambivalence.

\subsubsection{Overseas students and challenges in multicultural education}

Multicultural education was first studied in societies that have considerable ethnic minorities, such as in the United States (Banks et al. 2004). Most of this research concerns primary school minority children and is connected to problems of social stratification. Another strand of research studies overseas students, especially exchange students who go as sojourners to another country for about a year, and it is mainly concerned with adaptation issues. In recent years, multicultural education research has expanded to Europe and Australia, but it remains somewhat scattered without an establishment of its own. Educational anthropology has small departments in some universities. The study of learning across cultures has persistently used existing Western conceptions, and therefore it has missed essential elements of learning in other cultures, such as the motivational, affective, and moral aspects (Li \& Fischer 2004).

School achievement of minorities has attracted attention for over a century, as success of minority children has generally been worse than achievements of children of the dominant culture. Society expects all children to adopt the dominant school culture, and consequently, the poor achievement was long perceived to be caused by cultural deprivation of minorities (ibid., Nuelip 2001, AlitolppaNiitamo 2004). Subsequently, cultural difference came to be understood as neutral and not to reflect deprivation or inferiority. A structural view, the cultural-ecological theory (Berry et al. 2002) places 
cultures at an equal standing, and understands differences in cognition and learning as consequences of the environment and traditions. The critical pedagogy movement highlights structural oppressing forces in societies, that confuse and create obstacles for minorities, and that are replicated in mainstream school culture. Alitolppa-Niitamo (2004) emphasizes that even though research on minority education gives insights when the education of recent immigrants is studied, they need to be complemented by challenges related to migration and acculturation processes, and the segmentation of the acculturation paths of immigrants and individual differences need to be explored.

The question of overseas students in the U.K. was covered in an overview by McNamara \& Harris in 1997. The idea of overseas students has expanded and developed from the 1950s 'colonial' student stereotypes such as Asians as brainy but treacherous and Africans as childlike or savage. The studies point out that university education has undergone dramatic changes from being exclusive for a small elite to present day mass education where attention to individual students is scarce. However, many studies in the U.K. report a persistent conflict between overseas students (in particular, non-Western) expectations and the U.K. educational system. Because of the conflict, overseas students are unhappy and homesick which also causes cognitive failures, poor concentration, handing work in late, and decrements in work quality.

Previous cognitive styles and study practices influence the way students work with assignments. The phenomenon in ICT and engineering education has been discussed in, for example, Australia concerning Middle Eastern students (Stewart 2007); in New Zealand with regard to Pacific island students (Latu \& Young 2004), and in an American college in the Arab Emirates (Harnish 2003), to name a few. Stewart (2007) lists limited interaction with local students, low English language proficiency, cultural adjustment and plagiarism as issues that concern international students. In particular, his study highlights the unfamiliarity of international students with teaching styles requiring student activity, self-regulated learning, and problem based learning. Latu \& Young (2004) conclude that especially for Pacific island students, teachers should understand their role as facilitator, not boss, for collaborative learning to be effective. Accordingly, facilitators must consider teaching as a process of advancing and enhancing student's ability to learn. They introduce a slogan: "show us properly how to use the tools so that we will be able to finish the job".

Macrae (1997) classifies the potential challenges faced by incoming international students into language proficiency, familiarity to study facilities such as libraries, computer systems, and laboratories, customs in supervision, and academic practices. He presents in a table 2 the possible conflicting expectations about academic activities of overseas students and their supervisors. The picture is probably less clear-cut in reality, and cannot be directly applied to students of any particular background. Also supervisors' attitudes may be more varied depending on their pedagogical views and practices. 


\begin{tabular}{|l|l|l|}
\hline Academic activity & Student's expectation & Supervisor's expectation \\
\hline Learning & $\begin{array}{l}\text { Memorization and rote } \\
\text { learning acceptable }\end{array}$ & $\begin{array}{l}\text { The student develops ability } \\
\text { to think independently. }\end{array}$ \\
\hline Learning & $\begin{array}{l}\text { Teacher-led with teacher } \\
\text { telling student what to learn. }\end{array}$ & $\begin{array}{l}\text { The student takes on the } \\
\text { main responsibility for own } \\
\text { learning. }\end{array}$ \\
\hline Lectures & $\begin{array}{l}\text { Contain the complete course; } \\
\text { all the facts and the right } \\
\text { answers should be provided. }\end{array}$ & $\begin{array}{l}\text { Should sensitize students to } \\
\text { key issues; developing of } \\
\text { ideas through self-study. }\end{array}$ \\
\hline Course work & $\begin{array}{l}\text { Provides unquestionable } \\
\text { facts. Students listen. }\end{array}$ & $\begin{array}{l}\text { Process-oriented; raises } \\
\text { argument, stimulates } \\
\text { discussion. }\end{array}$ \\
\hline Dissertations & $\begin{array}{l}\text { Right answers should be } \\
\text { learned and reproduced on } \\
\text { demand }\end{array}$ & $\begin{array}{l}\text { Problem-solving and original } \\
\text { approaches are valued. }\end{array}$ \\
& $\begin{array}{l}\text { Copying and plagiarism are } \\
\text { legitimate since the outcomes } \\
\text { contain correct information. }\end{array}$ & $\begin{array}{l}\text { Critical argument, discussion, } \\
\text { evidence, evaluation and } \\
\text { originality are values; } \\
\text { plagiarism is virtually a } \\
\text { crime. }\end{array}$ \\
\hline
\end{tabular}

Table 2: Expectations on academic activities of international students and supervisors (adapted from Macrae 1997, 141).

Cortazzi \& Jin (1997) list, in the same volume, many observed differences in academic practices and communication between Chinese and British students, which are summarized in table 3. For example the order of presenting an argument in essay writing is opposite: the British style requires the main points and outline to be presented first, with background information following, whereas Chinese practice is to present the background and argument that lead up to the conclusion. When the Chinese write a scientific paper they prefer to omit the literature review as redundant and proceed immediately to their own research findings.

To add recent personal information from a British university, where American and English students, upon comparing their respective styles of essay writing, see obvious differences even in these two cultures (personal communication, 2007). Additionally, French essays are expected to follow a thesis antithesis - synthesis cycle. The Finnish writing style has been studied as well, compared to the English conventions, and has been found to be more straightforward and concise, rather listing the facts than presenting an argument. The differences in academic cultures are not limited to writing, but the whole research process can follow different traditions, even in highly specialized areas such as high energy physics, as researchers at CERN have noted (personal communication, 1998). 


\begin{tabular}{ll}
\hline British academic expectations & Academic expectations held by Chinese and other groups \\
\hline Individual orientation & Collective consciousness \\
Horizontal relations & Hierarchical relations \\
Active involvement & Passive participation \\
Verbal explicitness & Contextualized communication \\
Speaker/ writer responsibility & Listener/ reader responsibility \\
Independence of mind & Dependence on authority \\
Creativity, originality & Mastery, transmission \\
Discussion, argument, challenge & Agreement, harmony, face \\
Seeking alternatives in group & Single solution for pragmatic reasons \\
Critical evaluation & Assumed acceptance \\
\hline
\end{tabular}

Table 3: British and Chinese academic expectations (Cortazzi \& Jin 1997)

Cortazzi \& Jin (1997) present cases where the differences in writing conventions or seminar behavior have lead in misunderstandings and low marks. Supervisors may expect more active participation in discussions and seminars than student has been used to. In many cultures, students wait to be asked and wait their turn in debate, whereas interrupting others is permissible in Anglophone and Latin cultures. In more assertive cultures, supervisors perceive "polite" students as passive, whereas the more "polite" students feel that aggressive debating is impudent and inconsiderate.

\subsubsection{Immigration and research in multicultural education in Finland}

The number of immigrants has been very small in Finland until the 1990s. After the turbulences of gaining independence in 1917 and 1918, and the evacuation and resettlement of people from Karelia in 1940s, the Finnish population remained stable and without any influx of new groups. On the contrary, the only significant population movement consisted of the emigration of hundreds of thousands of Finns to Sweden. Though Finland received some hundreds of refugees from Chile in 1973, and some years later from Vietnam, the first significant immigrant group were the Somalis in the 1990s. The arrival of Somali refugees awakened Finns to see the challenges of a multicultural society, even though the reaction has been very slow (Alitolppa-Niitamo 2004). Simultaneously, an effort to internationalize higher education started at national level.

Anne Alitolppa-Niitamo (2004) conducted research on the school education of immigrant Somali children in the Helsinki area. Her findings very clearly indicate that the education system was not prepared to assimilate immigrants, and school achievement of the children is hampered by many obstacles within and outside the school system. The heterogeneity of immigrant groups is significant, even within each nationality, thus immigrants need tailored integration programs. On the other hand, some immigrant communities extend outwith national borders, such as the Somali refugees who keep 
contact with their relatives in many European countries and at home. The strong diasporic and transnational consciousness of such immigrant groups poses another challenge to the integration process.

Psychological acculturation refers to the changes that an individual experiences as a result of being in continuous first-hand contact with other cultures. Alitolppa-Niitamo (2004) concludes that immigrant acculturation paths take place in a multitude of ways, thus no universal 'best-practice' model fits for all. To understand the acculturation process, both a minority perspective (lack of equal opportunities) and acculturation perspective (the effect of newcomer status) are required. Her model of resources and constraints that influence the acculturation process and school achievement emphasizes the social capital of an immigrant, as presented in figure 8 . The framework should be seen as dynamic where the variables change over time. She calls for flexibility, diversity, and collaboration of various actors in the planning and implementation of educational policies and programs.

\section{NCOMI NG RESOURCES \\ HUMAN CAPITAL \\ documentability, parents' \\ education and attitudes, \\ prior schooling, health, \\ age at arrival, \\ language proficiency, culture, ethnicity, gender, religion \\ FINANCIAL CAPITAL}



\begin{tabular}{|c|}
\hline RECEI VI NG SOCI ETY \\
VARI ABLES \\
PRE-EXISTING ETHNIC \\
RELATIONS \\
LABOR MARKET AND \\
INSTITUTIONS \\
GOV. POLICIES AND \\
PROGRAMMES \\
CHANGING INTI BOUNDARIES
\end{tabular}

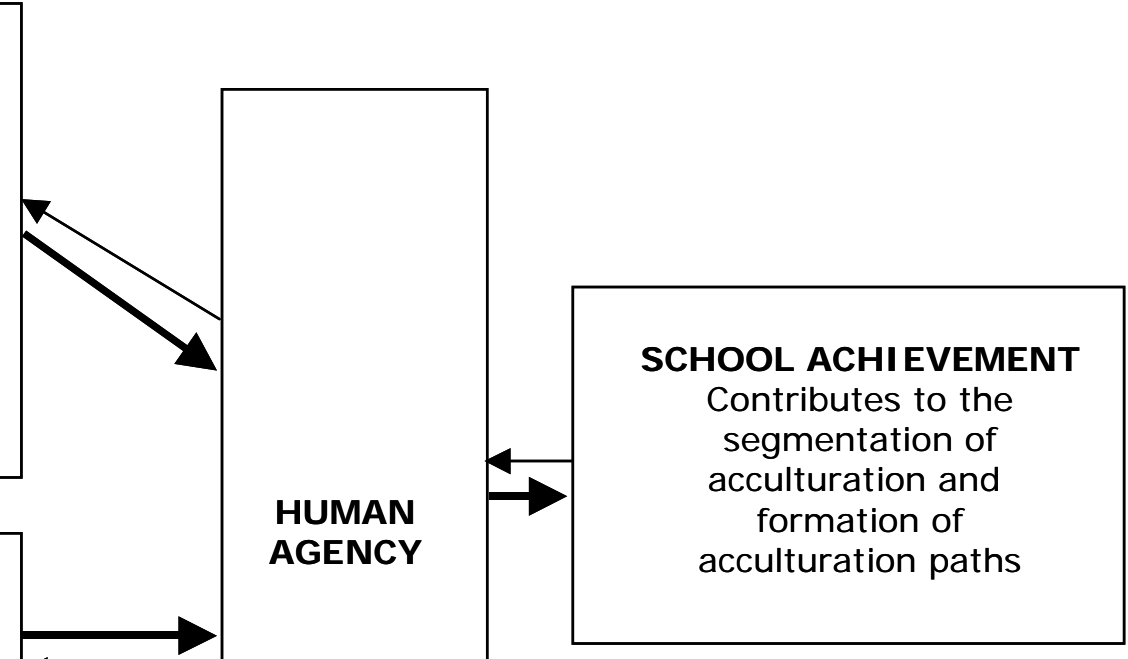

Figure 8: A framework explaining the variability of school performance of children with an immigrant background (Alitolppa-Niitamo 2004)

Alitolppa-Niitamo refers to the hegemonic position of the Finnish curriculum content in the schools. There is a lack of effort to adjust to student needs and background. In a typical case, a 15-year old Somali girl struggled with her English homework that she found overburdening: she was asked to 
translate an English text about ice fishing into Finnish. The girl had no idea about fishing or winter activities in general, no vocabulary in her mother tongue about that subject, and she was asked to translate from one foreign language into another (ibid.). The incident, unfortunately, is rather typical than exceptional: my daughter who is first-language English speaker was also given assignments for translating from English to Finnish in the Finnish school, and she received a lower grade in English because of problems in Finnish vocabulary. The Finnish school system has not been open to outside influence nor flexible in exceptional cases. The ideas of multicultural and inclusive education were not developed until the end of millennium. Still, the lack of resources in the educational system creates an obstacle of efficient acculturation: in a preparatory classroom for recent immigrants in Vantaa, there were 16 students of ages 6 to 13 years who spoke eight different languages, and only one teacher and one assistant who spoke Russian in the fall 2007 (Puustinen 2008).

The way learning in schools is broken down into many little, apparently disconnected pieces, acts against understanding, according to Alitolppa-Niitamo (2004). Learning should be designed as a cumulative process that includes continuities, in particular, for immigrants who already face a tremendous discontinuity from the previous practices.

However, multicultural understanding in the Finnish society is slowly improving in practice through the existence of a growing immigrant community (Abu Hanna 2007), and through several research efforts also in the field of education. The MONSU multicultural education research network connects researchers from research programs in the universities of Jyväskylä, Helsinki, Turku and Oulu, and other places. The organization for student exchange CIMO has published studies of foreign student adaptation (Kinnunen 2003). Hera network (Helsinki Education and Research Area) in the capital area has several activities to enhance collaboration of internationalization among universities, including joint marketing and research on future strategies. According to its recent study about the success of internationalization (Rogers 2007), the universities in Helsinki area have succeeded well in comparison to Danish, Dutch and U.K. universities in terms of strategic planning, employment of a large portfolio of means, and guidance and policy documents. However, students face difficulties (Helenius 2007) in immigration and adaptation to Finnish society, as well as in finding sufficient tuition in English. Some universities that offer programs in English have a narrow range of studies, and part of the courses are implemented as self-study modules only. The academic personnel is predominantly Finnish, and recruitment of international faculty requires improvement.

Since 1994, the university of Oulu has offered an international Master of Education Programme, headed by Rauni Räsänen (2003). The programme strives to develop intercultural learning and transformative pedagogy within teacher education, aiming to foster intercultural sensitivity and global awareness. That program has been the subject of action research, as well, and produced several research reports. Interestingly, students of that program were fairly unanimous about the crucial role of 
human encounters and challenging experiences in their intercultural learning, emphasizing face-to-face human and cultural encounters. They expressed a strong preference for personal communication as contrasted to virtual or self-study.

Lappalainen (2005) has developed a method called culturally sensitive teaching that combines handicrafts to language and culture studies for recent immigrants. She has introduced handicrafts to her basic Finnish courses for refugees. The language is learned in teams doing manual work and discussing their projects, which provides a safe and motivating environment, as the handicrafts are chosen by the participants, for example printing cloth, or even cooking together. Her method has been tried in other settings less successfully, therefore it may be context and person -dependent.

Marianne Teräs (2007) conducted experiments in a culture laboratory in a vocational school in Helsinki. The culture laboratory is an application of the 'change laboratory' that was developed at University of Helsinki. The aim of the change laboratory is to develop work practice, and, in Teräs' case, teaching and instruction to better accommodate needs of immigrants. In the culture laboratory, immigrant students work together with tutoring teachers to develop the educational practices of the school. They meet at regular intervals to discuss their findings and questions concerning Finnish school practices. The theory is based on the cultural historical activity theory and theory of expansive learning by Yrjö Engeström (2001).

Teräs discusses in particular the role of paper in Finnish education: the 'paper-trail' of student tasks (2007). She claims that paper is an essential and ubiquitous mediating artifact in Finnish learning practices. Children in Finnish schools are socialized in practices that are paper-dependent and paperdominated. This involves producing and using paper in various forms such as textbooks and study materials. Texts have become central artifacts instead of the subject matter itself. A 'paper trail' of a school assignment is described as a chain-like process of paper-related actions that has power relations and student-teacher interaction embedded. This process is different in different educational cultures, something a student has to learn anew.

The change laboratory demonstrated that students indeed found the Finnish school system very different from what they had previously experienced. The Finnish school appeared more open and student-centered, where students also had more responsibility in controlling their study process. The students generated over a hundred ideas and suggestions how to improve school practices and instruction, many of which were tried in practice, and about half of those were adopted permanently. (Teräs 2007) Thus, the research demonstrated that immigrant students are a resource that has not been efficiently used in the development of the education. Her findings, in spite of being on secondary level education, have potential applicability also to immigrant students in polytechnics. 


\subsection{The nature of engineers}

"Engineers aren't boring people, we just get excited over boring things." Anonymous engineer

A stereotypical image of an engineer is rather easy to draw. Recent graduates from EVTEK challenge it in many respects, such as a tiny shy Chinese woman who adores cats and manga, and a tall smiling African man who is bursting with new ideas. They hardly fit the image of a typical engineer as portrayed in numerous engineer jokes:

An architect, an artist and an engineer were discussing whether it was better to spend time with the wife or a mistress. The architect said he enjoyed time with his wife, building a solid foundation for an enduring relationship. The artist said he enjoyed time with his mistress, because of the passion and mystery he found there. The engineer said, "I like both." "Both?"

Engineer: "Yeah. If you have a wife and a mistress, they will each assume you are spending time with the other woman, and you can go to the lab and get some work done."

In fact, the question about the qualities of an engineer has not been problematic in engineering education before because, after all, the profession has attracted certain types of people, men mainly, who have been genuinely interested in technology, and uniform enough in their abilities. However, these days the numbers of students in engineering schools and technical universities are higher than before, and many young Finnish students try several fields of study before landing in their preferred choice. Moreover, technical colleges receive students from everywhere in the world, including developing countries. The students can no longer be considered 'typical', whatever it means. We face the question of a global engineer: do people subscribe to the same concept of an engineer everywhere? Is there a universal engineer? Additionally, the fields of engineering have expanded from the traditional machine, construction, mining, electronics, land surveying, etc. to disciplines that have blurred borders with business, biology, media studies, and so on. Technology has incorporated aspects that have made it cross-disciplinary to some extent.

\subsubsection{Engineering expertise}

Requirements for an engineer stem from the applications of technology. Firstly, the requirements are strongly derived from natural sciences. Second, engineering applications are practical, and the products need to fulfill business and user needs. For instance, the quality requirements for engineering programs in the United States are set by the ABET organization that has main professional engineering associations as its members. ABET accreditation is a non-governmental, peer-review process that aims at assuring the quality of the postsecondary education students receive. The criteria for the objectives and outcomes of engineering education are continuously reviewed and characterize the prevalent concept of the profession. 
ABET criteria: Objectives, Outcomes and Assessment (See http://www.abet.org )

Engineering programs must demonstrate that their students attain:

(a) an ability to apply knowledge of mathematics, science, and engineering

(b) an ability to design and conduct experiments, as well as to analyze and interpret data

(c) an ability to design a system, component, or process to meet desired needs within realistic constraints such as economic, environmental, social, political, ethical, health and safety, manufacturability, and sustainability

(d) an ability to function on multi-disciplinary teams

(e) an ability to identify, formulate, and solve engineering problems

(f) an understanding of professional and ethical responsibility

(g) an ability to communicate effectively

(h) the broad education necessary to understand the impact of engineering solutions in a global, economic, environmental, and societal context

(i) a recognition of the need for, and an ability to engage in life-long learning

(j) a knowledge of contemporary issues

(k) an ability to use the techniques, skills, and modern engineering tools necessary for engineering practice.

The criteria emphasize science and engineering skills, but recognize a wider expertise by mentioning understanding of business environment and society, ethics, and communication. Tenopir and King (2004) note that the criteria have undergone a major revision since 1990s, adding emphasis to 'soft' skills as contrasted to pure technical knowledge.

Recently, several universities in Europe and North America have formed a collaborative effort called CDIO (Conceiving — Designing — Implementing — Operating real-world systems and products) to advance engineering education (Crawley 2007). Their definition of engineering qualities is in accordance with the ABET definitions, thus proving unanimity on engineering qualities.

Several studies including expert interviews and surveys in the industry and higher education have been conducted in Finland to map the working life requirements among Finnish companies (Allt 2000). The major finding is the consensus that core technical engineering knowledge continues to be the principal requirement. Definitions of engineering competences are uniform across the industry: the profile of a good engineer includes a solid basic knowledge of the natural sciences and in-depth knowledge of the engineer's own technical discipline. In addition, several types of general working life competences are usually listed such as communication and internationalization skills, ability to learn, teamworking abilities and entrepreneurial attitudes. 
At EVTEK, we conducted a survey among our collaborator companies (including major telecommunications enterprises) and faculty in order to find out how they saw the requirements for our graduates in information technology in 2001 (Holvikivi et al. 2001). The results were similar to other surveys cited above, most of the respondents emphasizing basic engineering qualities, such as a pragmatic approach, problem-solving skills, and a good knowledge of technology and mathematics. Communication skills and teamwork abilities were also mentioned. The ability to develop professional knowledge and expertise throughout the career was deemed to be of growing importance.

\subsubsection{Engineering thinking and identity}

\section{Design process, creativity and problem-solving}

Expertise in engineering is conceived to consist of professional knowledge and understanding, as well as skills and practices. Eugene Ferguson (1992) stresses that in the process of engineering design, despite modern technical advances, good engineering is still as much a matter of intuition and nonverbal thinking as of equations and computation. He argues that visual thinking is essential and enriches engineering, relating a history of the use of perspective and projection illustrations. Design by drawing continues to be central in the planning process in electronics, civil and construction engineering, shipbuilding, mechanical engineering, as well as in information systems. The process of drawing is a method, a means of thinking in planning, and the final drawing is just one part of the process. Design includes calculations, and spatial planning, but as numerous studies have shown (Hakkarainen et al. 2004b), expertise is developed through social practice and it includes a significant proportion of tacit knowledge. Plans and designs do not control actions, rather, they function as artifacts that enable actions in different social contexts (Suchman 2007). The formal plan is hardly ever complete, thus allowing the space of action that is needed for its realization.

The elegance of the solution is as much in the planning process as in the physical drawing or in the final product. At the same time, design is a demanding problem-solving process where needs of manufacturing, marketing, customers and economy have to be met. There are, in fact, subcultures of design practices; the instructors at the Helsinki University of Technology can deduct, from their designs, the company in which students have done their trainee period (personal communication 2007). Similarly, program code shows individual styles. Based on my own experience, a programming teacher is able to tell from a piece of software whether it has been written by the student himself or if it is copied from another student (albeit students find it hard to believe).

Engineers apply this practice of thinking through designs in various areas of life. My colleagues at EVTEK produced an example of an engineering view of social relations, when they drew a digital circuit of the people that worked with our programme assistant (Figure 9). 


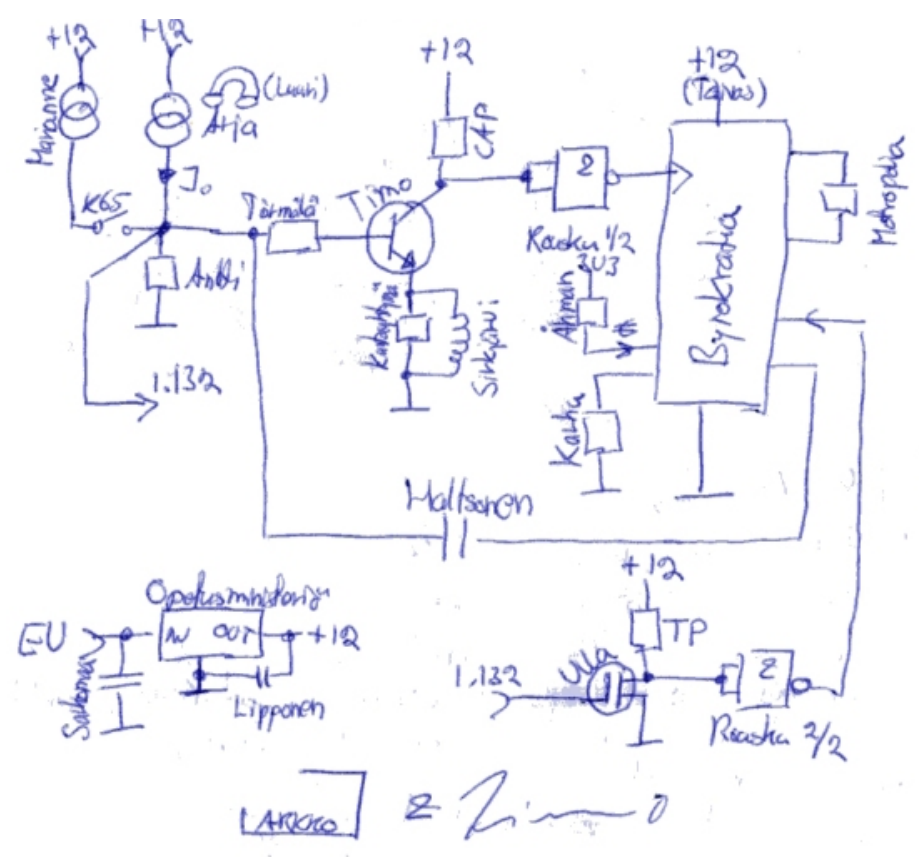

Figure 9: Social relations in the IT department (courtesy of Vuori \& Sauren)

A study of CAD engineers in a Finnish company proved that illustrations are the essence of the design in their work, the major means to transmit ideas and to document solutions. Even though the design process depends on software tools, CAD or CAE systems, there is still room for individual creation and style.

This was illustrated by the Designer KKK, who described how to fulfill the missing information in the design document:

'Even if you can't see from the picture a certain detail, and you don't know who even made the document, with my experience I can tell who drew the picture and then presume what the other designer had been thinking.'

(Björkstrand \& Lallimo 2006)

Engineering has been called an applied science that has as its goal the creation and improvement of products of technologies with immediate practical application, as contrasted to scientists who seek to develop theoretical solutions. Engineers typically work on projects assigned by their management, most often work in industry, conduct projects in teams, and focus their goals on company or organizational success (Tenopir \& King 2004, 37). The final criterion for engineering solutions is always functionality. Engineers produce designs, methods, and tools, and therefore they need to be pragmatic and rational in their work. However, the thinking process in engineering requires complex and abstract problem-solving comparable to medicine and law.

Engineers are very different from, for example, artists or architects in their way of professional thinking. Nevertheless, there are many artists who have an engineering education, as well as engineers who practice painting, music, theatre and other forms of art. Thus the different ways of thinking can be embodied in the same person. Sculptor and mechanical engineer Kaisa Ant-Wuorinen works with steel and experimental materials, such as plastics and discarded manufacturing material that require technical problem-solving. She has noted that in her work three kinds of esthetic thinking interact and 
compete: the aspiration for artistic, mathematical and engineering beauty. (Personal communication 11.7.2007)

\section{Social skills and rationality}

Engineers are always honest in matters of technology and human relationships. That's why it's a good idea to keep engineers away from customers, romantic interests, and other people who can't handle the truth.

Engineering jokes

Stereotypical engineers have no social skills. Nevertheless, in reality, engineers spend about half of their time in communication. A study of members of IEEE found that electrical engineers spent about $55 \%$ of their workday communicating, mainly with coworkers involved in the same projects. Engineering is context-specific and often involves proprietary information and, as a result, engineers tend to rely on conversations with internal colleagues and clients instead of external communication sources such as databases, standards and books that scientists use (Tenopir \& King 2004, 30).

The stereotypical image of socially awkward engineers is perhaps most pronounced in the United States, where social practices include much talk about emotions. In Finland, the engineering student culture traditionally includes lots of social interaction, especially male bonding through student pranks, drinking parties, excursions, sauna evenings, etc. that creates networks for the future careers. The interaction does not consist of analysis of human relations, but it is not radically deviant from other social interactions in Finland. On the other hand, in the United States, talking about emotions and mastering emotional social games is one of the glues that hold the social fabric together, and consequently, it is required as a social skill. "Without niceness, everyday life would be a more lonely, humiliating, frightening affair." (Clark 2004, 414). In contrast, societies that have a long history and a uniform tradition, emphasize more established structures and kinship relations, and personal behavior is subjugated to explicit rules, not social feelings.

Knorr Cetina $(1999,127)$ observed CERN physicists for a couple of years. The interaction of physicists (who are scientists or engineers) is characterized by a relative lack of the physiological subtext that associates human beings with behavioral tendencies, states of the body, etc. A woman physicist noted to Knorr Cetina that no-one asked about her marital status in over a year's time. "The mono-gendered physicist looks more like a male than a female" (ibid., 232). In fact, interviews with the physicists revealed that they actually considered the particle detectors as more 'human' than human beings in the workplace, and they described their interactions with the machinery in terms of working relationships that are characterized by trust. Nevertheless, they work as a self-organizing collective that is centered around a highly cooperative effort, even though social interaction is subjugated to interaction with the detector. 
Engineers have a strong belief that their thinking is thoroughly rational, and that they concentrate on the task at hand. Engineers are not thinking through feelings, or so the assumption goes, rather, they consider feelings as a disturbance to the rational thinking process. However, there is a fascination, excitement and even passion in technology. The idea of rational decision-making was discussed in section 3.1 where it was concluded that truly rational decisions in social and business context always rely on intuition because the problems are too complex to be simply calculated. In engineering, however, it is believed that solutions can be calculated unambiguously. To what extent this is true could be questioned, as many solutions are based on tradition and best practices. When, for example, changes of magnitude are needed, the basis of solution may become untenable and a need to redesign the system arises.

"Q: How do you drive an engineer completely insane?

A: Tie him to a chair, stand in front of him, and fold up a road map the wrong way."

Engineering jokes

Several personality inventories, such as the Kolb learning styles inventory (Kolb 1984) attribute lack of feeling and empathy to the engineering profession, based on the fact that the focus of work is in problem-solving and analytical thinking. However, this does not necessarily indicate a person who lacks empathy, because empathy is a separate feature of the brain system. Intuition and analytical thinking can coexist in various degrees (Aarnio 2007). A need to control thinking and feelings is often attached to an engineering mind, but on the other hand, social workers or psychiatrists more often face emotional situations where they need to control feelings of empathy.

Nevertheless, when human relations and feelings seem too difficult, dangerous, unpredictable, and threatening, it is easier to concentrate on mechanical devices that do not behave erratically, and the subsequent feeling of control gives assurance of safety. This creates a fallacy of predictability and control in life that is actually confined to technical environments only. In addition, people with autistic characteristics or Asperger's syndrome typically have narrow interests in mathematical or technical subjects, thus they often select a technical profession, being overrepresented in the student body of technical universities (Personal communication 22.11.2007).

The left hemisphere of the brain is the center for systematic thinking and control, and in engineering it needs to be well developed. It has proven dominant for major cognitive activities, such as problemsolving. The left hemisphere can exert powerful control over many tasks, such as visual search, even hijacking the attentional system (Gazzaniga 2002). It has been claimed that the main, though small, (cognitive) differences in male and female brains are in lateralization. Therefore it would not be surprising that more men are engineers than women. However, because lateralization is not an innate feature but develops during childhood, drawing definite conclusions on the gender differences is unfeasible. 
A recent study attempted to shed light to the personalities of computing students in the U.S. in order to find out factors that influence study success (Bélanger et al 2007). The researchers tested 390 computer science and information technology majors in several universities using questionnaires that included a coping strategy test and a test of emotional intelligence. The study did not reveal any clear correlations between study results and personality features, except of proving that self-efficacy explains study success and persistence in IT careers (as well as in other fields of study). Self-efficacy is defined as global confidence in one's ability across a wide range of demanding novel situations. In addition to self-efficacy, student success depends on previous computer experience and comfort level in the computing-related course work. In fact, the test population seemed to receive a higher emotional intelligence score than the comparison group. This is not surprising, taken that the comparison group did not deviate much from the test population. It consisted of students in civil engineering, mechanical engineering, chemistry and aerospace engineering, and the gender distribution was similar in both groups.

In Finland, systems developers have been studied by Isomäki (2002). Her research explored the conceptions of human beings by systems designers. She interviewed 20 designers and concluded that a majority targets their systems towards company functions, instead of paying much attention to human users. Only five of the designers had a holistic and human-centered view of information systems use.

\subsubsection{Technological and engineering cultures}

Tenopir and King $(2004,72)$ in their study on communication patterns of engineers note that engineers around the world are more alike than different. This they attribute to a unique body of knowledge, and the unique way of communicating, that defines an engineer. The major differences found in various studies are attributed to the level of funds and technologies that are available for engineers in different countries. The major cultural difference between Western and Asian engineers is proposed to be the stronger reliance on trust in Asia; Asian engineers be it from Korea, Thailand, China, or Japan, are willing to share information only if they perceive their counterpart to be knowledgeable and sincere.

Great technological advances were possible before the development of Western science, based on indigenous mathematical systems and accumulated craftsmanship. We should not forget pyramids in Egypt, Mesopotamia, Chile, and Mesoamerica, Roman hydraulic technologies, and so on. Modern technology is predominantly Western, but the origins of many inventions in China and India should be remembered. Additionally, East Asian countries are prominent players in developing modern ICTs: Japan and robotics, Japan in pharmaceutical technologies and chemistry, Korea in internet applications (virtual worlds), etc. (Also discussed in section 3.4 Knowledge)

Nokia is the best known Finnish engineering company with global operations. During its process in creating a global set of company values, personnel from all countries of operations and all professions 
participated in the discussion (Lilius, 2007). This process demonstrated that a telecommunications company could have a global company culture where the major differences in values were not among national cultures but among professions. A Mexican engineer found out that he was better able to communicate with engineers in other countries than marketing people in his own country. Similarly, the business studies teachers at EVTEK made a note about differences in communication styles between business and technology. A business lecturer commented that "the people from technology departments speak frankly and loudly in meetings", which was difficult for her to get used to.

Globally, noticeable differences in software development process have been detected between countries. A study by Cusumano et al. (2003) that compared software development practices in India, Japan, the U.S. and other countries (mainly Europe) found that the amount of code (469 lines in Japan vs. 209 in India) and frequency of defects in code varied significantly (0.020 defects per 1000 lines of source code in Japan vs. 0.400 defects in the US). This was attributed to differences in the process that emphasized specifications and design reviews in Japan, and crude code generation in the US.

Would it be possible to develop different kinds of technologies based on local cultural knowledge or outside the Western view of technology? The question has been raised for example in connection with women's studies, suggesting that women would design more human oriented systems. Sherry Turkle (1991) with a team at Harvard studied programming styles of female and male students and found a variety of styles, some of which were used more often by women than men. She developed the concept of "soft programming" that is less algorithmic and more object oriented, in today's terms. With modern user interfaces and high-level programming tools, the programming styles can be selected more freely than before, even though in large projects a certain engineering discipline is required.

Perhaps Western engineering has overemphasis on step-by-step analytical processes, and other kinds of approaches could enhance chances for innovations. Holistic, organic approaches are based on divergent thinking that foster creativity. In information technology more functional, object-oriented methods could be added to the systematic problem-solving ways.

Recently, it has been recognized everywhere that information technology graduates need globalization and diversity skills to a much larger extent than previous generations (Little et al. 2001). It is not enough for graduates to have technical capabilities; they will work in an environment with multicultural customers and clients. Hence, they need to be able to interact successfully in teamwork and teambuilding activities with colleagues from different cultural backgrounds. The products of their labors must be in line with the needs of a variety of diverse users. Engineering graduates need to develop an awareness of all aspects of globalization. 


\section{$4 \quad$ Research approach}

\subsection{Research problems}

The particular focus in the present study is on cognitive processes and learning strategies of students in multicultural groups and the development of professional expertise in engineering. The existing body of research on multicultural education gives indications of typical problems and challenges for immigrant students in general, as was discussed in section 3.3. Most of this research is not from the field of engineering or computer science education, though, thus the results need considerable adaptation for the purposes of this study. There is an enormous gap in knowledge concerning multicultural engineering education, and in particular, no theoretical framework for systematic research exists. Chapters 2 and 3 of this study provide an effort to construct a theoretical framework that covers the principal disciplines that study learning processes, cognition, and cultures. As far as I am aware, this is the first effort to outline a coherent theoretical basis for multicultural information technology education.

A number of questions have risen from the educational practice, and from efforts to find explanations and solutions to the problems that engineering educators face in a multicultural setting. Given this lack of research, new research is needed to seek answers to questions, such as:

- Is engineering knowledge universal? What kind of cultural differences may be found in engineering thinking?

- Are there actual differences in learning in engineering students that depend on their home culture? How are these differences displayed?

- How do ways of thinking and problem-solving of immigrant students differ from ways of thinking of Finnish teachers or students?

- How do students from differing backgrounds display evidence of understanding abstract concepts and technology?

- What methods or approaches in teaching would make it easier for (international) students to become competent engineers and to adapt to requirements for logical reasoning, algorithmic thinking, and systematical analysis?

Two puzzling cases of student behavior are presented here as illustrations of and a basis for the systematic examination of the complexity of challenges facing both teachers and students. One case focuses on an analysis of a product of a practical assignment by one individual, a PowerPoint presentation. The product of his work is what could be called a telling case (Mitchell 1984), illustrating the multidimensionality of misunderstanding assignments. Furthermore, it is not the only of a kind, in fact, another student handed in an exact copy of the presentation. 


\section{Puzzle 1: Jonathan}

The first assignment in the first-semester Introduction to computing course was to complete a small research task using internet and to report results in a PowerPoint presentation. The task was to compare Wikipedia to other information sources in the internet by comparing what information they provide on topics such as flash memories. A Kenyan student handed in a presentation called "Comparison between Wikipedia and Flash" where he compared how reliable the information on Wikipedia is compared to the reliability of flash memories. When he showed his report, I asked him whether those two are not different kinds of things, and he nodded, but he was happy with his work anyway. This puzzling case will be discussed in section 5.4 .

Box 1: The assignment in the puzzle Jonathan

\section{Comparison of search facilities}

Deliverable: A report on search results as a PowerPoint presentation In this exercise you learn to find information from the Internet, and report it as a PowerPoint presentation.

To do: Wikipedia is a new and valuable source of information. It is maintained by volunteers and the contents could change any moment. Make a small research comparing Wikipedia information with other sources on the Web. Select one topic from the list below, and find the Wikipedia explanation. Then, do a search using Google or some other search engine of your choice, and evaluate the Wikipedia information with these findings (at least two other sites). What risks are involved when relying on one source only, like Wikipedia?

Choose one of the following topics for your research:

- Repetitive strain injury or Ergonomics

- $\quad$ RSS file format

- USB

- flash memory

- Ajax programming

- Linux operating system

- podcasting

\section{The procedure:}

- Select appropriate keywords or phrases.

- Compare the results from at least three different sources.

- Remember to include the references (names of search engines and URLs of Websites that were used).

- Compile a report of your findings and conclusions. 
Box 2: Jonathan's presentation (unedited text)

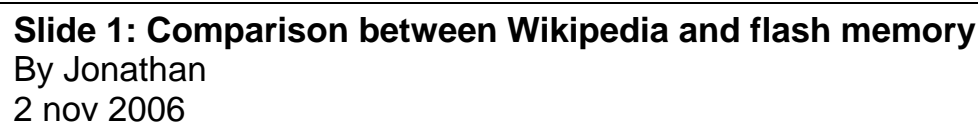

Slide 4: Study and its results

Wikipedia - provides information on the subject of content but the information provided may not be necessarily accurate.

Flash memory - provides accurate information that one has stored in it.information is not changed once it has been stored

\section{Slide 5: Comparison and evaluation}

Unlike the flash memory,wikipedia has information about almost everything but in flash memory, inforation available is only the one that has been stored.

The information in wikipedia is not necessarily accurate but the information in the flash memory is accurate

\section{Slide 6: Examples of information sources}

From wikipedia - A form of non-volatile computer memory that can be erased or reprogrammed

\section{Slide 7: Examples of relevant informaion}

Flash memory is a type of constantly powered nonvolatile memory that can be erased or reprogrammed

\section{Slide 8: conclusions}

It is always advisable to get accurate information from the flash memory but incase you want to get a variety of information,then the best source is the wikipedia.

\section{Slide 9: references}

http://electronics. Howstuffworks.com/

http://searchstorage.techtarget.com/

http://en.wikipedia.org/wiki/Flash_memory 


\section{Puzzle 2: $\quad$ Following instructions in the laboratory}

The second case focuses on practices in electronics and physics laboratories Each laboratory session consists of one task, which is performed according to the same default script:

1. Arrive at the starting time and form a team of two students and start work.

2. Read the instructions for the current assignment; ask for clarification if needed.

3. Plan your work.

4. Work step-by-step through the assignment.

5. Report measurement results.

In reality, teachers have observed another type of script that students tend to follow:

1. Arrive at some point during the scheduled time for the task (2-3 hours).

2. Meet friends and see what they are doing.

3. Make a team or try to join a team that has started working (and negotiate with the instructor about the team size).

4. Approach the equipment and start some action.

5. Call the instructor when things seem to go wrong.

6. etc.

The observed reality in the laboratories showed that this pattern causes delays in laboratory work, which became particularly problematic because of shortage of laboratory resources that are fully booked for the entire semester. To avoid delays, teachers have worked hard to improve laboratory instructions so that students would manage to complete lab assignments in time. Moreover, teachers explain regularly the importance of punctuality and self-discipline in the labs, but they have not been able to change the student script. The persistence of student actions will be discussed in section 5.6.

In both cases, selected for further analysis, teachers confronted a situation where communication failed in a manner that was unexpected, and moreover, difficult to understand or amend. Some new research problems emerged:

- What are the barriers of communication between teachers and students?

- How is engineering and scientific thinking learned and absorbed during the studies?

The immediate goal of this research is to analyze the diverse and ever-changing EVTEK international student body, which contains a great amount of individual variety in cognitive styles and problemsolving approaches in order to understand students' ways of thinking and learning approaches. Subsequently, the aim is to develop methods of education that respond to student needs. The practical research collects data on learning and student thinking, and interprets them through the theoretical construction. A cultural cognitive approach gives access to diversity of thinking processes. The research will suggest explanations that do not claim to be exhaustive, but it strives to provide a step 
further on our way to understanding. The ultimate aim of the research is provide a basis for exploring further the challenges of multicultural education, and ways of improving engineering education at polytechnics and universities. The research is rather ground-breaking and seeks to open new ways to see cultural influence on scientific thought processes, learning, and problem-solving.

\subsection{Strategy and design}

".. a scientist must also be absolutely like a child. If he sees a thing, he must say that he sees it, whether it was what he thought he was going to see or not. See first, think later, then test. But always see first. Otherwise you will only see what you were expecting. ... You can't possibly be a scientist if you mind people thinking that you are a fool."

Wonko the Sane in "So long, and thanks for all the fish"(Adams 1985, 587)

Valid research in engineering is traditionally considered as impersonal, objective, and quantitative. The researcher is required to be detached from the object of study, manipulating data in form of numbers, which, in fact, reflects a Newtonian epistemology, from the time before the discovery of quantum mechanics.

"The great extension of our experience in recent years has brought light to the insufficiency of our simple mechanical conceptions and, as a consequence, has shaken the foundation on which the customary interpretation of observation was based."

Niels Bohr (Atomic Physics and the Description of Nature, 1934)

Furthermore, Karin Knorr Cetina (1999) has disproved the ideal of uniform knowledge creation in sciences by closer study of laboratory practices of different fields of science. She observed the work of scientists in microbiological laboratories and at CERN, noting how they create knowledge, and, on metalevel, the construction of the machineries of knowledge construction. She claims a disunity of sciences that is characterized by a diversity of epistemic cultures. Culture in her context refers to the aggregate patterns and dynamics that are on display in expert practice and that vary in different settings of expertise. Her particular targets of observation illustrate this by comparison of the communitarian science of physics with the individual, bodily, lab-bench science of molecular biology. Despite obvious differences, both nevertheless have collective and embodied levels.

\subsubsection{Qualitative research}

This research is qualitative action research, drawing on case studies. The research process started by observations that could not be directly explained by available educational theories. An exploration of the theoretical field revealed a lacuna in the area of multicultural engineering education. The aim of this research is to find explanations and build a theoretical framework based on systematic collection of ethnographic observations and other data, analysis of findings and subsequent hypothesis testing through an iterative process. Educational setting is ideally suited to a hermeneutic cycle of theory formation, experimentation and evaluation due to the repetitive pattern of successive academic years. The yearly entrance of new student populations offers a fertile ground for testing the effects of multiculturality based on a multidirectional comparative perspective (Zaharlick \& Green 1991). Interestingly, the curriculum and educational setting have remained constant (except for the increasing use of network technologies) throughout the study, but the student population has changed visibly and 
unpredictably from year to year, creating a kind of ceteris paribus condition that is required by Gerring (2007) for methodologically sound research design.

On the other hand, the changing character of diversity in the groups prevents extensive statistical comparisons limiting the use of statistics to general variables on study group level such as course passing rates. The focus varies from individual level (how a student learns) to group level, and thus the scientific focus alternates between psychology of learning and shared cognition and collaborative education.

Flick et al. (2004) in their extensive handbook give a list of characteristics of qualitative research practice that this research aims to attain:

1. Spectrum of methods rather than a single method

2. Appropriateness of methods

3. Orientation to everyday events and/or everyday knowledge

4. Contextuality as a guiding principle

5. Perspectives of participants

6. Reflective capability of the investigator

7. Understanding as discovery principle

8. Principle of openness

9. Case analysis as starting point

10. Construction of reality as a basis

11. Qualitative research as a textual discipline

12. Discovery and theory formation as a goal

This research aims at describing and locating problems and proposing explanations. It follows traditional ethnographic fieldwork practice: the researcher goes in the field, participates in the life of the tribe, makes observations, and collects all data that can be found: histories, narratives, statistics, interviews (Ellen 1984). Simultaneously, the researcher sifts through theories and tries to organize her data in order to explain, and to generalize the cases (Flick et al, 2004, Gerring 2007). However, Töttö (2004) argues that it is misguided to talk about qualitative and quantitative research as separate because all research includes elements of both methods. In this regard, the present study is no exception in using mixed methods.

\subsubsection{Interrogative inquiry}

Every sentence I utter must be understood not as an affirmation, but as a question. Niels Bohr

The research process follows the ideas of the interrogative method of scientific inquiry presented by Jaakko Hintikka (2001). Interrogative logic is a general theory of rational reasoning, including scientific knowledge acquisition. It is an iterative process where questions are posed to nature, and the 
responses are subjected to deductive reasoning steps. Hintikka compares scientific discovery to the methods of classic detectives: the scientist works like Sherlock Holmes by eliminating wrong leads, and deducting from clues. He follows the ideas of Peirce who also played detective and called his method abduction (Flick et al. 2004). In abduction, the consciously working mind that relies on logical rules is allowed to be outmaneuvered, and a moment of revelation becomes possible. Abductive inference is an open attitude towards data, and seeks to find new meaning-creating rules. The hypothesis that is generated by abduction produces predictions that are successively tested in order to verify the assumptions. Thus the procedure consists of abduction, deduction and induction. The course of the research is illustrated in figure 10 .

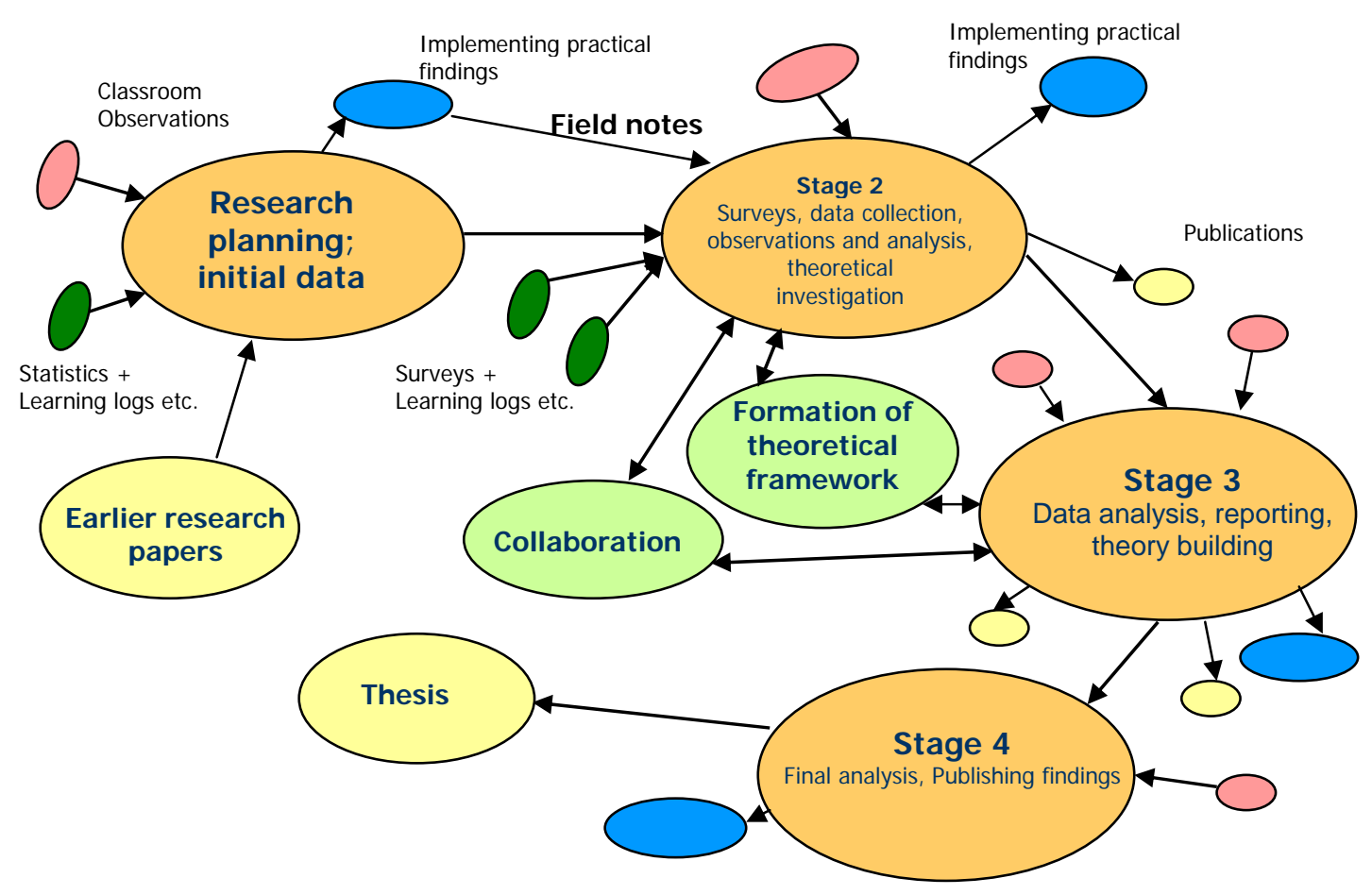

Figure 10: Research process

Therefore, the focus of the research is not in hypothesis testing. However, there are some preliminary hypotheses that results from my previous research and observations on multicultural training. According to Gerring (2007), social scientific study is often motivated by a suspicion that something "funny" is going on, and that was evidently the case here. The first "hypothesis" was that there are indeed differences in scientific and engineering thinking that are culturally produced, and specific educational methods are needed to address them. The earlier studies have been reported in my papers (Holvikivi 1991, 2002, 2003, and Holvikivi et al. 2001). Another starting assumption in this study was that there is no systematic difference in intelligence and capacity for learning between individuals from different cultures, in accordance with the current understanding in cross-cultural psychology (Berry et al. 2002). Rather, the differences are probably produced by educational systems and cultural 
practices. The nature of these differences and accurate causes for them need analysis, which is one of the main purposes of this research.

\subsubsection{Cross-disciplinary research}

The research is necessarily cross-disciplinary, applying a combination of methods. A constructive research approach that is common in educational action research and that is close to the methods used in the SimLab at Helsinki University of Technology (Smeds 2003) follows a hermeneutical cycle: the same study units and courses are repeated yearly, allowing a chain of improvements based on previous experience. Cross-disciplinary research is a major challenge, particularly for a lone researcher who has a natural preference for exact methods in science. Eventually, this is very much an engineering thesis that aims at finding pragmatic solutions using all available means and theory. The approach leads to an epistemic nomadism (Braidotti 1994, 93) that is situated in the "in-between" zones of sciences. The leading idea is to be instrumental in regard to research techniques: the question under investigation is always primary. The framework is depicted in figure 11 .

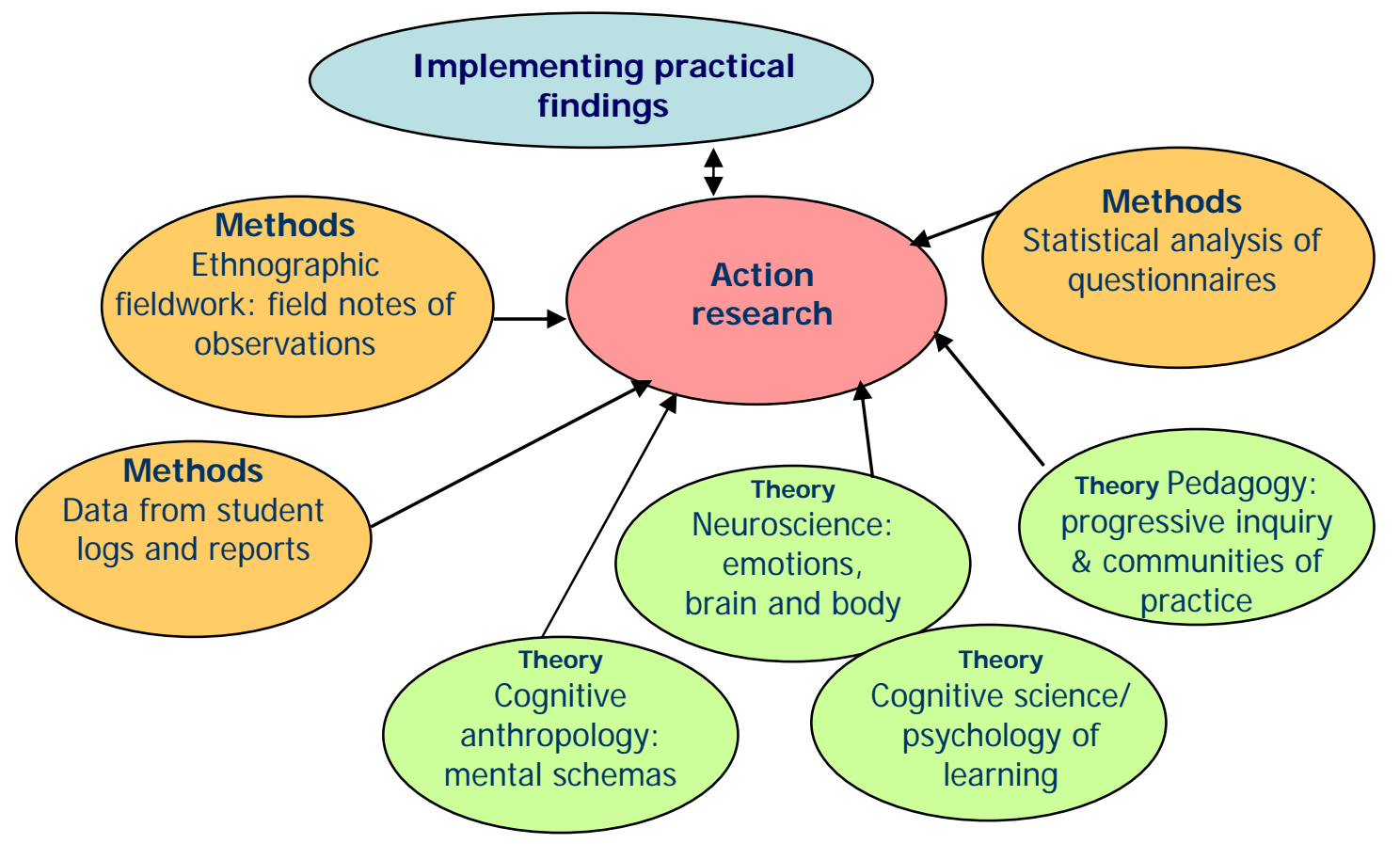

Figure 11: Research approach

My main strategy in this study has been to concentrate on methods and theories where I have the strongest background and that are natural to my cognitive and working styles. These are first of all computer science and information technology, practical engineering pedagogy, multicultural education, and cultural anthropology. For other fields of knowledge, I actively sought support from other research teams that have the expertise required: psychology, educational science, cognitive science, and theory of knowledge. Recent advances in these disciplines have brought about paradigm changes, which generates a risk of reliance on outdated theories (an illustration is the Kolb study that is described in section 5.2). Moreover, many research fields are extremely dispersed, and in some fields such as 
philosophy, strongly opposing schools of thought exist concerning questions of mind (Bennett et al. 2007).

Hutchins (1995) moved the study of cognition from laboratory to the "wild", to real-life settings. He claims that that is what anthropology needs to do as opposed to the controlled laboratory experiments of psychologists. My aim is to combine ethnographic data to other types of data that I have collected, such as, statistics, textual materials, and surveys; and to use research results from cognitive science and psychology to explain the findings. Additionally, I use the wealth of research in learning sciences.

\subsection{Research setting and landscape}

The EVTEK University of Applied Sciences was located in the Helsinki metropolitan area. It offered education in technology, business and arts and design. EVTEK was merged with another polytechnic $1^{\text {st }}$ August 2008, forming the Metropolia University of Applied Sciences. However, as this research has been conducted between 2001 and 2008, it is more accurate to speak of EVTEK, which was the name during that period. Before that, the official name was Espoo-Vantaa Institute of Technology (EVITech). EVTEK offers two four-year Bachelor of Engineering degree programmes where the language of instruction is English: information technology and media engineering. Both have Finnish language counterparts that are about twice the size. EVTEK has an annual intake of 70 international students who come from Europe, Africa, Asia, and occasionally America.

EVTEK Institute of Technology has two campuses, one in Leppävaara, Espoo and one in Myyrmäki, Vantaa. Information technology, media technology, building services engineering, and industrial engineering programmes are located in Espoo in a modern, white, three-storey glass and tile building. The classrooms are well-equipped with PCs and projectors as well as various other audiovisual devices. The number of students is nearly 2000 and staff 200. The school has advanced intranet, wireless and LAN services. Electronics labs, a gym, sports hall, library, cafeteria and other services are also found in the same building. Classrooms are mainly designed for lecturing and teacher-led instruction, with a few project rooms. Teachers' offices are next to the classrooms, which allows easy communication with teachers.

Leppävaara is one of the suburban centers in Espoo, with excellent commuting (train and bus), municipal, sports, and cultural services, and a huge shopping mall. Student dormitories where most international students live are scattered across the Helsinki area. Cultural and night-life activities, ethnic shops and cafes are mostly concentrated in the town center, whereas ethnic restaurants can be found in any suburb. Services and guidance in Finland are mainly offered in Finnish or Swedish, which is definitely an obstacle for recent immigrants, as Finnish words seldom resemble their English equivalents making even guessing their meaning impossible. 


\subsubsection{Goals of international programmes}

During the past fifteen years there has been a substantial expansion in the provision of both undergraduate and postgraduate programs offered in English, strongly encouraged by the government. Information technology and engineering were particularly emphasized in national policies (Committee on the international strategy of higher education institutions 2001). Internationalization was conceived to give prestige to polytechnics, and accordingly, international degree programmes were rewarded with supplementary funding from the Ministry of Education.

The student population in Finland is noted for its even quality, for example by the good average success in the international OECD PISA comparisons (OECD PISA Website). The Finnish school system provides equal opportunities to pupils, being remarkably uniform without elite or particularly bad schools. Moreover, Finnish EVTEK students come chiefly from the capital area, representing a population of mainly male students interested in higher professional education with a pragmatic inclination. Therefore, the home student body represents a low level of diversity, being rather homogeneous in all respects.

The Espoo-Vantaa Institute of Technology started an international Bachelor of Engineering programme in computer engineering in 1992 as part of its active internationalization effort (Leminen et al. 1994). The aim was stated to be to educate engineers capable of international operations and with a good knowledge of foreign languages. Another goal was to improve the educational atmosphere and the quality of instruction at EVITech. It was envisioned to act as basis for development of joint international courses, and to create opportunities for student and staff exchange and research cooperation. In the beginning, most of the students were Finnish nationals (table 4). The stated aims were soon achieved, and EVTEK continues to have active participation in numerous European and overseas collaboration efforts. When the international programme received more immigrant students, the aim was to prepare them for Finnish business culture and to create opportunities for them in industries that are based in Finland (Holvikivi et al. 2001). The names of international Bachelor of Engineering degrees were first computer engineering (that changed its name to information technology in 2001) and since 1997 digital information provision that was later changed into media engineering (Haltsonen et al. 1998).

\begin{tabular}{|llll|}
\hline & $\mathbf{1 9 9 2}$ & $\mathbf{1 9 9 8}$ & $\mathbf{2 0 0 7}$ \\
Finnish & $67 \%$ & $70 \%$ & $7 \%$ \\
International & $33 \%$ & $30 \%$ & $93 \%$ \\
\hline
\end{tabular}

Table 4: Shares of Finnish and international students in English BEng programmes 
International students in these programmes have diverse backgrounds: particularly in the early years, most came from the expatriate community in Finland. Presently, more than a half of the students arrive directly to Finland for the purpose of study from their often distant home countries. Usually, they are young high school graduates or have one or two years' prior college studies, the majority being men.

\subsubsection{Student backgrounds and recruitment}

To give an impression of the classroom composition, the cultural backgrounds are classified in table 5, divided into rough country groups. The grouping is purely pragmatic: Chinese are so numerous that they form one group, only recently have there been any other East Asians. Other Asians have been predominantly men from Islamic countries (Pakistan, Iran, Bangladesh), recently also from Nepal. Europeans come mainly from the U.K., Russia and Estonia, and occasionally from Italy or other countries. Others include North and South Americans and Australians. There have been over 60 different nationalities in the student body.

\begin{tabular}{|l|r|r|r|r|}
\hline $\begin{array}{l}\text { Countries / areas } \\
\text { of origin }\end{array}$ & $\begin{array}{l}\text { Share of } \\
\text { students in 1999- } \\
\text { 2002 }\end{array}$ & $\begin{array}{l}\text { Share of } \\
\text { students in 2004 }\end{array}$ & $\begin{array}{l}\text { Share of } \\
\text { students in IT } \\
\text { in 2005-2006 }\end{array}$ & $\begin{array}{l}\text { In media } \\
\text { eng. 2005- } \\
\text { 2006 }\end{array}$ \\
\hline Finland & $30-50 \%$ & $8 \%$ & $7 \%$ & $30 \%$ \\
\hline Other Europe & $10 \%$ & $20 \%$ & $14 \%$ & $25 \%$ \\
\hline Africa & $15 \%$ & $50 \%$ & $60 \%$ & $27 \%$ \\
\hline $\begin{array}{l}\text { China and East } \\
\text { Asia }\end{array}$ & $20-30 \%$ & $10 \%$ & $15 \%$ & $10 \%$ \\
\hline $\begin{array}{l}\text { Middle-East and } \\
\text { South Asia }\end{array}$ & $10-20 \%$ & $10 \%$ & $11 \%$ & $<5 \%$ \\
\hline Others & $<10 \%$ & $<5 \%$ & $<5 \%$ & $<5 \%$ \\
\hline
\end{tabular}

Table 5: Nationality distribution of EVTEK students in English BEng programmes

The recruitment process has been an important part of the identity of the programmes, as it has been done outside the collaboration of other polytechnics. It has relied on EVTEK -devised entrance examinations, including English tests. Whereas universities elsewhere depend on TOEFL and other standardized tests, ours has no fixed measure. As a consequence, the level of English proficiency of students varies from inadequate to nearly fluent. This explains part of the communication problem that is discussed elsewhere in this thesis.

In 1999 and 2000, groups of Chinese students were recruited directly from China. A team from EVTEK traveled to Beijing to organize entrance examinations. In recent years, entrance examinations have been arranged also in Finnish missions in Nepal, Ethiopia and Kenya by the local staff. Being located in the capital area, EVTEK also attracts international transfer students from provincial polytechnics elsewhere in Finland. 


\subsubsection{EVTEK experiences: efforts to address multiculturalism}

In the experimental phase of the media engineering programme at EVTEK, efforts to develop network-based learning methods for cross-cultural project groups were made (some are reported e.g. in Markkanen 1999 and Haltsonen et al. 1998.). A development plan for the IT curriculum was created as a project during pedagogical studies, lead by programme director Leinonen (Holvikivi et al. 2001). Another project tried to analyze problems concerning multicultural classrooms two years later by a group of teachers (Kitsnik et al. 2003). Moreover, EVTEK has participated in a number of European collaboration projects, for example to enhance virtual study environments, and presently, the EU funded KP-Lab project involves 22 partners, including the University of Helsinki and some enterprises in Finland. Several joint courses with other European universities are organized yearly in some partner location, where students and teachers from all universities gather. Moreover, EVTEK has an active student and staff exchange with European and Asian universities. The number of European exchange students participating in IT courses is significant.

Efforts to increase staff diversity have not been systematic nor successful. Presently, there are only three immigrant teachers among the IT faculty, and one of them is business teacher, and one an English language teacher. The Computer engineering programme had two different expatriate directors, both of whom held the position for one year, and both of whom resigned due to internal conflicts. There is no other international staff except student trainees.

Staff language skills have been a concern, therefore selected faculty members are regularly sent to language courses in the U.K. The issues of cultural diversity and teamwork have also been addressed in special workshops organized by outside consultants for the media students, as well as a couple of workshops for the faculty. So far, this cultural awareness has been rather sporadic, and has not penetrated the programmes in Finnish.

\footnotetext{
Here I have a little Idea for you ... next time before you decide to give us a lecture of religion or healthcare or something else why don't you start first a little pool and see how many students are interested in the subject... And maybe that's the answer to the problem with the empty auditorium once again today... I have a question for you... What is the purpose of the Introduction to Studies class at all? What we are doing now is much more "Introducing to Finland" than anything to do with our studies. I suggest you try to give us something practical if you want to bring the students back to the class, and most important something that we are interested in.

- Student comment on advisory courses (Oct 2006)
}

Unfortunately, the student union at EVTEK has not offered any activities to international students, as their range of activities has been limited to organizing trips and parties. 


\subsection{Data and analysis}

Empirical research data consists of a variety of materials: background information on study records in the student administration database; three surveys that have been conducted repeatedly; classroom observations collected in field notes during four years; and student materials from a number of courses over eight years, such as project reports, learning logs, and other assignments. The data are presented in table 6 and described below.

\begin{tabular}{|c|c|c|c|c|}
\hline Category & Content/ course & Amount & $\begin{array}{l}\text { Presented \& } \\
\text { analyzed in } \\
\text { sections }\end{array}$ & $\begin{array}{l}\text { Actor/ } \\
\text { producer }\end{array}$ \\
\hline $\begin{array}{l}\text { Study statistics } \\
\text { Official study } \\
\text { records }\end{array}$ & $\begin{array}{l}\text { Passing, grades, } \\
\text { Graduations, } \\
\text { Drop-outs }\end{array}$ & $\begin{array}{l}>1000 \text { Finnish } \\
\text { students, } \\
\text { > } 300 \text { Intl } \\
\text { students }\end{array}$ & $\begin{array}{l}4.3 .2,5.1 \\
5.4 .5\end{array}$ & $\mathrm{JH}, \mathrm{UF}$ \\
\hline $\begin{array}{l}\text { Course results/ } \\
\text { assessments }\end{array}$ & $\begin{array}{l}\text { Introduction to } \\
\text { computing } \\
\text { Application } \\
\text { development }\end{array}$ & $\begin{array}{l}100 \text { Finnish/ } \\
420 \text { Intl } \\
300 \text { Intl }\end{array}$ & 5.2 .2 & $\mathrm{JH}$ \\
\hline $\begin{array}{l}\text { Survey } \\
\text { questionnaires } \\
\text {-values \& thinking } \\
\text {-study preferences }\end{array}$ & & $\begin{array}{l}135 \\
62 / 62\end{array}$ & $\begin{array}{l}5.2 \\
5.1 .2,5.3\end{array}$ & $\begin{array}{l}\mathrm{JH} / \mathrm{LS} / \mathrm{TV} \\
\mathrm{JH}, \mathrm{UF}\end{array}$ \\
\hline \multicolumn{5}{|l|}{$\begin{array}{l}\text { Student produced } \\
\text { artifacts }\end{array}$} \\
\hline Written & $\begin{array}{l}\text { Learning logs } \\
\text { Personal reports } \\
\text { Project reports } \\
\end{array}$ & $\begin{array}{l}120 \\
30 \\
100 \\
\end{array}$ & $\begin{array}{l}5.4,5.5 \\
5.6 \\
\end{array}$ & \\
\hline Software & $\begin{array}{l}\text { Programs } \\
\text { XML designs }\end{array}$ & hundreds & 5.4 .2 & \\
\hline Online & Web sites & $>700$ & $\begin{array}{l}\text { 5.1.2, 5.4.1, } \\
5.6\end{array}$ & \\
\hline Communication & $\begin{array}{l}\text { Emails } \\
\text { On-line discussions }\end{array}$ & from five years & $5.4 .4,5.4 .5$ & \\
\hline Observations & $\begin{array}{l}\text { Software labs } \\
\text { Lectures } \\
\text { Physics labs } \\
\text { Electronics labs }\end{array}$ & from five years & $5.4,5.5,5.6$ & $\begin{array}{l}\text { JH \& } \\
\text { others } \\
\text { JH \& } \\
\text { others } \\
\text { MP } \\
\text { TL, AI }\end{array}$ \\
\hline
\end{tabular}

Table 6: Materials and data 


\section{Background information}

Background information on student performance for the research was collected from study records in the student administration database Winha concerning all information technology student groups between 2004 and 2007, both in the Finnish programmes and English (international) programmes. Course statistics of the two first-year courses given by the researcher in the years 2001-2007, Introduction to computing and Application development, have been used in the analysis of study performance. Informal information was received for instance in department meetings where teachers regularly reported their experiences with student groups. Moreover, several informal interviews with colleagues and other researchers were conducted during the years. These are recorded in the field notes.

\section{Surveys}

International students' attitudes, opinions and preferences were charted by collecting data through surveys. Two surveys were devised, one about scientific thinking and values (Appendix 1), and another about studies (Appendix 2). The surveys were initially conducted in 2005 on five different groups, both international and Finnish first-year students and faculty members. The survey questionnaires were given on paper to students in the classroom during regular classes such as Introduction to studies. For faculty, the survey was conducted in staff meetings, with an introduction of the research project in general. Though responding was voluntary, $100 \%$ of those present participated in all groups. The questionnaires had no identification information, thus responses cannot be categorized by nationality or sex. This choice is due to the low number of individuals in many nationalities and few women, in order to guarantee anonymity to the respondents.

Questionnaire answers were coded and entered into Excel tables. The section concerning values and attitudes was analysed using SPSS in order to find correlations in responses.

\section{Survey 1: values}

The first survey questionnaire was designed to investigate scientific thinking and cognitive approaches. It consisted of a four-page questionnaire with 57 multiple choice questions, six open questions, one calculation task and the Kolb learning styles test. The first page contained logical, mathematical, physical and technical reasoning tasks. The second page included a list of statements that were answered on a five-point scale from "strongly disagree" to "yes, strongly agree", mainly measuring values, and attitudes towards life and work. The third page presented cases that were intended to test technical inclination and "engineering" approach to technical problems. The last page of the survey questionnaire was a test of learning styles. Respondents were asked to value nine sets of four questions, and based on the self-reported preferences, they were placed on (Kolb) learning dimensions. 
The first survey was conducted in March /April 2005 to five groups: three first-year student groups and two faculty groups. In group codes, CAP refers to Information technology in English and 04 is the starting year. The respondents were as follows:

- CAP04S (group code), Information technology (English) students, 24 respondents

- LAP04S, Industrial engineering (Finnish) students, 10 respondents

- TP04S, Information technology (Finnish) students, 77 respondents

- teachers and laboratory staff, 26 respondents in two groups, $15+11$

The staff members were teachers in the Information technology and Media engineering departments. They had a PhD or MSc in engineering or science, the average age was around 50, and all of them were Finns with the exception of one Estonian. The students were first-year students from three programmes: The international Information technology programme had a total of 24 respondents from a variety of nationalities, 14 Africans, 4 Asians, and the rest Finns or of mixed nationality. The Finnish Industrial engineering group had ten respondents, five of them female. The largest group was that of Finnish Information technology students, 77 respondents.

\section{Survey 2: studies}

The other survey was designed to find out how international students perceive their studies. It contained 31 multiple choice or open questions about study attitudes, experiences, and expectations. It was targeted at first-year students, and conducted in the second semester after about five months of studies. It was given to the international groups in Information technology (CAP04S, 26 respondents) in March 2005 and in January 2006 (group CAP05S, 19 respondents) and Media engineering (DAP05S, 16 respondents) in March 2006. Part of the survey questions were similar to questions in an evaluation survey that is conducted regularly for the home student group. The evaluation is done after first study year as an on-line survey. The on-line system produces statistics of responses. Responses to similar questions were compared between groups. A summary of responses is in appendix 3 .

\section{Observations in classroom}

The research started with a continuous field note collection that contained my personal observations in the classrooms and among faculty. Moreover, I owe thanks to many colleagues who teach different types of courses for their valuable observations, as well as other staff. Their remarks have been recorded in the field notes, as well. The field notes in 2004-2008 contain 123 pages that are archived and that are available on request. Emails that are referred to in this thesis, and relevant discussions on the EVTEK internal discussion forum are also kept in archives.

\section{Learning logs and reports}

Much of the textual research material has been produced by the students: Students wrote learning logs in Introduction to computing course from 2002 until 2007. This assignment was an alternative to the written final examination, and selected by a varying share of students. Around one hundred and twenty 
learning logs have been used as material for this study, that is over 800 pages. Moreover, a multitude of assignment deliverables such as computer programs and Websites have been analyzed. Student quotes are repeated in this thesis in their original format, they have not been edited in order to keep the meaning intact.

In addition, complete materials of Application development projects are online on the EVTEK servers. The project evaluation reports by student teams (over a 100) have been collected, they contain approximately 500 pages.

\subsection{Limitations of the study}

\subsubsection{Researcher and research subjects: ethical questions}

Anthropologist Unni Wikan (1992) relates advice that she received from Balinese elders: "I must create resonance between the reader and my text. But first, they said, I must create resonance in myself with the people and the problems I seek to understand." Similarly, Barbara McClintock, a Nobel laureate and renown molecular biologist, stressed that she understood every plant she studied to the extent that she was able to "enter the maize gene", she had "a feeling for the organism" (Keller 1983). She also stressed her deep commitment: "I was just so interested in what I was doing I could hardly wait to get up in the morning and get at it. One of my friends, a geneticist, said I was a child, because only children can't wait to get up in the morning to get at what they want to do." (ibid., 70) Likewise, Karin Knorr Cetina (1999) describes physicists at CERN as symbionts with particle detectors, they feel as though they have an intuitive connection to the laboratory experiment. She herself applies what she calls a sensitive methodology to her research. I subscribe to a similar attitude; research must be a labor of love to yield valuable results.

As opposed to traditional information technology science which emphasizes objectivity, the subject is openly declared in contemporary ethnographic research: who is the researcher, and who are the research subjects. The research process aims at giving voice to the research subjects and letting them be heard. It recognizes personal, embodied experience, and the value of intuition and tacit knowledge. My claim is that through this approach we can gain information about student learning conditions and processes that would otherwise have been unexposed. In this work, the subjectivity is not concealed, but on the other hand, forthright presentation of data and the reasoning process open results for outside validation as is required (Anfara et al. 2002).

In quantitative research, a central value is attached to the observer's independence of the object of research. Qualitative research, on the other hand, relies on the investigator's (methodologically controlled) subjective perception as one component of the evidence (Flick et al. 2004). In this research, I am the solely investigator, a middle-aged female lecturer with an engineering education. This 
certainly affects my access to the informants, and what aspects of reality I pay attention to. Additionally, I have my own past experience as an expatriate in various countries and of a multicultural social life. My observations might as well be somewhat colored by the situation of my daughter who began her studies abroad at the same time as this research was initiated. The observations and data in this study are undoubtedly influenced by my own position, but this does not implicate that the results could not be generalized. They are products of an individual mind collaborating with other researchers; and as in any other research, the mind is located in a biological brain.

According to Michel Foucault (1975), a person becomes a subject through a set of interdictions and permissions, which inscribe one's subjectivity in a bedrock of power. Power relations as perceived by students influence the learning process, as well as processes of socialization and adaptation to the engineering profession. Moreover, the position of teacher - researcher, and the power of an observer is important in ethnographic research: there is no doubt of the power-relation, because a teacher has power that cannot be denied or alleviated. Students are at the bottom of power hierarchies, which, in case of immigrant students, are reinforced by their language handicap of not mastering Finnish. Despite the power relations, students have been guaranteed anonymity and voluntary participation in all surveys that were conducted for this research. In the absence of an ethical committee at EVTEK, the vice president of technical studies granted permission to the research. Naturally, pseudonyms are used throughout the thesis, and references to nationalities are given only when they do not point to a single individual.

Ethical questions in intercultural education have been discussed, for example, by Mason (2001). The situation is complicated in Finnish colleges because of the coexistence of competing cultures; the values of Finnish national culture are strongest, but then there is the professional engineering culture, cultural influences brought by the English language, and the variety of cultural values by international students. According to Mason, certain principles of multiculturalism and respect for others are universal: "This means that we are bound to respect the right of all cultures to live in accordance with their own beliefs and practices, but only in so far as these beliefs and practices are consistent with the principles associated with multiculturalism itself, primary among which is the principle of respect for the rights of others." (ibid.)

Mason's views agree with ethical views by Damasio derived through brain studies (2003). Damasio refers to Spinoza's concept of conatus which is man's natural inclination to strive toward preserving essential being, and assertion that virtue/ human power is defined by our success in this preservation of being by the guidance of reason. The highest virtue is the intellectual love, or in Spinoza's terms knowledge of God or Nature. 
Hermans (2002) discussed the situation of intercultural education in the Netherlands in 2002, and his findings could be extended to EVTEK without much effort. According to his study, certain issues are not considered in educational institutions, including the possibilities of adapting educational practice to the needs of pupils; incorporating indigenous knowledge and learning strategies into the curriculum; transforming the hierarchical system of schools to induce empowerment; awareness of teacher's own cultural and ethnic identity. The goals of this research are not emancipatory as such, but the conclusions could be empowering to engineering students, and even help Finns developing crosscultural understanding.

The education at EVTEK could have alternative goals: it could aim at developing standard Finnish engineers of all immigrant students, and, in fact, there is a strong institutional tendency towards this goal. I would ask if the Western engineer really is an ethical goal, and have we got a right to attempt to change people's thinking and values to such an extent. We could also subscribe to epistemological pluralism (Turkle 1992) which provides support during the adaptation phase but at the same time allows for individually shaped engineering identities. For instance, Native American students are known to consciously resist against education that changes their values, and even when they study science, they try to keep their traditional values (Lomawaima 2004).

\subsubsection{Possibilities and challenges of educational research}

Educational research in engineering is mired by the dilemma of the ideas of scientific research according to the engineering paradigm, and the practices enforced by reality on the other hand. Most of the research is, in fact, done by the educators themselves, not by objective observers, which is illustrated by the leading journals of the field, the IEEE Transactions on Education and the European Journal of Engineering Education. Therefore, the research is rather subjective and even action research by design. The requirements for paper formats in the journals favor statistical comparison and analysis of data for theoretical discussion or consideration of the sampling, nature and validity of the data. Because only explicit knowledge acquisition can be expressed in numbers, the measuring cannot catch processes of deep learning and understanding, or development of expertise and social skills, thus severely limiting the scope of study. Moreover, participation in the education process suggests that its results such as failure or success in courses and assignments often depend on factors that are not independent variables but context-dependent and known only to the participants.

Recently, the Journal of Philosophy of Education published two special issues (in volume 40) discussing prevalent methods in educational research. The papers denounce the false dichotomy between 'science' and 'non-science', and call for a critical approach to knowledge claims. The writers point out that the focus should not be in methods and producing data but instead to enhance understanding. Levering (2006) argues that from a phenomenological point of view, subjectivity is not so much a problem as an inevitable starting-point. Evers \& Wu (2006) explore the conditions under 
which the practices of generalization and making inferences concerning a wider class of phenomena from case studies is reasonable. They argue that an exploration of the remarkable amount of empirical knowledge that is contained within the theories that are used to make observations, to classify phenomena, and to understand and interpret cases is required in addition to the role of a pattern of inference known as abduction. These two conditions can be used to defend, as reasonable, the making of certain provisional generalizations from single cases.

\subsubsection{Survey method and self-reporting}

This research contains two surveys, both of which consist of mainly standard types of questions that are used in similar surveys. The analysis of results and comparison with observation data indicate that survey data in multicultural groups has to be used cautiously.

Surveys are regularly used for the purposes of finding out about values of cultural groups, learning styles, and so on, similarly to my efforts presented here. For example, work by Geert Hofstede has had an enormous impact on international business research. Probably the culture of business studies favors statistical and numerical analysis and ignores social and human factors that would need a deeper, anthropological and ethnographic understanding. Also in the field of cross-cultural training where fast and efficient solutions are expected (a company sends people to work abroad and they need a quick cross-cultural training), Hofstede's value sets provide an easy kit to present. A similar tendency is discernible in adult education where Kolb's LSI and other learning styles tests are commonly preferred as simple models that yield easily accessible statistics (Paige 2004).

It is well-known that people do not answer sincerely to all types of surveys. Surveys about eating or sexual habits are known to have a considerable error margin, and it is not even expected that people answer honestly. People do not intentionally lie but they prefer to see the facts in an optimistic way. The Economist discussed the chances of a black candidate (Barack Obama) being elected for the U.S. president in the June $16^{\text {th }}$ issue 2007 (The Economist 2007, 47). It referred to a study by the Pew research Centre in which $92 \%$ said that they were prepared to vote for a black candidate, up from $37 \%$ in 1958. The Economist noted that white voters no longer appeared to be lying about this. As recently as the early 1990s, polls for elections pitting a black candidate against a white one usually predicted that the black candidate would do much better than he or she actually did.

When Berry et al. $(2002,396)$ discuss studies in cross-cultural managerial behavior, they highlight problems that are close to mine in the survey study. Particularly it has been assumed that managers in individual and collective cultures would make decisions differently. However, a review of several studies does not show significant or constant differences between for instance American and Far Eastern managers. On the other hand, the authors note that studies about decision-making and risktaking are normally conducted not among real managers but student populations, who are presented 
hypothetical problems in laboratory situations. As Frank (2004) points out, the responses in laboratory situations do not necessarily reflect behavior in real life situations. Moreover, responses to questions about preferences or inferences are vulnerable to the presentation of the problem and the wording that is used.

Moreover, problems in self-reporting are much discussed in psychology (Keltikangas-Järvinen 2000). Because self-reporting is often the easiest or only method available, much of commercial testing of people relies on it. Self-reporting of reactions on feeling is particularly prone to be unreliable, according to Paul Ekman $(2004,122)$ : "I have some doubts whether the findings of $[\ldots]$ tell us what actually happens, as it is based on what people tell them, and none of us is aware of what our mind is doing at the moment it is doing it in the automatic appraisal process."

Klaus R. Scherer $(2004,139)$ describes the states of consciousness of one's mind as a Venn diagram (Figure 12) that divides the representations into three groups: 1) verbalization and communication of emotional experience, 2) conscious representation and regulation and 3) unconscious reflection and regulation. These three components overlap only partly, and that area is the zone of valid self-report measurement. Frith (2007) claims that there is a biological basis in the brain for separate representations. Therefore, it is never possible to be able to exactly describe one's experiences.

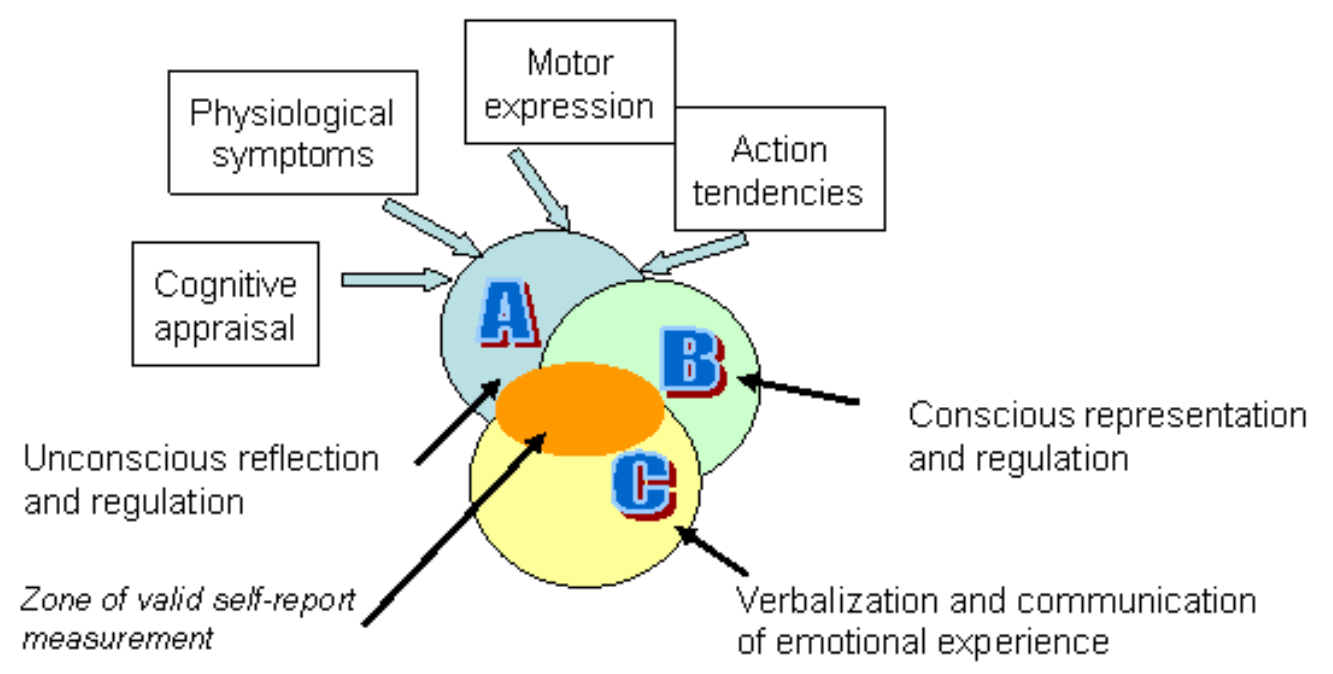

Venn diagram of three hypothetical types of central representation of component processes

Figure 12: Venn diagram of three hypothetical types of central representation of component processes (Scherer 2004) 
Moreover, the memory soon starts modifying experiences. In a study by Hamilton \& Fagott in 1988 university students were asked to remember stressful events in recent past and to rate them and report their coping strategies (D'Andrade 1995). Men and women recalled different events stressful, conforming to gender stereotypes. A second sample was asked to keep a journal of conceived stress during eight weeks. Here no difference surfaced between men and women. Another study shows that teachers are not protected against modified memories, either. Lakkala et al. (2007) report that teachers have a tendency to optimistic self-reporting when they are interviewed about using progressive inquiry in their classrooms. Actual observations reveal a more traditional classroom practice than interviews.

Learning logs appear to be the most useful mode of self-reporting, in particular when students write them immediately after lessons. Their recollections are vivid and reflect actual feelings and thoughts in the classroom, and the depiction of understanding and learning seems very realistic. Learning logs open a small window into the student thinking, being also instrumental in the development of instruction.

In sum, several limitations affect the interpretation of data. However, the various methods used in this research have different limitations, and when used together, they could mutually resolve problems of other methods. Therefore, the multimethod approach naturally seems strongest for this research effort. 


\section{$5 \quad$ Empirical research and results}

\subsection{Background data}

\subsubsection{Study records}

It is apparent from EVTEK study records that international students have different problems in passing courses and completing their degrees than home students. Until recently, however, graduation rates have been on the same level in the Finnish and English information technology programmes. The graduation rate in the English programme dropped from 64\% in 2005 to $30 \%$ in 2007. This trend is a consequence of the larger difference in international student backgrounds and increasing diversity of students. A need to analyze student performance and its hindrances has become more acute than ever. Previously, the problems that had been recognized when teaching international groups were twofold: First, differences in background studies in science (how much mathematics, physics, etc. students master), and second, deficient English skills. The language difficulty admittedly concerns both students and staff. However, these factors explain the trend only partially.

\begin{tabular}{|l|l|l|l|}
\hline Course & \multicolumn{2}{|l|}{ Passing rate } & \\
\hline & $\begin{array}{l}\text { National group } \\
\text { TP04 (Finnish IT) } \\
\text { n=73 }\end{array}$ & $\begin{array}{l}\text { International } \\
\text { group CAP03 (IT) } \\
\text { n=18 }\end{array}$ & $\begin{array}{l}\text { International } \\
\text { group CAP04 (IT) } \\
\text { n=26 }\end{array}$ \\
\hline Year & $2004-5$ & $2003-4$ & $2004-5$ \\
\hline $\begin{array}{l}\text { Application } \\
\text { development }\end{array}$ & $92 \%$ & $89 \%$ & $96 \%$ \\
\hline Programming in C & $47 \%$ & $11 \%$ & $27 \%$ \\
\hline Unix & $82 \%$ & $50 \%$ & $35 \%$ \\
\hline Digital circuits & $100 \%$ & $78 \%$ & $38 \%$ \\
\hline Integral calculation & $49 \%$ & $61 \%$ & $73 \%$ \\
\hline
\end{tabular}

Table 7: Course results for national and international students: passing rates

Study records of a couple of years were collected and analyzed in order to reveal most problematic areas. Records indicate that there are particular problems in learning computer science, programming, electronics, and other professional engineering subjects. Results of equivalent courses for the first-year international and home student groups in information technology were compared for the study years 2004-5 and 2003-4 (table 7). In group codes, CAP refers to Information technology in English and 04 is the starting year, and TP is a Finnish group. The results show that in mathematics, both student groups performed similarly. International students often have better mathematical skills from highschool than home students, which is known from the entrance examinations. Nevertheless, international student groups performed less well in courses that require laboratory practice 
(programming, Unix, digital circuits, physics). The differences remain constant over the years as a more recent comparison shows, in table 8 .

\begin{tabular}{|c|c|c|c|c|}
\hline Group & $\begin{array}{l}\text { CAP05 } \\
\text { (English } \\
\text { IT) }\end{array}$ & $\begin{array}{l}\text { CAP06 } \\
\text { (English } \\
\text { IT) }\end{array}$ & $\begin{array}{l}\text { TP05 } \\
\text { (Finnish } \\
\text { IT) }\end{array}$ & $\begin{array}{l}\text { TP06 } \\
\text { (Finnish } \\
\text { IT) }\end{array}$ \\
\hline Amount of students & 32 & 47 & 51 & 52 \\
\hline Introduction to Computing & $78 \%$ & $89 \%$ & $96 \%$ & $90 \%$ \\
\hline Application Development & $69 \%$ & $60 \%$ & $86 \%$ & NA \\
\hline Programming in $\mathrm{C}$ & $56 \%$ & $40 \%$ & $51 \%$ & $35 \%$ \\
\hline Unix & $69 \%$ & $51 \%$ & $94 \%$ & $83 \%$ \\
\hline Digital technology & $69 \%$ & $40 \%$ & $86 \%$ & $81 \%$ \\
\hline Physics & $56 \%$ & $45 \%$ & $69 \%$ & $54 \%$ \\
\hline Basic mathematics $(9 \mathrm{cr})$ & $88 \%$ & $83 \%$ & NA & NA \\
\hline Mathematics A (5cr) & NA & NA & $75 \%$ & $81 \%$ \\
\hline Mathematics B (5cr) & NA & NA & $57 \%$ & $62 \%$ \\
\hline Laplace \& integral calc. & $66 \%$ & $62 \%$ & $75 \%$ & $35 \%$ \\
\hline
\end{tabular}

Table 8: Completion of courses during one or two years of study in 2005-07

Nearly all students pass Introduction to computing, which teaches basic computer skills. There is variation in the results of programming courses which is due to factors like changing teachers. The teacher in Unix (Linux) is the same person for all groups, thus the difference between results in international and home groups has no external variables. Physics and digital technology require regular attendance in laboratory measurements, which is one of the reasons that international students fail more often than home students. Because these courses build the foundation for further studies, international students begin to lack behind in professional subjects already in the first study year.

\subsubsection{Self-conception and study motivation}

Part of the young Western population uses internet for social contacts and networking. Additionally, many immigrant studies report that expatriates often form communities that cross national borders (Alitolppa-Niitamo 2004). For example, Somali refugees who are scattered in many European countries stay in touch with each other through regular telephone and email contacts. Young people are known to spend hours daily on the internet sending messages, chatting, watching videos, listening to music, participating in discussions, browsing, taking tests, appearing in online photo galleries, and so on. Among the international student population at EVTEK there is a handful of 'Linux nerds' who maintain Websites and do programming in their spare time. In contrast, most of the students were just learning to take advantage of modern technologies like digital cameras and MP3 players during the period of this research. 
To understand international student backgrounds better, I attempted to figure out whether they live in a virtual world of global communications like their Western counterparts. The allegiances and interests of students were observed from the home pages that they created during the first study semester in 2000-05 (Holvikivi 2002). A significant proportion of the pages concentrated on presenting student home countries and backgrounds, displaying a strong national identity. Surprisingly, there were no traces of being part of transnational communities on-line. Facebook was nearly unknown still in 2007. However, also our students had mobile phones, which they also used intensively. On the other hand, not all of the networking part of migrant life was displayed on the home pages, such as frequent email and phone over the internet uses.

The attachment to home culture can also be detected in the survey reported in section 5.3 in the answers to the question "Who are the people you spend most of your time with inside school?" 12 students of 26 chose the option "Nationals of your country" but 16 also said that they spend time with "classmates of other nationalities". Half of the students spent time mainly with their home country nationals also outside school. Only four students reported that they interact with 'virtual' Internet friends whom they have not met in person. Unfortunately, international and home students do not mix well in Finnish universities, and foreign students often complain that they have few contacts with Finnish students (Kinnunen 2003).

Motivations for study were asked in the second survey. The respondents were 62 students from groups of the 2004 and 2005 intake. $68 \%$ of respondents gave interest in information technology as their main motivation, and additionally, 30\% aspired for an engineering degree (multiple selections were possible). $15 \%$ were indifferent to the choice, and $20 \%$ particularly wanted to study in Finland, and some mentioned free education. In fact, a couple of students from outside the European Union said that they would have preferred business or nursing studies, but apparently EVTEK was the easiest opportunity to get into Finland. However, study motivation seemed high in both groups.

\subsection{Surveys on values and thinking patterns}

\subsubsection{Survey design}

The first survey questionnaire was designed to broadly cover scientific thinking, world-view and cognitive style. It consisted of a four-page questionnaire with approximately one hundred questions (Appendix 1). The first page contained simple logical, mathematical, physical and technical reasoning tasks. The second page included a list of statements that were answered on a five-point scale from 'strongly disagree' to 'yes, strongly agree'. Some of the statements contained value assessments, attitudes towards life and work, thinking patterns, understanding of natural science, and beliefs in paranormal phenomena. 
The third page presented cases that were intended to measure technical inclination and a tendency towards an 'engineering' approach to technical problems. The questions were of type:

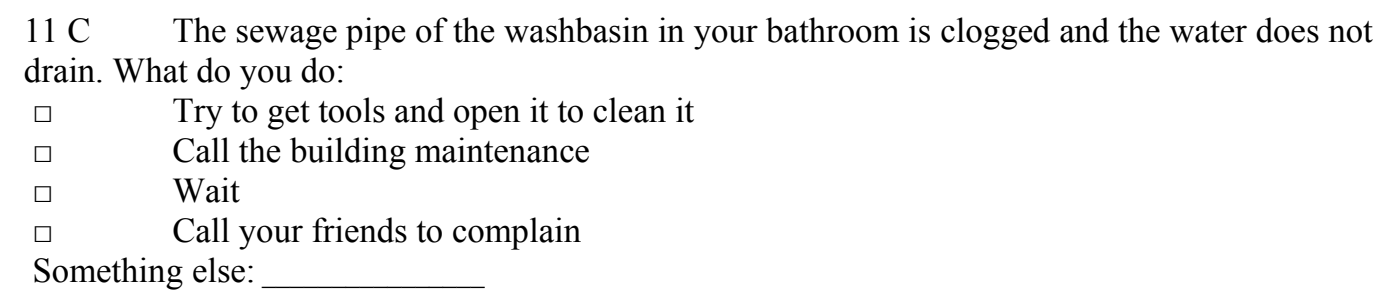

The survey was conducted in March /April 2005 to five different groups: three first-year student groups and two faculty groups. The respondents were as follows:

- CAP04S, Information technology (English) students, 24

- LAP04S, Industrial management (Finnish) students, 10

- TP04S, Information technology (Finnish) students, 77

- teachers and laboratory staff in IT (15) and media technology (11), 26

In the following analysis, Finnish groups are treated separately for the analytical tasks and considered together in the value section. Staff is considered as one unit unless stated otherwise.

The questionnaire was given to students in the classroom, where they were given as much time as needed to fill it in. The setting was informal, and conversation or asking for clarifications was allowed. However, students mostly kept quiet and concentrated on answering, thus the answers are individual responses and not a result of team decision-making.

The results were surprisingly varied in the sections that covered analytical thinking (table 9), whereas values and attitudes were more uniform. As somewhat expected, the students in industrial management performed less well in science and technical questions compared to other groups. However, their logical reasoning ability in solving syllogisms surpassed all other groups, which could have partly been due to the fact that half of them were female ('verbal' tasks). The results of analytical tasks are presented in subsection 5.2.2. Next subsection, 5.2.3, discusses values and attitudes. The results of the learning styles test were most unexpected, and they are examined in the following subsection. The analysis concludes with a brief discussion on use of surveys in measuring attitudes. 


\subsubsection{Logical thinking, mathematics and physics}

Analytical thinking was tested through logical syllogisms, a calculation task, and some questions including magnitudes and physical phenomena.

\begin{tabular}{|c|c|c|c|c|c|c|c|c|}
\hline \multirow{3}{*}{$\begin{array}{l}\begin{array}{l}\text { Results of } \\
\text { questionnaire } 1\end{array} \\
\text { Group } \\
\begin{array}{l}\text { Number of } \\
\text { respondents }\end{array}\end{array}$} & \multirow{2}{*}{\multicolumn{2}{|c|}{$\begin{array}{l}\text { Analytical } \\
\text { thinking }\end{array}$}} & \multicolumn{6}{|c|}{ March/April 2005} \\
\hline & & & \multicolumn{2}{|c|}{$\begin{array}{l}\text { CAP04S } \\
\text { (English IT) }\end{array}$} & \multicolumn{2}{|c|}{\begin{tabular}{|l|} 
LAP04S \\
(Finnish \\
IM)
\end{tabular}} & \multicolumn{2}{|c|}{$\begin{array}{l}\text { TP04S (Finnish } \\
\text { IT) }\end{array}$} \\
\hline & 26 & $\%$ & 24 & $\%$ & 10 & $\%$ & 77 & $\%$ \\
\hline \multicolumn{9}{|l|}{ Question } \\
\hline $\begin{array}{l}\text { Q1 Logical } \\
\text { statements: } 4 \text { correct }\end{array}$ & 6 & $23 \%$ & 5 & $21 \%$ & 2 & $20 \%$ & 24 & $31 \%$ \\
\hline 3 correct & 12 & $46 \%$ & 5 & $21 \%$ & 6 & $60 \%$ & 27 & $35 \%$ \\
\hline 2 correct & 5 & $19 \%$ & 6 & $25 \%$ & 1 & $10 \%$ & 11 & $14 \%$ \\
\hline $0-1$ correct & 3 & $12 \%$ & 8 & $33 \%$ & 1 & $10 \%$ & 16 & $21 \%$ \\
\hline $\begin{array}{l}\text { Q5 PC capacity: right } \\
\text { kind of figures }\end{array}$ & 19 & $73 \%$ & 15 & $63 \%$ & 4 & $40 \%$ & 53 & $69 \%$ \\
\hline $\begin{array}{l}\text { Q7 Number system } \\
\text { calculation right }\end{array}$ & 14 & $54 \%$ & 3 & $13 \%$ & 1 & $10 \%$ & 37 & $48 \%$ \\
\hline $\begin{array}{l}\text { Q9 Absolute zero } \\
\text { known }\end{array}$ & 10 & $38 \%$ & 9 & $38 \%$ & 2 & $20 \%$ & 26 & $34 \%$ \\
\hline
\end{tabular}

Table 9: Results of analytical thinking tasks

\section{Logical syllogisms}

The first four questions were logical statements taken from a study by Roy D'Andrade (1995). He compared responses to different kinds of syllogisms in American undergraduate students. The working hypothesis in the present survey was that the results would be similar or even better because all the respondents study science and engineering. Another hypothesis was that faculty would perform better than students. The logical questions were included as merely a check of overall validity, and no significant differences between student groups were expected. All groups performed worse in all syllogisms than the American student group in the above mentioned study (ibid.). The surprisingly high overall failure rate prompted closer analysis that has been presented more fully in my paper (Holvikivi 2007c).

In formal logic, a syllogism is an inference in which one proposition (the conclusion) follows of necessity from two others (known as premises). Three of the four statements presented in this study require different types of reasoning, and three cases have realistic content and one arbitrary content. 
Example question:

1B GIVEN: If it is raining then the roof is wet.

SUPPOSE: The roof is wet.

THEN:

(a) It must be the case that it is raining.

(b) Maybe it is raining and maybe it isn't.

(c) It must be the case that it is not raining.

This is an affirmation of the consequent problem with realistic content. Realistic refers to the fact that raining and wet roof can be seen naturally dependent (D'Andrade 1995).

In solving logical syllogisms, all other groups had around $70 \%$ success rate (at least three correct) except the group of international students, where only $42 \%$ succeeded (Table 9). Because of the small group size of international students (24), the test was later repeated for another group of first-year students (CAP06S) in 2007 with similar results: of 45 respondents, 17 got three or four correct (38\%). Therefore, the difference seems significant. Mathematical logic and philosophical logic follow exactly the same principles, thus students who study Boolean algebra (instead of verbal reasoning) should see the connection and use similar mental procedures. In the follow-up study in 2007, students were given Boolean AND and OR operations to solve, as well. Even though the rules were also given, $30 \%$ got the operations wrong.

Furthermore, the language effect was considered, because most international students are second language speakers. Did the respondents understand the statements correctly? Finnish students answered questions in Finnish, and international students in English. Part of the teachers answered the questions in English and part in Finnish. Their results are compared in table 10.

\begin{tabular}{|r|l|r|}
\hline Teachers & $\begin{array}{l}\text { English } \\
\text { N=15 }\end{array}$ & Finnish N=11 \\
\hline Question & Correct & Correct \\
\hline A & $12(80 \%)$ & $9(82 \%)$ \\
\hline B & $9(60 \%)$ & $8(73 \%)$ \\
\hline C & $12(80 \%)$ & $6(55 \%)$ \\
\hline D & $7(47 \%)$ & $8(73 \%)$ \\
\hline
\end{tabular}

Table 10: Number of correct responses by faculty, by the language of the questions.

In the faculty group, the D "modus tollens" statement yielded different results depending on the language; the statement in Finnish gave more correct answers than the English version. On the other hand, the statement C was better interpreted in English. This pattern agrees with D'Andrade's (1995) conclusion that the formulation of the question has a strong impact on the result in this particular type of reasoning task. The statements in Finnish were direct translations from English, but because Finnish is structurally very different from English, the translation could change the difficulty. Additionally, 
according to other research in think-aloud studies, problem solving seems closely connected to representation: even minor differences in the wording of a problem can lead problem-solvers to very different types of representations of that problem (Dunbar 1998). A more general conclusion is implied: cross-cultural comparisons of intelligence testing are precarious because of uncontrolled language variables influencing the outcome. However, the group sizes here are too small for any conclusive evidence.

Analysis of the survey disclosed that engineering students surprisingly often applied pragmatic, everyday reasoning when given syllogisms to solve. They chose the option that sounded reasonable disregarding logical rules (Holvikivi 2007c). A preference for pragmatic reasoning raises some concern over their ability to make good design decisions in their working lives. Though strict logical requirements are not necessary in everyday reasoning, scientific enquiry and professional decisionmaking in engineering and management require close adherence to logical rules.

Rips (1998) even proposes that to explain inferences solely on cognitive grounds is not viable. We cannot explain reasoning via prior cases, empirical probabilities, learning, evolution, and other methods that rely on past experience. Rips suspects that "what is missing in current theories of reasoning is a proper account of the role played by cognitive architecture, cultural practices, natural language, neural substrates, or world causal structure" (ibid.). In cross-cultural studies, North Americans have been found to base their decisions more on isolated facts, whereas East Asians place emphasis on background and contextual information (Nisbett \& Masuda 2006). The rational Chinese mind refuses to separate form from content.

\section{Transfer effect of arithmetic knowledge}

The calculation task in Question 7 (Table 9) contained a number system conversion. All IT students had studied binary and hexadecimal numbers just before the test, therefore they were assumed to be familiar with the task. The question was formulated a bit differently from standard math test in order to test the ability to apply arithmetic skills in a new setting.

Q7 There is a tribe called Paiela in Papua New Guinea that has a 14-based counting system (instead of decimal or binary). In case of a marriage contract, a Paiela groom has to give $20_{14}$ pigs (in the 14-based system) to the bride's parents. How many pigs does that make in the decimal system?

Again, the differences between groups are striking: The international group had similar results with the industrial management students who had no binary math in their curriculum, and much worse than the corresponding Finnish group. Normally, the international students pass first-year mathematics courses at a similar or slightly better rate than the Finnish group, as discussed in section 4.2 about study records. However, in this task, they did not achieve the same level. All these results support the assumption that the transfer of knowledge and skills is deficient from theoretical instruction to practical applications. The knowledge that has been absorbed remains in isolated units without integration to other areas of knowledge. Whether it is caused by a confused state of mind regarding 
studies in our school or whether it is a consequence of previous modes of education, is not revealed by this research. Another study that reported unsatisfactory reasoning ability in engineering students in Palermo attributed the bad performance to the Italian high school system, which focuses on humanistic knowledge (Capizzo et al. 2006).

When the results of questions 1 and 7 were discussed in the classroom, international students showed surprise of their poor performance, because they thought they had understood the tasks well and mastered logical operations. On the other hand, Finnish students complained about their poor calculation skills and insisted that they need a calculator for simple math. The problem in Finland is caused by the changes in the primary and high school curricula that reduced the number of courses in mathematics in 1980s and 1990s, causing a deterioration of basic math skills in the student population. The embodied nature of mathematics skills is not recognized, and repetitive calculation practice such as rehearsing the multiplication table or drilling calculations has been replaced by regular use of calculators. Moreover, the connection of the calculation performance to problem solving is often lost, which again worsens mathematical understanding (Hannula 2004).

Longitudinal data on calculation performance is available from course examinations. A simple arithmetic task that is directly connected to the subject of studies is included in the Introduction to computing course test. The task requires multiplication and division to calculate file size and transfer speed over network. The same calculation with varied figures has been given to all groups every year.

Examination question and answers:

You have a simple Notepad text file of 600 rows (ISO Latin 1 code, 8-bit), 50 characters on each row. Show your calculation on each step.

a) How many bits is one row of text? 400

b) How large is the file in $\mathrm{KB} ? 50 * 600=30000$ is $30 \mathrm{~KB}$

c) Approximately how many files of that size fit on a normal diskette? 1.44 MB/ $30 \mathrm{~KB}--->48$

d) I need to update Netscape to version 7. The program to be downloaded is about 25 MB. My ADSL connection achieves a speed of $300 \mathrm{kbps}$ for this transfer. How long does it take to download the update from the Netscape site? Give your answer in full minutes. $25000 * 8$ / 300 gives 667 seconds, about 11 mins

The numbers of correct answers vary from year to year, as seen in table 11. The media engineering students (DAP) normally show their 'artistic streak' in being bad in math and physics. The number of correct answers in Information technology (CAP) used to exceed 60\% until 2003, but the new kind of nationality mix starting from 2004 has changed the situation, and typical result in recent years has been $35-45 \%$ correct. 


\begin{tabular}{|l|r|l|r|l|r|l|l|}
\hline Group & $\begin{array}{r}\text { Correct } \\
\text { answers }\end{array}$ & Group & $\begin{array}{r}\text { Correct } \\
\text { answers }\end{array}$ & Group & $\begin{array}{r}\text { Correct } \\
\text { answers }\end{array}$ & Group & $\begin{array}{r}\text { Correct } \\
\text { answers }\end{array}$ \\
\hline CAP02S & $62 \%$ & CAP03S & $63 \%$ & CAP04 & $43 \%$ & CAP07S & $35 \%$ \\
\hline & & DAP03S & $40 \%$ & DAP04 & $10 \%$ & & \\
\hline & & LAP03S & $9 \%$ & LAP04 & $40 \%$ & & \\
\hline
\end{tabular}

Table 11: Examination results of file transfer calculation in different years

The failure in calculation indicates poor numeracy skills, and answers with the wrong magnitude indicate a weak number sense, as well. An answer with absolutely senseless numbers (like one millionth of a second) raises the question as to whether any reflection has taken place at all, or is the performance purely mechanistic. Similar failure to use analytical thinking is indicated in other test answers as well, pointing towards a mechanical approach to learning. Interviews with students would indicate that it is merely an adopted attitude than a persistent learning style. However, students need to become aware of the problems of their attitude in order to adapt an engineering way of working.

\section{Physics}

Jupiter is so far from the sun that the temperature can drop down to $-400^{\circ} \mathrm{C}$, true or false?

The question 9 about absolute zero (table 9) was aimed at measuring basic physics knowledge. Its positioning amongst very different types of questions apparently confused many respondents, and the question probably measured more quick wit and concentration than knowledge. Another question about physics (question 2, table 8), or perhaps about everyday world, asked explanation of airplane weight loss.

2 On a London - Miami flight the pilot announces that initially the plane will have a cruising altitude of 10000 feet but it will climb higher when it becomes lighter. Explain.

Industrial management students all except one $(90 \%)$ said that the plane climbs higher because it becomes lighter as it uses up fuel. In the CAP04 group, only $30 \%$ gave this explanation. Others suggested gravity, clouds, friction, flying ability of the pilot, or "when upward force is supported by force underneath".

\subsubsection{Values and attitudes}

About twenty of the survey questions concerned attitudes towards natural and supernatural phenomena and beliefs in predestination. They were designed to discern to what extent respondents confused scientific and magical beliefs, and also contained a value component analogous to, for example, the international World Values Surveys by social scientist (http://www.worldvaluessurvey.org/). The questionnaire has no predecessor, therefore it was originally experimental, attempting to probe how much information a survey could yield in addition to observations and study statistics. Value statements were collected from various sources, using anthropological knowledge about cultural differences. Several questions in the survey acted as checks, probing similar beliefs in a less obvious manner. 
The hypothesis in the survey was that international students would express more magical beliefs and traditional values than the Finnish student population. However, the analysis of five-scale value statements supports this hypothesis only weakly. In fact, a principal component analysis (PCA) of responses to value statements gave two components that differentiated international groups from the Finnish groups, which were "seriousness in work" and "carefree" attitude. The response patterns in direct questions were more or less similar in all groups, only slight differences could be detected in orientation to a traditional worldview and magical thinking in the international group.

Technology students expressed in this survey weaker belief in magical and paranormal phenomena than the general population: one-third of the Finnish population believes in some kind of telepathy (Aarnio 2007), whereas only one fifth of both the Finnish and international students expressed a belief that spirits of dead people can communicate with the living. However, a larger share of respondents believes that "You can receive a warning about an approaching danger in a dream", 39\% of the international students and $27 \%$ of the Finnish students. Magical beliefs were less common, though more popular among the international student group: $23 \%$ carry amulets (vs. $7 \%$ of Finnish) and 17\% consult horoscopes (6\% of Finnish). Perhaps somewhat surprisingly, $34 \%$ of international students and $18 \%$ of Finnish students agreed with "Some people can make others ill by putting a curse on them." Belief in curses and witchcraft is common in Africa, but less common in Finland. Nevertheless, the prevalence of paranormal beliefs is low compared to North American studies, where three fourths of people subscribe to at least one paranormal belief.

Responses to following questions which ask about magical beliefs correlated positively.

I always carry an amulet to bring good luck

Some people can make others ill by putting a curse on them

You can receive warning about an approaching danger in a dream.

It is crucial to consult a horoscope before making an important decision about one's life.

Spirits of dead people can send messages to the living through dreams.

The average of combined assessments (1-5 scale) to these five questions was 9,6 for international students, and 7,7 for Finnish students. Both groups express suspicion towards magical beliefs, but Finnish students even more.

Also a group of five questions that measured traditional worldview got higher support from the international group with an average 11.4 compared with 8.4 for Finnish students. Again, both groups are mainly against these statements:

Spirits of dead people can send messages to the living through dreams.

"You can see clearly only with your heart."

"It is a good thing to speak the truth; but it is a better thing to know the truth and to talk about date stones."

"You can only feel complete near the place where you were born." 
However, more differences arouse in free format responses, where it was less obvious what the questions were about. One question about natural phenomena gave a larger variety of answers from the international group.

10 There was a powerful earthquake on Dec $26^{\text {th }} 2004$ that caused a devastating tsunami. 35 minutes before the earthquake was registered by seismic sensors, the aboriginal Onge people on the little Andaman island retreated from their villages to the hills in the center of the island, and they all survived. This is a fact. How would you explain it?

About two thirds of Finnish students explained this incident by traditional knowledge of nature or following animals; explanations that were also given by the journalist who reported this story (Jiwa 2005). The rest declined to comment. One third of international students also gave similar reasons, "they probably followed the animals", or "science is not all about learning. You may be scientific if you absorb the world." 20\% suggested God's interference. Many international students, especially from Africa, are practicing Christians. Several did not answer, though.

Certain differences in intellectual activities and interests could be discerned in the survey. International students claimed to memorize telephone numbers (64\%) better than the Finnish students (49\%), and stories and texts by heart $(73 \%$ vs. $47 \%)$. This is in accordance with the assumed educational background differences. No difference in spatial orientation was expressed, as in both groups, $90 \%$ of respondents preferred maps to verbal instructions. Playing analytical games (chess, Monopoly) was more common among Finnish students (71\%) than international students (52\%), and also preferences for word games were higher among the Finnish (64\% vs. 58\%). On the other hand, international students were better oriented in time (26\% vs. $15 \%)$, and more interested in nature (54\% vs. $41 \%$ "I enjoy learning the names of living things in our environment, such as birds and trees") than Finnish students.

\section{Student views on work}

International student attitudes towards studies and work were generally more serious than in the Finnish groups according to their responses to the questionnaires. The finding is not unexpected, because immigrants make a huge financial investment in their studies compared to Finnish students. Additionally, Finnish students have more choices, and many of them indeed change their study place once or twice. Statement (20) in the value survey "I have future targets in mind regarding my career and education." gave an average 4.2 among the international students compared to 3.6 among home students. This result complies with the claims that Asian and African achievement motivation is socially oriented. A student's intrinsic motivation may in fact contradict with social expectations, but the latter may nonetheless be given preference in her mind. The comparatively high retention rate of international students after the first study year (as compared with home students) proves that many of them opt to continue their studies despite low achievement and obvious lack of interest in technology. On the other hand, one successful Korean student transferred to a school of economics according to his father's wishes, even though he expressed satisfaction with studies at EVTEK. 
A principal component analysis (PCA) of responses to value statements gave two components that differentiated international groups from the Finnish groups. PCA can be used for dimensionality reduction in a data set by retaining those characteristics of the data set that contribute most to its variance, by keeping lower-order principal components and ignoring higher-order ones. The components were as follows:

\section{Component 1: "seriousness in work"}

Statement 20: "I have future targets in my mind regarding my career and education."

Statement 21: "When faced a complex task I usually break it down into manageable parts."

Statement 30: "When given a new task I always brainstorm' ideas."

Statement 31: "I know my own strengths and weaknesses when it comes to planning and meeting targets."

Statement 37: "An important quality for a student is an intense and honest desire for knowledge."

One of these statements (30) was popular among the international group probably because they had just studied brainstorming techniques, therefore its long-term validity is less sure.

\section{Component 2: "carefree attitude"}

Statement 32: "When I am with my family I never think about my work or studies."

Statement 35: "Tomorrow will take care of itself:"

Statement 46: "Never do today what you can put off till tomorrow."

\begin{tabular}{lrrr}
\hline & Average & Variation & N \\
\hline CAP (English) & 5.7 & 2.5 & 22 \\
TP (Finnish) & 8.0 & 2.3 & 74 \\
\hline Total & 7.5 & 2.5 & 96 \\
\hline
\end{tabular}

Table 12: PCA of the value survey

The carefree attitude was more common among Finnish students who have less at stake as they stay in near their families and supporting networks.

\section{A comparison with recent research}

Kia Aarnio's (2007) dissertation on "Paranormal, superstitious, magical, and religious beliefs" is concerned about defining paranormal and finding out the extent of such beliefs in Finnish populations. First of all, they are not uncommon among Finns, either educated or less educated, and other value surveys have shown that about one-third to half of Western populations subscribe to various kinds of magical thinking. 
Aarnio attempts to define paranormal beliefs in a consistent and scientific manner "as category mistakes where the core attributes of psychological, physical, and biological phenomena are confused with each other." The core knowledge concept stems from Elizabeth Spelke's team at Harvard, referring to human innate understanding of the world that already infants or toddlers possess, such as concepts of physical continuity, numbers, the difference between animate and inanimate objects, etc. However, anthropological studies show that these concepts are shared only on most rudimentary level (see also Verran 2001, discussed in section 2.4), therefore their applicability to adult thinking is more limited than Aarnio assumes. For example, even though children have an intuition of what characterizes a living being from an object, the difference between living and non-living is not that clear cross-culturally, concerning many natural objects such as trees, rivers, mountains, or stellar bodies. Most, if not all traditional cultures (including the Karelian and Saami traditions), attribute spiritual features to natural objects.

Aarnio's studies have been conducted among the Finnish population, therefore her theoretical constructions do not pose problems in that context, but their applicability to my data is more limited. Surprisingly, she also makes a strong statement about the human mind, which is more philosophical than psychologically valid: "Already toddlers know that states of mind are mental, immaterial and subjective, while states of the physical world are material and objective." As has been shown in section 2.2, states of mind are inseparable from the body and physical world. Moreover, Aarnio separates religious beliefs from other kinds of magical thinking, which in a cross-cultural context would appear rather problematic. She includes a belief to ghosts, telepathy, or guardian angels into magical beliefs but does not include in this category belief in an immaterial god (religion) or prayer.

Aarnio's studies revealed that the best predictors of paranormal beliefs were intuitive thinking and a humanistic world view, while low analytical thinking was a less important predictor. The finding that paranormal beliefs mainly arise from an intuitive system, instead of a malfunctioning analytical system, explains why the beliefs do not vanish with the increase of education, scientific knowledge, and rational thinking. Therefore, a tendency to paranormal beliefs is not a good predictor for analytical thinking ability, which indicates that the applicability of this part of my survey to explain cognitive behavior is very limited. As Aarnio concluded, thinking does not develop from magical to rational, because they are complementary and not opposing kinds of thinking. Intuitive and analytical thinking are separate systems.

\section{Summary}

The results of the value survey presented in this thesis would direct interpretation to a direction that students display uniform semantic knowledge about science but different worldviews. All technology students know the language of Western materialistic thinking and technological values, but they are not equally able to apply that thinking to real-life cases. 


\subsubsection{Learning styles}

One of the efforts to gain insight into the learning process of our students was a test of learning styles, which was the last page of the survey questionnaire. I had my own experience of being introduced to the LSI (Learning Styles Inventory) by David Kolb during my pedagogical studies at the Jyväskylä teachers' education institute. We were given the test, and I was pleased with my results, because I got what was described as a typical engineer profile. Accordingly, my naïve assumption was that most of my colleagues would also get a similar profile, which then could be compared with students' results. The assumption is based on Kolb's claims that data on the relationship between the learning style of adult respondents and their undergraduate major suggests a long term component in the learning style (Boyatzis \& Kolb 1991).

The Kolb LSI divides people into four categories of learners based on four dimensions of thinking styles (Kolb 1984). The four dimensions are abstract conceptualization, active experimenter, reflexive observer and concrete learner. Respondents are asked to value nine sets of four questions, and based on the self-reported preferences, they are placed on learning dimensions. The resulting categories of learners are converger, diverger, assimilator and accommodator. Engineers are classified as convergers who "... grasp experience through abstract conceptualization and transform their experience through experimentation. The convergers prefer dealing with objects, rather than people, and are often considered unemotional. They are strong in practical application of ideas, can focus on hypo-deductive reasoning on specific problems, and are believed to have narrow interests. Convergers (abstract conceptualization/ active experimenter) are motivated to discover the relevancy or 'how' of a situation."

The majority of teachers (total number of respondents was 20) in this study were predominantly in the assimilator quarter, where scientists are located, despite their industry backgrounds. Four results were in the diverger area and, unpredictably, only one in the converger area. Similarly, the students seemed to have all other learning styles except converger, but the variation among students was large and most students were near the assimilator/ diverger axis. The result was so strikingly different from expectations that the test was obviously not able to reliably discern engineering thinking (Holvikivi 2007b). In the LSI, the amount of questions is too small to pass the criteria of a scientific experiment, and the questions are self-evaluating, not set in any context.

An extensive study by the Learning and Skills Research Centre (Coffield et al. 2004) contains an overview to previous studies on learning styles, covering over 4000 studies on the three most common theories. The report compared the 13 most popular learning styles theories, including Kolb's LSI, assessing their scientific validity in terms of internal consistency, test - retest reliability, construct validity and predictive validity. Only one of the models, that of Allinson and Hayes, met all four criteria, whereas Kolb's and Dunn's models only met one. The report (ibid.) summarizes its findings by 
recommending alternative approaches to improve educational methods, such as developing metacognition and learning skills, and formative assessment.

An unexpected difficulty with the test was the complexity of the question sheet. Even faculty members complained about the difficulty of the questionnaire. The test-taker is instructed to value four statements: "Rank the statements in the order of applicability to you. You write 4 alongside the statement which suits you best and 1 alongside the one that least agrees with how you learn (So: 1, 2, 3 or 4)." An example of the choices:

You tend to work mainly intuitively based on your feeling

You are very results-oriented

You try in the first instance to think logically

You tend to ask yourself questions

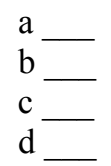

Around $40 \%$ of student answer sheets in the international students group had to be rejected because they gave the same points to several options. In the Finnish group, only 5\% made the same mistake.

In sum, the validity of the learning styles testing in this study turned out to be negligible for several reasons. First, the questionnaire was unintelligible to part of the respondents, who, perhaps justifiably, assessed several statements equally. Secondly, the self-reporting required in the questions is too demanding to be performed in a quick survey.

\subsubsection{Assessment of survey method in measuring values}

The answers to value statements in all groups were overall consistent without large differences between groups. Therefore, young and old respondents obviously took the questionnaire seriously, trying to give sincere or possibly correct answers. All technology students know the semantics of Western materialistic thinking and technological values, and would not admit superstitions. Sometimes the answers were even overzealous: nearly all students strongly disagreed with the statement: "If you see awful things happen you can become blind." Over half believed that "There is a reason for everything, and science will be able to find it."

Amado Padilla (2004) discussed response patterns by ethnic respondents, noting that differences have been detected between cultural groups. For instance, the Hispanic culture promotes a social script of simpatia that mandates politeness and discourages criticism. The tendency to offer socially desirable or acquiescent answers is not limited to Hispanic culture. In this study, the ethnic background of individual respondent is not known; therefore reliable data on cultural groups are not available. We just have to assume that some responses might have been influenced by social scripts.

A gap between theory and book learning and practice seems wide for many international students. For example, many responded that they would try to fix if their CD-drive was broken - which would be dangerous and impossible for them to complete. Despite the unpopularity of magical beliefs in this 
survey, I have seen students of all nationalities reading horoscopes from the Web. Once in an exam a student borrowed my pen, and when submitting his paper he noted: "your pen did not bring me luck!" Therefore, the value survey did not reveal all cross-cultural differences that might exist.

Moreover, the wording of some questions and instructions turned out to cause problems in understanding for a few students. Language difficulties affected performance mainly in inference tasks, applied questions, and particularly in the learning styles section.

\subsection{Survey on study preferences}

The survey on study habits and preferences contained 31 multiple choice and open questions about study attitudes, experiences, and expectations. It was targeted at first-year students, and conducted in the second semester after about five months of studies. Part of the survey questions were similar to another evaluation survey that is conducted for the home student group after first year, in order to be able to compare responses. The comparison survey was online.

The survey was completed on paper in the classroom during compulsory lessons, and all students that were present responded, altogether 62 students. The nationalities and sex distribution of respondents are summarized in table 13. This information is collected from the attendance list, but the questionnaires had no identification information, thus the responses cannot be categorized by nationality. That choice is due to the low number of individuals in many nationalities in order to guarantee anonymity to the respondents.

\begin{tabular}{|l|l|l|l|l|}
\hline Group & $\begin{array}{l}\text { TP05S } \\
\text { (Finnish IT, } \\
\text { comparison group) }\end{array}$ & $\begin{array}{l}\text { DAP05S } \\
\text { (English } \\
\text { media eng.) }\end{array}$ & $\begin{array}{l}\text { CAP05S } \\
\text { (English IT) }\end{array}$ & $\begin{array}{l}\text { CAP04S } \\
\text { (English IT) }\end{array}$ \\
\hline Time & May 06 & March 2006 & Jan 06 & March 05 \\
\hline Finns & 62 & 4 & 0 & 2 \\
\hline East European & 0 & 6 & 1 & 1 \\
\hline 'Western' & 0 & 3 & 0 & 2 \\
\hline African & 0 & 2 & 15 & 13 \\
\hline West/South Asian & 0 & 0 & 2 & 4 \\
\hline East Asian & 0 & 2 & 1 & 4 \\
\hline Women & $<4$ & 7 & 5 & 3 \\
\hline Total & $\mathbf{6 2}$ & $\mathbf{1 7}$ & $\mathbf{1 9}$ & $\mathbf{2 6}$ \\
\hline
\end{tabular}

Table 13: Survey respondents 
Students in the international groups (CAP and DAP) expressed content with the high technological level of EVTEK facilities, good instruction and their international community. The motivation in the beginning of studies is high for two thirds of students but about $25 \%$ are not sure if the choice of studies was right, figures that are very similar to Finnish students responses. One third reports that passing courses was difficult (same percentage in the Finnish group), and about $10 \%$ found the studies easy ( $20 \%$ of Finnish students).

The most conspicuous result from the survey was the deficiency in communication: students reported that they did not understand what was expected of them and that they were not able to convey this to teachers and staff. More than half of the respondents told that they found directions unclear. This difficulty was particularly connected with laboratory assignments, as up to $65 \%$ of the respondents stated that they often failed to understand instructions. On the other hand, only $20 \%$ reported language difficulties. The failure in following procedures was, in fact, well known earlier from classroom observations. This problem will be discussed in depth in section 5.5.

Information technology students made justified complaints about tight schedules and an overload of work because they had 35-40 hours classroom instruction per week. Many also reported having problems in settling in Finland and arranging their lives. Only 2 students reported encountering racism in their studies. The questionnaire did not explicitly ask about part-time jobs, but some students mentioned in open responses that most of them also have jobs and thus their time-management is very difficult. Students are allowed to work legally in part-time jobs, but they may also have illegal jobs and come to school in the morning already tired after a night's work.

As students of Evtek ourselves, working part-time, we have limited amount of time to comprehend most of the materials presented to us in the class. In addition, we lack the motivation to go through endless text that we are required to study in order to obtain the necessary skills and knowledge given by the course.

- Beginning of a project plan by a team of CAP06 students

The attitude to teachers and other staff was generally very positive. The students seemed to receive from teachers the kind of attention that they expected. Good lecturing skills and friendliness were particularly appreciated. About half of the students felt that they had personally changed when beginning their studies, and in most cases that indicated that they felt more mature and confident. In the IT groups students mentioned that certain teachers had influenced them strongly but in the media engineering group, most students felt the influence of their fellow-students as most important. That group turned out to be particularly cohesive, as they organised several voluntary activities together.

\subsubsection{Finnish and international preferences for teaching modes}

The predominant mode of instruction during the first year involves the teacher explaining using the blackboard and chalk or overheads, because the curriculum contains mathematics, physics, languages, and other basic subjects. Media students are more exposed to other instructional modes than IT students, such as teamwork, projects, learning logs and PowerPoint presentations. The typical set of 
assignment types is presented in table 14. The background experience or lack of experience may have some effect on student-expressed preferences.

The favoured method of teaching in all groups is the blackboard method; in the Finnish group it was selected by $83 \%$ of respondents. The figure for media students was lowest, only $50 \%$. Overheads are liked almost as much in all groups, but PowerPoints get only a $40 \%$ support. Discussions in the classroom are selected by $40 \%$ of students, whereas team discussions are liked by one fifth only. Presentations by other students are generally disliked, because they are perceived as unreliable and useless, the Finnish group holding the strongest views against them (only three students liked it).

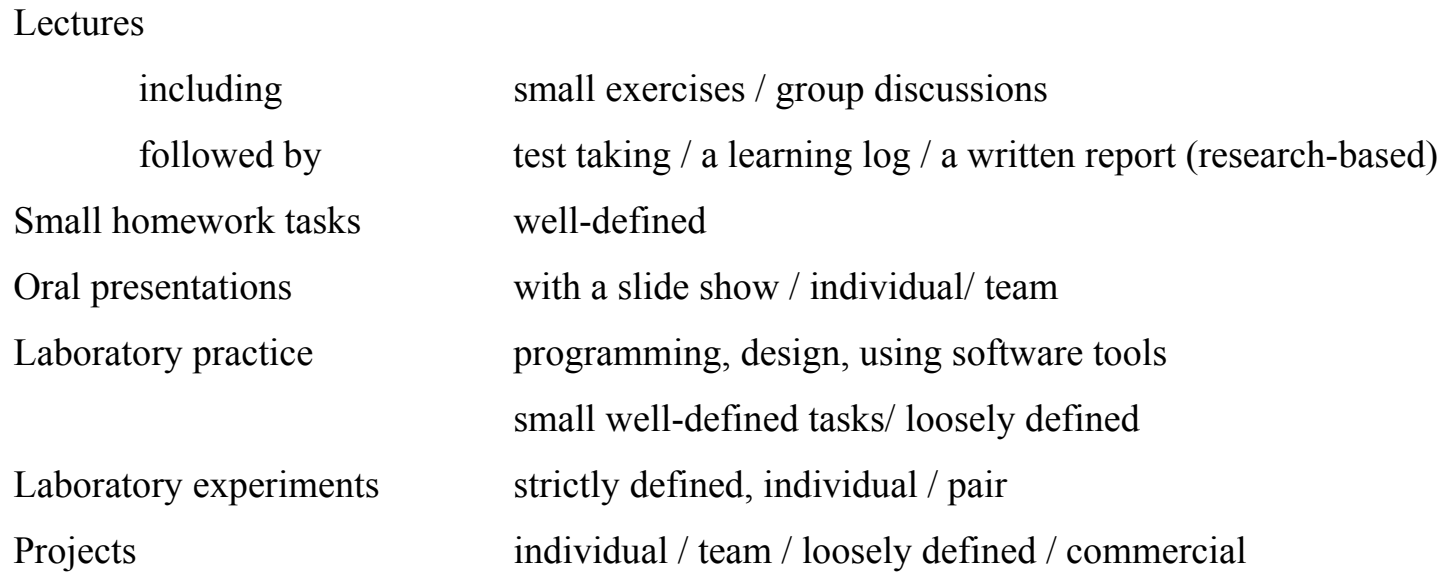

Table 14: Types of typical assignments

The kinds of assignments that students preferred were predominantly small assignments in the classroom. The international students showed higher preference for these (70\%) than Finnish students (54\%). The only group that had experience with projects, namely the media students, showed a $63 \%$ preference for projects, whereas other groups were more suspicious, only $39 \%$ of the Finnish students selecting that option. They had no project during the first year, thus it was not because of bad experience but rather prejudice. Unfortunately the common types of assignments in computer engineering, namely laboratory experiments and programming tasks, did not get much support. In the CAP04S group only $12 \%$ selected laboratory measurements as their preferred method of study. Only $23 \%$ of Finnish students and $35 \%$ of international students liked programming. Studying for examinations was the least popular learning activity, selected by only between 6 and $23 \%$ of respondents in the different groups. However, the kind of study unit that includes lectures and an examination was preferred by most students $(52-72 \%)$, thus the preference was not very clear. The idea of doing research and writing reports or essays individually did not appeal to any groups.

It is a common problem in educational institutions that students depend heavily on Internet sources for information, and have few scruples in copying directly from the Web. Despite this trend, most of our 
students actually preferred traditional classroom instruction, with lectures and laboratory practice. Only one third of students would like to attend virtual courses. Finnish students, too, revealed a similar preference. To the question "If you have major difficulties understanding a study subject and passing a course what do you do about it?" the most common answers were "Read the material repeatedly", "Repeat the exercises over and over again" and "Ask another student for help". Of the total 26 respondents, 14 said that they would go to the library to find books or journals where the subject is explained better, and one half, that is 13 , would "Search the internet to find more information". This could partly be because many first-year students were not yet fluent computer users. Moreover, the intranet tool for material distribution and submitting assignments was not yet fully adopted at the times of the survey.

A little over half of the students expressed interest working in teams, either in doing small tasks or projects. International students showed more interest in teamwork than Finnish IT students, but actually the Finnish industrial engineering students who had most experience in teamwork were most favourable (70\%). In this case, the mode of the questionnaire and the situation where students respond might have had surprisingly strong effect on responses, as a comparison with course feedback forms displays. The standard course evaluation form includes a question about working in teams and team projects. In one course where all assignments were individual students expressed full satisfaction (5 of 5) with teamwork in their responses. Besides, they claimed to have attended in average 40 hours contact lessons, when only 35 were given. A result of this kind probably reflects more a general satisfaction, and less a detailed evaluation of the course.

The results of this survey seem to be in accordance with research from other continents. Lomawaima $(2004,441)$ stresses that it is nearly impossible to categorize students according to ethnic background when it comes to study methods. There is a great variety of learning preferences within each ethnic group, and content of education should be more important than methods. Even though there are certain studies which indicate that Korean American secondary students have a major preference for kinesthetic learning, and negative preference for group learning (Pang et al. 2004), the results have not been replicated in other studies. According to Latu \& Young (2004), teachers teaching classes where Pacific island students are involved must be aware of their cultural background and expectations. Latu \& Young mention the traditional hierarchical structure of their communities and "the ignominious characteristics of their culture" as factors that restrain them from asking questions and actively participating in class discussions. They also propose that the fast changing ICT must be introduced cautiously to ensure that passive Pacific island background students will be able to see the benefits of using such technologies and adapt accordingly. Personally, I partly disagree with this conclusion, having taught ICT in Micronesia to very enthusiastic young government officials (Holvikivi 1991). 
The interpretation of results is difficult, because the preferences that are expressed in this questionnaire do not fully correspond to success in studies in different subjects. Typically, computer nerds are assumed to be solitary workers and avoid social interaction, but a low preference for programming is not consistent with the image of a nerd. Some of the preferences may be affected by the first year study experiences, and the ways of implementing certain kinds of methods, e.g. how well the projects were conducted. On the other hand, aversion to reading and writing tasks is natural for technology students on bachelor level. International students showed perhaps more open attitudes towards varied modes of instruction, despite their actual difficulties in directing and controlling their own learning. The full answer statistics are presented in Appendix 4.

\subsubsection{Student views on engineering profession}

A final question in the survey concerned student conceptions of their future prospects as engineers (table 15). The respondents were from groups CAP04S and CAP05S (English IT), LAP04S (Finnish Industrial management), TP04S (Finnish IT), and DAP05S (English Media engineering). International students have a bit more confidence that they will be good engineers when they graduate, those who were not sure about it were students who were not sure about their choice of study, either.

The reasons that students gave were classified into four categories. Answers that contained a combination of reasons were entered into all categories, thus the sum of percentages exceeds $100 \%$. For example the answer

"Because I study very hard. I understand many practical things inlife from school. In future, with hardworking, I will be very good engineer."

was entered to 'hard work' and 'education'. International students attribute the results of studies more to hard work than personal qualities or motivation compared to the Finnish students, which is consistent with prevalent cultural understandings of intelligence.

\begin{tabular}{|c|c|c|c|c|}
\hline \multicolumn{5}{|c|}{$\begin{array}{l}\text { Responses to "Do you think you will be a good engineer? } \\
\text { Why?" }\end{array}$} \\
\hline \multirow[b]{2}{*}{ Responses \& reasons } & \multicolumn{2}{|c|}{$\begin{array}{l}\text { International } \\
\text { students }\end{array}$} & \multirow{2}{*}{$\begin{array}{r}\begin{array}{l}\text { Finnish } \\
\text { students }\end{array} \\
87\end{array}$} & \\
\hline & 59 & & & \\
\hline Good engineer: yes & 43 & $73 \%$ & 58 & $67 \%$ \\
\hline Hard work & 18 & $31 \%$ & 4 & $5 \%$ \\
\hline Motivation, interest & 16 & $27 \%$ & 26 & $30 \%$ \\
\hline Education and skills & 16 & $27 \%$ & 26 & $30 \%$ \\
\hline Personal qualities & 12 & $20 \%$ & 23 & $26 \%$ \\
\hline
\end{tabular}

Table 15: Student views on engineering 
Many students list technical knowledge, analytical and problem-solving skills as important. However, the most often occurring quality in student responses was creativity or innovation, which was mentioned by seven respondents. Probably other courses that they took at that time had influenced this view. Social skills, organization (or efficiency) and life-long learning were mentioned by three international students respectively. Three students also mentioned patience. Students perceptions of what makes a competent engineer were found to be very much in accordance with the ABET criteria, and with the views in the Finnish industry (see section 3.4).

\subsection{Observations and analysis}

Two puzzling cases of student work were presented earlier as research problems. In both cases, student actions were unexpected in a manner that was difficult to understand in the Finnish context. This section reports observations, primarily from the first-year Introduction to computing and Application development courses - first-year courses in which the students' backgrounds are most influential. However, observations are not limited to these two courses, but also cover my XML and User interfaces courses, student projects and final year theses, as well as observations reported by other teachers from a variety of courses. This section seeks to find models to explain behavioral patterns that occur frequently. Finally, some suggestions are presented how to deal with them.

\subsubsection{Classroom observations in first-year courses}

As a new student in Finland the I am not used to having to work with computers in class rooms, use of projectors in class and PowerPoint presentation. - African student 10.11.2007

One day in December 2004, late in the first semester, a student came grinning to me: "I have my home pages installed now, and you can check all my assignments. I realized that the home pages cannot be PowerPoint files, and now they work." I was stunned: "I told you so a hundred times," was my immediate thought. I had been teaching HTML page creation from the beginning of semester, and explained many times that a home page has to be called index.html. This incident illustrates how limited the influence of a teacher might be in learning; evidently, it is not the simple process of transferring information from the teacher's memory storage to that of the students. Rather, information needs to be processed and adopted by the student before it can be put into practice.

The networked study environment at EVTEK is technologically advanced and rather complex to understand. All incoming students need guidance in learning to work with it fluently. Most teachers, too, have difficulties from time to time. A substantial effort to build an integrated working environment and move to networked based systems was done in 2005, when the school intranet portal, through which students could access course information, general bulletins and announcements, study materials, their own files, the enrollment system and study records, was set up. In addition to the portal system, IT students also need to master working with local workstations in classrooms, LAN and Linux-based services, as well as common applications such as word processing, email, spreadsheets, and graphics. 
"Even though it seems for me that I know how to manage file, since I already missed the lecture class during that lecture hour, it happened for me a big question if I do not know many things on it." - African student December 2006

First-year international students form a heterogeneous group consisting of a variety of skill levels from computer illiterates to Linux nerds. Central concepts of information technology such as server, network, file and software are self-evident to part of the students and completely new to another part. Student ability to work with computers and networks, as well as ability to adapt to the systems, varies depending on previous experience, effort, and capacity. Even though the examples and analysis in this section concern mainly problematic cases, there are, of course, many successful students as well. As a matter of fact, some of the highest marks in Introduction to computing have gone to African and Asian students in 2005 and 2006 despite their low computing skills in the beginning of the semester. The success of these students is explained by the usual factors of student achievement (see section 3.1): self-discipline, rigor, motivation, interest in the study subject, and high level of self-regulation and metacognition.

\section{Particularly difficult concepts in information technology}

In the course of Introduction to computing classes in 2004, I made a list for myself of things that need to be emphasized next time. The list included several basic concepts that were difficult for students to grasp:

- Stress on file naming and file types and extensions. Text file, image file (binary), formatted file (Word)

- local computer, network, remote computer

- navigation in the Windows file system; file paths

- different programs and tools for different operations: Browser for viewing, editor for editing and file transfer utility (from field notes December 2004)

The first problematic concept is a file. People who have not worked with computers, do not know that information is kept in units called files that need to be named, and saved, and that have a certain format which is indicated in the name by a file type extension (.doc). One student was sitting in front of a computer with a Word document and asked me how to send it to his Linux home directory. "Where did you save it?" I asked. He looked perplexed, not understanding what "save" meant. Another student particularly asked what a file is and how it differs from a document. However, because most students are familiar with computer work, these fundamentals are explained rather cursorily, assuming that students master the basic vocabulary. The basics are not easily adopted by all novices, and some students keep on losing their files, saving them in wrong locations, not finding them, and also accidentally deleting files. One student walked into my office to get advice about a problem with his file. When I asked him to show the file, he said that it is on the (local) D:-drive. He had saved it on his home computer! The major difficulty seems to be caused by the complexity of the environment: there are several hard disks and directories available, remote and local computers and a plethora of application software for novice users (table 16). 


\begin{tabular}{ll}
\hline Computer network & PCs in classrooms \\
& $\begin{array}{l}\text { local disk space } \\
\text { removable storage (flash memory) } \\
\text { application software }\end{array}$ \\
& Local area network (LAN), log in \\
& disk space \\
& study information \\
& course materials, assignments \\
& announcements, discussions \\
& remote resources (Linux server) \\
& Web, incl. some course materials
\end{tabular}

Table 16: Use of artifacts in the EVTEK computer environment

Because the differences between file types are difficult to grasp, the instruction emphasizes that information is stored in many formats. Still, students often rename files with the wrong extension because they find it difficult to connect the concept of application software and how it processes data in a particular way. "How does the computer know what kind of file it is?" asked one student. Even abstract concepts might be confusing: After a lecture on Boolean operations (AND, OR, NOT), a student told me that she knew them already, and indeed she could apply the rules. But she could not figure out where they were performed: "is it done on the disk?"

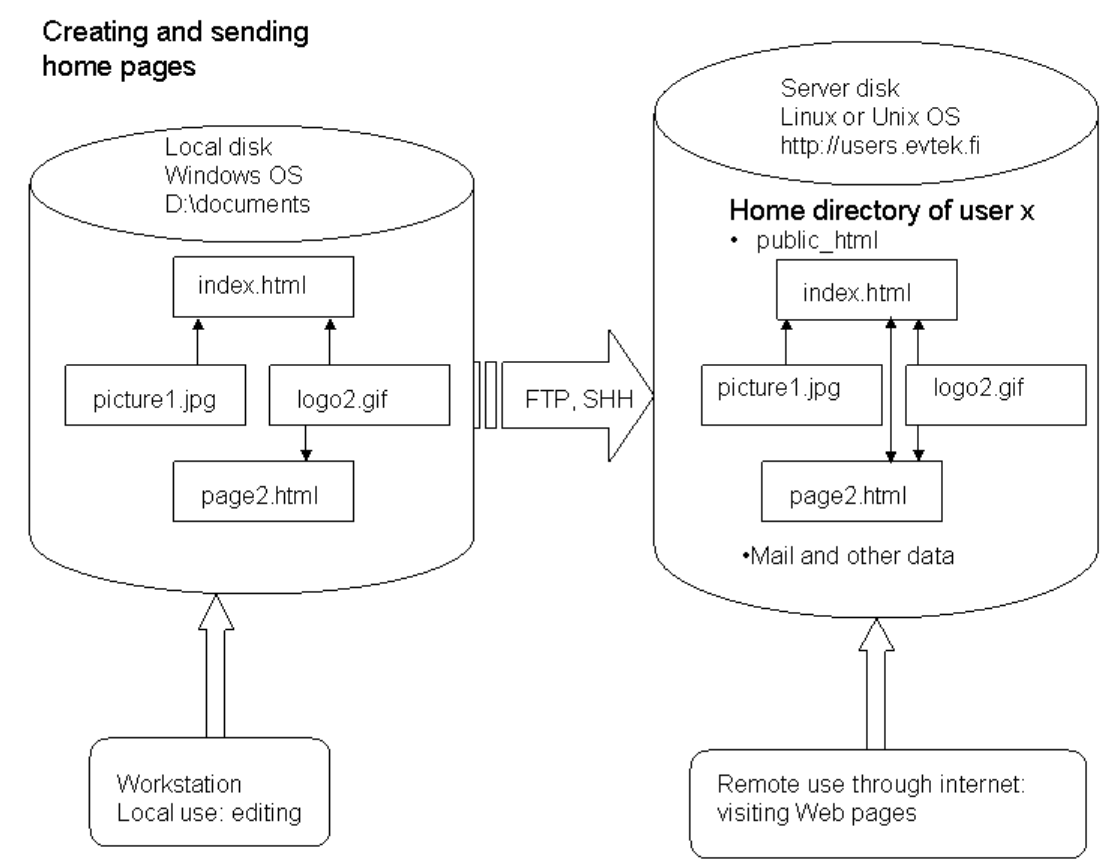

Figure 13: Sending files to server: Linux directories 
One of the first assignments is to create home pages. The assignment is designed to cover main aspects of the environment in an integrated manner, such as the difference between local computer and remote server space, private and shared storage areas, text (HTML) files and images, cross-referencing, and updating. All actions included are simple as such, but to master the incorporated practices is demanding, because it requires an understanding of the entire system, and good working discipline. The procedure that students are supposed to follow is to save a local copy of the file for editing, test the edited file and then send it over and install to the internet server. The process is described in a diagram that shows remote and local disks, and the transmission (figure 13).

However, students often try to shortcut by editing directly on the server: they open a remote connection and double-click the file. File association settings start a browser where editing is not possible. Then the student calls instructor and complains that he does not want to edit in the browser. The instructor tells the correct procedure, perhaps also shows it on the workstation. Next time the student repeats his actions, and sometimes again a third and fourth time. I suggest two explanations for the persistence of the wrong action: 1) no schema of the network environment exists in the mind of the student, because he lacks a foundation; 2) the student is impatient and lacks perseverance and concentration with computer operation because he has not previously learnt appropriate working habits. Both of these barriers are difficult to overcome.

Access control and rights to files in a network are central to application development, but they are difficult even for students who make a serious effort to understand. One student wanted to make everything very clear, and sort out if a 'home page' and a 'Website' were different. She also wondered how sites like the BBC site did not get messed up as people could see the HTML code. The difference between having access to download a file (requesting HTML pages) and having editing access to the server was still conceptually unclear to her. Her problems, as well as other conceptual difficulties are related to forming right schemas of the networked working environment.

\section{Understanding assignments and work habits}

The puzzling case of Jonathan who handed in a comparison of the reliability of a physical device and information content of Wikipedia was presented as one of the research problems in section 4.1.

The first assignment in the Introduction to computing course is to complete a small internet research task and report results in a PowerPoint presentation. The task is to compare Wikipedia to other information sources about a given topic e.g. flash memories. One student handed in a presentation called "Wikipedia vs. Flash" where he compared how reliable information in the on-line encyclopedia Wikipedia is compared to the reliability of flash memories. Later, another student followed the example and handed in more or less of a copy of the treatise.

How is this to be explained? The student Jonathan was a fluent computer user, who had no technical difficulty in completing the work. He was also fluent in English, which was his school language. The presentation that he made followed the given outline, and had the appearance of a completed assignment. I suggest three explanations that all might be applicable to a certain degree in his case: 
1) Motivational and study practices: The student is used to delivering work that has the correct form but the content is of less importance. He is not accustomed to think deeply about what he is doing in school assignments, rather he is a rote learner and mechanical performer.

2) Cognitive/ learning skills: The student has no practice in analytical and independent thinking and comparison.

3) Cognitive: The underlying concepts that are practiced in this exercise are not clear to him. He has an epistemological problem with information value and information sources, as well as an ontological problem in understanding of networks, data and hardware.

The other student who copied this work, in addition to the above, had severe difficulties using computers and understanding our study practices, and in his case it was clearly a question of being completely oblivious to the purpose of the assignment. Both students apparently found the requirements overburdening and dropped out in two years.

Many assignments in my courses are loosely-defined, allowing the student to select the subject and presentation within certain limits. Consequently, there is no exact right answer. This mode of working may, in the beginning, be difficult to understand for students who are accustomed to more controlled tasks. In fact, two exchange students (an Italian and a Chinese) told me that they had never had so much freedom in their course work as here. (See also list of assignment types in table 14)

There are numerous cases that reveal the confused state of mind of recent immigrants. Because of the late arrival of many students in the fall 2005, and their low level of computing skills, I arranged two extra laboratory sessions (5 hours altogether) where I went through the essentials. Part of the students who were invited to this lab did not attend, however, and the whole Ethiopian group just left after halfan hour of the second session, presumably to attend a social function. Nonetheless, some students who opted for not taking extra lessons later complained in their learning logs that they had had too few laboratory sessions.

A couple of the students came to me in October, six weeks after the beginning of semester, to ask how to write a learning $\log$ (a learning diary) when they had not taken any notes during the lectures. I said that I was sorry but would not take any responsibility of their ignorance because I had gone over the procedure of keeping a learning log in almost every lecture. Additionally, all course requirements were published on the course pages. Other students who were present in the lab agreed with me. There had been enough information but those students (all immigrants) either did not understand it or were overloaded by the amount of new information they received in the beginning of studies.

Another incident shows a profound lack of understanding of programming tasks: A student came to ask about his test results. He had not been able to complete a code tracing task (a Javascript code, for which he was asked to tell the result) in the test. When I told him that his answer was not correct, he 
said that he remembered how one student explained the code in the class and the result was like in his answer. His point was interesting because

1) How could he be sure that it was exactly the same code?

2) Why did he insist on remembering it right and did not try to go through the code and show that it works the way he believes?

The student had practiced Javascript coding with different examples, but apparently he saw the solutions as fixed models instead of a continuum of variations in coding details.

\subsubsection{Alphabetical order, student names, and character systems}

In the fall 2004, the lectures in Introduction to computing were the very first classes on Monday morning. After that, students were supposed to divide into two groups, and to take either computing or circuits labs. The division into groups had not been done, thus I took the class list and divided it into two halves in alphabetical order. I told the students that if their last name started with A to $\mathrm{K}$ they were in group $\mathrm{A}$, and from $\mathrm{K}$ to $\mathrm{Z}$ in group $\mathrm{B}$. Many students could not follow this instruction because they did not know in which half their last name was positioned. The problem concerned mainly Chinese and Ethiopian students. One reason is the precedence of their native character system in their minds, and they have not internalized the English alphabet. Another reason is the structure of names: 'last name, first name' sequence is not clear because Chinese write in 'last name first name' - order without a comma, and Ethiopians and Moslems have no last names, instead they use first names of their fathers as additional names. Furthermore, some African and Chinese students also use self-assigned English nicknames, and varied spellings of their names.

A curious incident happened in 2005 in the middle of semester, when a student appeared in the lesson for the second time. I went to ask his name and he was offended that I did not remember it. "I told you my name last time and showed my work." I could not locate the name in the student list, either, and it turned out that he was using a third name, not the ones that were on the list. I was feeling exasperated because we had a large group of recently arrived students from Ethiopia, who all had very unfamiliar sounding and long names, moreover, many of the names looked very similar. The students also looked very much alike to us teachers and staff at that point, as we were not yet accustomed to that nationality. Foreign names are actually such a problem that some faculty members do not even try to remember them because the Finns have no pattern in the brain (schema) for these names. Especially Chinese names such as Wang Xi are very difficult for us, because we do not recognize differences between first names and last names, or female and male names. That somewhat influences student - teacher relationships, especially if the students look alike as well. The students do not yet carry name cards in the institute that would help with identification.

Chinese, African and Middle Eastern names also pose a problem to the Finnish course administration: we use the last name (family name) as principal criterion in, for example, sorting alphabetical lists. 
Students also have ID numbers but many do not learn these long numbers by heart. Moreover, many students change their official names during their studies after they have realized how names are used in Finland.

I had a big name confusion today. In the morning one guy signed up with a team but I could not add his name to Netpro [database], because it was already there, but I could not get it using search. He is now using name Abdela Eskindir, but two years ago he was Taddese Eskendir. And because they have received new student numbers, it is even more difficult. Last week Van Hai came to transfer a course, and it turned out that he is Phan Hai in our system. Then Breket Kashay completed his work but I could not find his name on the list. With the help of other Ethiopians we concluded that he is now Woldemicael Bereket. And my friend Amos joined a group as Moses.

Field notes 24.1.2008

Furthermore, it has become apparent that native character systems influence the student's ability in producing syntactically correct programming code that makes heavy use of punctuation and special characters. For instance, Chinese ideographic characters and Ethiopian (Amharic) syllabic scripts differ from Latin character systems in their punctuation and sentence structure. Some of the students with syllabic or ideographic background are not fully fluent with the alphabet. They have not internalized the $\mathrm{ABC}$-order and consequently, cannot locate information quickly from lists, for example file names in a sorted list. Moreover, students mix up upper and lower case, and make mistakes in punctuation and spacing. Unfamiliarity with the Latin alphabet affects not only reading and writing in English, but it makes coding and debugging a strenuous exercise. Some students simply 'cannot see' when there are errors in code like a missing bracket or semicolon, or a space missing between a command and its parameters. Often the difficulty is very persistent, and it would apparently need some specially targeted drilling to overcome. As speculated in section 2.3 , it could be deeply ingrained in brain circuits.

Whether the writing problem also affects thinking in program design, is an interesting question. Some recent British studies indicate that handwriting skill is connected to student essay writing quality including structure and variety of ideas, presumably because fluent writing lets thoughts flow better and poor handwriting itself hampers a child's ability to express himself (Flynn \& Stainthorp 2006). Additionally, Karppinen (2006) claims, based on research on the Japanese, that writing ideographic characters is an embodied skill that influences thinking fundamentally by affecting the balance of left and right hemispheres of the brain.

\subsubsection{Learning logs}

As mentioned above, students are asked to write learning logs in the Introduction to computing course that starts in the beginning of first semester. The course consists of 14 hours of lectures on computer science and 28 hours of practical assignments with Microsoft Office and internet applications like the HTML language. The instructions for learning logs advise students in the following manner at http://www.evtek.fi/ jaanah/IntroC/learninglog05.htm : 
The learning log is a kind of a diary of your own learning, but confined to the topics of the course and lectures. You need to take notes during the lecture, and for this purpose you need a notebook and a pen (laptop computers are not allowed in these lectures). You are not supposed to copy the teacher's notes, however, but to present a personal viewpoint, assessing your own learning at the same time. The learning log can also include pictures, etc. If you miss a lesson, study the topic on your own from the textbooks or internet, and make observations based on self-study. You need to cover every lecture. The length of the log should be between 2500 and 6000 words.

The learning logs are private, and they are handed in as a Word file to me.

About each lesson, include remarks: What did I expect to learn? What was the main focus of the lecture? What was the essential content? What was new and interesting for me? What did I know beforehand? My own reflections about the subject, Was there any discussion in the classroom? Open questions, something I did not quite understand. How could the presentation of subjects be improved, what could be done to help me learn better? Other observations about computer science studies.

Finnish and international students alike, despite their diverse school backgrounds, often find the assignment slightly confusing, due unfamiliarity with the task. Until now, only one Canadian student admitted being familiar with reflective writing. However, most students understand the objectives of the task and eventually write interesting logs that contain a reasonable amount of reflection on the course subjects and their own learning. The extracts that are presented here are only a tiny fraction of the accounts written in over 120 student journals.

The learning log assignment was new to all students, and especially Chinese students had difficulties in understanding its idea. It seemed to be too far from anything they were used to doing in their studies. Many Chinese speak little English, and do not always understand what is said to them, thus a learning $\log$ was an incomprehensible assignment. Some students resorted into copying text from the internet ending up with nonsensical reports. One girl who twice handed in a document with texts copied from here and there, insisted on trying a third time, and finally she wrote a sensible and analytical learning log. Similarly, other Chinese who grasped the idea, also handed in good logs. Obviously, there was no problem in the kind of personal reflection that was required, but in seeing the objective of the assignment.

Technology students are not necessarily inclined to writing long reports, and some find the task burdening. Hence, they have an option to take an examination instead of writing a log. The excerpts from logs presented here are verbatim, spelling errors included, to avoid any misinterpretation by the researcher. The assessment of this assignment is based more on effort than on grammar or spelling. As a matter of fact, sometimes poor spellers get an inspiration and write long stories with much reflection, showing considerable progress during the semester. Therefore, the benefits of having to write a $\log$ depend much on student commitment and motivation to the task.

In the beginning of my experiments, many learning logs had long passages that were copied from the Web, fairly blindly, even containing references to other parts of the Website, its pictures, and so on. Obviously, the students could not understand that the assignment was to produce personal reports, and 
afterwards, when personal writing was strongly emphasized in instructions, copied parts were considerably shorter. When I gave learning log feedback, all students were shy to look at it, not being accustomed to getting verbal feedback.

Students commented about the assignment mainly favorably in the learning logs:

Jaana introduced one of the projects of the course, which is this learning log I'm writing right now. Seemed kind of daunting at first, not quite what I was expecting. But I'm sure this'll work out just fine. - Finnish student

This is my learning $\log$ I don't know if it is the right one but I did wht I could and thanks to my teacher - Kenyan student

Parts of learning logs are hard to interpret because they contain unexpected statements that seem to be unconnected to the course and assignments. The logs may also reveal absurd assertions that contradict with reality. There are students who completely fail to perceive their own learning habits or process. The following passage was written by a student who often failed to show up in the class:

I am always ready to apply my maximum effort to stretch my hands to catch up every thing I have to.

The facade given in writing may be far from daily practice, which could also be a culturally produced phenomenon, as the importance of appearance varies greatly between cultures. However, sometimes the remarks are so perplexing that the interpretation is beyond imagination. The following excerpt seems to have no connection to the classroom situation, for example there was never a lady in a white dress:

......Here you go the class starts. Know the teacher is talking, An ex-beautiful lady with a white dress, she seem quite confident in what she is teaching. Here voice might be scary for the first time but through time I guessed that, here voice is going to make harmony with my mind because I know many teachers over all looks changes as class progresses.

Normally, the logs that were closest to fiction were written by students, who expressed a strong preference for teacher-led instruction and unfamiliarity with independent working. They seem to be an indication of deep discomfort with our education system and its practices, and possibly also a failure to understand the assignment. The emotional aspect is explored next.

\subsubsection{Emotions in the classroom}

Emotional well-being is a prerequisite for successful learning. Cognitive actions are never separated from the feelings and bodily functions. Many studies show that a positive emotional state improves understanding and memory and facilitates problem-solving (Isen 2004). I have been practicing small friendly gestures - for example, in evening classes when the students were tired, I brought cookies and juice to the class. Small offerings are also a sign of compassion. On the other hand, a less well planned gesture can turn against itself: one student told me how she got chocolates from a teacher before a language test, and then she became so thirsty that she could hardly concentrate on the test. Moreover, even though giving gifts and offering sympathy improve social cohesion, they follow cultural norms that might change their intended meaning, and are therefore difficult in multicultural interaction (Clark 2004). 
When we make decisions we consider the facts and likely outcomes based on personal experience. In fact, we pay much attention to future outcomes, and what kind of emotions they raise. In the case of foreign students, their emotional situation assessment (feeling) is not always compatible with the current situation, because their earlier experiences are from a different environment. If students are used to being scared of teachers, and have an experience of teachers as unsympathetic authorities, they interpret teacher actions from that point of view, and fail to come to ask for help or explain difficulties. The distrust also leads to misunderstanding of teacher actions and statements, which could be interpreted as hostile, especially when given in the terse Finnish communication style.

Students intuitively invoke wrong schemas in some situations based on their earlier experience as the examples below illustrate:

- A girl handed in a learning log assignment that was fully copied from another student in another group. She had only changed her name to it to make it appear her own. This log was written in a very personal style, thus there was no difficulty in recognizing the source. When I called the girl to explain, she explained that she had been sick and was worried about the deadline and handed in a copy just to meet the deadline. However, she had not asked for extension of the deadline, which was mentioned as an option in instructions, nor did she inform me that her log was a temporary copy. Her actions did not make any sense in our environment, but possibly they made sense in her accustomed educational setting where plagiarism may not be strictly sanctioned or where teachers cannot be approached. Or where teachers do not actually read through student work.

- Another girl also handed in a learning log that she had copied, even though she did not even attend lectures. She obviously did not understand the nature of the assignment. Nevertheless, she was punished by not getting the grade and asked to retake the course, and she sent me two apologizing notes that were intended to convey a feeling of deep regret. That did not prevent her from handing in copied assignments in another course later. Two years later, she came to me to ask for a recommendation letter for a foreign university, and asked me to be her thesis supervisor. Plagiarism is discussed more below.

Ability to learn in a given situation is dependent on the emotional and motivational states. Fear is a particularly effective emotion and it can disrupt all chances for learning. International students sometimes describe effusively their worries, especially in the beginning of the studies.

Before came to the first lecture I felt a bit worried that I could follow the lecture but after first I felt very ok and got confidence. - Korean student

I am proud of myself today because I have joined a class that really makes me learn new things. - Kenyan student

It is quiet nice that I am very happy of the selected topics for lecture. -Ethiopian student

Students also remark on the difficulty in learning computer terminology and the endless amount of jargon and abbreviations they have to face. 
I saw some motherboards, then people were busy talking about the motherboard configuration man that was bad for me I did not like it at all. But at least I went ahead and looked at some photos to get the pictures so that I can get used to it. - Kenyan student

In my fifth lecture I was able to learn something on the UNIX structure. I had no idea what this was and even the word UNIX made me hate the lecture at first I had decided that I would shut my mind as this was becoming too much. I was therefore not able to get much from this lecture. - Kenyan student (another)

Failure in a course or an exam prompts feelings of being mistreated by those students who are least accustomed to our ways. They may send emails complaining that 'I tried so hard but still I was not rewarded.' Some students have the feeling that attending a course should be rewarded regardless of their achievements. They may come to the teacher to negotiate about their grades, and to convince the teacher to give them a higher grade, even though the assessment scheme has been published and given to all students in the beginning of the course.

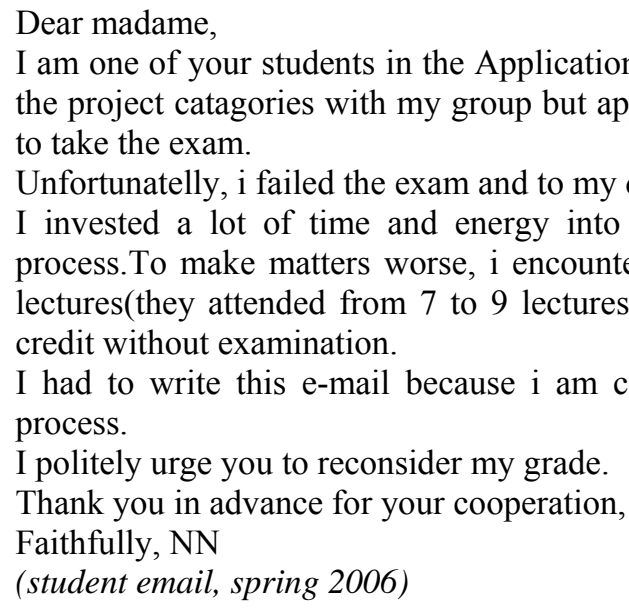

Because students tend to circulate misinformed gossip, they may believe that other students get privileges that are denied to them. Moreover, immigrant students face difficult life situations, many admit to being home sick, and that makes them more suspicious and unhappy. The emotional atmosphere in Finland might differ strongly from students' home society, and therefore increase anxiety. Expressions of emotion are subdued, and especially Finnish young men have been found to have a negative scale of feelings where 'feeling OK' is the best feeling. Hostility is unusually common among Finns (Keltikangas-Järvinen 2000). A Dutch anthropologist (Mesquita) related how she felt that her own emotional display was inadequate when she had moved to the United States (Mesquita \& Markus 2004). She describes the Dutch emotional landscape as close to the Finnish: the Dutch practice is to be articulate, and not to be afraid to speak up for oneself even if this may hurt or dismay other person. In contrast, the American social norm emphasizes promotion and displays of happiness in social interaction. The difference requires considerable adjustment of one's emotional reactions and coping with conflict situations, which often even goes unnoticed but, nevertheless, causes stress.

International students in particular expect emotional maturity and self-control from each other and from themselves. In their group discussions, they easily point out what is deemed to be childish behavior. Because the understanding of maturity and intelligence varies considerably between cultures, 
the shared ideal of maturity is interpreted in different ways. Collectivist cultures emphasize controlled behavior in social relations, whereas individualist cultures expect independence.

Bennett \& Castiglioni (2004) stress that for cultural self-awareness it is necessary to become sensitive to the feeling of appropriateness that accompanies the patterns of behavior in a culture. Immigrant students especially may feel out of place in a new college environment where many practices including attendance requirements, grading, classroom behavior, and strictness of procedures are all unfamiliar to them. They struggle to find that feeling of appropriateness. Reflection on the situation helps in becoming conscious of and sorting out bewildering feelings and enhances self-regulation. Consequently, being aware of feelings towards the new situation and new settings assists in the translation of cognition and attitude into appropriate behavior.

Many student learning logs have references to feelings of comfort, anxiety, frustration, or pride of success. They also comment on the classroom atmosphere and social relations in the group:

The whole educational system, teacher-student connection are very different. The atmosphere of the lecture is very warm and amicable. - Russian student 2004

African students in particular are confronted with racism in Finnish society. Therefore, they occasionally suspect it also in the school. One of the teachers got into a conflict with a group of Ethiopian students who had messed up their project presentation. They had saved the presentation file on an email account from where they could not retrieve it successfully at the time of the presentation. Instead, they had shown an unfinished draft. When the teacher had told them that this was not acceptable, the three boys had walked out in rage. They had come back some days later accusing the teacher of giving them inferior treatment to Finnish students. "We are as smart as Finnish students, we are not worse than they are."

"I think some extra classes have to be prepared to help those who have trouble in their computer related homework and exercise." Ethiopian student

"What I honestly saw from this course and others already given is repetition and underestimation given by the teachers to those students coming from poor countries. It seems like they think we have never been around computers. "Ethiopian student (another)

In private discussions, and sometimes on the on-line discussion forum of EVTEK, African students mention racism of Finnish society, as an entry on 19.12.2007 shows:

Finland has highest quality of life in the world -Reader's Digest

If you're thinking of where to relocate for happier life, your problem is solved! Finland once again takes the top spot in an international survey on the best places to live,

Yes, being born or residing in Finland is like winning the lottery! Although I wonder if things privacy, purchasing power, conscription, immigration, xenophobia and racism are factors in this survey?

so let's talk about what u love in Finland!

Students mentioned racism in the school only twice in the survey about studies, but claims of prejudice from Finnish students have been made in the discussion forum a few times. "No interacting amongst finns and foreign students" was a comment in the survey in 2006. 


\subsubsection{Space and time and group relations in multicultural classrooms}

As the statistics in table 5 (section 4.3) showed, the distribution of nationalities in the international programmes was very different in the first ten years from what it is now: there was a considerable amount of Finns in each group, and Asian students constituted a large share compared to the dominance of Africans in the last three years of the study. Finnish students in the group act as cultural mediators (Karppinen 2006) who know how to study in Finland, and give other students an example of behavior. When the group has only a few Finns or other Europeans, the entire group struggles in finding appropriate ways.

A multicultural classroom is, in many aspects, similar to a multiethnic society: when the ethnic groups are not separated into clearly discernible ghettoes but mix freely, no divisions are formed and people interact peacefully. A certain number of home nationals helps immigrants adapt to the habits of Finnish educational culture and adjust to the society. When the multicultural classroom has large numbers of students of some other single nationality, the adaptation process is slower, and students remain in separate nationality circles. In the late 1990s, groups of Chinese students were recruited directly from PR China. The experience was not solely positive because the integration of the young Chinese took longer than expected, and accordingly, the recruitment was stopped. Recently, in 2005-2007, Ethiopian and Kenyan students have formed a significant part of the classroom. For instance, it has not been possible to create enough culturally mixed teams in team projects. Moreover, students have been reluctant to mix because the group as a whole has been divided along racial lines that caused tension.

One of the teachers noticed in January 2007 that his media engineering students sit in the classroom in two groups: the 'white half' is on the left hand side and the 'black half' on the right hand side. When he gave them team assignments, the two halves refused to mix. I saw the same phenomenon, which remained stable during the semester, only one Finn occasionally sat on the right hand side. The situation was nearly as grim in the information technology group, where the students decided to sit 'whites' in the front rows and 'blacks' in the back rows. This division also reflected their participation in classroom discussions that were dominated by American and European students. Students were not happy about the situation and there was a heated exchange in the intranet discussion forum about classroom activity, as some students felt that certain nationalities dominate the learning space and disturb others. The Asian view is known to be that talking may interfere with thinking; therefore, it is not desirable in the classroom. Euro-Americans are noted to be more likely to think verbally and believe that talking is conducive to thinking ( $\mathrm{Li} \&$ Fisher 2006). The Finnish view is perhaps closer to the Asian attitude.

J. wrote: "You made a 'complaint' (what you stated on this portal about the X class amounted to a complaint) against teacher $\mathrm{N}$ on this board without taking any steps other than to state it here, if you have a complaint then voice it in the proper manner to the correct people." 
R. wrote: "How did you know that I didn't take any pre-steps? Do you really know what's been happening? Or you just took the opportunity and tried in vain to degrade my constructive comment?"

J. wrote: "If you feel you have a problem with the way I behave then speak to me rather than this open letter format, I would respect and appreciate that more as I am sure everyone else in the class would also."

R. wrote: "Open letters, messages or comments are quite effective and do work too. You only need more time and experience to realise this fact."

- A fraction of the argument in the discussion forum

This unfortunate situation was exceptional and mainly due to the unbalanced distribution of nationalities, as well as lack of measures to prevent conflict.

Group dynamics in international groups are complicated due to several reasons. First of all, the groups may be large with many subgroups. Second, some groups have had a difficult start in recent years, because so many students arrived several weeks after the beginning of the semester (due to delayed visa or other problems), and thus were not able to fully integrate to the group. Late arrivals formed nationality 'ghettoes', which caused tensions among students. Moreover, some courses were joined by transfer students who had started their studies at other polytechnics, and were not part of the main group and not known to others. However, a racial and ethnic mix could also be a basis for a happy community if differences are tolerated but not emphasized, and in particular, when nationality groups are not clearly discernible.

Group unity is reflected in graduation rates of different kinds of groups: in the case of industrial management students, around $80 \%$ complete their studies, whereas only $50 \%$ of the Finnish information technology students do. The Finnish information technology is a large and loose group of about a hundred students. The industrial management group, on the other hand, is comprised of 25 students who quickly learn to know each other. Moreover, the industrial management students start working in team projects already in the first semester, which seems to prevent drop-outs efficiently. The international groups were small, composed of 25-40 students, until 2005, which might also have contributed to a relatively high graduation rate of over $60 \%$. After the group size grew to around 60 , the graduation rate has declined.

According to Berry et al. (2002) the goal in acculturation should be to achieve integration (figure 14). Students who mix to work together towards common goals and who are involved in various activities forget cultural backgrounds and divisions, finally forming a study group that has a feeling of belonging together. In our experience, a good group spirit enhances student chances for passing courses, which is clearly shown by cases of student groups where every student completes courses aided by friendly peer- pressure. Nevertheless, the institute needs to actively promote integration by study guidance and planned intervention, for instance in the advancement of cross-cultural communication. 


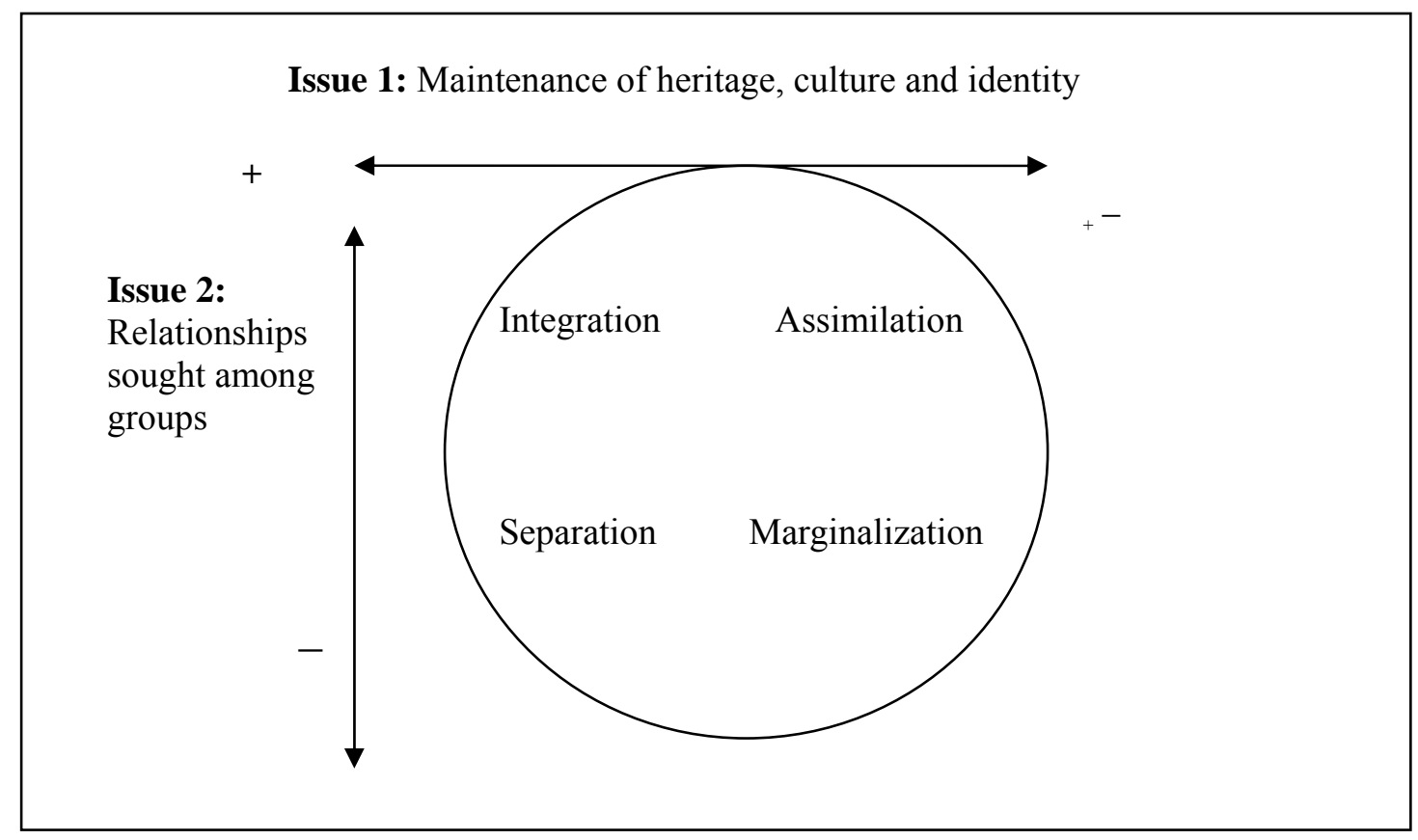

Figure 14: Acculturation strategies in ethnocultural groups (Berry et al. 2002, 354)

\subsubsection{Summary and evaluation of observations}

My aim in this section 5.4 has been to analyze which differences in study practices would be easy to manage, and what kind of measures would be effectual. Here I give a summary of practical findings. General results are discussed further in chapter 6.

\section{Student awareness and self-regulation}

One of my African students summarized the importance of the right mental framework and preparedness very nicely in his learning log:

The teacher introduced herself by telling us her names. I was pleased to hear that she has ever worked in Tanzania, because she would understand me better. She introduced the learning methods that we shall use throughout the coarse. She also gave us an overview of all that was ahead of us, by showing us the timetable on her home page. This was very important because it made us prepare psychologically on what is ahead of us. -Tanzanian student

Educators tend to underestimate the time that is needed to absorb computer science concepts and practice in technology to reach the level of proficiency required in working in a modern networked IT environment, because most home students have it already. One inexperienced student wrote in her learning log:

I actually thought everybody was a new comer to networks but I was wrong mean this requirements I new a few live the server has to be there then the computers and the internet the rest I was so surprised how people knew all this things at times it makes me feel like I don't know any thing . - Kenyan student 
Fortunately, this was written by a hardworking student who could catch up relatively quickly through systematical and intensive effort. The learning log assignment assisted in self-reflection and guidance for self-study. Student awareness of the new situation and analysis of differences is conducive to adaptation. Even though student self-regulation skills are essential, instructors also need to give appropriate support early in the studies.

\section{Teacher authority}

Classroom practices and teaching vary widely between countries. For example, as described in section 3.2, Massoudi (2002) makes a revealing comparison of expectations of students and teachers in Eastern and Western traditions in order to develop a model for an ideal or 'true teacher'. His approach highlights a difference between attitudes - in the Finnish education the role of student is increasingly emphasized.

In many countries where teachers are absolute authorities, rote learning and obedience are demanded. Students are not allowed to challenge them or to reinterpret what is taught, or to add their own views. Chinese students often show unwavering respect towards teachers. On the other end are North American students who often stand out as active and challenging to the teachers. The favored teaching style in Finland supports students in creating their own interpretations, and asking questions is mostly allowed, even encouraged (albeit with some exceptions). The authority of a teacher is open to mistaken interpretations if student experience associates it with discipline and blind trust on teacher's words. It is difficult for students to determine what is appropriate behavior towards teachers unless they are specifically instructed. For instance, emails from students vary from highly respectful to casual SMS style language.

However, strong reliance on teachers does not seem to be a persistent attitude, and most students learn to work independently and interactively if given guidance. This is probably due to the fact that much independence and self-reliance is required from international students because of the new environment anyway.

The relationship at our institute between teachers and students is rather close because of small group sizes. Teachers usually know each student by name, though this depends on the teacher and study unit. Sometimes students do not expect to be known that well, especially when they hand in assignments that are partly copied from other students. They are also surprised to find out that teachers actually read their assignment work and remember it, and thus get caught for plagiarism. Furthermore, a few students come from environments, e.g. Russia, where teachers can be bribed and grades bought or negotiated, which is unheard of in Finland. Russian students know that they cannot negotiate grades here, but students from far-away countries sometimes try. 


\section{Rote learning}

When a student learns course material by heart, a Finnish teacher may feel that it is because of a lack of deep understanding or missing study skills. On the other hand, the claim that, for example, Chinese students prefer rote learning has been challenged by a number of studies (Li \& Fischer 2004, Haller et al. 2007). Reflection has been shown to be an important means of understanding for 'Confucian Heritage students'. In fact, repetition is part of a process of reflection leading to deep learning. Moreover, a combination of learning strategies is probably efficient, especially for Chinese and other students with a wanting knowledge of English, and learning by heart may be a clever starting approach. They need a certain amount of memorizing in order to be able to answer exam questions. Subsequent reflection and repetition will support understanding and finally lead to solid knowledge. Li \& Fischer (2004) claim that the typical Chinese strategy includes application and possibly challenging the material only as the final step of learning. Therefore, a long term approach in the instruction would be better than short courses. On the other hand, rote learning is very efficient in learning languages, coding, etc., and especially Finnish students, who do not even know the multiplication tables by heart, are disadvantaged in this respect.

\section{Plagiarism}

The problems of plagiarism are rampant everywhere because of easy network access to information sources (Duff et al. 2006, Kaynak et al. 2008), and not exclusively connected to international students. We had at least one case of a fully copied dissertation by a Finnish student. Plagiarism cases often accumulate in new nationality groups, requiring swift attention from teaching staff. In autumn 2005 four Ethiopian students handed in a copied learning log to me, and all of them were chastised. Next year there were no cases among Ethiopians, but in another nationality.

If a person is accustomed to learning by imitation, and considers an exact copy as the highest form of accomplishment, the concept of academic fraud is undoubtedly difficult to grasp. Certain educational backgrounds seem to be more tolerant of plagiarism than others. "[ ] Investigation of the characteristics of citations in Chinese writing suggests that there plagiarism can be considered an expert strategy reflecting how composition has traditionally been taught. An MEd student from a northern African country thought it was legitimate to copy from books since he agreed with the ideas and found similar ones in many books. [ ] However, there is also the possibility that different cultures may not place the same taboo on plagiarism as does the West." (Todd 1997, 182) This is certainly true with regard to Japan, where imitation is the sincerest form of flattery (Karppinen 2006, 228), and individual credit for an innovation is of little importance. Therefore, teaching the Chinese to avoid copying is a never-ending task, as many of them have no feeling of doing wrong, and, as my observations demonstrate, are not ashamed of being caught. 
However, the learning of proper citation, referencing, and paraphrasing is a time-consuming process for many students, and it might continue until the final thesis writing.

The principal advance that I consider this course gave me is about the copy right rules. I was totally blind about it before. I just copied and pasted any thing what I needed without taking care of its copy right attributes. When I browsed web pages to learn more about the same topic, I also came to know about Plagiarism. Thanks to Application Development course that taught me about copy right rules. If I remained unaware of it, my thesis would have been considered "cheated thesis" and my degree would have been in danger. - Pakistani student

I have supervised several final year theses where the first version was a collection of copied materials from the Web. However, after a couple of editing rounds the student was able to produce a self-written report, which contained personal experience and indicated learning and a higher level of understanding. Report writing competence can be developed in all students, though it would need more emphasis in the curriculum.

\section{Embodied cognition}

Some of the cognitive problems experienced by international students are noticeably bodily manifested as clumsiness. A trivial example is the lack of dexterity in using a computer mouse, especially double-clicking which, for beginners, is difficult. Also middle-aged Finnish students sometimes find it very difficult to learn the mouse movements and rapid enough clicking. Unfortunately no training in motor skills has been offered, even though these difficulties would require intensive drilling.

Cultural artifacts surround us, transmitting a collective memory of the practices in our society. Immigrant students encounter a completely new set of cultural artifacts, for instance in electronics laboratories. Students might be uncomfortable with measuring devices or connecting wires because of a lack of exposure to technical equipment earlier in their studies and everyday life. They repeatedly connect the plugs in an oscilloscope the wrong way, or burn their integrated circuits with false connections. One group of African students developed a set of instructions about changing light bulbs and fuses, where they posted strong warnings about the dangers of electricity, which in our environment sounded exaggerated. Their previous experience did not introduce a caring relationship to technical artifacts, which, on the other hand, is discernible in the emotional attachment of many Western men who maintain and polish their cars and other technical gear with devotion. Some course offerings address the unfamiliarity with technology by providing hands-on practice. However, as discussed further in the next section about following instructions, the problem is complex and multifaceted.

\section{Summary}

This research has again confirmed the view that international students pose a challenge for educators because of their background variety. The teacher can adjust her way of instruction according to the needs in a group when the students come from one culture only (Holvikivi 1991), but in a 
heterogeneous classroom the needs are varied and even conflicting. It has also been demonstrated that the practices in our environment cannot simply be enforced by explaining what is required, because it takes a long time to fully internalize new schemas whether they are related to classroom behavior, social relations, study tasks, or depend on familiarity with cultural artifacts.

\subsection{Following instructions - puzzle solved?}

Electronics and physics laboratory sessions have a default script that is repeated each time:

1. Arrive at the starting time and form a team of two students and start work.

2. Read the instruction for current assignment; ask for clarification if needed.

3. Plan your work.

4. Work step-by-step through the assignment.

5. Report measurement results.

In reality, many laboratory sessions follow another type of script:

1. Arrive at some point during the scheduled time for the task (2-3 hours).

2. Meet friends and see what they are doing.

3. Make a team or try to join a team that has started working (and negotiate with the instructor about the team size).

4. Approach the equipment and start some action.

5. Call the instructor when things seem to go wrong.

6. etc.

Hutchins (1995) studied social cognition (actions of a navigation team) in the navy, and noted that it is an organization where seamless human co-operation is of central importance. Part of the co-operation is always performed through mediating artifacts, instructions. Because the personnel is in constant turnover, the military is simultaneously a learning organization, and the nature of operation does not allow any margin for big mistakes. Hutchins examines a particular type of mediating artifact, namely written procedural instructions. A starting apprentice relies on the written instruction that may be expressed in a sequence of steps. The apprentice performs one step, checks it on the list, and proceeds to the next step. If the instruction is clear enough, he does not even need to understand deeply its meaning or his own actions. Later, after many repetitions, the person starts to remember the process without instructions, and an understanding of it is eventually internalized.

The unwritten assumption in our laboratory instructions is similar to the situation that Hutchins analyzes. Hutchins mentions possible problems in following instructions, for example skipping a step and having to trace it backwards. However, he does not discuss the procedural idea itself, but assumes that the apprentice who is learning the process proceeds stepwise without being specifically trained to do so. Apparently, this is a cultural schema that is shared so strongly between any technical personnel that it is invisible to even a trained anthropologist. Because even the simple task of following steps in 
order can be solved in many ways, we have to be able to account for this kind of cognitive performance. Hutchins notes that there is similar activity in all societies, even in nonliterate societies; unfortunately his analysis stops before scrutinizing them. It has become obvious in our situation that the schema of procedural instruction is a product of certain cultural or educational practices, and it is not invoked automatically in all students.

Other researchers of social cognition have examined learning processes through sets of instructions; Wertsch (1985), for instance, presents several studies. The subjects have been mainly of small children or dyads of a child and an adult instructor. In a study in rural Brazil he examined adult-child dyads carrying out a task of making a copy farmyard with a model. Similar experiments were also recorded in the U.S. The child in each of the dyads was a six-year-old. In half of the dyads the adult was the child's mother, and in the other half, a teacher. The mothers had spent very little time in school. The mothers organized intrapsychological functioning so that they took on a great deal of the responsibility of executing the strategic steps in the goal directed action, whereas the teachers organized it as instructional activity. For the mothers, it was the activity setting in which they carried out tasks with children on a day-to-day basis. The underlying hypothesis is based on a Piagetian model of cognitive development, in which children of certain age should be able to follow a stepwise procedure, and if they are not, it is presumably a question of an underdeveloped attention span or other cognitive problem. These cases could be interpreted as settings of guided apprenticeship instruction, where interpersonal knowledge is transformed to intrapersonal knowledge, according to the ideas of Vygotsky.

\subsubsection{The laboratory as a social space}

Finnish and international students differ in their behavior in the lab sessions. Finnish students are mostly satisfied with written instructions in the laboratories, and ask for very little guidance, whereas students in international groups tend to communicate more with others and instructors also when doing lab assignments and pay less attention to written instructions, to the dismay of teachers. A business teacher described that when students are assigned to work in groups where one is responsible, they mainly socialize and do not follow instructions, they are not prepared for their presentations, their PowerPoints are cluttered with verbose information directly from the Web. Basically, their practices are disorganized.

My suggestion is that especially African students have a strong schema of social interaction that takes precedence over formal rules, and it is extended also to study environments and workplaces: When you meet people first time in a day, you pay personal attention to them. You greet them, you ask how they are doing and engage in small talk that has to last a couple of minutes in order to show sufficient consideration. My personal experience from Tanzania reminds me strongly of this schema: every morning my colleagues entered my office and chatted for a while, and because there were many 
people in the department, it took at least half an hour. For a Finnish person, this first seemed like a huge waste of time, but after some months I learned to appreciate the opportunity to get acquainted with the organization and become part of the social network in a new country.

Lady Caroline: In my young days one never met anyone in the society who worked for their living. It was not considered the thing.

Hester: In America those are the people we respect most.

Oscar Wilde: A woman of no importance

Another influential social factor is the attitude towards manual work, expressed here by a member of British upper class. Wealthy people in third world countries always have servants, chauffeurs, etc., thus a good position in the society means not having to do manual labor. Therefore, students may have an aversion for any kind of hands-on activity. Subtle values and attitudes may influence enthusiasm for practical engineering. As a matter of fact, a group of Kenyan students insisted to their Finnish teacher in fall 2006 that Finns must be poor because they cannot afford servants.

Some students come from cultures with a strong oral tradition such as the Somali culture (AlitolppaNiitamo 2004, 140). They have a preference for personal communication, which can be observed in regular visits to teachers' offices. Finnish technology students normally prefer e-mail communication, and they are accustomed to finding instructions in study guides and Web pages, whereas international students rely more on spoken word and non-verbal modes of communication. In the case of the students who find it difficult to work based on written instructions, an apprenticeship mode of learning would perhaps be more familiar. The instruction at Finnish universities relies strongly on mediating artifacts, such as written or computerized materials. Finnish and Western students are accustomed to a textual learning environment, and have inbuilt schemas for working in it. The "paper-trail" discussed by Teräs (2007) is part of their behavior, and papers (or documents on computer) are essentially integrated in the work.

The previous schooling experience of immigrant students may consist mainly of teacher-led lectures that require memorizing of presented material, less informal learning having taken place in personal contact. The laboratory setting is a completely new kind of classroom environment, and students may lack a model for controlling their work in it. If the student's schoolwork schema consists only of teacher speaking and student listening, she may not know how a more active role should be acted upon, and the underlying structure of the situation remains unclear. She lacks means of self-regulation if the purpose of the assignment is not understood.

\subsubsection{Procedure schema and abstract thinking}

It happens often when students work with laboratory assignments that a student follows instructions in somewhat random order, not from beginning to end. All assignments to learn application software or coding proceed stepwise, but a student may skip some steps or start from the middle of the exercise, for example when she is supposed to create a Word document or Excel table. In the fall 2005 two students (one from Africa, the other from South Asia) took the instruction sheet for creating a Word 
document, shuffled it, turned it upside down, finally folded it, and left the laboratory without even starting or asking a question. I am not yet able to explain that incident. Possibly they were as bewildered as I am at Starbucks when I simply want a cup of coffee, but I have to give a number of specifications from a long selection list. Starbucks have even printed a 24-page leaflet of how to order (2006).

The Linux practice that is done in the fifth study week is a very traditional computing task: students type commands on command line and send them to a remote computer. They are expected to get a feeling of command line interface and how the computer system processes simple tasks like saving and coping files. Typically, different styles of doing it have been observed:

- Fluent students go through the instructions fast, see what happens, and even ask for some additional advice (how to move a file, etc.).

- Some East Asian students type very fast all lines, possibly not in correct order, and they may not follow on the screen what happens. They perform it as a typing task, and finally they are perplexed that files are not there as expected.

- Many computer illiterate students try to follow the instruction and concentrate, but they even tell to the teacher that they are confused and do not quite understand what it is all about. They do not notice the subtle messages from the system, and do not understand if they get an approval or error message. Then they simply repeat their actions that are often mistyped.

The communication process with the computer fails because the human is not accustomed to purely formal communication, possibly does not even feel that it is a communication situation. The idea of a dumb computer that blindly follows instructions has turned out to be demanding to adopt, even though I have explicitly tried to hammer it to students' minds, for example by giving them code tracing practice to do during the lectures. Students attempt to just find a solution intuitively, in spite of being told to emulate computer. The difficulty involved in understanding computers was discussed in section 3.1 through studies by Suchman (2007), Clancey (2005), and others.

Why so many Chinese and other East Asian students - though by no means all of them - have to type so fast and take no time for thinking, is inexplicable to me at the moment. I have not found any study that would shed light to it. Studies on Asian learning styles emphasize a slow and thorough approach to learning; Asian students are supposedly focused on each component and practice a skill repeatedly and meticulously until they master it (Li \& Fischer 2004). Possibly the contemporary culture gives much pressure, because these students also tend to do many things at the same time: a Chinese girl used to send emails, browse the Web, listen to music or watch videos, and attend chats while doing laboratory work. When I went to help her and give instructions, she was always ahead of the instruction, and did wrong things, which then forced us to restart the whole thing. She gave the impression that she could not concentrate on the work. 
Hutchins $(1995,315)$ remarks that following a written procedure and counting have important structural similarities. Both involve coordination of sequence of tags with a partitioning of objects or events. Following a procedure "consists of coordinating the sequential transitions through the list of steps with the movement through the collection of actions to be taken of the partition between those things that have not yet been accomplished and those things that have already been accomplished." Thinking consists of bringing bits of mediating structures into coordination, the thinker providing the coordination among many structured media - some internal, some external, some embodied in artifacts, some in ideas, some in social relationships (ibid., 316). The research of Clancey (2005) and Ivarsson \& Säljö (2005) illustrate how school-age children already interpret technological representations based on their previous experience and mental frameworks, leading to variation even in the same society with different subcultures (see section 3.1).

Moreover, a certain amount of functional understanding of processes, in addition to technical skills, is a prerequisite for successful professional engineering work (Moss 2005) also for students in the laboratory. Additionally, understanding abstract concepts and capability in algorithmic thinking are required in performing laboratory experiments. Understanding computers requires an understanding of formal systems. In formal systems, a set of phenomena is encoded as symbols, and the symbols are manipulated by reference to their form only. The meanings of symbols are not interpreted while they are being manipulated. Hutchins $(1995,360)$ considers the mastery of formal systems to be the key to modern civilization. Certainly, it is the foundation of sciences.

To perform constrained thinking such as deductive reasoning, engineering design, or programming is difficult because a person has to ignore most ordinary analog and associative thinking and adhere to the controlled case. Scientists such as physics researchers are better trained to think in a restricted, artificial system than others. Mortimer \& Wertsch (2003) explain that the language of science has different grammar, and their research shows that students are reluctant to switch from the natural language code to the theoretical speech genre used by science teachers.

Moreover, the relationship to technology depends on familiarity with technical artifacts, which would be displayed in an easy and caring attitude towards technical devices. On the other hand, epistemological views also affect student behavior in the laboratories. Technical systems require a deterministic view of systems, and a trust in the ability to control the equipment in a causal manner. As discussed in 3.2, many societies do not share the technological epistemology that is predominant in Western culture, and in particular, a prerequisite for engineering. A mental schema of an uncontrollable environment is realistic in relation to nature but it cannot be extended to engineering work. 


\subsubsection{Communication and language}

The surveys among students (section 5.3) revealed that students themselves feel strongly a deficiency in communication: students reported that they did not understand what was expected of them and they were not able to convey this to teachers and staff. More than half of the respondents told that they found directions unclear. This difficulty was particularly connected with laboratory assignments, as up to $65 \%$ of the respondents stated that they often failed to understand instructions. The failure in following procedures was known previously, thus the teachers had already attempted to address it by improving their instructions. On the other hand, the home national students did not complain about the same sets of instructions, thus they cannot be deficient. Interestingly, the failure to understand instructions does not directly correspond with the English proficiency of the student. Nevertheless, $20 \%$ of students reported language difficulties as well. That figure may be too low because Chinese students were underrepresented in the survey population.

The chances for misunderstanding are evidently higher when English is a second language for both instructors and students. Moreover, students have learnt different varieties of off-shore English, which means in practice that people do not speak the same language. The extracts of student writings in this report demonstrate how different styles of English students have. Teachers sometimes contribute to the variety: a teacher warned students in the classroom that "bad boys will be sent to a long holiday". A student who had very refined English himself felt deeply offended.

The Finnish communication style is in a way extremely condensed, as also Karppinen (2006) has stressed. In addition to being brief and blunt, it may also contain too little information. On the other hand, simply difference in 'dialect' causes misunderstandings and amusing situations: we had a group of Kenyan girls who used to giggle in the classroom, and one teacher became upset because she felt that they were laughing at her. However, the girls also giggled in my classes, and I also had a group of Vietnamese students who burst into laughter unexpectedly during my lectures. Most probably the students were simply unaccustomed to our expressions, and felt embarrassed from time to time.

However, some students also had difficulties following instructions taken from North American textbooks, which they found too long and verbose. The failure to understand seems to be connected to the procedural style of the instruction, and also maybe to the unwritten assumptions of what the student is expected to understand without being told. As the discussion on logical reasoning failures and failures in filling in the Kolb questionnaire indicate (section 5.2), the language issue is rather complex. In addition to understanding a language, active reading skills include an ability to structurally parse texts, to create analogies, and to process the contents for understanding and evaluation. Advanced reading skills are required for analytical use of information in thinking and problem-solving. Advanced reading in a foreign language is achieved through a time-consuming learning process that includes learning of cultural codes as well as the language itself. The comparison 
task that was described through case Jonathan turned out to be a challenging first assignment for many immigrants who seemingly had not practiced analytic tasks before.

In sum, the factors that affect laboratory behavior are manifold, including social schemas and codes of behavior, scripts of classroom activity, cultural values regarding work and status, communication modes, and language issues. However, the most important factors seem to be schemas in regard to procedural thinking and action, functional understanding of processes, and the relationship to technology, all of which are parts of the cognitive competence of an engineer.

\subsection{Teamwork}

Project work is a standard method in engineering practice, therefore practicing it during education is good preparation for working life. In addition to separate project management courses, there are also large-scale efforts to integrate project work to studies, such as the CDIO initiative (Crawley et al. 2007). The CDIO model introduces students to teamwork already in the first study semester, which is a way recommended also by specialists in teamwork research Kozlowski and Ilgen (2007), and the skills are deepened at later phases of studies.

The research on multicultural teamwork is still inadequate compared to the importance of the topic (Bakir et al. 2004). Studies in group interaction have found group cohesiveness to be an indicator of performance, even though the commitment to the task apparently is the reason for high performance and cohesiveness. Research on the effects of heterogeneity to productivity and cohesion has produced contradicting results. In sum, heterogeneity can cause intragroup conflict, miscommunication, and lack of trust, but on the other hand, it can increase diversity in thinking and creativity. None of these consequences has been proven to be necessary, however. A great number of factors contribute to the success or failure of a project in any case, and because of the complexity of the situation, student projects are difficult to control (Kutay et al. 1999, 57). The evaluation of project success can be based on performance in the process or the quality of the resulting product. In education, the final criterion is naturally the learning outcome, which in case of project skills, will be best detected in subsequent projects.

This research case aims at elucidating favorable conditions for successful multicultural teamwork in software engineering projects. I attempt to find which conditions improve project performance and student learning. The setting is a first-year introductory course to software engineering. Initial research questions were concerned about the composition of teams: are homogeneous or heterogeneous teams better and in which respect, and what are the advantages of having multicultural teams, if any. 


\subsubsection{Course set-up}

The first project course for our information technology students is Application Development in the second term of the first year. Students work in small teams in planning and implementing an application, which usually is a Website. It is the first team project ever for most of the students. I am the instructor of the Application Development course for the international IT group since 1999. The research findings presented here are based on student deliverables, such as project documentation, evaluation reports, Websites, classroom observations that are recorded in the field notes, and other materials, such as emails. The course has been modified yearly based on analysis of previous experiences and technical infrastructure requirements but the structure has remained same over the years. Thus, it is typical action research on educational setting. Earlier findings were reported in a conference paper in 2003 (Holvikivi 2003).

Part of the learning takes place in classroom, and part through a networked learning environment. The process is very transparent, as the teams post their plans, reports, products and documentation on a Website where everybody can follow the progress. This method was developed by Veli-Pekka Lifländer (1999), and by EVTEK participation in international teamwork projects through internet within the EU Leonardo program (Markkanen 1999, Donzellini et al 1999). In addition to learning from one's own team process and among team members, teams also learn from each other, which brings a kind of friendly competition to the process.

Students can select the content and topic of their project site freely, even though they are encouraged to find a real client who needs a Website. Typical clients include ethnic restaurants, family hotels, sports teams, travel agents and other small companies. Students normally engage in a lively discussion about the choice of topic, because they want to find a topic that motivates the whole team. The main emphasis of the course is in the application of systems analysis and systems development methods, the basics of systems development life cycle. Students have a project framework with a list of deliverables, a set of documentation templates, and milestones that they follow during the semester (see the course site at http://www.evtek.fi/ jaanah/ApplicationD). Additionally, students also learn to work as a team, and to deal with typical problems that occur during the software development process. They learn project management, select roles in their teams, and plan and divide the job evenly.

First-year students have no programming experience yet. Websites were selected as an application area because they require only modest technical skills, and students are already familiar with the application area. Website development allows selection among wide range of tools and methods, therefore students usually find these projects motivating. Many students invest extra effort in creating the product because of genuine interest to learn more, competitive spirit, or to add something to their portfolio when they look for summer jobs. 
For the first two years I taught the course, students formed teams based on nationality. However, as it seemed that it caused very uneven project results, I encouraged them to create mixed teams whenever possible. We also had an agreement that the multicultural effort was assessed positively. However, the effect of heterogeneous groups to project results was by no means obvious despite an overall impression that it had positive consequences. This research analyses teamwork performance of students based on project documentation and ability to deliver a product; the productivity of teams based on their product features; and social consequences to group cohesion based on project evaluation reports and researcher observations.

\subsubsection{Project results}

The total number of projects was 80 in the years 2001 - 2007, with 269 students participating. Of the total, eight projects were never completed. The minimum requirement for completion was a project plan, a functional product (website or software), and a project evaluation report. All projects that had an external customer (21 projects) were also completed successfully. All projects did not necessarily produce a full website but at least a functional prototype. This must be attributed to high motivation, as there often was poor support from the customer side: for instance, customers had no time to send content for the site, such as pictures or descriptions of the company.

I have given a similar course to the Finnish industrial management students three times. Their group consists of 25 students, forming a closely-knit group. They are less interested in Web technologies than IT students and hence less ambitious or innovative in these projects. On the other hand, they have had a project management course in the previous semester, and due to their familiarity of project practices they usually complete $100 \%$ of their projects. The unity of the group has a significant effect on student performance, as the students look after each other and give mutual support, thus ensuring that everybody passes the course.

An analysis of successful and less successful projects in the international group confirms that on average, mixed teams achieved the best results in performance and product quality. Teams that consisted of several nationalities and had at least one European or American student (46) succeed in their projects in 37 cases, and only nine of these teams had difficulties in completing the task. On the other hand, in exclusively Asian teams there were four good and three weak projects, in mixed Asian and African teams similarly four good and three weak projects, and in all-African teams three good and ten weak projects.

Naturally, there are no fundamental cultural or genetic cognitive differences between the students at large, and individual students even from the same cultural background can have very dissimilar competencies. Educational backgrounds that do not encourage individual effort or collaboration of 
students produce students who are unfamiliar with teamwork and unable to plan their work. Student personalities in cross-cultural teams make each case different.

\subsubsection{Project cases}

Students were encouraged to form multinational teams for two reasons that had been observed. First of all, teams are inclined to feel rivalry, and it is not desirable to set nationalities against each other. Secondly, one-nationality teams tend to have certain typical problems because of narrow variety of skills. For instance, many of our Finnish and Chinese students write rather poor English, whereas some African students who were taught in English at school write fluently. Our Chinese students are often strong in sciences, but they rarely have any experience in self-directed study. Thus, it seemed counter-productive to let Chinese students form a team, even though they would have preferred to communicate in Chinese. In a case where a bunch of Finnish and European boys who have written programs already in high-school team up, the team might have little communication, and produces minimal documentation but advanced programs. As a result they have learned very little of team interaction, client relationship or the need to document software. Moreover, in a situation where most of the technical skill is concentrated in a few teams, the other teams struggle with developing their technical savvy and may fail to deliver at all, which in turn causes bitterness.

Students that form a one nationality team tend to emphasize their home country and cultural background. In 2006 and 2007 there were five predominantly Chinese teams, and all of them initially chose Chinese culture as their subject (Chinese Chess, wildlife, cities, spring festival). Typically the teams proceeded by browsing the Web to find images and the resulting site was a mix of styles. One site attempted to present Chinese Chess, copying all pictures from other sites, and adding decorative page backgrounds that made reading hard. I persuaded one team of three Chinese and one African to reconsider their choice, after which they decided to present the city of Raahe where they had studied before. Their site was a personal and interesting view to small town life in the north consisting of a number of their own photographs. When the team presented the site in the classroom, the French exchange students in the audience were thrilled, and a lively discussion about Finnish countryside followed. Thus they succeeded in crossing cultural communication borders.

A successful although surprising case was a team that developed a Website about the Chinese spring festival in 2006: the team had five members, one British man and four Chinese women. The British man was an experienced programmer, whereas the Chinese students were novices to Web development and, moreover, their English was poor. Against all odds, the team succeeded in communication to an extent that the British team leader was able to convince his team not to take images from other Websites, but instead to produce their pictures and other site content themselves. One team member showed remarkable talent in drawing the Chinese horoscope signs. The team also scanned photographs of their family celebrations and ended up with a very personal site that pleased both the 
Western and the Chinese eye. They reported learning a lot about cross-cultural communication, project management and systems development knowledge, and showed due pride in their achievement. In this case, the role of the instructor was merely to be a facilitator.

Similarly, African students often chose themes such as national parks in Africa or history of Ethiopia, unless they decided to present cars or football teams. With the choice of topic and site style they enforced stereotypes. The sites often consisted of blinking images, incoherent style and lots of copied material, all features that reflected unfamiliarity with the Web. One site of this kind was produced by an all-Kenyan team that chose to explain electric installations in student dormitories, as described in their final report:

The site was aimed at the students living in HOAS apartments but anyone with electrical accessories can use this site. Our site is working according to the intended purpose. It will also enlighten those who cannot tell the difference between a fuse and a switch or a plug. The site will also be liable to change with the new technology that is quickly coming up.

Actually, the site had no instructions whatsoever that could be used, but it had links to UK electric stores that sell appliances that follow local UK standards which are entirely different from Finnish appliances. The team started by realizing that standards of electric appliances are very different in Finland from their own country, but ended up in creating bewilderment. The final report did not address that issue at all, probably because of their own confusion. It could also reflect a separation of discourse and reality in Kenyan education that is very far from the pragmatic engineering.

In many cases, female students have been central in organizing the teamwork showing good social skills. Interestingly, the male students from Africa and South Asia that seemed to have felt most at a loss in the new environment, had 'adopted' a European girl as a mother figure. Teams that were formed on this kind of basis, had tremendous difficulties because the 'mother' lacked authority to enforce regular working pattern and thus ended up doing most of the work.

Some multinational teams succeeded well in combining their cultural differences into interesting projects. One West-Indian-Finnish-Chinese-African team created a Website about cooking in their respective countries. Another team consisting of African, Finnish and Chinese students made a site where they compared marriage customs in their home countries. They seemingly enjoyed working with their projects enormously, as they had a chance to know more about each other's backgrounds and share experiences which they were proud of. There was a certain feeling of finding unity in being different.

\section{Quotes from project reports}

Our inter-personal communication skills are also developed during these three months. We begin to think a better way to encourage each other in stead of quarrelling all the time. Actually most of us can do much better even than we could imagined before if communicate with each other properly. We assure that those skills will be a great bonus to us for doing some other projects and for the future working life. (a student from West Africa) 
Ms. J. H. suggested that it may not be a good idea that people who came from same country be in a group, because we need different idea and we should get used to work with the people who has a different culture. That is why Matti, John, Daniel and me- Chun are working together towards a same target. The project topic is decided to be a wedding culture website since we came from three quite different country- Finland, Tanzania and China. It would be our pleasure to let people get to know more and more about our country and our culture. (a student from China)

During construction of this website, I faced challenges where I wanted to implement something on webpage but I didn't have the resources. Also working under pressure where teammate Chun was putting a lot of pressure. But overall I learned that a good product required hard work. From the design of this website, I have learned deeply more about marriages in other counties (Finland, China). The different cultures suggest different expectations from married couple. Maybe someday I will marry a Chinese woman... (a student from Tanzania)

We had several plan and ways on how to do the project. But finaly we realize that we dont have have enough time to meet so often. Then we reach to the conclusion that each member will do mostly of the project on its own and then when we meet every one should have something from what we have agreed. The work process wasnt good, it was so difficult to get everybody to do something.I was the project manager I tried my best to put the team together but I couldnt. Then we decided everybody to do individual job but also the result wasn't good at all. Our participation to the project wasn't encouraging which led to delay and difficult job at the end. What I have learned from this project is, how important to have a good layout of the project plan. Mostly important is to follow the schedule and to be realistic and work hard in order to get what you need. Our group is a good example of bad project management.We didnt follow the schedule the members didn't work hard and didnt provide good cooperation. (African student)

\subsubsection{Lessons learned}

A multicultural classroom is in many aspects similar to a multiethnic society: when the ethnic groups are not separated into clearly discernible ghettoes but mix freely, no divisions are formed and people interact peacefully. A certain number of home nationals helps immigrants to adapt the habits of Finnish educational culture and to adjust to the society. Generally, the most successful project teams were formed when there was enough variety in the student group.

Teams experience internal conflicts and disagreements as a normal part of the team process. Student personalities in a cross-cultural team make each case different, and often students try to hide internal team conflicts from other teams and the instructor. Students from cultures that emphasize social harmony seem to believe that conflicts are failures. Emotions may run high during the process but normally teams find it rather amusing afterwards if they succeed in their project. Nevertheless, serious conflicts have to be dealt with by the instructor, and, if necessary, team compositions need to be changed.

According to our experience, whenever students are motivated they are able to complete projects even with a low level of skills, because the projects are small. Unfortunately, not all students are that motivated or they are not accustomed to plan their work independently, and in that case they need some pushing. A project manager or another motivated team member who has natural authority over other team members, good social and teamwork skills, and understanding of project management principles, can save his or her project. A successful team needs to have:

1. sufficient technical skills,

2. motivation and self-control, 
3. ability to work together, and social skills,

4. discipline and regular working habits; understanding of schedules and deadlines,

5. communication abilities,

6. English writing ability (to produce documentation).

None of these requirements is necessarily attached to multicultural teamwork, but sometimes the working habits prevalent in some nationalities combined with a modest technical capability cause difficulties in the project. Typically, failures in projects are caused by:

1. problems in commitment to the teamwork

2. personality conflicts within a team,

3. differences in working habits (punctuality, responsibility)

4. problems in understanding of the task,

5. inability to plan the work: divide the tasks and schedule them.

These findings are similar to Napier and Johnson (2007) who also found that foremost barriers to teamwork satisfaction were lack of participation in teams, inadequate technical skills, and poor communication. In their study, the success of small multicultural student teams was measured by questionnaire responses that indicated the immediate student satisfaction. Teams with least diversity (all-male or all-US students) expressed greatest amount of teamwork satisfaction. As opposed to their results, cultural diversity in our case did not produce inferior results, which could partly be due to the longer duration of this course. In Napier and Johnson's study (2007) students worked together only two weeks, which is a very short time to form close working relationships and to overcome potential initial prejudice.

\subsubsection{Conclusions}

In sum, nationalities or cultural backgrounds are not the decisive factor that explains teamwork results. More important is the combination of abilities and skills in the team, which does, however depend on schooling background. General factors influencing teamwork success work in multicultural teams as well. Such factors are the presence of dominant individuals, previous experience in teamwork, technical skills, regular work habits, social skills and willingness to co-operate, motivation, instructor guidance and support, etc.

According to the socio-cultural theory of learning (Vygotsky 1962, Hakkarainen et al. 2004a), construction of knowledge is done through social interaction. There is interaction not only between a teacher and a student but first of all between the students in teams and in the group. Students have ample opportunity to acquire tacit cross-cultural knowledge and competence in multicultural teams. Through their own discovery students can acquire a deeper understanding of cultural differences than by studying 'how-to' lists of cultural patterns. If students work in monocultural teams, their process 
and results often emphasize national stereotypes, and the distance between the cultural norm (in this case Finnish) and the 'exotic' foreign becomes pronounced. In multicultural teams, on the other hand, this is avoided as their role is to be individual team members instead of representatives of a nationality. Individual students can bring their unique experience to the team process, having an opportunity to integrate their past into the new study environment. In the best cases, a truly multicultural co-operative unity is formed. Moreover, diversity in a team has been proven to encourage innovation and creativity, also by many of our projects. The findings are rather unambiguous and encouraging for multicultural education. 


\section{$6 \quad$ Findings and discussion}

\subsection{Scientific contribution}

This research has confirmed the assumption that multicultural students cannot be regarded as a coherent group. Therefore, the thesis focuses on individual variety rather than cross-cultural differences between groups. There are observed dissimilarities between cognitive styles of individuals from the same country even though nationals of one country usually share surface behaviors. Their approaches to learning may be very different, and expatriates in particular tend to deviate from standard norms. At EVTEK, we have no systematic knowledge of the backgrounds of our students, because the recruitment is not targeted at groups but individuals. We do not know from which segment of their respective societies they come from, or whether they represent similar segments within a country or across countries. Moreover, their educational backgrounds vary from special high schools to national colleges. Therefore, any conclusions about a particular national culture or educational system would be unwarranted based on this research.

Even though Finnish students are the most homogeneous student population in the OECD countries (Pisa study at http://www.pisa.oecd.org/), they nevertheless have a variety of approaches to learning. The differences in other groups are more pronounced: some Asian and African students have fully Western schooling and study habits, whereas others have had little previous exposure to Western style education. Rather, they might, for instance, be predominantly rote learners and passive listeners. As a matter of fact, based on the group level differences in course passing rates, I attempted to create a nationality based model to explain within group differences, but the effort was not successful: each nationality provides us with top students as well as failing students, and despite discernible learning style differences between nationalities, no clear correlations or useful coefficients for a formula could be developed. Therefore, the answer to the second research question (in section 4.1) regarding differences in learning depending on home culture is definitely positive, even though the differences are displayed in a variety of ways that were described in the previous chapter.

The research question regarding the presumed universality of engineering thinking was explored through a literature study in section 3.4. It seems to indicate that engineering knowledge is indeed universal to a certain extent. Moreover, engineering students willingly subscribe to the engineering thinking that is promoted in the education, as the survey results show. The other questions were concerned on how the ways of thinking of immigrant students differ from ways of thinking of Finnish teachers or students, and how do students from differing backgrounds display evidence of understanding abstract concepts and technology. These questions were explored in the previous chapter, and main findings are summarized below. Moreover, a number of suggestions for improving teaching methods and communication are given in section 6.2. Table 17 summarizes where the main 
findings are presented. The problem of how engineering thinking is learned and absorbed during the studies is only partially covered in this work, and it requires further research.

\begin{tabular}{|c|c|c|}
\hline $\begin{array}{l}\text { Cognitive competences } \\
\text { and problem areas }\end{array}$ & Theory presented in sections & $\begin{array}{l}\text { Findings } \\
\text { discussed in sections }\end{array}$ \\
\hline Social relations & $2.2,3.1 .3,3.4 .2$ & $5.3 .1,5.4 .5,5.5,6$ \\
\hline Teamwork & 2.4 .3 & 5.6 \\
\hline Social cognition & $2.4,3.1 .4,3.1 .5,3.2 .3$ & $5.5,5.6,6$ \\
\hline Language abilities & $2.3 .2,2.3 .3,3.2 .3$ & $5.2 .2,5.2 .4,5.4 .3,6$ \\
\hline English writing & $3.2 .2,3.3 .2$ & $5.4 .2,5.4 .3,5.4 .4,6$ \\
\hline Plagiarism & 3.3 .2 & $5.4 .3,5.4 .4,5.4 .6$ \\
\hline Language variation & 3.3 .2 & $5.4 .2,5.5 .3$ \\
\hline Communication style & $3.2 .5,3.3 .2,3.3 .3$ & 5.4.5, 5.5.1, 5.5.3 \\
\hline Number sense & $2.3,3.1 .3,3.2 .2,3.2 .3$ & $2.4 .3,3.1 .7,6$ \\
\hline Program coding & $2.4 .3,3.1 .7$ & $5.4 .1,5.4 .2,6$ \\
\hline Memory & $2.3 .1,2.3 .2,2.3 .5,3.1 .5$ & $5.4 .6,6$ \\
\hline Self-regulation & $2.4,3.1 .6,3.4 .2$ & $5.1 .2,5.4 .6,5.5,6$ \\
\hline Metacognition & $2.4 .3,3.1 .4,3.1 .6,3.2 .5$ & 6 \\
\hline Emotional control, intuition & $2.2 .3,2.3 .4,2.3 .5,3.1 .2$ & $5.4 .4,6$ \\
\hline Self-reporting & 2.3.5, 3.1.1, 4.5.3 & $5.2 .3,5.2 .4,5.2 .5,5.4 .3$ \\
\hline Analytical abilities & $2.3 .3,3.1,3.4 .2$ & $5.4,6$ \\
\hline Rationality & $3.1 .2,3.4 .1$ & 5.5 \\
\hline Critical analysis & $2.4,3.1 .3$ & $5.4,5.5 .3$ \\
\hline Logical reasoning & 3.1.1, 3.1.7 & $5.2 .2,5.4 .1,5.5 .2$ \\
\hline Scientific thinking & $2.3 .3,2.4,3.1 .1,3.2 .1,3.2 .3$ & $5.2 .2,5.4,6$ \\
\hline $\begin{array}{l}\text { Performing laboratory } \\
\text { experiments }\end{array}$ & $3.2 .4,3.2 .5$ & $5.5,6$ \\
\hline $\begin{array}{l}\text { Applying theory } \\
\text { in practice }\end{array}$ & $3.1 .4,3.1 .5,3.2 .3$ & $5.4 .1,5.5,6$ \\
\hline $\begin{array}{l}\text { Following step-by-step } \\
\text { procedures }\end{array}$ & 2.4 .3 & $5.4,5.5$ \\
\hline Technical skills & $2.3 .5,3.3 .2$ & $5.5 .2,5.4,6$ \\
\hline Embodied skills & $2.2,3.2 .5$ & $5.4 .1,5.4 .6,6$ \\
\hline
\end{tabular}

Table 17: Cognitive competences and problem areas 


\begin{tabular}{|c|c|c|}
\hline $\begin{array}{l}\text { Cognitive competences } \\
\text { and problem areas }\end{array}$ & $\begin{array}{l}\text { Cultural difference } \\
\text { expectations }\end{array}$ & Examples of findings \\
\hline $\begin{array}{l}\text { Social relations } \\
\text { Teamwork } \\
\end{array}$ & $\begin{array}{l}\text { - more important in } \\
\text { collectivist cultures }\end{array}$ & $\begin{array}{l}\text { - important } \\
\text { - enriched by multiculturalism }\end{array}$ \\
\hline $\begin{array}{l}\text { Language abilities/ } \\
\text { English writing } \\
\text { Plagiarism } \\
\text { Language variation/ } \\
\text { Communication style }\end{array}$ & $\begin{array}{l}\text { - influence understanding } \\
\text { and thinking } \\
\text { - copying common } \\
\text { - great cultural differences }\end{array}$ & $\begin{array}{l}\text { - problems in understanding } \\
\text { and self-expression } \\
\text { - problem area } \\
\text { - misunderstandings and } \\
\text { conflicts }\end{array}$ \\
\hline Number sense & $\begin{array}{l}\text { - develops from infancy } \\
\text { onwards }\end{array}$ & $\begin{array}{l}\text { - deficiencies stemming from } \\
\text { school background }\end{array}$ \\
\hline Program coding ability & $\begin{array}{l}\text { - conceptually difficult; } \\
\text { characters embrained }\end{array}$ & $\begin{array}{l}\text { - conceptually difficult; } \\
\text { character system dependent }\end{array}$ \\
\hline Memory & $\begin{array}{l}\text { - complex, rote learning } \\
\text { common in some places }\end{array}$ & $\begin{array}{l}\text { - timing effects; } \\
\text { memorizing skills }\end{array}$ \\
\hline Self-regulation & - greatly influences learning & - greatly influences learning \\
\hline Self-reporting & $\begin{array}{l}\text {-always unreliable, brain- } \\
\text { based difficulty }\end{array}$ & $\begin{array}{l}\text { - unreliable, depends on } \\
\text { expectations }\end{array}$ \\
\hline $\begin{array}{l}\text { Analytical abilities } \\
\text { Rationality }\end{array}$ & $\begin{array}{l}\text { - produced in education } \\
\text { - Western ideal }\end{array}$ & $\begin{array}{l}\text { - great variation } \\
\text { - less important in other } \\
\text { cultures }\end{array}$ \\
\hline Critical analysis & - learnt in school & - deficiencies \\
\hline Logical reasoning & - depends on schooling & - deficiencies in logic \\
\hline Scientific thinking & - worldviews differ & - practical differences \\
\hline $\begin{array}{l}\text { Performing laboratory } \\
\text { experiments }\end{array}$ & $\begin{array}{l}\text { - depends on procedural and } \\
\text { embodied skills }\end{array}$ & $\begin{array}{l}\text { - most problematic area in } \\
\text { international groups }\end{array}$ \\
\hline $\begin{array}{l}\text { Applying theory } \\
\text { in practice }\end{array}$ & - needs targeted training & $\begin{array}{l}\text { - attitudes against practice, } \\
\text { connection missing }\end{array}$ \\
\hline $\begin{array}{l}\text { Following step-by-step } \\
\text { procedures }\end{array}$ & $\begin{array}{l}\text { - universal ability, human- } \\
\text { machine difference }\end{array}$ & $\begin{array}{l}\text { - application depends on } \\
\text { context, problematic }\end{array}$ \\
\hline Technical skills & & $\begin{array}{l}\text { - depends strongly on cultural } \\
\text { background }\end{array}$ \\
\hline Embodied skills & $\begin{array}{l}\text { - brain patterns develop until } \\
\text { adulthood }\end{array}$ & $\begin{array}{l}\text { - depend strongly on cultural } \\
\text { background }\end{array}$ \\
\hline
\end{tabular}

Table 18: Cultural differences in cognitive competences and examples of findings

This research has revealed a systematic deviation that is repeated each year: certain group level differences in study performance between international students and Finnish students persist as long as the composition of the international student group follows a wide distribution of nationalities. The difference seems to be correlated to the degree of cultural diversity in the international group. 


\section{Cognition: Language and writing skills}

The failure to understand instructions was discussed in section 5.5. Communication problems hinder learning gravely, and as concluded, they incorporate more than language proficiency, such as style of instructions, reading skills, assumptions of student understanding, and ability to use English in problem-solving. This study also implies that language affects ability in formal reasoning to a high degree, as described in section 5.2. People may apply different types of thinking when using their native language and when using a second language. The results suggests that language as a medium of study has a stronger effect on learning in science and engineering than is commonly believed. If this finding is confirmed by later studies, more attention should be paid to the modes of instruction in foreign language study programmes in general.

Moreover, what the student's native character system is seems to have a strong impact on reading and writing English. Students who learn the Latin alphabet as their second character system, often encounter difficulties also in program coding. The interplay between English writing, character systems, program coding, embodied writing skills, and visual perception can be located within the theoretical framework that has been developed in this thesis. Success in technological education depends on mathematical thinking and numerical abilities that were learnt and internalized during earlier phases of education.

\section{Number sense, reasoning and technology}

When I studied at school we've learned how to use abacus. It's very simple and handy device for adding and subtraction. Also for our calculations we used slide-rule. I'm sure that Finnish schoolboys have no idea how to use it. - Russian student in 2005

The development of number sense in infants and accumulation of enumeration skills and mathematical abilities in childhood were discussed in section 3.2. A person's relationship to mathematics, science, and counting develops from early childhood on. The adolescent brain seems to be particularly apt in learning algebraic equations compared to adult brain. Moreover, the acquisition of formal mathematics relies on the ability to learn rules and procedures, and it is connected to word association and language activity in the brain (Neuroscience and education 2007). Therefore, differences in mathematics education as well as wide-ranging cultural backgrounds produce significantly varied scientific capabilities in our students, which have been observed in this study.

In Finland, several changes have taken place in mathematics education: the level of mathematics taught in middle school has decreased, calculators were introduced in schools, and students no longer acquire the skill of mental calculation by sufficient repetition. Consequently, their relation to numbers is purely abstract without an embodied experience, and an error in calculation (wrong number typed or wrong formula used) goes unnoticed because the wrong magnitude of the result does not alert the student. There are striking differences between students in this respect, and it seems that Eastern European, French, Asian, and some (but not all) African schools produce mathematically capable 
students, whereas the Finnish school system no longer guarantees adequate mathematics skills, as was noted in section 5.2 .

Additionally, the schema of procedural instruction appears to be the product of certain cultural or educational practices, and one that is not automatically invoked in all students. This finding suggests that the theory of internalized cultural schemas is also highly applicable to scientific thinking, which explains culturally produced differences in cognition. Functional understanding of processes, in addition to technical skills, is required in engineering studies and professional work. Familiarity with technology is acquired through constant exposure, and it produces deterministic and causal formal thinking. Understanding computers requires an understanding of formal systems and abstract concepts, and capability in algorithmic thinking. Rational reasoning and intuitive thinking are both needed, and a student has to be able to choose the appropriate mode consciously.

\section{Embodied cognition and feelings}

This work has revealed how embodied experience affects student capacity to adopt skills in a technological environment. Performance in electronics and physics laboratories as well as basic computing skills depend on a student's previous internalized experience. Engineering appears to be a predominantly practical science, and expertise in engineering incorporates a great number of cultural schemas, parts of which are embodied.

There is much evidence in this thesis of the influence of feelings and emotional states in learning. Immigrant students, in particular, are in a vulnerable position, and therefore their feelings surface more visibly than in the case of home students. These findings are contradictory to the predominant paradigm of detached rationality in engineering, suggesting a need for revision.

\section{Cultural schemas in classroom}

The discussions in sections concerning laboratory work (5.5) and teamwork (5.6) disclose the importance of cultural schemas in student behavior. Their values and earlier adapted classroom practices are internalized to the extent that students hardly even realize that they would need to modify their practices. Enforced social scripts and communication patterns dominate behavior, not only in immigrant students but in all humans.

\subsection{Practical implications}

A number of methods have been tried and applied throughout this research to create an integrated learning environment where studies are not split into disconnected parts. The methods are based on the theories of progressive inquiry, social cognition, and intelligence as a shared activity. These include:

- Use of journals and learning logs to improve student metacognition and selfregulation. Most students find them inspiring and report that reflection has improved their learning. 
- Group discussions and team assignments enhance shared cognition and metacognition.

- Teamwork is one of the means to foster student collaboration. Multicultural teamwork can be a rewarding experience for students when it is conducted with close guidance by the instructors, and when due attention is paid to the composition of the teams.

- Teamwork additionally encouraged less-structured collaborative learning and selfcreated study groups.

The practical methods have been applied repeatedly several times over years, the feedback has been assessed, and the results have been encouraging. Therefore, the recommendation of their application in multicultural engineering education is justified by this research.

\section{Student cognitive self-regulation}

Sternberg's (2005) concept of successful intelligence was introduced in section 3.1. It incorporates three aspects of intelligence: analytical, practical and creative. According to Sternberg, instruction which utilizes all three aspects, is more successful in teaching culturally diverse student groups compared to traditional instruction that emphasizes memorizing. Moreover, student self-regulation takes place through metacomponents of intelligent activity, the executive processes, which plan and control activity, thus being instrumental for successful performance. Self-regulation should cover cognitive, emotional, and motivational activity. In the present study, the learning and reasoning processes of many students appear to be lacking in these metacomponents, and the curriculum has not explicitly addressed the development of self-regulation.

The necessity of rational and pragmatic action in professional life coupled with the poor performance of the student groups surveyed leads to the conclusion that logical, systematic thinking, as well as connection of theory and practice, should be more heavily emphasized in education. Engineers need to be able to select an appropriate way of thinking in each situation, and to be able to alternate between everyday thinking modes, strict formal thinking, and creative, heuristic problem-solving. A good ability to reflect on one's cognitive functions and high metacognitive skills are indispensable. Thus, the aim to develop metacognitive abilities and self-regulation needs to be explicitly addressed in the curriculum.

\section{Recommendations for practice: recruitment and an adaptation period}

The resource constraints in universities do not allow much individual attention and tutoring, thus the students have to be able to adapt to the mode of instruction. The community of students and teachers needs to be functional. According to our experience, the best recipe for a good learning community is a mix of cultures where no single cultural group is overly dominant. Therefore, appropriate attention should be given to student selection. The educational institution needs to recruit students who will graduate in due time, in order to secure funding, in addition to all other factors such as reputation, atmosphere among students and staff, and ability to collaborate with industry. Moreover, the students need an assurance that they have been selected for studies that they will be able to complete, and that 
they will find a job after graduation. Studies in a foreign country are an enormous financial, social and psychological investment from students and their families, thus every possible effort should be made to guarantee the success of this effort.

The EVTEK entrance examination has thus far tested mainly memorizing and analytical ability. It consists of a school mathematics test and English writing. Many of the abilities that are excepted from engineers have not been tested at all, partly on the assumption that incoming students share interest in engineering and consequently have certain inclinations such as pragmatic attitudes. However, that assumption can not be extended to international students with extremely diverse backgrounds.

Based on the results of this research and Sternberg's intelligence theory I propose a tentative intelligence requirement for a bachelor of engineering in IT (table 19). The table has three columns: the profile of a (hardware) computer engineer, the profile of software engineer and a profile for media engineer. The requirement is on scale 0 to 3,1 corresponding to the everyday activity level of a layperson, 2 corresponding to modest professional level ability and 3 top level skill. Additionally, immigrants need more social and emotional intelligence, and every-day problem solving than home students.

\begin{tabular}{|l|l|l|l|}
\hline Cognitive ability & $\begin{array}{l}\text { Computer } \\
\text { engineer }\end{array}$ & $\begin{array}{l}\text { Software } \\
\text { engineer }\end{array}$ & $\begin{array}{l}\text { Media } \\
\text { engineer }\end{array}$ \\
\hline 1. Memory & 1 & 1 & 1 \\
\hline 2. Analytical & & & \\
\hline 2a Problem solving & 2 & 2 & 2 \\
\hline 2b Formal knowledge (verbal) & 1 & 1 & 1 \\
\hline 2c Numerical, quantitative & 2 & 2 & 1 \\
\hline 2d Deductive, reasoning & 2 & 3 & 1 \\
\hline 2e Spatial & 2 & 1 & 2 \\
\hline 3 Practical & & & \\
\hline 3a Technical problem-solving & 3 & 2 & 2 \\
\hline 3b Everyday problem-solving & 1 & 1 & 1 \\
\hline 3c Working life problem-solving & 1 & 2 & 2 \\
\hline 3d Motor ability & 2 & 1 & 2 \\
\hline 3e Social intelligence & 1 & 1 & 2 \\
\hline 3f Emotional intelligence & 0 & 1 & 2 \\
\hline 4 Creative & & & \\
\hline 4a Visual & 2 & 1 & 2 \\
\hline 4b Verbal & 1 & 2 & 2 \\
\hline 4c Abstract, hypothetical & 2 & 2 & 1 \\
\hline 4d Motor & 0 & 0 & 0 \\
\hline & & & \\
\hline
\end{tabular}

Table 19: Tentative requirements for student cognitive abilities 
Immigrant students normally arrive in Finland just at the beginning of the semester, or sometimes even a few weeks late. They face a new situation in studies, and at the same time they need to adapt to the life in Finland, to settle to a new place, to find housing, etc. Moreover, they do not speak the language of the country. Their situation should be acknowledged by giving them time and advice in settling and adapting to their new life. Many universities in the U.S. and U.K. require an preparatory course for overseas students that, in some cases, lasts a full semester or a year. This type of pre-semester preparatory course should also be considered in Finland (Helenius 2007). More time is needed for adaptation to a new environment, and especially the forming of new behavioral schemas requires a long time. Good support and personal guidance in studies would help in adjustment, and organized tutorial meetings such as a culture laboratory would be extremely useful (Teräs 2007).

\section{Curriculum, time and instruction}

You can't think and hit at the same time.

Yogi Berra (baseball legend)

Permanent learning and memory formation require certain timing and repetition, therefore the timing of learning should be planned in intervals that facilitate learning. Even the consolidation of the simplest memories requires a certain amount of time. A pedagogical movement in Finland reminds us to "give time to think!" (Karjalainen et al. 2003). Learning cannot be rushed, neither can the absorbing of theoretical knowledge or practicing skills.

Experience at EVTEK confirmed that a three month break in studies at the right time, namely the practical training period in the third year, significantly helped students develop their professional identity and understanding. This offers one example of how curriculum planning and the spreading of the studies in an optimal way over the four-year period is crucial for student development.

The present scheduling of studies does not take this into account, quite to the contrary; the schooldays are packed with individual lessons that follow each other without breaks in between. However, recently started curriculum planning tries to combine individual small courses into larger units that would help integration of knowledge and allow more flexibility in scheduling. Moreover, the daily routines need to adjusted, in order to ensure protected and disturbance-free learning intervals and relaxing breaks. A busy schedule during the day causes self-planned breaks, which the students take at their own initiative and thus disturb the learning of the whole group.

Communality, that is, learning in communities is recognized as a new productive mode of education. Engineering instruction is moving strongly from individual effort towards team and project work. In addition to collaborative learning methods and guided projects, the learning environment should also encourage the creation of spontaneous self-study groups. International students in particular want attachment to communities, and often initiate efforts to create groups to help each other in studies. Unfortunately the organization of the curriculum and student activities has not been supportive of 
these efforts and they have died out rather soon. Organized support would also help students learn to understand the differences between beneficial co-operation and plagiarism.

\section{Epistemological and ethical challenges}

The research shows that culturally produced schemas indeed affect learning in engineering education. Schemas are adopted thinking patterns that do not change easily. Education that seems to provide predominantly isolated facts to the student does not affect her schemas. The challenge is to give instruction in a holistic, integrating way, that aids in the development of new thinking patterns and eventually new schemas.

A polyglot or multilingual upbringing early in life has been proven to enhance intellectual capacity, because it affects somatosensory system at a time when the functions are still polymodal and overlapping in the brain. Most of our students have a good general intelligence level, especially students who have already passed different types of education, and they demonstrate a flexible and illustrious attitude by willing expatriation to what often is an unknown country. These are students who have an amazing capacity to adapt to a new environment and develop. Therefore, the students are certainly disposed to adopting the modes of instruction and to modifying their habits. The students are normally in their early twenties, thus their brain is still in its development phase, and the plasticity allows for the easy adaptation of new cognitive skills.

However, the ethical question of modifying students values and attitudes remains unsolved. In order to educate professional engineers, student moral and social values should not be sacrificed. We should aim at seeking a best of both worlds -combination. For instance, Finnish and African cultures are in many ways opposites, one stressing individual achievement and the other social ties. When I had a broken ankle in the fall 2007, and I was consequently absent for a month, several Asian and African students showed great concern for my condition, and their emails always started with a polite inquiry after my health. Moreover, many African students have maintained an ability to avoid stress and time pressures. The abandonment of such behavioral patterns would be most unfortunate for their individual well-being.

Many students come from societies that have stronger oral traditions, and rely less on instruction on paper than the Finnish society. First-hand knowledge is separated in many epistemologies from book knowledge, even though our Western thinking does not emphasize, or even recognize that difference. A person who connects only first-hand knowledge to reality has difficulties in connecting theoretical studies to practice, unless the instruction succeeds in integrating them.

Learning by observation and imitation is the way human children start. Observation is a powerful method that is probably underutilized in academic education. Our instruction relies heavily on written 
instruction and individual activity, and very little on demonstration and collective practicing. Behaviorism has been labeled as outdated, mechanical, surface teaching, and consequently is out of fashion. Nevertheless, teaching practices in polytechnics already contain a fair amount of laboratory practice and hands-on activity, more so than in many third world school systems where the students come from.

Western engineering emphasizes step-by-step analytical processes, even though other kinds of approaches could enhance chances for innovations. Holistic, organic approaches are based on divergent thinking that foster creativity. In information technology, more functional, object-oriented methods could be added to the systematic problem-solving ways.

In engineering thinking, much of the work is done through categorizing and drawing system descriptions: charts, graphs of processes, flowcharts, algorithms, categorisations, structures, data base concept charts, entities, object classes, etc. The descriptions are part of the design and documentation and, moreover, they also act as tools in thinking, and therefore could be a means of describing it. In this respect, the shared and contextual nature of design work, its social processes, and mediating structures are essential parts of the cognitive process. Probably the best way to develop engineering thinking in students is to support and practice this process of creating formal descriptions without trying to influence the internal process that will, in any case, remain a unexplained. As discussed in section 3.1, scientific and engineering thinking processes are very difficult to trace or analyze, because subjects are not even themselves able to express them. Instead of describing the processes we have to revert to understanding the premises and looking for ways to facilitate problem-solving and analytic processes.

In order to develop student thinking, metacognitive and self-regulative processes need to be enforced: the understanding of learning tasks, planning, monitoring, and regulation of learning and motivation, and reflection on the process and outcome of learning. Students need support in deep understanding of abstract concepts, capability in algorithmic thinking and logical reasoning, as well as the ability to consciously apply them to practice.

\subsection{Evaluation of the study}

The surveys among students and staff were conducted in a traditional manner. They were done on paper to ensure equal access, and it indeed resulted in a high response rate. As was noted in the survey results (sections 5.2 and 5.3) however, the responses cannot be interpreted at face value. There were several reasons for the unreliability of results, including problems in self-reporting, language and comprehension problems, and misguided expectations of respondents. One of the survey sections, namely the Kolb learning style test, turned out to be a disaster, yielding useless results. This was rather surprising compared to its overall popularity in engineering education. 
Surveys that are used in research are required to be confidential, and therefore it is assumed that responses are reliable. The confidentiality condition was met in these surveys, but the reliability of the responses turned out to be poor. Even though the respondents most probably had sincere intentions, the answers were not strictly truthful, because international students obviously strived to give 'correct' answers. The weak reliability of results was confirmed by case study results (learning log statements and classroom observations), as well as in comparison with course feedback forms.

Dennett explains that "There are circumstances in which people are just wrong about what they are doing and how they are doing it. It is not that they lie in the experimental situation, but that they confabulate; they fill in the gaps, guess, speculate, mistake theorizing for observing. The relation between what they say and whatever it is that drives them to say what they say could hardly be more obscured. To sum up, subjects are unwitting creators of fiction." (Dennett 1991, 94, emphasis original) I believe that this is what happened in my surveys as well.

\section{Qualitative and quantitative methods compared}

Psychology is crap science.

A physicist at CERN

Engineers and scientists generally shun behavioral sciences (Firth 2007), partly because these apply statistical analysis and quantitative methods to data that are not phenomenally exact. As an engineer, I am no exception in this respect. Nevertheless, I also gathered quantitative data using questionnaires in this research. I have used both qualitative and quantitative methods in order to achieve results that are mutually complementary, that is a process called triangulation. For example, Berry et al. $(2002,287)$ recommend that cross-cultural psychology use both quantitative and qualitative methods that should be compatible, therefore there is no necessary controversy (also Flick et al. 2004, 172). Moreover, Gerring (2007) and Töttö (2004) underscore that, first of all, the research has to make sense.

Triangulation of methods and perspectives is particularly useful for theory development, when it serves to elucidate divergent perspectives. Flick gives an example of interviews and observations of actions that differ from each other (Flick et al. 2004, 180). In this research, explicit triangulation, comparison of survey data with observations and self-reports, has been applied, as illustrated in table 20. Moreover, a public disclosure and open explanation of methods and data has been attempted as much as practically possible. 


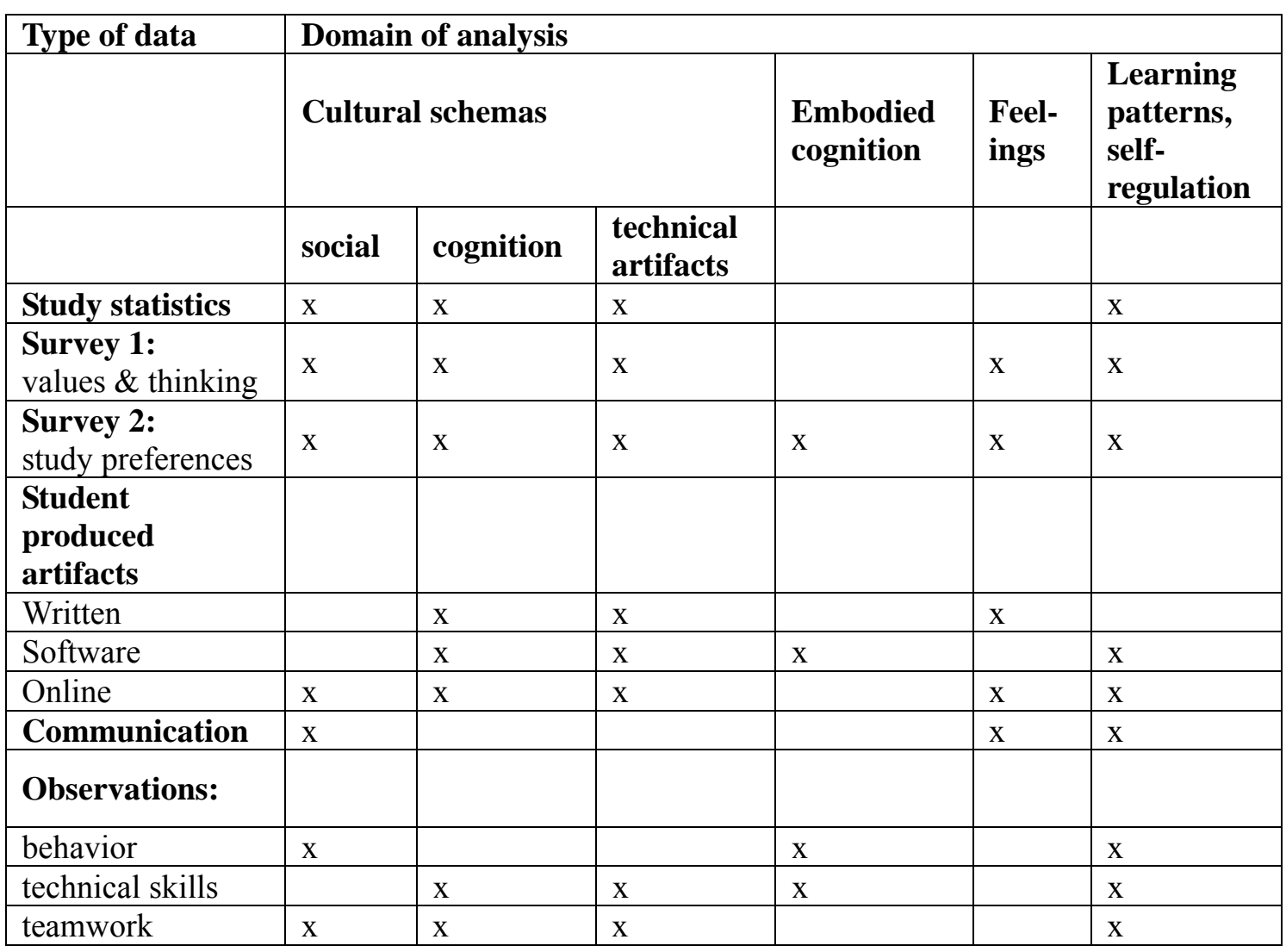

Table 20: Data analysis domains, use of theoretical tools

The anthropological method employs interviews combined with long-term observation. The combination of methods has, for instance, revealed that in tribal societies where men have secret ceremonies, it is commonly assured that women do not know the men's secrets. Observations show, however, that women may discuss the secrets among themselves, and even men might be aware of it. Still, the socially mediated contract upholds the belief that the secrets are indeed secret (Reiter et al. 1975). As shown in this research report, observations in the classroom were partly contradicting with survey results, and some questionnaire answers were, in reality, misleading. There was a discrepancy between words and deeds, which made an elaborate data analysis futile. Additionally, a systematic classification of textual data such as student writings was difficult, due to the poor quality of writing; most students are second-language English speakers who often use non-standard expressions. Extracts of student texts in this report illustrate the point. However, as a teacher - observer I had access to classroom interaction and the tacit knowledge that arose from daily interaction and which helped in the interpretation of results.

Objective and quantitative methods are seldom available for educational research due to resource constraints. However, Sternberg (2005) has demonstrated that quantitative research is possible: he uses control groups that are selected in various ways, and repeats the methodological experiments in different settings in different countries. Because of the requirement of enormous resources and large 
research teams, this is very costly and time-consuming research approach. It has not been, to my knowledge, attempted by other researchers. Even the famous OECD PISA studies that compare student abilities between a number of countries only measure outcomes of education, not outcomes of educational methods (Pisa study at http://www.pisa.oecd.org/). However, with seriously limited resources, the multidisciplinary research approach that was applied in this study turned out to be fruitful. 


\section{Conclusions}

This work has sought to shed light on how students in multicultural groups learn technology. It puts forth a novel understanding of the learning process, demonstrating that anthropological theory of mental schemas and social cognition, as well as new findings in neuroscience can be combined with sociocultural theories of learning in order to formulate a theoretical framework for engineering education. This framework has been shown to be useful in explaining student behavior in multicultural groups and in devising efficient modes of education. The study has brought to light the often ignored embodied, emotional, motivational, and social aspects of cognition in learning of technology. The cross-disciplinary approach is supported by empirical research findings in information technology education. It leads to an expanded view on contructing expertise in engineering education, as summarized in figure 15.

Experts in neuroscience and psychology have a cautiously optimistic view towards applying neuroscience in education (Neuroscience and education 2007). However, this research shows that when interpreting practical classroom experiences, neuroscience can indeed illuminate and explain individual learning processes on a general level, even though detailed descriptions of the process are still missing. The analysis of student problem-solving and thinking processes can be taken a step further with the help of brain studies, as these elucidate limitations of the analysis and factors affecting thinking.

A noteworthy finding that resulted in this research is the intricate interplay between English writing, character systems, programming, embodied writing skills, and visual perception. Through the theoretical framework that has been developed here, the thus far unexplored problem area was detected. With the indications of the problem, further research could be designed to find accurate explanations and appropriate solutions. The connection of program coding, different categories of mathematical thinking, and numerical abilities, as well as the process of how numbers are learnt and internalized, is a fascinating future area of study. Neuroscience assists in understanding the biological basis of mathematics and problem-solving capability, and how these skills are ingrained in the brain.

Cultural differences in cognition and in learning information technology have been shown to be significant though complicated because of the variety of individualized cultural schemas in a multicultural environment. Diversity is a consequence of student educational backgrounds, life histories, and national cultures, which, however, are too varied to be categorized meaningfully. Internalized schemas are therefore a valuable concept in simultaneously revealing the importance and limitations of culture when trying to understand multicultural student groups. 


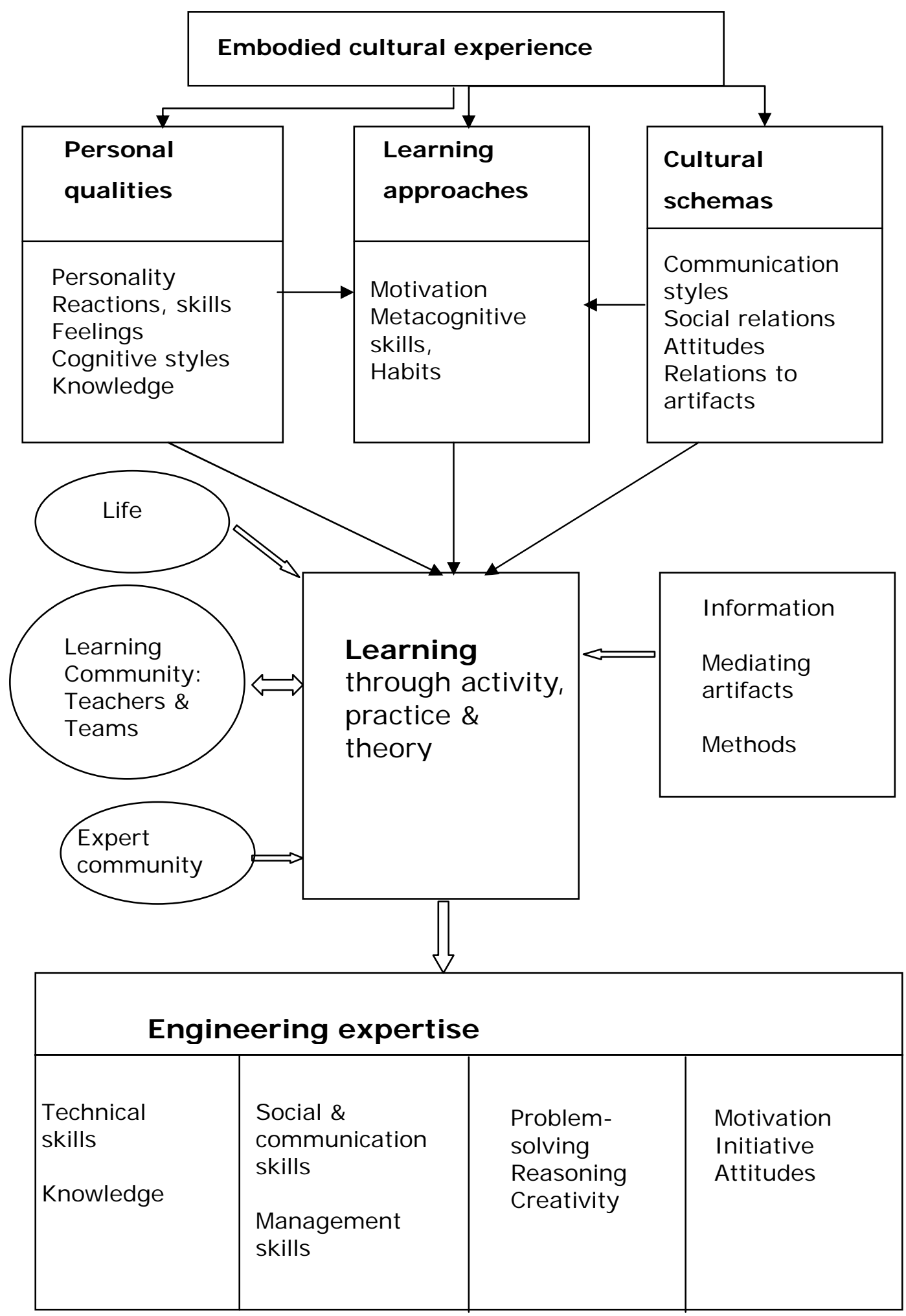

Figure 15: Constructing engineering expertise

Students need a learning environment where they can utilize their capacities and potential to become experts in information technology. Educational approaches that respond to the needs caused by student diversity are required. This study supports the view that a standardized, technology-centered instruction does not fully meet the needs in multicultural student groups. Methods should increasingly 
be based on encouraging students to be active learners who are able to reflect their understanding, cognitive processes, and progress in study. Education must provide the means to support development of student self-regulation. Moreover, we have to create a learning community where foreign students could act as a resource that could enrich our world, and where they could take part as active agents in developing our curriculum as also Crowther et al. have stressed (2000).

The analysis of the present situation shows that immigrant students are in many cases strongly anchored to their backgrounds, and experience a significant gap between their home culture and the Finnish environment. This inevitably causes stress and difficulties in adaptation - a problem that should be addressed by the educational environment. This research has highlighted some key problems in current practices, including a deficient recruitment policy that fails to select a functional mix of new students. Moreover, preparatory courses, well-established student support functions that also provide personal guidance and tutoring, and the formation of a cohesive student community would all alleviate integration problems. Collaborative learning that is implemented as a structured experience assists students in sharing experiences and coping strategies, and in supporting each other.

In this thesis, means to address the diversity of the classroom are proposed, and implications for the classroom and teaching are suggested. These include appropriate timing of learning and memorizing, a holistic and integrating approach to learning, and the acknowledgment of emotional and motivational factors in successful learning. Student self-reflection, understanding of metacognitive skills, and consequent improvement in self-regulation are supported by the use of learning logs, teamwork in mixed teams, and organizing specific orientation courses for reflection and getting familiar with the study environment. A variety of teaching methods that recognize the multimodality of thinking processes, provision of alternative ways to pass study units, and also concrete instruction to facilitate real understanding are some of the recommended means. The faculty needs to be open to student insights and feedback. An emotionally supportive learning environment would increase chances for student integration.

This research has disclosed how internalized cultural schemas influence student behavior in many different contexts. First of all, the case of not following instructions in laboratory indicated unfamiliarity with procedural work, which has been assumed to be a universal cognitive ability. This research shows that even though the ability may be innate, its application in particular context is learnt. Moreover, students continued to follow their earlier schemas of social behavior instead of adapting the 'laboratory script', i.e. the rigorous following of instructions. Therefore, technology education has to take different forms in different cultural settings.

Secondly, students' experiences of previous modes of instruction remain as schemas in their minds. If the earlier instruction has kept theory removed from practical application, students have to learn to 
integrate the knowledge to practice. This requires a different type of learning: instead of memorizing, the knowledge needs to be processed and applied. The instrumental nature of engineering knowledge has to be internalized. Possibly a change in attitudes towards hands-on work is needed, as well, if a student's value system undervalues manual labor.

One of the practical problems is plagiarism which is quite clearly not considered an offence by students who have been accustomed to learning by imitation. The cultural analysis of learning practices reveals that attitudes towards copying are varied and not easily changed because of their internalized character.

Last but by no means least is the student's relationship to technology and scientific world-view, which is a fundamental part of culture. Literature studies indicated a wide variety that has been observed in practice in this research. The reconciliation of differing world-views is a major challenge in multicultural technology education, which has not been seriously addressed yet.

On the other hand, resource constraints in universities do not allow much individual attention and tutoring, thus students have to be able to adapt to the mode of instruction. The findings of this study suggest that there are certain factors that limit the chances of success even in well-arranged settings: if the new material to be learned is outside the zone of proximal development of the student, its integration into existing knowledge is impossible. If there are no appropriate mental schemas to build on, confusion arises. Sometimes the gap between current and former educational cultures is simply too broad to be closed. Moreover, the community of students and teachers needs to be functional. According to our experience, the best recipe for a good learning community is a mix of cultures where no single culture is overly dominant. Additionally, a cultural mix appears to be conducive for creative teamwork and innovative projects.

\section{Proposals for future research}

This research has called for attention to various areas of study that have hitherto been ignored, attempting to indicate directions that would need further study. In doing so, it raises more questions than it answers. The variety of methods in educational research offers the possibility to continue work in several directions. The analysis and methods of this research have been constrained by the limited resources of a solitary researcher, and the researcher's position as a teacher. The findings underscore the importance of further study in cognitive and learning processes of engineering students, preferably through cross-cultural and interdisciplinary research collaboration. The expanded view of constructing expertise in multicultural settings as presented in figure 15 has been applied to engineering education in this work, but it remains to be tested whether it might also be applicable in other areas of professional education. 
The analysis of laboratory work was based on observations. In order to gain in-depth understanding of student procedural work or problem-solving approaches videotaped experiments in the laboratory could give a more detailed picture. Additionally, the great amount of material that has been collected would be worth a closer scrutiny. Learning logs in particular provide a wealth of information on student views that has not been fully analyzed yet. Moreover, issues of language and communication emerged as important, and they offer interesting opportunities for further study.

Further research in brain studies would be needed in order to understand the difficulties that the Latin alphabet and its complicated punctuation cause in program coding for students who learnt other character systems before it. Deep knowledge of the neurological processes would produce guidelines for adequate and targeted educational interventions, and simultaneously, reduce underestimation of the complexity of scientific and mathematical skills.

However, the current research has concentrated mainly on incoming students and the beginning of studies. Therefore, the development of student thinking over the four-five year study period has not yet been traced yet. Interviewing successful students would provide information on their coping strategies and adaptation experience. Moreover, interviews would probably be an appropriate way to explore the issue of gender in technology studies, as the small number of female students in the current sample precludes statistical surveys. Alternatively, a wide research collaboration between universities would enable detailed, culture-specific and method-specific studies. Many educational institutions in Europe are in a similar position in offering English language degrees, therefore international research efforts would considerably enhance our understanding of problem areas. 


\section{References}

Aarnio, K. (2007) Paranormal, superstitious, magical, and religious beliefs. Department of Psychology. Studies 44: 2007, University of Helsinki, Finland

ABET. At http://www.abet.org, accessed 12.4.2008

Abu-Hanna, U. (2007) Sinut. Helsinki: WSOY.

Adams, D. (1985) So long, and thanks for all the fish. New York: Random House.

Ahmed, S.(2004) The Cultural Politics of Emotion. New York: Routledge.

Alitolppa-Niitamo, A. (2004) The Icebreakers. Somali-speaking youth in metropolitan Helsinki with a focus on the context of formal education. Helsinki: The family federation of Finland, The population research institute. D42/2004

Allt, S. (2002) Working life feedback in Finnish higher engineering education. Helsinki: TEK.

Anfara, V.A., Brown, K.M. \& Mangione, T.L. (2002) Qualitative analysis on stage: Making the research process more public. Educational Researcher Oct 2002, 28-38.

Asante, M.K. (2001) Transcultural realities and different ways of knowing. In V.Milhouse, M.K.Asante \& P.O.Nwosu (Eds.) Transcultural realities. Interdisciplinary perspectives on cross-cultural relations. (pp. 71 - 81). Thousand Oaks: Sage.

Bakir, A., Landis, D. \& Noguchi, K. (2004) Looking into studies of heterogeneous small groups. In D.Landis, J.M.Bennett \& M.J.Bennett (Eds.) Handbook of Intercultural Training. (pp. 416433). Thousand Oaks, CA: Sage.

Banks, J.A. \& Banks, C.A.M. (Eds.) (2004) Handbook of research on multicultural education. San Francisco, CA: Jossey-Bass.

Beauvoir, S. de (1949) Le deuxième sexe. Paris: Gallimard. [The Second Sex.]

Bechtel, W. \& Abrahamsen, A. (2002) Connectionism and the Mind: Parallel Processing, Dynamics and Evolution in Networks. Second Edition. Oxford: Blackwell Publishers.

Bechtel, W. \& Graham, G. (Eds) (1998) A companion to cognitive science. Oxford: Blackwell Publishig.

Bélanger, F., Lewis, T., Kasper, G., Smith, W. \& Harrington, K.V. (2007) Are computing students different? An analysis of coping strategies and emotional intelligence. IEEE Trans. Educ., 50, 188-196.

Bennett, M. J. \& Castiglioni, I. (2004) Embodied ethnocentrism and the feeling of culture. In D.Landis, J.M.Bennett \& M.J.Bennett (Eds.) Handbook of Intercultural Training. (pp. 249 - 265) Thousand Oaks, CA: Sage.

Bennett, M.R., Dennett, D., Hacker, P. \& Searle, J. (2007) Neuroscience and Philosophy: Brain, Mind, and Language. New York: Columbia University Press.

Bereiter, C. (2002) Education and Mind in the Knowledge Age. New Jersey, London: Lawrence Erlbaum Associates.

Bergson, H. (2000/ 1900) Nauru. Tutkimus komiikan merkityksestä. [original Le Rire. Essai sur la signification du comic. 1900] Helsinki: Loki kirjat.

Berk, L., Tan, S., Fry, W., Napier, B., Lee, J., Hubbard, R. and Lewis, J.(1989) Neuroendocrine and Stress Hormone Changes During Mirthful Laughter. American Journal of the Medical Sciences. 298(6), 390-396

Berry, J. W. (2004) Fundamental psychological processes in intercultural relations. In D.Landis, J.M.Bennett \& M.J.Bennett (Eds.) Handbook of Intercultural Training. (pp. 166- 184) Thousand Oaks: Sage.

Berry, J.W., Poortinga, Y.H., Segall, M.H. \& Dasden, P.D. (2002) Cross-cultural psychology. Research and applications. Second edition. Cambridge: Cambridge University Press.

Biersack, A. (1982) The logic of misplaced concreteness: Paiela body counting and the nature of primitive mind. American Anthropologist 84 (4), 811-829

Biggs, J. (1999) Teaching for quality learning at university. What the student does. Buckingham: Society for research into higher education and Open University Press.

Björklund, C. (2007) Hållpunkter för lärande: småbarns möten med matematik. Åbo : Åbo Akademis förlag. [Critical conditions of learning - toddlers encountering mathematics.] Dissertation. Department of Early Childhood Education, Faculty of Education, Åbo Akademi University, Jakobstad. 
Björkstrand, R. \& Lallimo, J. (2006) Knowledge intensive design system - an attempt for better engineering environment. In J.Malmqvist \& F. Berglung (Eds.), Proc 1st Nordic Conf. on Product Lifecycle Management - NordPLM'06, 243-253. Göteborg: Chalmers University of Technology.

Boden, M. A. (1987) Artificial intelligence and natural man. Second edition, expanded. London: MIT Press.

Bourdieu, P. (1998) La domination masculine. France: Seuil.

Boyatzis, R.E. \& Kolb, D. (1991) Assessing individuality in learning: The learning skills profile. Educ. Psychology, 1991:3/4, 279-296.

Braidotti, R. (1994) Nomadic subjects: embodiment and sexual difference in contemporary feminist theory. New York: Columbia University Press. (2002) Metamorphosis. Towards a materialist theory of becoming. Oxford: Blackwell Publishers.

Braverman, J. D. (1972) Probability, Logic, and Management Decisions. McGraw Hill.

Capizzo, M., Nuzzo, S. \& Zarcone, M. (2006) The impact of the pre-instructional cognitive profile on learning gain and final exam of physics courses: a case study. Eur. J. Eng. Educ., 31, 717-727

CDIO. At http://www.cdio.org, accessed 15.4.2008

Chen, G.M. (2001) Toward transcultural understanding. A harmony theory of Chinese communication. In V.Milhouse, M.K.Asante \& P.O.Nwosu (Eds.) Transcultural realities. Interdisciplinary perspectives on cross-cultural relations. (pp. 55- 70). Thousand Oaks: Sage.

Christie, A. (1993/ 1955). Hickory Dickory Dock. London: Harper Collins.

Clancey, W. J. (2005). Modeling the perceptual component of conceptual learning - A coordination perspective. In P.Gärdenfors \& P. Johansson (Eds).Cognition, education, and communication technology. (pp. 109 - 146). NJ: Lawrence Erlbaum Associates.

Clark, C. (2004) Emotional gifts and 'you first' micropolitics; niceness in the socioemotional economy. In A. S. R. Manstead, N. Frijda, \& A. Fischer (Eds)., Feelings and emotions. The Amsterdam Symposium (pp. 402-421). Cambrigde: Cambridge University Press.

Claxton, G. (2005). The Wayward Mind: An Intimate History of the Unconscious. Little, Brown.

Coffield, F., Moseley, D., Hall, E. \& Ecclestone, K. (2004) Should we be using learning styles? Learning and Skills Research Centre. London.

Coltelli, L. (1990) Winged words. American Indian writers speak. Lincoln and London: University of Nebraska Press.

Committee on the international strategy of higher education institutions. Memorandum for the Ministry of Education 2.11.2001

Cortazzi, M. \& Jin, L. (1997) Communication for learning across cultures. In D. McNamara \& R. Harris (Eds.) Overseas students in higher education. Issues in teaching and learning. (pp. 7690) London: Routledge.

Craig, A.P. \& J.J. Beishuizen. (2002) Psychological testing in a multicultural society: universal or particular competencies? Intercultural Education, 13(2), 201-214

Crawley, E. F., Malmqvist, J., Östlund, S. \& Brodeur, D.R. (2007) Rethinking engineering education. The CDIO approach. New York: Springer.

Crowther, P., Joris, M., Otten, M., Nilsson, B., Teekens, H. \& Wächter, B. (2000) Internationalisation at home. A position paper. European Association for International Education

Crump, T. (1990) The anthropology of numbers. Cambridge: Cambridge University Press.

Crystal, D. (1987) The Cambridge encyclopedia of language. Cambridge: Cambridge University Press.

Cusumano, M., MacCormack, A., Kemerer, C.F. \& Crandall, B. (2003) Software development worldwide: the state of the practice. IEEE Software, 20(6), 28 - 34

Dai, D.Y. \& Sternberg.R. (Eds.) (2004) Motivation, emotion, and cognition: Integrative perspectives on intellectual functioning and development. NJ: Lawrence Erlbaum Associates.

Damasio, A.(1999) The feeling of what happens. Body, emotion and the making of consciousness. Vintage UK: Random House.

(2003) Looking for Spinoza. Joy, sorrow and the feeling brain. Vintage UK: Random House. (2004) Emotions and feelings. A neurobiological perspective. In A. S. R. Manstead, N. Frijda, \& A. Fischer (Eds)., Feelings and Emotions. The Amsterdam Symposium (pp. 49-57).

Cambrigde: Cambridge University Press.

D'Andrade, R.(1995) The development of cognitive anthropology. Cambridge: Cambridge University Press. 
Dane, E. \& Pratt,M.G. (2007) Exploring intuition and its role in managerial decision making. Academy of Management Review. 32(1), 33-54.

Davidson, J.E.\& Sternberg, R. (Eds.) (2003) The psychology of problem solving. Cambrigde: Cambridge University Press.

Deacon, T.W. (1998) Language evolution. In W. Bechtel \& G. Graham (Eds.), A companion to cognitive science (pp. 212-225). Oxford: Blackwell Publishing.

Debiec, J., Doyère, V., Nader, K \& LeDoux, J. (2006) Directly reactivated, but not indirectly reactivated, memories undergo reconsolidation in the amygdala. Proc Natl Acad Sci U S A., 103(9), 3428-3433

Dehaene, S., Izard, V., Pica, P,. \& Spelke, E.S. (2006) Core knowledge of geometry in an Amazonian indigene group. Science, 311, 381-384.

Demarest, A. (2004) Ancient Maya. The rise and fall of a rainforest civilization. Cambridge: Cambridge University Press.

Dennett, D.C., (1991) Consciousness Explained. London: Penguin Books Ltd

Dobbs, D. (2006). Big answers from little people. Scientific Am. Mind, 16, 38-43.

Donzellini, G., Ponta, D., Bailey, C. \& Xu, D. (1999) Learning electronic systems design with a project based course on the network. In Proc of Enable99. Espoo, 114-121

Duckworth, A.L. \& Seligman, M.E.P. (2005) Self-discipline outdoes IQ in predicting academic performance of adolescents. Psychological Science, 16, 939-944.

Duff, A. H., Rogers, D.P. \& Harris, M.B. (2006) International engineering students—avoiding plagiarism through understanding the Western academic context of scholarship. Eur. J. Eng. Educ., 31(6), 673-681.

Dunbar, K. (1998) Problem solving. In W. Bechtel \& G. Graham (Eds), A companion to cognitive science (pp. 289-299). Oxford: Blackwell Publishing.

Earley, P. C. (2006). Leading cultural research in the future: a matter of paradigms and taste. $J$ of Intl Business Studies, 37(6), 922-931

Eckerdal, A \& Berglund, A. (2005) What does it take to learn 'Programming thinking'? In Proc of ICER'05 (Seattle, Washington, October 1-2, 2005) ACM Press, New York, 135-142

Ekman, P. (2004) What we become emotional about. In A. S. R. Manstead, N. Frijda, \& A. Fischer (Eds)., Feelings and emotions. The Amsterdam symposium (pp. 119-135). Cambrigde: Cambridge University Press.

Eminah, J.(2003) The interaction of traditional beliefs and scientific ideas: the case of hiv/aids conceptualization by university students. Proc UNESCO Conf. on Intercultural Educ., Jyväskylä. CD-ROM.

Engeström, Y. (2001) Expansive learning at work: Toward an activity-theoretical reconceptualization. Journal of Education and Work. 14(1), 129-152.

Erkinjuntti, T., Alhainen, K., Rinne, J. \& Soininen,H. (2006) Muistihäiriöt ja dementia. Helsinki: Duodecim.

European Journal of Engineering Education, Special Issue: Globalization and its impact on engineering education and research, 2006(3).

European Social Survey. At http://www.europeansocialsurvey.org/, accessed 15.3.2008

Evans, J. St. B.T. (2002). Logic and human reasoning: an assessment of the deduction paradigm. Psychological Bulletin. 128(6), 978-996

Evers, C. W. \& Wu, E.H. (2006). On Generalising from Single Case Studies: Epistemological Reflections. J of Philosophy of Educ., 40( 4), 511-526

Fan, Y. (2000). A classification of Chinese culture. Cross Cultural Management, 7(2), 3-10.

Fara, P. \& Patterson, K.(Eds.) (1998) Memory. Cambridge: Cambridge University Press.

Ferguson, E.S. (1992) Engineering and the mind's eye. MIT Press.

Fitzgerald, S., Simon, B. \& Thomas, L. (2005) Strategies that students use to trace code: an analysis based in grounded theory. In Proc. of ICER'05 (Seattle, Washington, October 1-2, 2005) ACM Press, New York, 69-80

Flick, U., von Kardorff, E. \& Steinke,I. (Eds.) (2004) A companion to qualitative research. London: Sage.

Flynn, N. \& Stainthorp, R. (2006). The learning and teaching of reading and writing. London: John Wiley.

Foster, D.J. \& Wilson, M.A. (2006) Reverse replay of behavioural sequences in hippocampal place cells during the awake state. Nature, 440, 680-683. 
Foucault, M. (1975) Surveiller et punir: Naissance de la prison. [Discipline and Punish: The Birth of the Prison]

Foundation for Endangered Languages. At http://www.ogmios.org/home.htm, accessed 24.2.08

Frank, R.H. (2004) Introducing moral emotions into models of rational choice. In A. S. R. Manstead, N. Frijda, \& A. Fischer (Eds.) Feelings and emotions. The Amsterdam Symposium (pp. 422-440). Cambrigde: Cambridge University Press.

Frith, C. (1998) Deficits and pathologies. In W. Bechtel \& G. Graham (Eds), A companion to cognitive science (pp. 380-390). Oxford: Blackwell Publishing. (2007) Making up the mind: How the brain creates our mental world. Oxford: Blackwell Publishing.

Gardner, H. (1993) Multiple intelligences: The theory in practice. New York: BasicBooks.

Gazzaniga, M. S. (2002) The split brain revisited. , 12(1), 27-31

Gernet, J. (1996) A history of Chinese civilization. Second edition. New York: Cambridge University Press.

Gerring, J. (2007) Case study research. Principles and practices. New York: Cambridge University Press.

Goh, J.O., Chee, M.W., Tan, J. C. \& Venkatraman, V., and Hebrank, A., Leshikar, E., Jenkins, L., Sutton, B.P, Gutchess, A. \& Park,D.C. (2007) Age and culture modulate object processing and object-scene binding in the ventral visual area. Cognitive, Affective, \& Behavioral Neuroscience, 7 (1), 44-52

Gärdenfors, P. \& Johansson, P. (Eds.) (2005) Cognition, education, and communication technology. NJ: Lawrence Erlbaum Associates.

Hakkarainen, K., Lonka, K. \& Lipponen, L. (2004a). Tutkiva oppiminen. Järki, tunteet ja kulttuuri oppimisen sytyttäjinä. [Progressive inquiry learning: Reason, emotions and culture] Porvoo: WSOY.

Hakkarainen, K., Palonen, T., Paavola, S.\& Lehtinen, E. (2004b). Communities of networked expertise. Professional and educational perspectives. Elsevier. Oxford.

Hallen, B. (2003) Not A House Divided, J on African Philosophy: Issue 2.

Haller, C., Fisher, R. \& Gapp, R. (2007) Reflection as a means of understanding: Ways in which Confucian Heritage students learn and understand organisational behaviour. Multicultural Education \& Technology Journal. 1(1), 6-24

Haltsonen, S., Leinonen, T. \&Markkanen, H. (1998). International BEng programs in computer engineering and digital information provision at EVITech. Symposium on Intelligent systems in control and measurement. Proceedings. Miskolc, Hungary.

Hannula, M.M., \& Lehtinen, E. (2005). Spontaneous focusing on numerosity and mathematical skills of young children. Learning and Instruction, 15, 237-256.

Hannula, M.S. (2004) Affect in mathematical thinking and learning. Turku, Finland: Annales universitatis Turkuensis B 273.

Harnish, D. (2003) An Arab-American project to improve technical education: sustaining intercultural educational collaboration during tense times. In Proc. UNESCO Conf. on Intercultural Educ., Jyväskylä,CD-ROM.

Harrison, R. (1989) Signs, songs, and memory in the Andes. Translating Quechua language and culture. Austin: University of Texas Press.

Hautamäki, A. (Ed.) (1988) Kognitiotiede. [Cognitive Science] Helsinki: Gaudeamus.

Helenius, M-L. (Ed.) (2007) Joint services - challenges of integrating international students. International Degree Student Services in the Metropolitan Area. A report commissioned by the Helsinki Education and Research Area.

Hermans, P. (2002). Intercultural Education in two teacher-training courses in the north of Netherlands. Intercultural Educ., 13:2, 183-200.

Hickok, G., Bellugi, U. \& Klima, E. (2002) Sign language in the brain. Scientific Am. Mind 12(1), 4653

Hintikka, J. (2001) Filosofian köyhyys ja rikkaus. Nykyfilosofian kartoitusta. [Essays on modern philosphy] Art House. Helsinki.

Hodder, I. \& Hutson, S. (2003) Reading the past. Current approaches to interpretation in archaeology. Cambrigde: Cambridge University Press.

Hofstede, G. (1991) Cultures and organizations: Software of the mind. London: McGraw-Hill. 
(2002) Dimensions do not exist: A reply to Brendan McSweeney. Human Relations, 55(11), $1355-1361$.

Holvikivi, J. (1991) Working with microcomputer users in developing countries- cases from Tanzania, Micronesia and the Maldives. In I.V. Erikson, B.A. Kichenham \& K.G. Tijdens (Eds.). Women, work, and computerization. (pp. 175-184). Amsterdam: North Holland.

(2002) International students in information technology education - where do they locate themselves? Crossroads in Cultural Studies: Fourth International Conf. June 29 - July 2, 2002, Tampere. (unpublished)

(2003). Cross-cultural teamwork in information technology education. Proc of the UNESCO Conf. on Intercultural Educ., Jyväskylä. CD-ROM.

(2007a). Culture and cognition in information technology education. Eur. J. Eng. Educ., 32 (1), 73-82

(2007b). Learning styles in engineering education: the quest to improve didactic practices.

Eur. J. Eng. Educ., 32 (4), 401 - 408

(2007c). Logical Reasoning Ability in Engineering Students: A Case Study. IEEE Trans Educ., 50(4), 367-372

Field notes 2004-2008.

Courses site. Available online at: http://www.evtek.fi/ jaanah/ Accessed 12.4.2008

Holvikivi, J., Leinonen, T. \& Toivio, L. (2001) Information Technology. Koulutusohjelman opetussuunnitelman kehittäminen. Opetussuunnitelmatyötä ohjaavat parametrit. [Curriculum development] Jyväskylän Ammattikorkeakoulu. Ammatillinen opettajakorkeakoulu. Päättötyö.

Hutchins, E. (1995) Cognition in the wild. Cambridge, MA: MIT Press.

Isen, A. M. (2004) Some perspective on positive feelings and emotions: positive affect facilitates thinking and problem solving. In A. S. R. Manstead, N. Frijda, \& A. Fischer (Eds.) Feelings and emotions. The Amsterdam Symposium (pp. 263-281). Cambrigde: Cambridge University Press.

Isomäki, H.-K. (2002) The prevailing conceptions of the human being in information systems development: Systems designers' reflections. University of Tampere. Department of Computer and information sciences. A-2002-6. Tampere.

Ivarsson, J. \& Säljö, R.(2005) Seeing through the screen: Human reasoning and the development of representational technologies. In P. Gärdenfors \& P. Johansson (Eds). Cognition, education, and communication technology (pp. 203-222) Mahwah, NJ: Lawrence Erlbaum Associates.

Izard, V., Dehaene-Lambertz G. \& Dehaene S. (2008) Distinct Cerebral Pathways for Object Identity and Number in Human Infants. PLoS Biol 6(2): e11

Jiwa, H. (2005) Kuudes aisti pelasti onge-kansan. Kumppani 2005(2), 22-23

Johansson, P. \& Gärdenfors, P. (2005). Introduction. In P. Gärdenfors \& P. Johansson (Eds.) Cognition, education, and communication technology (pp. 1-20) Mahwah, NJ: Lawrence Erlbaum Associates.

Kalat, J. W. (2004) Biological Psychology. $8^{\text {th }}$ Ed. Belmont, CA: Thomson Wadsworth.

Kandel, E. (2006) The new science of mind. Scientific Amer Mind, 17(2), 62-69

Karjalainen, A., Alha, K. \& Jutila, S. (2003) Anna aikaa ajatella - Suomalaisten yliopisto-opintojen mitoitusjärjestelmä . Oulun yliopisto, Opetuksen kehittämisyksikkö.

Karppinen, M. (2006) Cultural patterns of knowledge creation. Finns and Japanese as engineers and poets. Helsinki School of Economics. A-271.

Kaynak, O., Braun,R. \& Kennedy, I. (2008) Guest Editorial Plagiarism. IEEE Trans Educ 51(2), 149151

Keller, E. F. (1983) A feeling for the organism. The life and work of Barbara McClintock. New York: W.H.Freeman and Company.

Keltikangas-Järvinen, L. (2000) Tunne itsesi, suomalainen. [Know thyself, Finn] Porvoo: WSOY

Kinnunen, T. (2003) "If I can find a good job after graduation, I may stay". Ulkomaalaisten tutkintoopiskelijoiden integroituminen Suomeen. [in Finnish: Foreign degree student integration to Finland] CIMO 2003 2B.

Kirsh, D. (2005) Metacognition, distributed cognition, and visual design. In P. Gärdenfors \& P. Johansson (Eds). Cognition, education, and communication technology ( pp. 147-179) Mahwah, NJ: Lawrence Erlbaum Associates. 
Kitsnik, P., Nurminen, T., Piironen, A. \& Saurén, K. (2003) Facing Cultural Differences in Multicultural Learning Environment. Jyväskylän Ammattikorkeakoulu. Ammatillinen opettajakorkeakoulu. Päättötyö.

Knierim, J.J. (2007) The matrix in your head. Scientific Am. Mind. 18(3), 42-49.

Koch, C. \& Preuschoff, K. (2007) Betting on Consciousness. Scientific Am. Mind. 18(3), 16-17.

Kolb, D.A. (1984). Experiential learning: experience as the source of learning and development. New Jersey: Prentice Hall. (1998) Experiential learning: From discourse model to conversation. Interview. Lifelong Learning in Europe, 1998 (3), 148-153.

Kozlowski, S.W. \& Ilgen, D.R. (2007) The science of team success. Scientific Am. Mind. 18(3), 54-61.

Knorr Cetina, K. (1999) Epistemic Cultures: How the Sciences Make Knowledge. Cambridge, MA: Harvard University Press.

Kutay, C., Ho, P. \& Whale, G. (1999) Internet Based Groups in Computer Science: Helping Groups Work. Proc of Enable99. Espoo, 56-68

Lakkala, M., Ilomäki, L., \& Palonen, T. (2007) Implementing virtual, collaborative inquiry practices in a middle school context. Behaviour \& Information Technology, 26(1), 37-53.

Lakoff, G. \& Johnson, M. (1999) Philosophy in the flesh. The embodied mind and its challenge to Western thought. New York: Basic Books.

Landis, D., Bennett, J. M. \& Bennett, M. J. (Eds.) ( 2004) Handbook of Intercultural Training. Thousand Oaks: Sage.

Lappalainen, E.-M. (2005). Kulttuurisesti sensitiivinen opettajuus. Käden, kielen ja kulttuurin oppimisen ymmärtäminen maahanmuuttajien koulutuksessa ja opettajan kasvupolulla. [Culturally sensitive teaching practice] Saarijärvi: Gummerus.

Latu, S. \& Young, A. (2004). Teaching ICT to Pacific Island Background Students. Sixth Australasian Computing Education Conference (ACE2004), Dunedin. Conferences in Research and Practice in Information Technology, Vol. 30.

Leminen, E., Haltsonen, S. \& Hämäläinen, M. (1994) International engineering education in Finland: B.Eng. program in computer engineering at EVITech. ASEE Annual Conf. Proc. 482-485.

Léoni, V., Mullet, E. \& Chasseigne, G. (2002) Aging and intuitive physics. Acta Psychologica. 111(1), 29-43.

Levering, B. (2006) Epistemological issues in phenomenological research: How authoritative are people's accounts of their own perceptions? J of Philosophy of Educ., 40 (4), 451-462.

Levine, L. J. \& Pizarro, D. A. (2004) Emotion and memory research: A grumpy overview. Social Cognition, 22(5), 530-554

Li, J. \& Fischer, K.W. (2004) Thought and affect in American and Chinese Learners' beliefs about learning. In D.Y.Dai \& R. Sternberg (Eds.) Motivation, emotion, and cognition: Integrative perspectives on intellectual functioning and development. (pp. 385-418) NJ: Lawrence Erlbaum Associates.

Liebertz, C. (2005), A Healthy Laugh. Scientific Amer Mind. 16(3), 90-91

Lifländer, V. (1999) Expansive knowledge construction in network-based project learning. Proc of Enable99. Espoo, 33-45

Lilius, A-L. (2007) Nettiaika toi uudet arvot. Talouselämä 15.6.2007, 20-26

Little, J.C., Granger, M., Adams, E.S., Holvikivi, J., Lippert, S.K., Walker, H.M. \& Young, A. (2001) Integrating Cultural Issues into the Computer and Information Technology Curriculum, ACM SIGCSE Bulletin, 33(2).

Lomawaima, K.T. (2004) Educating Native Americans. In J.A.Banks \& C.A.M. (Eds.). 2004. Handbook of research on multicultural education (pp. 441-461 ) San Francisco: Jossey-Bass.

Lotkowski, V. A., Robbins, S. B. \& Noeth, R.J. (2004) The role of academic and non-academic factors in improving college retention. ACT Policy report.

Macrae, M. (1997) The induction of international students to academic life in the United Kingdom. In D. McNamara \& R. Harris (Eds.) Overseas students in higher education. Issues in teaching and learning. (pp. 127-142) London: Routledge.

Maguire, E.A., Gadian, D., Johnsrude, I., Good, C.D, Ashburner, J., Frackowiak, R. and Frith, C. (2000). Navigation-related structural change in the hippocampi of taxi drivers. Proc Natl Acad Sci U S A., 97(8), 4398-4403.

Mankiller, W. \& Wallis, M. (1993) Mankiller. A chief and her people. New York: St. Martin's Press. 
Manstead, A. S. R., Frijda, N. \& Fischer, A. (Eds.). (2004) Feelings and emotions. The Amsterdam Symposium. Cambridge: Cambrigde University Press.

Margulies, C., Tully, T. \& Dubnau, J. (2005) Deconstructing Memory in Drosophila. Current Biology, $15,700-713$

Markkanen, H. (1999) Network-based project learning - Netpro project experiences. Proc of Enable99. Espoo, 103-113

Masataka, N., Ohnishi, T., Imabayashi, E., Hirakata, M. \& Matsuda, H. (2007) Neural correlates for learning to read Roman numerals. Brain and Language, 100, 276-282

Mason, M. (2001) The ethics of integrity: educational values beyond postmodern ethics. $J$ of Philosophy of Educ. 35 (1), 47-69.

Massoudi, M. (2002) On the qualities of a teacher and a student: an Eastern perspective based on Buddhism, Vedanta and Sufism. Intercultural Education, 13(2), 137-155.

Matsumoto, D., Nezlek, J.B. \& Koopmann, B. (2007) Evidence for Universality in Phenomenological Emotion Response System Coherence. Emotion, 7(1), 57-67

McNamara, D. \& Harris, R. (Eds.) (1997) Overseas students in higher education. Issues in teaching and learning. London: Routledge.

McSweeney, B. (2002) Hofstede's model of national cultural differences and their consequences: A triumph of faith - a failure of analysis. Human Relations, 55, 89-117.

Menninger, K. (1969) Number Words and Number Symbols: A cultural history of numbers. Cambridge: Cambrigde University Press.

Milhouse, V., Asante, M.K. \& Nwosu, P.O. (Eds.) (2001) Transcultural realities. Interdisciplinary perspectives on cross-cultural relations. Thousand Oaks: Sage.

Mitchell, J.C. (1984). Case studies. In R.F.Ellen (Ed.), Ethnographic research. A guide to genral conduct. (pp. 237-241) London: Academic Press.

Mortimer, E. \& Wertsch, J. (2003) The architecture and dynamics of intersubjectivity in science classrooms. Mind, Culture, and Activity, 10, 230-244.

Moss, J., Kotovsky, K. \& Cagan, J. (2006) The role of functionality in the mental representations of engineering students: Some differences in the early stages of expertise. Cognitive Science, 30 , $65-93$

Myers, D. G. (2007) The powers and perils of intuition. Scientific Amer. Mind, 18:3, 24-31

Mäki, E. (2008). Exploring and exploiting knowledge: Research on knowledge processes in knowledge-intensive organizations. Helsinki University of Technology. Department of Industrial Engineering and Management. Doctoral Dissertation Series 2008/1. Espoo.

Napier, N. P. \& Johnson, R.D. (2007) Technical Projects: Understanding Teamwork Satisfaction In an Introductory IS Course. J of Information Systems Educ. 18(1), 39-48

Needham, Roger. (2000). Keynote address in the 5th Annual Conference on Innovation and Technology in Computer Science Education; ITiCSE'00. ACM: SIGCSE ja SIGCUE.

Neuroscience and Education. (2007) Issues and Opportunities. A Commentary by the Teaching and Learning Research Programme. University of London.

Neville, H. (2007) Experience shapes human brain development and function. Cicero- symposium Lifelong-learning and the brain. Helsinki 20.11. 2007

Nisbett, R.E. \& Masuda, T. (2006) Culture and point of view. In R.Viale, D. Andler \& L. Hirschfield (Eds.) Biological and cultural bases of human inference. (pp. 49-70) New Jersey: Lawrence Erlbaum Ass.

Nonaka, I. \& Takeuchi, H. (1995) The Knowledge-Creating Company. How Japanese Companies Create the Dynamics of Innovation. New York/Oxford: Oxford University Press

Norenzayan, A. (2006) Cultural variation in reasoning. In R.Viale, D. Andler \& L. Hirschfield (Eds.) Biological and cultural bases of human inference. (pp. 71-95) New Jersey: Lawrence Erlbaum Ass.

Nuckolls, C.W. (1998) Cognitive anthropology. In W. Bechtel \& G. Graham (Eds). A companion to cognitive science (pp. 140-145 ). Oxford: Blackwell Publishing.

Nuelip, J. W. (2003). Intercultural Communication. A contextual approach. Boston: Houghton Mifflin Company.

Oakes, J., Joseph, R. \& Muir, K. (2004) Access and achievement in mathematics and science. In J.A.Banks \& C.A.M. (Eds.). Handbook of research on multicultural education. (pp.69-90) San Francisco: Jossey-Bass.

OECD. (2007). Understanding the Brain: The Birth of a Learning Science. 
Pisa. Programme for International Students Assessment. At http://www.pisa.oecd.org/ accessed 27.4.2008

Oxford tutoring system. At http://www.learning.ox.ac.uk/ Accessed on 15 July 2006.

Paavola, S. (2006) On the origin of ideas: An abductivist approach to discovery. Doctoral dissertation, Philosophical Studies from the University of Helsinki 15.

Padilla, A. (2004). Quantitative methods in multicultural education research. In J.A.Banks \& C.A.M. (Eds.). Handbook of research on multicultural education (pp. 127 - 145 ). San Francisco: Jossey-Bass.

Paige, R.M. (2004) Instrumentation in intercultural training. In D. Landis, J.M.Bennett \& M.J.Bennett (Eds.) Handbook of intercultural training. (pp. 85-128) Thousand Oaks: Sage.

Pang, V.O., Kiang, P.N. \& Pak,Y.K. (2004) Asian Pacific American students. In J.A.Banks \& C.A.M. (Eds.). Handbook of research on multicultural education (pp. $542-563$ ). San Francisco: Jossey-Bass.

Pascalis, O., Scott, L.S., Kelly, D.J., Shannon, R.W., Nicholson, E., Coleman, M. \& Nelson, C. A. (2005) Plasticity of face processing in infancy. Proc Natl Acad Sci U S A. 102: 5297-5300.

Piaget, J. (1988). Lapsi maailmansa rakentajana. (Six essays) Juva: WSOY.

Piaget, J. \& Inhelder, B.,(1969) The psychology of the child. New York: Basic Books

Polk, T.A. \& Farah, M.J. (1998) The neural development and organization of letter recognition: Evidence from functional neuroimaging, computational modeling, and behavioral studies. Proc Natl Acad Sci U S A., 95(3), 847-852.

Proust, M. (1919) À la recherche du temps perdu. Du côté de chez Swann. Editions Gallimard

Puustinen, M. (2008). Melkein mahdoton tehtävä. [An almost impossible task] Opettaja 2008(8-9), 12-14.

Reinikainen, P. (2007) Sequential explanatory study on factors connected with science achievement in six countries: Finland, England, Hungary, Japan, Latvia and Russia. University of Jyväskylä.

Reiter, R. R., (Ed.). (1975). Toward an anthropology of women. New York: Monthly Review press.

Rips, L. (1998) Reasoning. In W. Bechtel \& G. Graham (Eds). A companion to cognitive science (pp. 299-305). Oxford: Blackwell Publishing.

Rizzolatti, G., Ferrari, P.F., Rozzi, S. and Fogassi, L. (2006) The inferior parietal lobule: where action becomes perception. Novartis Foundation Symposium 2006, 270, 129-140

Rogers, T. (2007) The state of internationalisation in institutions of higher education in Helsinki. A report commissioned by the Helsinki Education and Research Area.

Rose, S. P. (1998) How brains make memories. In P.Fara \& K.Patterson (Eds). Memory. (pp. 134-161) Cambridge: Cambridge University Press.

Räsänen, R. (2003) The role of experiences and human relations in transformative intercultural learning. Proc of the UNESCO Conf. on Intercultural Educ., 15-18 June 2003, Jyväskylä. CDROM.

Scherer, K.S. (2004) Feelings integrate the central representation of appraisal-driven response organization in emotion. In A. S. R. Manstead, N. Frijda, \& A. Fischer (Eds.) Feelings and emotions. The Amsterdam Symposium (pp. 136-157). Cambrigde: Cambridge University Press.

Schneider, D. M. (1984) A critique of the study of kinship. Ann Arbor: The University of Michigan Press.

Schwartz, D. L., Martin, T. \& Nasir, N. (2005) Designs for knowledge evolution: towards a prescriptive theory for integrating first- and second-hand knowledge. In P. Gärdenfors \& P. Johansson (Eds). Cognition, education, and communication technology (pp. 21-54) Mahwah, NJ: Lawrence Erlbaum Associates.

Searle, J. (2007) Putting consciousness back in the brain. In Bennett, Maxwell R., Dennett, Daniel C., Hacker, Peter \& John Searle. Neuroscience and philosophy: Brain, mind, and language (pp.97-124). Columbia University Press: New York.

Shin, S., Morgeson, F. \& Campion, M. (2007) What you do depends on where you are: understanding how domestic and expatriate work requirements depend upon the cultural context. $J$ of Intl Business Studies. 38(1), 64-83.

Smeds, R. (2003) Guest Editorial: Simulation for accelerated learning and development in industrial management. Production Planning and Control, Special Issue: Simulation for accelerated learning and development in industrial management, 14(2), 107-110.

Starbucks Coffee Company. (2006) How do you like it? It's your drink. U.K.

Stein, L. A. (2000) The Rethinking CS101 Project. At http://www.cs101.org/ Accessed on 2.8.2006 
Sternberg, R. J. (2005) The Theory of Successful Intelligence. Revista Interamericana de Psicología/Interamerican Journal of Psychology. 39(2), 189-202

Stewart, R. A. (2007) Investigating the link between self directed learning readiness and project-based learning outcomes: the case of international Masters students in an engineering management course. Eur. J. Eng. Educ., 32(4), 453-465

Strauss, C. \& Quinn, N. (1997) A cognitive theory of cultural meaning. New York: Cambridge University Press.

Suchman, L. A. (2007) Human and machine reconfigurations: Plans and situated actions. Cambridge: Cambridge University Press

Särkämö, T., Tervaniemi, M., Laitinen, S., Forsblom, A., Soinila, S., Mikkonen, M., Autti, T., Silvennoinen,H., Erkkilä, J., Laine,M., Peretz, I. and Hietanen,M. (2008). Music listening enhances cognitive recovery and mood after middle cerebral artery stroke. Brain 131(3), 866876

Taylor, D.S. \& Nwosu, P.O. (2001) Afrocentric empiricism. In V.Milhouse, M.K.Asante \& P.O.Nwosu (Eds.) Transcultural realities. Interdisciplinary perspectives on cross-cultural relations. (pp. 299 - 311). Thousand Oaks: Sage.

Tenopir, C. \& King, D. W. (2004) Communication patterns of engineers. New Jersey: IEEE Press. Wiley.

Teräs, M. (2007) Intercultural learning and hybridity in the culture laboratory. Dissertation. University of Helsinki, Department of Education.

Thagard, P. (2004) Cognitive Science, The Stanford Encyclopedia of Philosophy (Winter 2004 Edition), Edward N. Zalta (ed.), URL = http://plato.stanford.edu/archives/win2004/entries/cognitivescience/

No date needed because this is an archived page

The Economist. (2007). The campaign's brightest star. June $16^{\text {th }} 2007,47-48$.

Todd, E.S. (1997) Supervising overseas students: problem or opportunity. In D. McNamara \& R. Harris (Eds.) Overseas students in higher education. Issues in teaching and learning. (pp. 173-186) London: Routledge.

Triandis, H.C. (2004) Foreword. In D. Landis, J.M.Bennett \& M.J.Bennett (Eds.) Handbook of intercultural training. (pp. ix-xii) Thousand Oaks: Sage.

Turkle, S. \& Papert, S. (1992) Epistemological pluralism. J of Mathematical Behavior, 11(1), 3-33.

Töttö, P. (2004). Syvällistä ja pinnallista. Teoria, empiria ja kausaalisuus sosiaalitutkimuksessa. [Deep and shallow] Tampere: Vastapaino.

Verran, H. (2001) Science and an African logic. Chicago: University of Chicago Press.

Vesisenaho, M. (2007). Developing university-level introductory ICT education in Tanzania: A contextualized approach. University of Joensuu, Computer Science, Dissertations 16.

Viale, R. (2006) Introduction: local or universal principles of reasoning. In R.Viale, D. Andler \& L. Hirschfield (Eds.) Biological and cultural bases of human inference. (pp. 1-31) New Jersey: Lawrence Erlbaum Ass.

Viale, R., Andler, D. \& Hirschfiled, L. (Eds.) (2006) Biological and cultural bases of human inference. New Jersey: Lawrence Erlbaum Ass.

Vygotsky, L.S. (1962) Thought and language. Cambridge Mass: MIT Press. (1978) Mind in society. The development of higher psychological processes. Cambrigde, MA: Harvard University Press.

Ward, C. (2004). Psychological theories of culture contact and their implications for intercultural training and interventions. In D. Landis, J.M.Bennett \& M.J.Bennett (Eds.) Handbook of Intercultural Training. (pp. 185-216) Thousand Oaks: Sage.

Wartofsky, M.W. (1979) Models. Representation and the scientific understanding.Dordrecht, The Netherlands: Reidel.

Warwick, Kevin. 2007. At http://www.kevinwarwick.com/, accessed 29.12.2007

Watson, G. \& J-G.A.Goulet. (1992). Gold in, gold out: the objectification of Dene Tha accounts of dreams and visions. $J$ of Anthropological Research 48, 215-230

Weil, S. (1957). Painovoima ja armo. Keuruu: Otava.

Welsch, R. (1994). Indi'n Humor: Bicultural Play in Native America (rev.), South Dakota History, 24:1, $50-51$

Wertsch, J. V. (1985) Vygotsky and the social formation of mind. Cambrigde, MA: Harvard University Press: 
Wierzbicka, A. (1999) Emotions across languages and cultures. Diversity and universals. Cambrigde: Cambridge University Press.

Wikan, U. (1992) Beyond the words: the power of resonance. Am. Ethnologist 19:3, 460-482

Winston, J. S. \& Dolan, R.J. (2004) Feeling states in emotion: functional imaging device. In A. S. R. Manstead, N. Frijda, \& A. Fischer (Eds.) Feelings and emotions. The Amsterdam Symposium (pp. 204-222). Cambrigde: Cambridge University Press.

Wittgenstein, L. (1953) Philosophical Investigations: The German Text with a Revised English Translation: German Text, with a Revised English Translation. Blackwell; 3Rev e. edition (Jan 2002)

Woodruff, E. (2005) Manifold relational understanding. Proc of Symposium on Adaptive models of knowledge, language and cognition AMKLC05. Espoo, pp. 8 - 16.

World Values Surveys. Available at http://www.worldvaluessurvey.org/, accessed 31.8.2008

Zaharlick, A. \& Green, J.L. (1991) Ethnographic research. In J. Flood, J. Jensen, D. Lapp \& J. Squire (Eds.) Handbook of research on teaching the English language arts. (pp. 205-214). New York: Macmillan Publishing Co.

Öhman, A. \& Wiens, S. (2004) The concept of an evolved fear module and cognitive theories of anxiety. In A. S. R. Manstead, N. Frijda, \& A. Fischer (Eds.) Feelings and emotions. The Amsterdam Symposium (pp. 58-80). Cambrigde: Cambridge University Press. 


\section{Index}

\section{A}

abduction, 95, 107

ABET, 81, 82, 130

academic writing, 76, 136, 138, 146

acculturation, 72, 75, 78, 79, 143, 144

ACM, 4, 41, 57

action research, $6,79,96,106,155$

activity theory, 15, 37, 38, 40, 80

change laboratory, 80

culture laboratory, 169

acupuncture, 62

Adams, Douglas, 93

ADHD attention deficit hyperactivity disorder, 35

affect, 56, 62, 72

concept of, 31,33

positive, $33,34,138$

Africa, 97, 99, 119, 120, 158

African

culture, 170

science, 16,62

thinking, 65, 66

values, 3, 62

Ahmed, Sarah, 12

algorithm, 44, 46, 71, 166, 171

Alitolppa-Niitamo, Anne, 1, 73, 74, 77 - 79, 111, 150

alphabet, 64, 135

Latin, 17, 19, 136, 165, 179

Alzheimer's disease, 23

Amazonean people, 30

Amharic, 136

amygdala, 22, 34, 46

Andean

people, 58

songs, 3

animal cognition, 26, 27

rhesus monkeys, 63

anthropology, 4, 7, 11, 14, 32, 38, 96, 97, 104

educational, 74

symbolic, 7

apprenticeship, 45, 149, 150

Arab Emirates, 75

artifacts, 7, 8, 12, 15, 30, 37, 50, 53, 68, 83, 147, 148, 152

cultural, 15,17 artificial intelligence, 11, 41, 43, 46

Asperger's syndrome, 86

assessment, 1, 41, 137, 140

formative, 55, 124

methods, 52

attention, 22, 34 - 36, 45, 86

deficit, 13, 28, 35

attitudes, 56, 95, 119, 145, 170

work, $3,62,112,121,150$

Australia, 40, 74, 75

Austria, 9, 10

\section{B}

\section{Basque, 67}

Beauvoir, Simone de, 12

behaviorism, 40, 41

Belgium, 10

beliefs

magical, 62, 118, 119, 122, 124

religious, 36, 121, 122

Bennett, Maxwell, 43, 97

Bennett, Milton J., 10, 16, 17, 141

Bereiter, Carl, 4, 39, 50, 51

Berry, John W., 7 - 9, 12 - 16, 32, 54, 62, 69, 74, 95, 107, $143,144,172$

bilingualism, 66, 170

biodiversity, 58

Björklund, Camilla, 63

blindness, 28, 124, 147

body and mind, 12, 17, 18

Bohr, Niels, 93, 94

Braidotti, Rosi, 8, 12, 59, 74, 96

Braille, 28

brain

damage, 25

functioning, 20, 28

hemispheres, 19 - 21, 25, 35, 86, 136

human, 18 - 21, 31, 46, 65

lateralization, 21, 86

organization, 18, 19, 26, 32

scanning, 18, 19

science, 11,20

Brazil, 149 
problems, 2, 140, 154

British

society, 150

universities, 76, 77, 169

Buddha, 36

Buddhism, 62

business studies, 72

\section{C}

calculation, 44, 116, 165

Canada, 9, 54

CDIO, 40, 82, 154

CERN, 3, 69, 76, 85, 93, 104, 172

character systems, 17, 135, 136, 165, 175, 179

China, 18, 62, 87, 99, 142, 159

Chinese

characters, 17

culture, 32, 54, 61, 157

science, 59,61

Chomsky, Noam, 11

Christie, Agatha, 65

CICERO, 18

CIMO, 79

cognition

cultural, 12

shared, 4, 5, 39, 68, 94, 167

situated, 15, 68

social, 11, 148, 149, 166, 175

cognitive anthropology, 7

cognitive development, 3, 27, 30, 38, 50, 53, 65, 149

cognitive difference, 67

cognitive science, $2,4,11,18,36,43,44,96,97$

cognitive style, $1,57,62,75,92,112,162$

Cole, Michael, 38

collaboration, 20, 38, 41, 98, 99, 167, 178, 179

EU, 100

collaborative learning, 40, 42, 75, 94, 156, 169

communication

ability, 160

Chinese, 61

cross-cultural, 9, 138, 143, 158

engineering, $85,87,88$

human-machine, 48,151

intercultural, 2, 9, 17

non-verbal, 70

personal, 80 community, 16, 69, 99, 177, 178

in study, 40, 167

multicultural, 8, 14, 79, 126, 143

competence, 36,42

cognitive, 53

cultural, 160

computer

games, 120

operation, 133

PC, 114

users, 4,87

computer industry, 40

computer science, 17, 40, 57, 87, 96, 110, 136, 137, 144

computers, 37, 48, 57, 68, 130 - 134, 137, 144, 152, 166

conatus, 105

conceptual artifacts, 37,39

Confucian, 8, 61

connectionist models, 39, 46

consciousness, 18, 22 - 24, 29, 43, 46, 73, 77, 78, 108

constructivism, 37, 40, 41

context-dependent, 7, 20, 106

cooperation, $49,85,98,140,159$

cortex, 19 - 28, 31, 35

prefrontal, 34

counting, 47, 63 - 65, 67, 116, 152

skills, 63

creativity, $8,17,33,36,69,83,88,130,154,161,171$, 178

Cree, 54

critical pedagogy, 75

cross-cultural psychology, 7, 12, 95, 172

cross-cultural training, 107

cross-culturalism, 8

Crump, Thomas, 51, 65, 66

cultural self-awareness, 16, 141

culture

collective, 16, 69, 107

collectivist, 9

definition of, 7

educational, $8,80,142,159,178$

embodied feeling of, 16, 17, 141

engineering, $8,73,87,105$

indigenous, 7, 65

individualist, 9, 16, 141

national, 7, 9, 10, 88, 162, 175

culture laboratory, 80 
curriculum, 1, 41, 53, 55, 78, 93, 100, 106, 116, 126, 167, 169,177

planning, 2, 169

\section{D}

Damasio, Antonio, 18, 29, 31, 32, 35, 46, 105

d'Andrare, Roy, 7, 8, 14, 73, 109, 115

decimal, 67, 116

decision-making, 11, 48, 86, 107, 113, 116

rational, 45, 46

decontextualization, 54, 58

Dennett, David, 18, 24, 43, 172

dichotomy, 106

difference, 12, 66, 95, 111, 120, 133, 158, 164, 170

concept of, 12

cultural, 3, 9, 12, 62, 69, 74, 87, 89, 140

gender, 109

racial, 13

diversity, 36, 78, 88, 92, 98, 110, 154, 161, 175 - 177

cultural, $8,9,32,55,94,100,160,164$

in science, 93

dreams, 60, 119

Drosophila, 26

duality, 12, 61

dyslexia, 28

\section{$\mathbf{E}$}

ecocultural framework, 13

education

engineering, 2, 4, 36, 37, 40, 75, 81 - 84, 89, 93, 104, $167,170,171,175$

multicultural, 4, 6, 36, 37, 72 - 79, 89, 96, 161

science, $18,50,55,65$

Egypt, 50, 87

Ekman, Paul, 32, 108

email, 103, 111, 112, 130, 140, 141, 145, 151, 155, 170

emotion

concept of, 31

emotions, 22, 33, 35, 46, 56, 58, 85, 140

basic, 32

Engeström, Yrjö, 38, 80

engineering

competence, 82,154

design, 83, 84, 116, 152, 171

expertise, 2, 74, 81, 82, 176

identity, 74, 169 qualities, $82,83,168$

skills, 82

engineers, $81-89,98,106,123,129,130,168,170$

English

fluency, 73, 75

language, 66, 79, 105, 179

entrance exams, 99, 110, 168

epileptic patients, 24

epistemic, 39

culture, 93

nomadism, 96

epistemic logic, 5

epistemology, 2, 40, 59 - 62, 69, 74, 93, 106, 134, 152,

170

cultural, 59

genetic, 12,50

historical, 50

Erkinjuntti, Timo, 20, 24

Espoo, 97, 98

ethics, 36, 42, 54, 82, 104 - 106, 170

Ethiopia, 99, 135, 158

ethnography

fieldwork, 94

Eurobarometer, 10

evaluation, 26, 41, 77, 91, 125, 128, 144, 154 - 156

evolution, 11, 46, 116

EVTEK

staff, 6, 40, 83, $100-103,113,126,153,171$

student association, 100

expatriate, 73, 74, 99, 100, 105

experience expectant period, 28

experiment

physics, 69

psychological, 35

expert, 71,82

expert community, 37,176

expertise, 39, 42, 47, 52, 56, 69, 71, 83, 89, 93, 96, 106,

166

in team, 68

\section{$\mathbf{F}$}

fear, 21, 32, 46, 47, 139

feeling

concept of, 31

feelings, 5, 12, 18, 20, 29 - 32, 46, 86, 124, 135, 138 -

141,166 


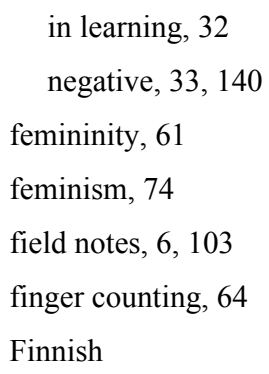

Freud, Sigmund, 9

Frith, Chris, 14, 18, 20, 24, 25, 35, 50, 108

frontal cortex, 46

frontal lobe, 31

\section{G}

Gärdenfors, Peter, 4, 41

Geertz, Clifford, 7

Gerring, John, 94, 95, 172

Ghana, 16

globalization, 9, 10, 88

Greece, 10, 59

H

Hakkarainen, Kai, 2, 4, 37, 39, 53, 56, 83, 160

Hannula, Markku, 51

Hannula, Minna, 63

harmony, 59, 159

Harrison, Regina, 3, 58

Helsinki, 2, 47, 77, 79, 80, 83, 96, 97

Helsinki University of Technology, 2, 83, 96

Hera network, 79

heuristics, 35, 44, 46, 71, 167

higher education, $1,37,42,77,82,98$
Himanen, Pekka, 17

Hintikka, Jaakko, 5, 37, 44, 65, 67, 94

hippocampus, 22 - 27, 34, 36

hiragana, 19

HIV/AIDS, 16

Hofstede, Geert, 9, 61, 107

home pages, $8,112,130,133$

horticultural, 64

Hutchins, Edwin, 3, 4, 8, 12, 15, 39, 44, 64, 67, 68, 97, 148,152

hypothalamus, 22

\section{I}

IBM, 9, 61

ICT, 128

identity, 16, 74, 83, 99, 106, 112

IEEE, 41, 106

IFIP, 3

imitation, 29, 146, 170, 178

immigrant

students, 1, 75, 80, 89, 98, 105, 106, 141, 150, 159

immigrants, 12, 47, 72 - 74, 78, 100, 111, 120, 134, 162, $166,168,177$

in Finland, 39, 77, 79, 80, 97

inanimate objects, 59, 122

India, $62,87,88$

indigenous knowledge, 58, 60, 106

informants, 105

information

olfactory, 22

sensory, 21,22

information technology, 57, 88, 96 - 98, 131, 171

users, 3, 131, 133

information technology education, 1, 4, 5, 37, 40, 41, 75, $83,89,175$

innovation, $36,88,161$

instructions, 52, 68, 92, 120, 125, 126, 136 - 139, 147 -

$153,158,165,177$

integration, 78,143

intelligence, 14, 30, 32, 52 - 58, 65, 68, 69, 87, 95, 116, $129,140,166,168,170$

creative, $48,53,56,167$

cultural, 72, 73

distributed, 39

emotional, 168

general (GI), 12 
IQ, 14, 52, 53, 54

practical, 54, 70

sensorimotor, 30

social, 168

successful, 53

intelligent action, 48

intelligent activity, 53, 167

intercultural education, 106

intercultural training, 16, 79

internet, 25, 57, 87, 90, 111, 112, 127, 133, 136, 137, 144, 155

intuition, 30, 45 - 47, 69, 83, 86, 104, 122

Isen, Alice, 33, 34, 138

\section{J}

Japan, 62, 66, 69, 87, 88, 146

Japanese

culture, $3,16,59,64,70,73$

values, 54,59

writing, 17, 18, 136

Johansson, Petter, 4, 41

Jyväskylä, 79, 123

\section{K}

Kalat, James W., 14, 18, 20, 25, 28, 34, 35, 50, 70

Kandel, Eric, 18, 23

kanji, 17, 19

Karppinen, Merja, 17, 59, 62, 70, 136, 142, 146, 153

katakana, 19

Kenya, 54, 99

Knorr Cetina, Karin, 3, 68, 69, 70, 85, 93, 104

knowledge

acquisition, 38, 39, 61, 94, 106

artifacts, 58

building, 4, 37, 39

core, $30,63,122$

creation, 41,93

cultural, 51, 88, 160

declarative, 52

embodied, 5, 17, 65, 69, 70

empirical, 107

first-hand, 45, 52, 59, 60, 170

innate, 30, 122

procedural, 52, 152

tacit, 46, 69, 70, 83, 104, 173

theoretical, 50, 57, 169 transfer, 50, 116

Kolb, David, 4, 86, 96, 102, 123, 153

Korea, 87

Korean

values, 47,120

Kosrae (FSM), 17

Kpelle, 66

$\mathbf{L}$

laboratory, 111

electronics, 147

experiments, 19, 26, 45, 97, 127, 152

molecular biology, 70

protocols, 70

situations, 108

language

development, 28

learning, 28

skills, 49, 58, 72, 100, 126

speech, 18, 21, 29, 30, 35, 63, 152

laughing, 34, 153

laughter, 31

learning

dialogical, 39

intercultural, 80

metaphors, 35, 39

process, 3 - 5, 27, 33, 37 - 39, 51, 64, 71, 72, 89, 105,

$123,149,153,175,178$

progressive inquiry, 5, 37, $39-41,109,166$

trialogical, 39

unconscious, 35

learning by doing, 39

learning $\log , 6,103,137$ - 139

learning sciences, 4, 5, 18, 36, 37, 97

learning styles, 4, 86, 102, 113, 123 - 125, 151

Kolb LSI, 107, 123

linguistics, 32

Linux, 90, 111, 130 - 132, 151

Luria, Alexander, 38, 59

\section{M}

Maldives, 3

marriage, 52, 64, 116, 158

masculinity, 61

mathematics, 43, 55, 60, 64, 65, 82, 110, 111, 114 - 117, $126,165,168,175$ 
learning, 51, 56

maturity, 140

McClintock, Barbara, 104

meaning, 35, 49, 95, 148, 152

cultural, 7, 8, 9, 10, 14, 73

shared, 8, 69

mediating artifacts, 5, 39, 80, 148, 150

mediating structures, 67, 68, 152, 171

medicine, 16, 60, 62, 84

traditional, 16

memorization, 57

memory

consolidation, 23, 27, 34

declarative, 24, 52

episodic, 14, 23, 28

long-term, 23, 25, 27, 34

procedural, 24

short-term, 19, 24, 27

spatial, 26

taxonomy, 24

working, 14, 22 - 24, 34

mental models, 51

Mesoamerica, 58, 87

metacognition, 55, 58, 124, 131, 166, 167

metacognitive skills, 167, 177

Metropolia, 1, 97

Micronesia (FSM), 3, 15, 17, 128

mind

as container, $39,40,50$

human, 18, 30, 35, 38, 43, 67, 122

minorities, $12,53,54,55,74,78$

mirror neuron system, 29

mobile phone, $18,45,112$

modality, 21, 22, 23

molecular biology, 70, 93, 104

monolingual, 66

MONSU, 79

motivation, 22, 33, 37, 53, 56, 72, 111, 112, 120, 126,

$129,131,137,156,159,171$

multiculturalism, 7, 8, 9, 100, 105

music, 25, 34, 58

\section{$\mathbf{N}$}

Nan Madol, 3

Native American, 60, 106

navigation, $3,15,26,48,67,131,148$
Netherlands, 106, 140

networking, 74, 78, 85, 111

neural activity, 26

neural networks, 23, 39, 46

neurons, $21-28,34$

neuroscience, 4, 5, 11, 18, 32, 36, 39, 43, 51, 175

neurotransmitters, 22

Neville, Helen, 13, 28, 66

New Zealand, 75

Nokia, 87

nomadism, 3, 8, 74

number system, 19, 64, 65, 116

numerals, 19, 62, 67

Roman, 18

numerosity, 63

\section{$\mathbf{O}$}

Obama, Barack, 107

objectivity, 3,104

observation, 29, 43, 60, 65, 93, 101, 105, 109, 172

observer, 104, 105, 123, 173

OECD, 18, 36, 98, 162, 174

Omaha, 60

ontology, 2, 62, 134

otherness, 12

Oulu, 79

Oxford university, 55

\section{$\mathbf{P}$}

Pacific, 15, 128

Paiela, 64, 116

Papua New Guinea, 64, 116

Parkinson's disease, 31

PBL (problem based learning), 40, 41

pedagogical studies, 2, 40, 100, 123

pedagogy, 4, 18, 36, 79, 96

perception, 5, 12, 18, 20 - 23, 29 - 32, 46, 50, 53

learning, 45

modes of, 50

subjective, 104

visual, 21, 28, 50, 165, 175

personality, 15, 16, 32, 72, 73, 86, 87, 140, 160

perspective, in art, 50

PET scans, 32

philosophy, 12, 18, 43, 97

physicists, $69,85,104,152$ 
physics, 60, 65, 76, 93, 110, 111, 114, 118, 126, 148, 166

Piaget, Jean, 12, 29 - 31, 40, 41, 50, 66, 149

pilotage, 68

plagiarism, 75, 76, 139, 145, 146, 170, 178

plasticity, brain, 28,170

polymodality, 36

polytechnic, 1, 2, 40, 80, 93, 97 - 99, 143, 171

power relations, 105

practice

cultural, 7, 96, 116

engineering, 8, 82, 154

prejudice, 47

problem-solving, 2, 33, 36, 38, 52, 55, 64, 71, 83 - 89, 92,

$116,117,130,138,153,162,165-168,171,175,179$

process, 44

skills, 41, 57, 58, 83

technical, 84

procedure

written, 64, 152, 153

program coding, 19, 135, 165

programming, 57, 127, 152

object oriented, 58,88

skills, 57, 157

project management, 154 - 159

Proust, Marcel, 20, 23

psychology, 4, 7, 10, 14, 15, 18, 29, 31, 53, 94, 96, 97,

108, 175

cognitive, 11,43

\section{Q}

qualitative research, 93, 94, 104

quantitative research, 94, 104, 173

Quinn, Naomi, 4, 10, 14, 15, 39, 73

\section{$\mathbf{R}$}

racism, 107, 126, 141

rational thought, 44

rationality, 12, 18, 84 - 86, 94, 116, 166, 167

rats, 26

reasoning, 44, 49

logical, 58, 59, 89, 113, 153, 171

recruitment, 79, 99, 142, 162, 167, 177

refugees, 77,80

representation, 47, 48, 50, 116, 152

cultural, 15

in brain, 14, 23, 31, 108 visual, 49

research methods, 5, 104

respect, $72,105,145$

robots, 25, 59, 62, 70, 87

Rose, Steven, 20, 25, 26, 35

rote learning, 76, 146

Russian

science, 38

\section{S}

Säljö, Roger, 49, 50, 152

schema, 7, 15, 19, 57, 73, 133, 135, 175 - 178

cultural, 3, 4, 10, 14, 15, 39, 67, 139, 148, 166, 170, 175,177

definition of, 10, 14

in psychology, 47

marriage, 10, 15

procedure, $149,150,166$

shared, 73

social, 149,154

Schneider, David, 7

schools, 78, 79, 97, 98, 106, 165

high, 52, 54, 99, 117, 162

primary, $54,65,74$

scripts, 10, 56, 92, 136, 148, 154, 166

social, 124

self-awareness, 41, 145

self-discipline, 54, 92, 131, 159

self-efficacy, 87

self-regulation, 56, 131, 141, 150, 166, 167, 171, 177

self-reliance, 15

self-reporting, 44, 108, 124

sensitive period, 28

shame, 32

sign language, 28

SimLab, 2, 96

skills

enumeration, 63

hands-on, 70, 147

kinesthetic, 70

mathematical, 51, 63, 165

motor, 25, 147

technical, 152, 166

sleep, 27

Smeds, Riitta, 2, 96

smell, 23, 27 
social processes, 30

social psychology, 38

social relations, 16, 85, 142, 143, 159

social science, 61

software, 83, 131, 132, 150, 156, 157

educational, 41

software design, 58

software engineering, 41, 84, 88, 154, 155, 168

sojourners, 1, 72, 74

Somali

culture, 150

immigrant, 78

refugees, 77, 111

Soviet Union, 38

speech, 18, 21, 29, 35, 63

internal, 64

Spelke, Elizabeth, 63, 122

Spinoza, 105

spirituality, 16, 59, 62, 122

stereotype, 55, 75, 81, 85, 109

Sternberg, Robert, 4, 48, 53 - 57, 70, 71, 167, 173

Strauss, Claudia, 4, 10, 14, 15, 39, 73

stress, 34, 109, 140

students

African, 131, 141 - 144, 147, 149, 157, 158, 162, 170

American, 32, 62, 72, 76, 87, 114, 128, 142, 145, 160

Asian, 131, 151

British, 157

Chinese, 61, 62, 72, 99, 135, 137, 142, 145, 146, 153, 157

Ethiopian, 134, 135, 141, 146

exchange, 1, 74, 79, 98, 100, 142, 157

Finnish, 113, 119 - 121, 126, 142

French, 157, 165

international, 74, 75, 110, 112, 119, 121, 126, 141, $143,149,158,169,177$

Kenyan, 150

Korean, 120, 128, 139

Pacific, 75

Russian, 141, 145, 165

Vietnamese, 153

subitizing, 63

subjective, 122

subjectivity, 105, 106

Suchman, Lucy, 45, 48, 83

surgeons, 68

Switzerland, 10 syllabary, 17, 19, 136

syllogism, 59, 113 - 115

symbols, 7, 19, 30, 48, 152

synapses, 22, 27, 28

systems designers, 87

\section{$\mathbf{T}$}

Tanzania, 3, 144, 149, 159

teacher

role, $71,76,145$

teamwork, 39, 71, 82, 83, 88, 100, 126, 128, 142, 143, $154-160,166,167,177,178$

Teräs, Marianne, 1, 39

thalamus, 22

thinking, 53

algorithmic, 2, 35, 58, 88, 89, 152, 171

analogical, 35, 44

analytical, 57, 86, 118, 122

holistic, 59, 62

in brain, 23

logical, 30, 46, 114, 115

mathematical, 52, 165

scientific, 2, 43, 62

time, 60, 169

timing in learning, 26, 36, 169

TOEFL, 99

transculturalism, 9

transfer effect, 51, 52, 115, 116

transference, 66

translation, 58, 62, 64, 79, 115

Turku, 79

Tutu, Desmond, 17

\section{U}

U.S. American, 15, 29, 60, 61, 71, 107

U.S. Americans, 66, 116, 119

understanding, 104, 126, 130, 133, 148, 153, 165, 175,

179

a joke, 51

concept of, 50, 51

cross-cultural, 9, 18, 106, 159

cultural, 129

deep, 57, 58, 106, 146, 171

United Kingdom, 19, 75, 79, 99, 100, 158

United States, 7, 9, 15, 40, 52, 54, 55, 57, 73, 74, 81, 85, $88,107,140,149$ 
navy, 67

universities, 169

universal grammar, 11, 43

university

faculty, 79, 114, 115, 124, 135, 177

staff, 97, 98, 110, 113, 135, 146, 167

University of Applied Sciences, 1, 97

University of Helsinki, 2, 18, 37, 80, 100

user interface, 48 - 50, 151

\section{V}

value

surveys, 10, 61

value systems, 9, 60, 178

values

cultural, 36, 106

Vantaa, 79, 97, 98

Verran, Helen, 65, 66, 122

vigesimal, 67

visual processing, 29

visual system, 23

Vygotsky, Lev, 4, 15, 30, 37 - 39, 149, 160
W

Web pages, 150

Website, 98, 104, 111, 133, 137, 155, 157, 158

Weil, Simone, 32

Wertsch, James V., 30, 38, 53, 64, 149, 152

West Africa, 65, 66, 158

Wilde, Oscar, 71, 150

witchcraft, 16, 119

Wittgenstein, Ludwig, 9, 20, 43, 44, 47

women, 12, 47, 55, 85, 109, 113, 125

World Values Survey, 10, 118

$\mathbf{X}$

Xerox, 48

$\mathbf{Y}$

Yoruba, $65-67$

$\mathbf{Z}$

zone of proximal development, 5, 38, 178 


\section{Questionnaire Instructions}

The aim of this study is to develop the education given at EVTEK. It is part of a research project about engineering studies.

These questions do not test your personal abilities or your intelligence. There are no right or wrong answers.

This questionnaire has 2 parts:

1) questions about scientific thinking,

2) Kolb's learning style inventory.

Please fill in all pages. In the part 1 , you can leave a question unanswered, and skip it, if you so prefer.

In part 2, you have to answer all questions in order to get the results. Calculate your results on the summary page. You can keep the summary sheet.

Your answers will be handled in strict confidence. The data will be used for research purposes only. No identification information is collected.

Thank you!

Jaana 


\section{Questionnaire: 1 Technology and science}

1. Please circle the correct answer to each of the questions below:

1A GIVEN: If Jim cut himself then Jim would be bleeding.

SUPPOSE: We found out that Jim did not cut himself.

THEN:
(a) It must be the case that Jim is bleeding.
(b) Maybe Jim is bleeding and maybe he isn't.
(c) It must be the case that Jim is not bleeding.

1B GIVEN: If it is raining then the roof is wet. SUPPOSE: The roof is wet. THEN:
(a) It must be the case that it is raining.
(b) Maybe it is raining and maybe it isn't.
(c) It must be the case that it is not raining.

1C GIVEN: If Roger drank tea then Tom sat down. SUPPOSE: Roger did not drink tea. THEN:
(a) It must be the case that Tom sat down.
(b) Maybe Tom sat down and maybe he didn't.
(c) It must be the case that Tom did not sit down.

1D GIVEN: If this rock is a garnet then it is a semi-precious stone. SUPPOSE: This rock is not a semi-precious stone. THEN:
(a) It must be the case that this rock is a garnet.
(b) Maybe this rock is a garnet or maybe this rock is not a garnet.
(c) It must be the case that this rock is not a garnet.

2 On a London - Miami flight the pilot announces that initially the plane will have a cruising altitude of 10000 feet but it will climb higher when it becomes lighter. Explain:

3 In Finland $52 \%$ of all households have a home computer. $65 \%$ of households have internet connection, and $95 \%$ have cell phones. Do you see any implications?

4 Give two suggestions how to improve the OVI portal system:

1

2

$5 \quad$ What is the capacity of the computer you mostly use?

RAM $\quad$ processor __ hard disk space__ internet connection speed

6 What are populations of the following countries (in millions), circle the right answer:

$\begin{array}{llllll}\text { USA } & 5 & 60 & 120 & 285 & 1030 \\ \text { UK } & 5 & 60 & 120 & 285 & 1030 \\ \text { India } & 5 & 60 & 120 & 285 & 1030 \\ \text { Finland } & 5 & 60 & 120 & 285 & 1030 \\ \text { Nigeria } & 5 & 60 & 120 & 285 & 1030\end{array}$

$7 \quad$ There is a tribe called Paiela in Papua New Guinea that has a 14-based counting system (instead of decimal or binary). In case of a marriage contract, a Paiela groom has to give $20_{14}$ pigs (in the 14-based system) to the bride's parents. How many pigs does that make in the decimal system?

8 What kind of improvements would you suggest to the EVTEK classrooms? 
I have future targets in mind regarding my career and education... strongly disagree

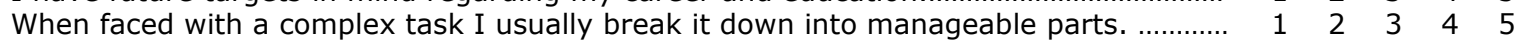

I think about work and study problems most of the time.

I like to work with others as part of a team.

I can remember lots of telephone numbers.

I often mix up right and left.

I know stories and texts by heart.

I like to relax and forget about my work and studies in the weekend.

I always carry an amulet to bring good luck

I am very different inside from what I show to other people.

When given a new task, I always 'brainstorm' ideas.

I know my own strengths and weaknesses when it comes to planning

and meeting targets.

When I am with my family I never think about my work or studies.

I consider the likely outcomes of my solutions to problems before I carry them out. ......

I don't trust a person who asks too many questions.

"Tomorrow will take care of itself."

There are many things in the world that cannot be explained.

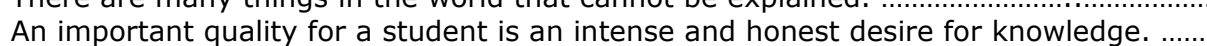

Some people can make others ill by putting a curse on them.

You can receive a warning about an approaching danger in a dream.

There is a reason for everything, and science will be able to find it.

"You can only predict things after they happened."

There is life elsewhere in the universe, not only on the earth.

Bad luck charms can only harm you if you believe in them.

"To be uncertain is to be uncomfortable; but to be certain is to be ridiculous."

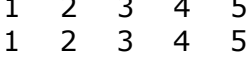

It is crucial to consult a horoscope before making an important decision about one's life..

"Never do today what you can put off till tomorrow."

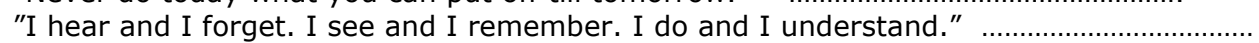

If you see awful things happen you can become blind.

Dogs can understand over 50 words.

$\begin{array}{lllll}1 & 2 & 3 & 4 & 5\end{array}$

$\begin{array}{lllll}1 & 2 & 3 & 4 & 5\end{array}$

$\begin{array}{lllll}1 & 2 & 3 & 4 & 5\end{array}$

$\begin{array}{lllll}1 & 2 & 3 & 4 & 5\end{array}$

$\begin{array}{lllll}1 & 2 & 3 & 4 & 5\end{array}$

Jupiter is so far from the sun that the temperature can drop down to $-400^{\circ} \mathrm{C}$

Spirits of dead people can send messages to the living through dreams.

"Life is what happens to us while we are making other plans."

"You can see clearly only with your heart."

"If I make my bed hard that's where I'm gonna sleep."

"Sometimes I sits and thinks, and then again I just sits."

"It is a good thing to speak the truth; but it is a better thing to know the truth and to talk about date stones."

"Only foolish people laugh a lot."

"You can only feel complete near the place where you were born."

"Knowledge is power."

$\begin{array}{lllll}1 & 2 & 3 & 4 & 5\end{array}$

$\begin{array}{lllll}1 & 2 & 3 & 4 & 5\end{array}$

The desirable and necessary qualities for a student are humility and respect for other people's points of view.

I can tell the time without consulting a clock.

I love playing chess, checkers or Monopoly

I enjoy word games (e.g. Scrabble \& puzzles)

I prefer a map to written directions

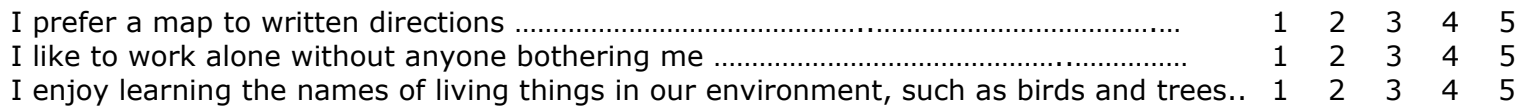

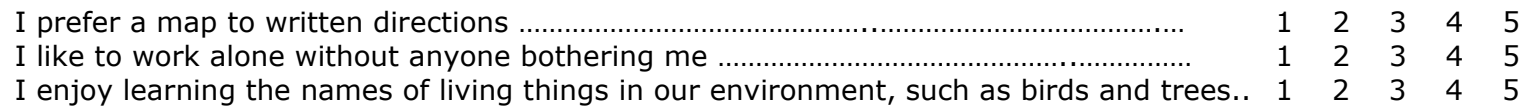


10 There was a powerful earthquake on Dec $26^{\text {th }} 2004$ that caused a devastating tsunami. 35 minutes before the earthquake was registered by seismic sensors, the aboriginal Onge people on the little Andaman island retreated from their villages to the hills in the center of the island, and they all survived. This is a fact. How would you explain it?

11 Imagine the following situations. What would you do? (check all that apply)

A. You need to get air tickets from an airline office (no on-line reservation). When you enter the office, you see a long line waiting for tickets. What would do you most probably do:

$\square$ Start complaining about lousy service

$\square$ Start calling your friends to spend time better

$\square$ Take a newspaper or book and start reading it while waiting

$\square$ Think of ways how the ticket selling could be organized better to avoid long lines

Something else:

B Imagine that you have a PC that is 3 years old. One day the CD-drive breaks down. What would you do:

$\square$ Join an internet discussion to ask for help

$\square$ Try to fix it

$\square$ Remove it and go to buy a better one and install it

$\square$ Decide to buy a new PC

$\square$ Take the PC to a shop and ask them to replace the drive Something else:

C The sewage pipe of the washbasin in your bathroom is clogged and the water does not drain. What do you do:
$\square$ Try to get tools and open it to clean it
$\square$ Call the building maintenance
$\square$ Wait
Something else:
$\square$ Call your friends to complain

12. When you use an interactive Internet site like Winha or Ovi do you tend to
$\square$ Get annoyed with the system
$\square$ Think how the user interface could be improved
$\square$ Explore new functionalities on the site
$\square$ Feel helpless

$\square$ Think of how the design and outlook of the system could be improved

13 What are the characteristics of a good engineer? 


\section{Questionnaire $2 \quad$ Test your learning style (Kolb's test)}

This test is intended to determine the way in which you learn. Remember that in this list of statements there are never any right or wrong answers. Everyone has their own ideas, opinions and studying habits. This test does not indicate your capacity for learning.

Below you will find nine groups of four statements. Rank the statements in the order of applicability to you. You write 4 next to the statement which suits you best and 1 next to the one that least agrees with how you learn (So: 4, 3, 2, or 1). In between these you'll probably find it sometimes difficult to give a ranking, but you're nonetheless asked to give each statement a different score. Fill in the score (1-4) on the line to the right of each statement.

1. a You look for differences and distinctions

You want to try something out first

You concentrate on details

You focus on useful practical applications

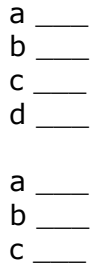

You let things happen, regardless of what they are

You are above all focused on what is relevant and important

You analyze the situation first

You don't make any value judgments or choose a particular standpoint

3. a You feel involved and mixed up with things

You tend to look and listen

You tend to think and analyze

You want to get things done

4. a You tend to take things as they are

You tend to take risks in what you do or say

You tend to make value judgments

You try to be very much aware of what's happening

5. a You tend to work mainly intuitively based on your feeling

You are very results-oriented

You try in the first instance to think logically

You tend to ask yourself questions

6. a You find abstraction and concept formation important

You tend to pay attention to what happens

You prefer things to be tangible (touchable)

You are above all active and practical in your method of working

You are concentrating to the here and now

You first let everything filter through your head and think about it

You tend to be prepared for what is still to come

You have a mainly pragmatic no-nonsense nature

You tend to be directed to gaining experiences

You tend to gather information while listening and looking

You tend to structure phenomena within a logical framework

You tend to test and experiment with ideas and hunches 


\section{Appendix 2: Surveys on studies \\ Questionnaire}

\section{Studies at EVTEK}

The aim of this study is to develop the education given at EVTEK. It is part of a research project about engineering studies.

These questions do not test your personal abilities or your intelligence. There are no right or wrong answers.

Your answers will be handled in strict confidence. The data will be used for research purposes only. No identification information is collected.

Thank you for your co-operation!

1. Why did you come to study Information Technology at EVTEK? (check all that apply)

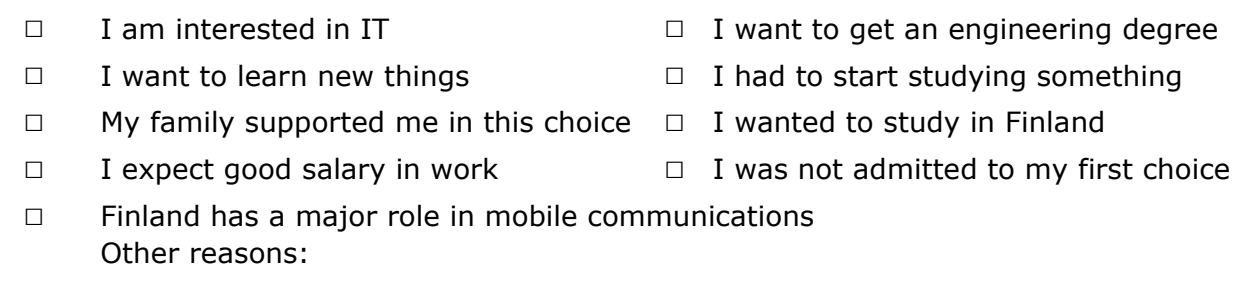

$2 \quad$ Studying in EVTEK is:

$\square$ More difficult than I expected $\square$ Much as I expected $\square$ Easier than I expected
Explain in what way:

3 Are you happy with your choice of studies?

$\square \quad$ Yes, I feel that this is my field

$\square \quad$ I would like to study something else

$\square \quad$ I am not quite sure if this field is the right for me

$\square \quad$ I would like to select another technical field

$\square \quad$ I am not happy with my choice

$\square \quad$ I would like stop studying altogether

$\square \quad$ I would like to study in another country

$4 \quad$ What kind of problems have you encountered in your studies? (check all that apply)

$\square \quad$ Time management

$\square$ Lack of motivation

$\square$ Too much work at the same time

$\square$ Planning of workload

$\square$ Concentration on studies because of other problems

$\square \quad$ Teachers do not understand me

$\square \quad$ Instructions are not clear enough $\square$ Courses are too difficult

$\square$ Courses are too easy

$\square$ Too many other activities

$\square \quad$ Language difficulties

$\square \quad$ Other students are very different from myself

$\square$ Racism or prejudice

$\square \quad$ Understanding the rules in EVTEK

Something else: 


\begin{tabular}{|c|c|c|c|}
\hline & yes & mostly & not often \\
\hline In the lectures & $\square$ & $\square$ & $\square$ \\
\hline $\begin{array}{l}\text { When going lab } \\
\text { assignments }\end{array}$ & $\square$ & $\square$ & $\square$ \\
\hline In the examinations & $\square$ & $\square$ & $\square$ \\
\hline
\end{tabular}

$6 \quad$ What has been the biggest challenge for you in the first year?

$7 \quad$ What particularly interests you in your studies? Why?

$8 \quad$ What other subjects would you like to study if you had the opportunity?

9 If you fail a course what is usually the explanation?
I did not study hard enough
$\square$ The teacher did not fully explain the requirements
$\square \quad$ I am not good in that subject
$\square$ The teacher was not good
I did not like the course
$\square$ I could not concentrate because I had too many other things on my mind
$\square$ Something else:

10 If you have major difficulties understanding a study subject and passing a course what do you do about it? (check all that apply)
$\square$ Read the material repeatedly
$\square$ Repeat the exercises over and over again
$\square$ Ask another student for help
$\square$ Ask the teacher to explain it again
$\square$ Search the internet to find more information
$\square$ Give up because this is not your strong area
$\square$ Decide to take the course later when you know more
$\square$ Decide to take the course when there is another teacher
$\square$ Go to the library to find books or journals where the subject is explained better
$\square$ Think it over and try to find an alternative approach to the subject

\section{What do you value in a teacher? (check all that apply)}
$\square$ Gives clear lectures
$\square$ Provides good learning materials
$\square$ Knows the subject well
$\square$ Encourages students to learn
$\square$ Helps you in your life
$\square$ Is friendly
$\square$ Has authority
$\square$ Is ready to answer questions and helps in study problems
$\square$ Something else 
$\square$ The teacher explains subjects on the blackboard $\square$ The teacher uses PowerPoint presentations to explain subjects

$\square$ Students make presentations on course topics $\quad \square$ The teacher uses lecturing and overheads to explain

$\square$ The teacher asks questions and requires discussion in the classroom

$\square$ The teacher gives assignment to discuss subjects in groups

$\square$ A virtual course without classroom lectures: lecture materials on the internet, discussion forums, chats and returning the assignment through the net

13 What kind of assignments do you prefer? (check all that apply)
$\square$ To learn a text well
$\square$ To do a project to create a product
$\square$ To do research on a given subject
$\checkmark$ Small tasks and exercises
$\square$ To write a program
$\square$ To complete a set of measurements or lab experiment and report results

14 What are your preferred study methods? (check all that apply)
$\square$ Lectures, reading and exam
$\square$ Individual lab assignments
$\square$ Group lab assignments
$\square$ Group projects
$\square$ Lectures and home work
$\square$ Individual research projects
$\square$ Reading books and writing a summary or essay
$\square$ Something else:

15 When studying in EVTEK what do you think is

Best:

Worst:

16 What has been the most important experience in your studies until now?

Has it changed your thinking in any way? $\square \quad$ No $\square$ Yes, how?

17 Do you think you have changed as a person? $\square$ No $\square$ Yes, how?

18 Who are the people who have most influenced you in your studies?

19 Do you think you will be a good engineer?

Why do you think so? 


\section{Questionnaire: 1 Technology and science question classes}

- explain the reasons for questions in part 2 (time, magical beliefs, control of life, number orientation, need to fix things, hands-on feeling, scientific view, logic, ..)

- continue with more exact reasons, number the questions in 9 and explain cross-checking

\section{Sources of questions:}

1. Banks, James A. \& Banks, Cherry A. McGee (editors). 2004. Handbook of research on multicultural education. Jossey-Bass. San Francisco.

2. Berry, John W., Poortinga, Y.H., Segall, M.H., Dasden, P.D. 1992. Cross-cultural psychology. Research and applications. Cambridge University Press. Cambridge.

3. Crump, Thomas. 1990. The anthropology of numbers. Cambridge University Press.

4. D'Andrade, Roy. 1995. The development of cognitive anthropology. Cambridge University Press.

5. Lustig, Myron W. \& Koester, Jolene. 2003. Intercultural Competence. Internpersonal communication across cultures. Fourth edition. Allyn and Bacon. Boston.

6. Massoudi, Mehrdad. 2002. On the qualities of a teacher and a student: an Eastern perspective based on Buddhism, Vedanta and Sufism. Intercultural Education, Vol 2(13), pp. 137-155.

7. McNamara, David \& Harris, Robert. (editors) 1997. Overseas students in higher education. Issues in teaching and learning. Routledge. London.

8. Skills Self-Assessment Audit, UniS Skills Project Pilot Pack (Audit.doc) WWW

9. MI Inventory. Multiple intelligences test. (mitest.html) WWW

10. Wordsworth's dictionary of Quotations

11. Jiwa, Hoslo. Kuudes aisti pelasti onge-kansan. Kumppani 2/2005 pp.22-23

12. Toelken, Barre 1996. From entertainment to realization in Navajo fieldwork. In jackson, Bruce \& Ives, Edward D. (eds.): the world observed: reflections on the fieldwork process. University of Illinois Press.

13. Burgos-Debray, Elizabeth (toim.)1984. I, Rigoberta Menchú. London: Verso. 1984

14. Wikan, Unni. Beyond the words: the power of resonance. Am Ethnologist 19:3 (1992) 460-482

15. Eminah, John. 2003. The interaction of traditional beliefs and scientific ideas: the case of hiv/aids conceptualization by university students . Proceedings of the UNESCO Conference on Intercultural Education, 15-18 June 2003, Jyväskylä. CD-ROM.

16. Biersack, Aletta. 1982. The logic of misplaced concreteness: Paiela body counting and the nature of primitive mind. American Anthropologist 84 (4): 811-829

\section{List of questions:}

1. Logical thinking (S1)

1A GIVEN: If Jim cut himself then J im would be bleeding.

SUPPOSE: We found out that J im did not cut himself.

2 Physics, analytical thinking ( $\mathrm{JH}$, Finnair pilot)

On a London - Miami flight the pilot announces that initially the plane will have a cruising altitude of 10000 feet but it will climb higher when it becomes lighter. Explain:

3 Numbers, analytical thinking ( $\mathrm{H}$, Finnair Blue Wings statistics distorted)

In Finland $52 \%$ of all households have a home computer. $65 \%$ of households have internet connection, and $95 \%$ have cell phones. Do you see any implications? 
$4 \quad$ Engineering attitude, analytical thinking $(\mathrm{J} H)$

Give two suggestions how to improve the OVI portal system:

$5 \quad$ Technical interest $(\mathrm{JH})$

What is the capacity of the computer you mostly use?

$6 \quad$ Numbers (J H, MMM Vuosikirja)

What are populations of the following countries

$7 \quad$ Mathematics ( $\mathrm{H}, \mathrm{S} 16)$

There is a tribe called Paiela in Papua New Guinea that has a 14-based counting system (instead of decimal or binary). In case of a marriage contract, a Paiela groom has to give $20_{14}$ pigs (in the 14based system) to the bride's parents. How many pigs does that make in the decimal system?

\section{$8 \quad$ Engineering attitude $(\mathrm{JH})$}

What kind of improvements would you suggest to the EVTEK classrooms?

9 You see a list of statements, sayings and proverbs below. How true are they?

20 I have future targets in mind regarding my career and education

When faced with a complex task I usually break it down into manageable parts.

I think about work and study problems most of the time.

I like to work with others as part of a team.

I can remember lots of telephone numbers.

life control, fatalism (S8) problem solving; eng (S8) stress/ involvement

working habits (S8)

memory; eng (S9)

I often mix up right and left.

I know stories and texts by heart.

memory

memory (S9)

I like to relax and forget about my work and studies in the weekend.

I always carry an amulet to bring good luck

magical beliefs

personality

I am very different inside from what I show to other people.

problem solving (S8)

When given a new task, I always 'brainstorm' ideas.

I know my own strengths and weaknesses when it comes to planning

and meeting targets.

life control; eng (S8)

32 When I am with my family I never think about my work or studies.

I consider the likely outcomes of my solutions to problems before I carry them out.

I don't trust a person who asks too many questions...

fatalism (S12)

working habits; eng (S8)

"Tomorrow will take care of itself."

There are many things in the world that cannot be explained.

fatalism, life control; eng (S10) science; eng

An important quality for a student is an intense and honest desire for knowledge.

Some people can make others ill by putting a curse on them.

fatalism, magic

You can receive a warning about an approaching danger in a dream. science, magic

study attitude (S6)

There is a reason for everything, and science will be able to find it.

"You can only predict things after they happened."

There is life elsewhere in the universe, not only on the earth.

Bad luck charms can only harm you if you believe in them.

science; eng

nature control, science; eng (S10)

science

magic

"To be uncertain is to be uncomfortable; but to be certain is to be ridiculous." nature control (S10)

It is crucial to consult a horoscope before making an important decision about one's life. magic

"Never do today what you can put off till tomorrow."

working habits, activity (S10)

"I hear and I forget. I see and I remember. I do and I understand."

working habits, studying (S10, Chinese

proverb))

48 If you see awful things happen you can become blind.

49 Dogs can understand over 50 words.

science

science

J upiter is so far from the sun that the temperature can drop down to $-400^{\circ} \mathrm{C}$ physics

Spirits of dead people can send messages to the living through dreams. magic

"Life is what happens to us while we are making other plans." " nature control (S10)

"You can see clearly only with your heart."

rationality, personality (S14)

"If I make my bed hard that's where I'm gonna sleep."

personal responsibility, life control

"Sometimes I sits and thinks, and then again I just sits."

"It is a good thing to speak the truth; but it is a better thing to know the

truth and to talk about date stones."

"Only foolish people laugh a lot."

social control (S10, Arabic proverb))

"You can only feel complete near the place where you were born." ocial control, science

"Knowledge is power."

science, social control 
The desirable and necessary qualities for a student are humility and respect for other people's points of view.

social control, study attitude (S6)

I can tell the time without consulting a clock.

rationality, engineering

I love playing chess, checkers or Monopoly

problem solving (S9)

I enjoy word games (e.g. Scrabble \& puzzles)

problem solving (S9)

I prefer a map to written directions

I like to work alone without anyone bothering me

science; eng (S9)

66 I enjoy learning the names of living things in our environment, such as birds and trees. science (S9)

10 Analytical thinking, magical beliefs $(\mathrm{JH}, \mathrm{S} 11)$

There was a powerful earthquake on Dec $26^{\text {th }} 2004$ that caused a devastating tsunami. 35 minutes before the earthquake was registered by seismic sensors, the aboriginal Onge people on the little Andaman island retreated from their villages to the hills in the center of the island, and they all survived. This is a fact. How would you explain it?

\section{Engineering type reactions}

Imagine the following situations. What would you do? (check all that apply)

A. You need to get air tickets from an airline office (no on-line reservation). When you enter the office, you see a long line waiting for tickets. What would do you most probably do:

67 Start complaining about lousy service

68 Start calling your friends to spend time better

69 Take a newspaper or book and start reading it while waiting

70 Think of ways how the ticket selling could be organized better to avoid long lines

71 Try to estimate how long the waiting will take

72 Start talking to other people in the queue

73 Utter a quick prayer

$74 \quad$ Give up

B I magine that you have a PC that is 3 years old. One day the CD-drive breaks down. What would you do:

$75 \quad$ Join an internet discussion to ask for help

76 Remove it and go to buy a better one and install it

77 Take the PC to a shop and ask them to replace the drive

$78 \quad$ Try to fix it

79 Decide to buy a new PC

80 Ignore it and continue working without a CD-drive

C The sewage pipe of the washbasin in your bathroom is clogged and the water does not drain. What do you do:

81 Try to get tools and open it to clean it

$82 \quad$ Call the building maintenance

83 Wait

$84 \quad$ Call your friends to complain

Something else: $85 \quad$ Kodin putkimies

\section{Engineering type reactions}

When you use an interactive Internet site like Winha or Ovi do you tend to

$86 \quad$ Get annoyed with the system

87 Explore new functionalities on the site

88 Think of how the design and outlook of the system could be improved

89 Think how the user interface could be improved

$90 \quad$ Feel helpless

13 What are the characteristics of a good engineer?

14 Engineering thinking; analytical; social control

Any comments on this questionnaire? 
Appendix 4: Summary of answers to survey 2

\section{Summary of DAP05S questionnaire \& Comparison with CAP results March 2006, January 06, March 05}

\section{Respondents:}

$\begin{array}{llll}\text { Group } & \text { DAP05S } & \text { CAP05S } & \text { CAP04S } \\ \text { Finns } & 4 & 0 & 2 \\ \text { East European } & 6 & 1 & 1 \\ \text { "Western" } & 3 & 0 & 2 \\ \text { African } & 2 & 15 & 13 \\ \text { West/South Asian } & 0 & 2 & 4 \\ \text { East Asian } & 2 & 1 & 4 \\ \text { Women } & 7 & 5 & 3 \\ \text { Total } & \mathbf{1 7} & \mathbf{1 9} & \mathbf{2 6}\end{array}$

1. Why did you come to study Media Engineering/IT at EVTEK? (check all that apply) alternatives given:
$11 / 11 / 21 \quad$ I am interested in ME/IT
$5 / 11 / 14 \quad$ I want to learn new things
$5 / 6 / 10 \quad$ I want to get an engineering degree
$5 / 3 / 8 \quad$ I expect good salary in work
3/ 2/ $7 \quad$ My family supported me in this choice
4/ $1 / 4 \quad$ I wanted to study in Finland
$3 / 2 / 1 \quad$ I had to start studying something
$1 / 0 / 2 \quad$ I was not admitted to my first choice
Other reasons:
$0 / 13 \quad$ education is free

2 Studying at EVTEK is:

2/ 8/ 6 More difficult than I expected;

11/ $7 / 17$ Much as I expected;

4/ 1/ $2 \quad$ Easier than I expected

3 Are you happy with your choice of studies? alternatives:

$12 / 13 / 18$ Yes, I feel that this is my field

5/ 4/ $6 \quad$ I am not quite sure if this field is the right for me

$1 / 0 / 0 \quad$ I would like to study in another country

$0 / 3 / 0 \quad$ I would like to study something else

$0 / 0 / 1 \quad$ I would like to select another technical field

Nobody selected:

- I am not happy with my choice; ; I would like stop studying altogether

$4 \quad$ What kind of problems have you encountered in your studies? alternatives:

12/ $11 / 13$ Time management

6/ 11/ 15 Too much work at the same time

6/3/8 Lack of motivation

5/ 6/ 5 Concentration on studies because of other problems

3/ 5/ $9 \quad$ Instructions are not clear enough

4/ 4/ $8 \quad$ Planning of workload

2/ 5/ $4 \quad$ Language difficulties

$1 / 2 / 2 \quad$ Other students are very different from myself;

$1 / 0 / 2$ Courses are too easy

2/ 1/ 2 Too many other activities;

$0 / 1 / 1 \quad$ Courses are too difficult;

$0 / 0 / 2$ Racism or prejudice;

$0 / 1 / 2 \quad$ Understanding the rules in EVTEK; 
0/ $1 / 0$ Teachers do not understand me

5 Do you normally understand what is expected from you?

$\begin{array}{llll} & \text { Yes } & \text { mostly } & \text { not often } \\ \text { In the lectures } & 9 / 4 / 15 & 8 / 11 / 8 & 0 / 5 / 3 \\ \text { When doing lab } & 9 / 7 / 8 & 7 / 11 / 10 & 1 / 2 / 5 \\ \text { assignments } & 12 / 8 / 16 & 5 / 12 / 9 & 0 / 0 / 0 \\ \text { In the examinations } & \end{array}$

$6 \quad$ What has been the biggest challenge for you in the first year?

Several students mentioned:
$1 / 3 / 3$
to adopt to the culture, food, weather
$0 / 1 / 2$
the education system, computer skills
$0 / 3 / 2$
2/ $2 / 4$
overload of work
Finnish language
$0 / 1 / 3$
time management
4/ $1 / 1$
to complete all courses
$3 / 0 / 1$
mathematics
motivation

7 What particularly interests you in your studies? Why? (open question):
4/ $1 / 5 \quad$ programming
4/ $7 / 5 \quad$ lab works, practice
7/ $0 / 0 \quad$ Web design
5/ $0 / 0 \quad$ image processing, photoediting
$2 / 0 / 2 \quad$ learning new things
$1 / 0 / 1 \quad$ language studies
$1 / 0 / 1 \quad$ maths
$0 / 1 / 1 \quad$ DC
0/ $2 / 2$ telecommunications

8 What other subjects would you like to study if you had the opportunity? (open question)

1/ 5/ 4 business and finance; business software

$-/ 2 / 5 \quad$ media technology

0/ 3/ 2 biology, medicine, nursing

3/ 0/ 1 more languages

3/ 0/ $0 \quad$ art, graphics

4/ $0 / 0$ animation, games

9 If you fail a course what is usually the explanation?

$14 / 14 / 20$ I did not study hard enough

2/ $2 / 5$ The teacher was not good

2/ 6/ 5 I could not concentrate because I had too many other things on my mind

$0 / 1 / 4 \quad$ The teacher did not fully explain the requirements

5/ 6/ $0 \quad$ I did not like the course

$5 / 0 / 7 \quad$ I am not good in that subject

10 If you have major difficulties understanding a study subject and passing a course what do you do about it? (check all that apply)

10/ 9 / 18 Read the material repeatedly

7/ $7 / 15$ Repeat the exercises over and over again

13/ 11/16 Ask another student for help

4/ 8/ 9 Ask the teacher to explain it again

10/ 12/13 Search the internet to find more information

8/ 11/ 14 Go to the library to find books or journals where the subject is explained better

5/ 5 /7 Think it over and try to find an alternative approach to the subject 
2/ 1 /1 Give up because this is not your strong area

5/ 2 /4 Decide to take the course later when you know more

$0 / 2$ /1 Decide to take the course when there is another teacher

11 What do you value in a teacher? (alternatives)

$14 / 11 / 21$ Is ready to answer questions and helps in study problems

14/ 14/ 20 Provides good learning materials

$11 / 13 / 19$ Is friendly

15/ 11/ 18 Gives clear lectures

$15 / 13 / 18$ Knows the subject well

10/11/ 16 Encourages students to learn

1/ $1 / 4$ Has authority

0/ 1/ 2 Helps you in your life

12 What kind of lectures do you prefer? (check all that apply)

9/ 11/ 19 The teacher explains subjects on the blackboard

8/ 8/ 11 The teacher asks questions and requires discussion in the classroom

$10 / 10 / 9$ The teacher uses lecturing and overheads to explain

3/ 4/ $8 \quad$ The teacher gives assignment to discuss subjects in groups

9/ 9/ 8 The teacher uses PowerPoint presentations to explain subjects

5/ 3/ 8 A virtual course without classroom lectures: lecture materials on the internet, discussion forums, chats and returning the assignment through the net

3/ $2 / 3 \quad$ Students make presentations on course topics

13 What kind of assignments do you prefer? (check all that apply)

12/ 13/ 18 Small tasks and exercises

6/ 9/ 13 To do research on a given subject

$11 / 10 / 13$ To do a project to create a product

6/6/10 To write a program

$1 / 4 / 5 \quad$ To learn a text well

5/ 8/3 To complete a set of measurements or lab experiment and report results

14 What are your preferred study methods? (check all that apply)

9/ 10/ 17 Lectures, reading and exam

8/ 5/ $11 \quad$ Individual lab assignments

8/ 9/ $11 \quad$ Group lab assignments

4/ 6/ 9 Individual research projects

7/ 6/ $9 \quad$ Lectures and home work

6/ 6/ $7 \quad$ Group projects

4/ 4/ 3 Reading books and writing a summary or essay

15 When studying in EVTEK what do you think is

Best:

$4 / 3 / 11 \quad$ resources, facilities

$3 / 1 / 2 \quad$ Lab sessions

4/ $1 / 0$ other students, friends

$1 / 3 / 3$ teachers, education

Worst:

$3 / 2 / 5$

$3 / 3 / 3$

$1 / 0 / 1$

$4 / 0 / 0$

$1 / 3 / 0$

schedule \& long days;

delivery of some lectures or classes, teaching style

Other students not motivated

mathematics

food

16 What has been the most important experience in your studies until now?

17 Do you think you have changed as a person? 
9/ 5/ $11 \quad$ No

7/ $12 / 12$ Yes, how?

2/ 3/ 6 more confidence; 1/ 2/ 2 more independent

18 Who are the people who have most influenced you in your studies?

1/ 7/ 10 some teachers;

12/ 2/ 5 fellow classmates;

3/ 5/ 2 my family;

19 Do you think you will be a good engineer?

$11 / 14 / 21$ Yes,

4/4/3 Probably,

$1 / 1 / 0 \quad$ No

Why do you think so?

Types of reasons:

$1 / 6 / 9$ good education gives the knowledge and skills

$6 / 4 / 8 \quad$ hard work

4/ 2/ 6 personal qualities and inclination

4/ 4/ 4 motivation

$1 / 1 / 2$ interest 


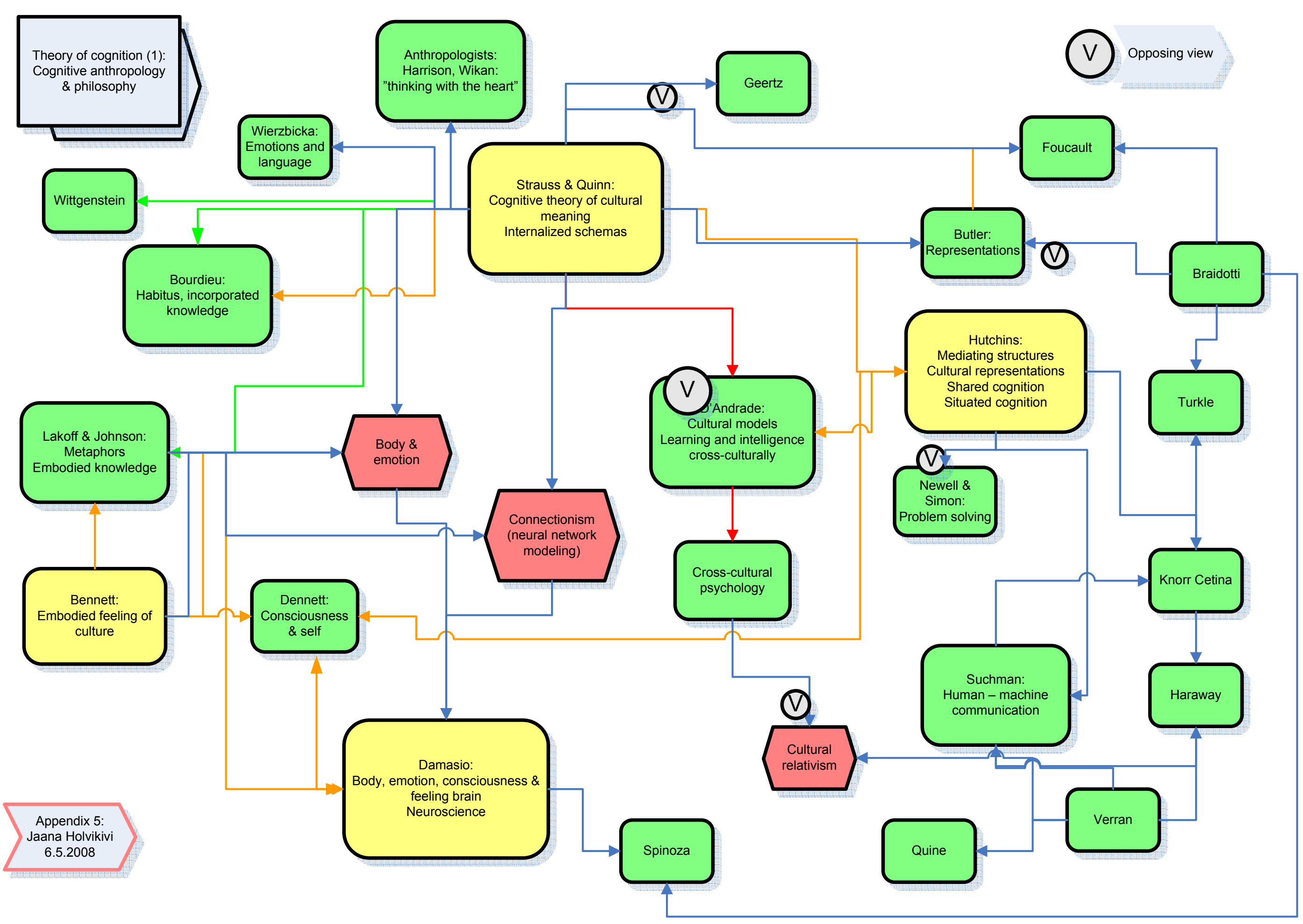




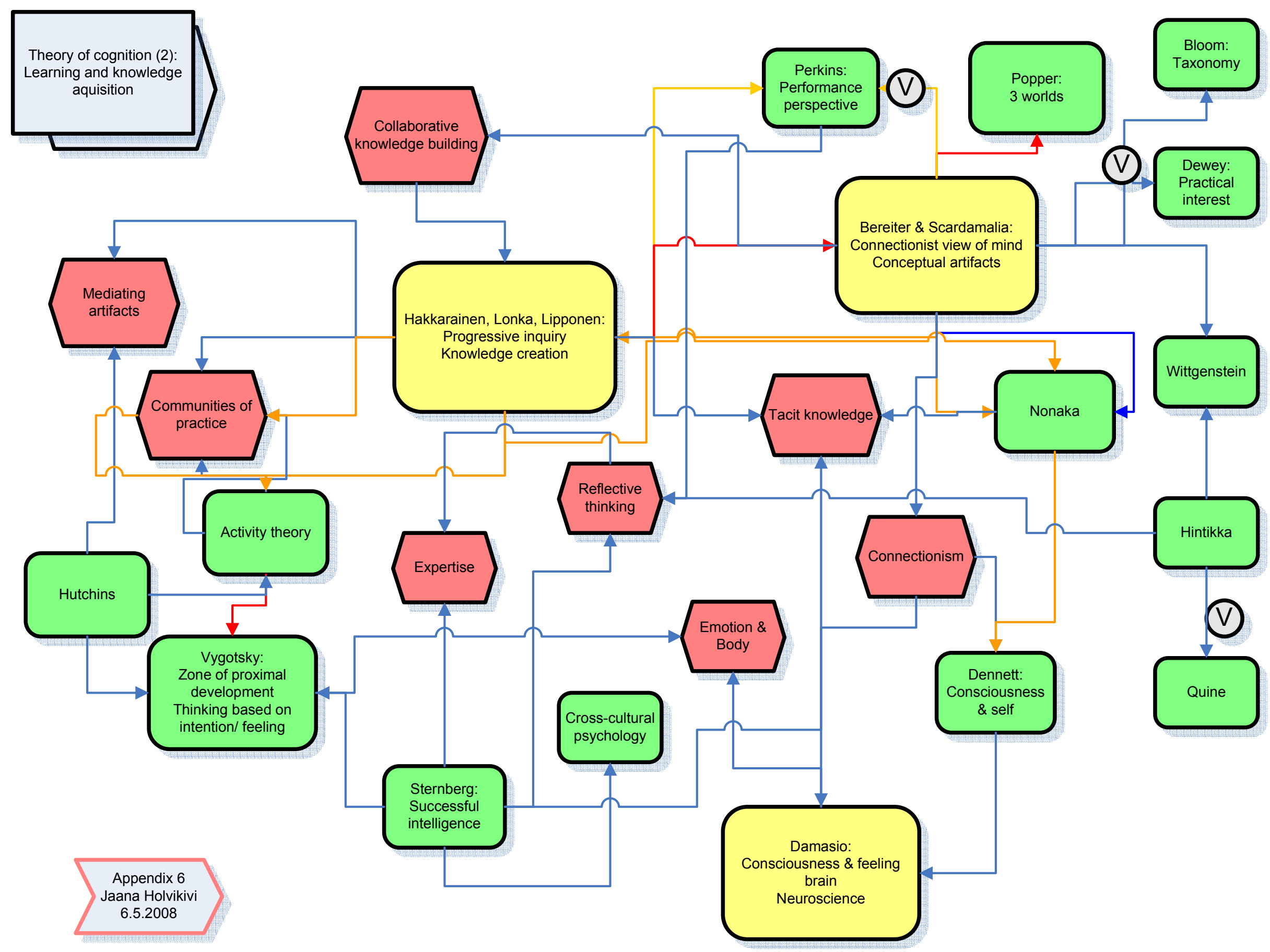




\title{
Helsinki University of Technology SimLab \\ Publications
}

\author{
Editor-in Chief \\ Riitta Smeds, D.Sc. (Tech.) \\ Professor \\ Department of Computer Science and Engineering \\ SimLab \\ P.O. Box 9220 \\ FIN-02015 TKK \\ Finland \\ riitta.smeds@tkk.fi
}

\section{Dissertation Series}

ISSN 1458-8226

Doctoral and Licentiate's Theses from the SimLab research unit. The quality of the Dissertation Series publications in ensured by the formal review process of the Theses.

\section{Report Series}

ISSN 1458-8234

Reports from SimLab research projects, as well as proceedings of scientific workshops and conferences organized by SimLab. The submitted Report manuscripts are reviewed by experts.

\section{Teaching Material Series}

ISSN 1458-8242

Teaching Materials include lecture material, as well as editions of selected seminar papers and project assignment reports of students. The submitted Teaching Material manuscripts are reviewed by experts.

\section{Working Paper Series}

Working Papers can introduce new research projects and research ideas, and discuss current phenomena. They can also include manuscripts that are ultimately intended for publication in high-quality academic journals. The Working Papers do not have an ISSN or an ISBN code. Thus they are unofficial publications, but they can still be referenced. The Working Papers are published only on the Internet. The submitted Working Papers manuscripts are reviewed by experts. 


\section{Publications}

\section{Dissertation Series \\ ISSN 1458-8226}

1. Haho, P. 2002. Simulointipeleihin perustuvan kehittämismenetelmän hyötyjä liiketoimintaprosessien kehittämishankkeissa. Hyvän kehittämismenetelmän menestystekijöitä Licentiate's Thesis. Espoo, Helsinki University of Technology, Department of Industrial Management and Department of Computer Science and Engineering, (in Finnish). $125+3$ p. ISBN 951-22-6286-X

2. Moisio, A. 2005. Implementing ICT-supported training in organizations - a service and relationship management view. Licentiate's Thesis. Espoo, Helsinki University of Technology, Department of Computer Science and Engineering. 110 p. ISBN 951-22-8002-7

3. Luukkainen, S. 2008. Management of Technological Discontinuity in the Telecommunications Industry - A Study of Incumbent Vendors' Innovation Process. Doctoral Thesis. Espoo, Helsinki University of Technology, Department of Computer Science and Engineering. 203+3 p. ISBN 978-951-22-9198-4

4. Kilpiö, A. 2008. Opettajien teknologiasuhteen luonne ja muodostuminen. Doctoral Thesis. University of Helsinki, Department of Social Psychology. Espoo: Helsinki University of Technology, SimLab Dissertation series 4, (in Finnish). 259 p. ISBN 978-951-22-9200-4

5. Holvikivi, J. 2009. Culture and Cognition in Information Technology Education. Doctoral Thesis. Helsinki University of Technology, Department of Computer Science and Engineering. Espoo: Helsinki University of Technology, SimLab Dissertation series 5. 198 p. ISBN 978-951-22-9785-6.

\section{Report Series}

ISSN 1458-8234

1. Kilpiö, A. 2003. Opettajuus ja verkko-opetus. Master's Thesis. University of Helsinki, Department of Social Psychology. Espoo: Helsinki University of Technology, SimLab Report series 1, (in Finnish). 131+3 p. ISBN 951-22-6371-8

2. Hirvensalo, A., Evokari, J., Feller, J., Pekkola, K., Turunen, P. \& Smeds, R. 2003. R\&DNet Final Report. Process Innovation in Collaborative R\&D. Lessons Learnt from the Telecommunication Industry. Espoo: Helsinki University of Technology, SimLab Report series 2. $110+8$ p. ISBN 951-22-6494-3

3. Kytösalmi, M. 2004. Organisaatiomuutoksen ja tietojärjestelmähankinnan yhteensovittaminen prosessin kehittämisen menetelmiä soveltaen. Master's Thesis. Helsinki University of Technology, Department of Computer Science and Engineering. Espoo: Helsinki University of Technology, SimLab Report series 3, (in Finnish). 92+20 p. ISBN 951-22-6997-X

4. Syväoja, H. 2004. Customers' and service providers' organizational capabilities in succesful IT outsourcing: a case study. Master's Thesis, Helsinki University of Technology, Department of Computer Science and Engineering. Espoo: Helsinki University of Technology, SimLab Report series 4. 72 p. ISBN 951-22-7436-1

5. Lignell, L. 2004. Malli tietojärjestelmävaatimusten tunnistamiseksi liiketoimintaprosessia kehittäessä. Master's Thesis, Helsinki University of Technology, Department of Computer Science and Engineering. Espoo: Helsinki University of Technology, SimLab Report series 5, (in Finnish). 109 p. ISBN 951-22-7434-5 
6. Pietilä, A. 2004. Asiakkuusprosessin systeeminen mallintaminen sen kehityskohtien tunnistamiseksi. Master's Thesis, Helsinki University of Technology, Department of Computer Science and Engineering. Espoo: Helsinki University of Technology, SimLab Report series 6, (in Finnish). 100 p. ISBN 951-22-7447-7

7. Lemmetty, M. 2005. Verkostoituva kaupunkisuunnittelu: prosessin kehittämisen näkökulma. Master's Thesis, Helsinki University of Technology, Department of Computer Science and Engineering. Espoo: Helsinki University of Technology, SimLab Report series 7, (in Finnish). 105 p. ISBN 951-22-7629-1

8. Leinikka, L. 2005. Prosessitieto verkottuneissa projekteissa - tapaustutkimus rakennusteollisuudesta. Master's Thesis, Helsinki University of Technology, Department of Computer Science and Engineering. Espoo: Helsinki University of Technology, SimLab Report series 8, (in Finnish). 93+2 p. ISBN 951-22-7631-3

9. Markkula M.-L., Kilpiö A. \& Smeds, R. (toim.) 2005: Helmiä Verkossa: Katsaus Helmihankkeeseen 2001-2005. Espoo: Helsinki University of Technology, SimLab Report series 9, (in Finnish). 59 p. ISBN 951-22-7676-3

10. Smeds R., Riis J., Haho, P. \& Jaatinen, M. (eds.) 2005: Experimental Interactive Learning in Industrial Management: New Approaches to Learning, Studying and Teaching. Proceedings of the $9^{\text {th }}$ Workshop of the IFIP WG 5.7, June 5-7, 2005, Espoo, Finland. Espoo: Helsinki University of Technology, SimLab Report series 10. 157 p. ISBN 951-22-7724-7.

11. Haho, P. \& Vänttinen, M. (toim.) 2005: KIMPASSA kohti parasta palvelua: KIMPPA esitutkimushankkeen loppuraportti. Espoo: Helsinki University of Technology, SimLab Report series 11. 36+1 p.

12. Södergård, R. 2005. Kahden liiketoimintayksikön yhteistoiminnan kehittäminen: palveluprosessien yhdistäminen ja koordinointi. (Developing collaboration between two business units: integrating and coordinating the service processes.) Master's Thesis, Helsinki University of Technology, Department of Computer Science and Engineering. Espoo: Helsinki University of Technology, SimLab Report series 12, (in Finnish). 93+11 p. ISBN 951-228004-3

13. livonen, P. 2005. Toimiva palveluverkosto - Tapaustutkimus julkisen ja yksityisen sektorin yhteistoiminnasta kotihoitopalveluissa. (Functional service network - A case study from public and private sector collaboration in home care services.) Master's Thesis, Helsinki University of Technology, Department of Computer Science and Engineering. Espoo: Helsinki University of Technology, SimLab Report series 13, (in Finnish). 78 p. ISBN 951-22-8000-0

14. Valkeapää, E. 2006. Asiakasnäkökulma strategisen allianssin palvelukehitysprosessin alkuvaiheessa. (Customer orientation in the early phases of new service development process in a strategic alliance.) Master's Thesis, Helsinki University of Technology, Department of Computer Science and Engineering. Espoo: Helsinki University of Technology, SimLab Report series 14, (in Finnish). 85+3 p. ISBN 951-22-8111-2

15. Jaatinen, M., Hirvensalo, A., Smeds, R., Södergård, R., Valkeapää, E., Koriseva, M., Seppänen, J. \& Soback, D. (eds.), 2006. Co-Create Final Report: Co-Creation of Business Models in Company Networks - Customer Orientation, Innovation, and Common Understanding in Collaborative Business. Espoo: Helsinki University of Technology, SimLab Report series 15. 139+6 p. ISBN 951-22-8236-4

16. Rantanen, P. 2006. Palveluiden hankintaprosessissa tarvittava osaaminen: tapaustutkimus kuntien sosiaali- ja terveyspalveluiden hankinnasta. Master's Thesis, Helsinki University of 
Technology, Department of Computer Science and Engineering. Espoo: Helsinki University of Technology, SimLab Report series 16, (in Finnish). 91+12 p. ISBN 951-22-8332-8

17. Soback, D. 2007. Jaetun vision luominen verkostossa - Case -tutkimuksia Espoon sosiaali- ja terveyspalvelujen verkostossa. Master's Thesis, Helsinki University of Technology, Department of Computer Science and Engineering. Espoo: Helsinki University of Technology, SimLab Report series 17, (in Finnish). 99+2 p. ISBN 978-951-22-8925-7

18. Haho, P., Vänttinen, M. \& Kilpiö, A. (toim.), 2007. Kimpassa tuloksiin: KIMPPAtutkimushankkeen loppuraportti. Espoo: Helsinki University of Technology, SimLab Report series 18, (in Finnish). 244 p. ISBN 978-951-22-8923-3

19. Koriseva, M. 2007. Viestintä verkostoituneen liiketoimintaprosessin koordinoinnissa. Master's Thesis, Helsinki University of Technology, Department of Computer Science and Engineering. Espoo: Helsinki University of Technology, SimLab Report series 19, (in Finnish). ISBN 978-951-22-8932-5

20. Söderlund, O. 2007. Strategy implementation in inter-organizational collaboration: Comparison of cases with deliberate and emergent strategies. Master's Thesis, Helsinki University of Technology, Department of Computer Science and Engineering. Espoo: Helsinki University of Technology, SimLab Report series 20, 99+2 p. ISBN 978-951-22-8934-9

21. Väyrynen, E., Huhta, E., Hänninen, K. \& Söderlund, O. 2007. Uuden kaupunkialueen suunnittelu ja toteutus verkostossa - Tutkimusnäkökulmia tapaus Suurpeltoon. Helsinki University of Technology, SimLab Report series 21 (in Finnish). Espoo. ISBN 978-951-229230-1

22. Sarakorpi, A. Palvelutuotteen modulointiprosessi monitoimijaverkostossa - CASE: hoiva-, koti- ja asumispalvelut. Master's Thesis, Helsinki University of Technology, Department of Computer Science and Engineering. Espoo: Helsinki University of Technology, SimLab Report series 22, (in Finnish). 106+2 p. ISBN 978-951-22-9491-6

23. Maunula, A. The implementation of building information modeling (BIM) - A Process Perspective. Master's Thesis, Helsinki University of Technology, Department of Computer Science and Engineering. Espoo: Helsinki University of Technology, SimLab Report series 23, 83+2p. ISBN 978-951-22-9644-6

24. Hirvensalo, A., Kaste, K., \& Maunula, A. 2009 ECPIP Finland Final Report. Helsinki University of Technology, SimLab Report series 24. Espoo. ISBN 978-951-22-9240-5

\section{Subscription}

Helsinki University of Technology

Department of Computer Science and Engineering

SimLab

P.O. Box 9220

FIN-02015 TKK

Telephone: +358-9-4515037 